\title{
DISTÂNCIA DE CULTIVARES EM RELAÇÃO AO MELHOR GENÓTIPO NA ANÁLISE DE GRUPOS DE EXPERIMENTOS
}

VERA LÚCIA MONELLI

Licenciada em Matemática

Orientador: Prof. Dr. Roland Vencovsky

Dissertação apresentada à Escola Superior de Agricultura "Luiz de Queiroz", da Universidade de São Paulo, para obtenção do título de Mestre em Agronomia, Área de Concentração: Estatística e Experimentação Agronômica.

$P$ I R A C I C A B A

Estado de São Paulo - Brasil

Janeiro - 1996 
Monelli, Vera Lúcia

Distância de cultivares em relação ao melhor genótipo na análise

de grupos de experimentos. - - Piracicaba, 1996.

178p. : Il.

Dissertação (mestrado) - - Escola Superior de Agricultura Luiz de Queiroz, 1996.

Bibliografia.

1. Análise de variância 2. Milho - Interação genótipo ambiente - Análise de série temporal 3. Milho - Melhoramento - Análise estatistica I. Titulo

CDD $\quad 633.18$ 


\section{DISTÂNCIA DE CULTIVARES EM RELAÇÃO AO MELHOR GENÓTIPO NA ANÁLISE DE GRUPOS DE EXPERIMENTOS}

VERA LÚCIA MONELLI

Aprovada em : 15.03 .1996

Comissão julgadora:

Prof. Dr. Roland Vencovsky ESALQ/USP

Prof. Dr. Jose Eduardo Corrente ESALQ/USP

Dr. Antonio Carlos da Silva

AGROCERES

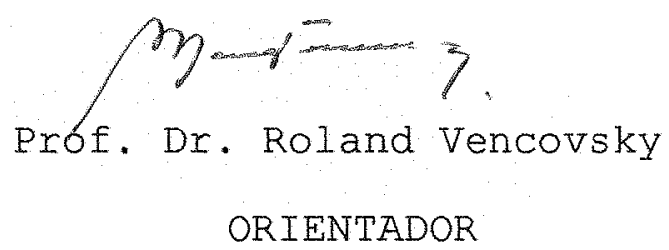


A meus pais: João e Lúcia.

irmãos : João, Claudinei, Sebastião e Aparecida. sobrinhos: Lauro, Constantino e Telma.

e a Paulo.

que trazem alegria a minha vida 


\section{AGRADECIMENTOS}

Agradeço a Deus por ter me dado o dom da vida e a todos que, de uma forma ou outra, contribuiram para a realização deste trabalho, e de forma especial:

Aos professores e funcionários do Departamento de Matemática e Estatística da Escola Superior de Agricultura "Luiz de Queiroz" (ESALQ) da Universidade de São Paulo (USP) em Piracicaba-SP, pelos ensinamentos e amizade.

A Sementes Agroceres, em especial ao Dr. Urbano Campos Ribeiral e ao senhor Valdemar Naspolini Filho, pelo incentivo e apoio constante que tornaram possivel a realização deste curso.

Ao Prof. Dr. Roland Vencovsky, pela orientação e amizade.

Ao Prof. Dr. Jose Eduardo Corrente, pela amizade, ensinamentos e colaboração.

Ao Dr. Joaquim Ap. Machado, pela amizade e estimulo inicial na atividade científica.

A todos os Pesquisadores do Departamento de Pesquisa da Agroceres e aos colegas de Santa Cruz das Palmeiras pelo companheirismo, amizade e estímulos recebidos. 


\section{SUMÁRIO}

Página

LISTA DE FIGURAS • • • • • . • • • • • • • • •

vii

LISTA DE TABELAS . . . . . . . . . . . . . . .

xvii

RESUMO . . . . . . . . . . . . . . . . . . . . . xxxiii

SUMMARY . . . . . . . . . . . . . . . . . . . . XXXVIi

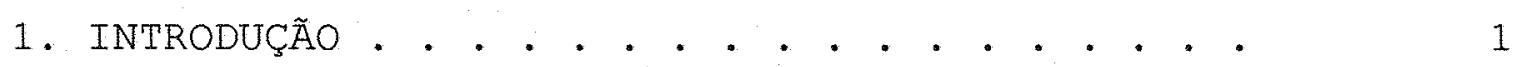

2. REVISÃO DE LITERATURA . . . . . . . . . . . . . 4

2.1. A Cultura do Milho . . . . . . . . . 4

2.2. Interação Genótipos x Ambientes . . . . . 6

2.3. Adaptabilidade e Estabilidade . . . . . 11

2.4. Método e estimação da distância à produtividade máxima . . . . . . . . 32

2.5. Estatística de ordem . . . . . . . 34

3. MATERIAL E MÉTODO . . . . . . . . . . . . . . . 38

3.1. Análise Individual . . . . . . . . . 38

3.2. Análise Conjunta . . . . . . . . . . 42

3.3. Desenvolvimento da distância de um tratamento em relação a um melhor genótipo . . . . . . . . . . . . . 50

3.3.1. Variável produtividade . . . . 50

3.3.2. Variável 음 de tombamento... . . 53

3.4. Análise Gráfica . . . . . . . . . . . 57 
Página

3.5. Estudos de Simulação para a Distribuição Normal . . . . . . . . . . . . . . 59

3.6. Análise da Estabilidade e Adaptabilidade.

3.6.1. Análise da Estabilidade com base nas distâncias $D p_{i}$ e $D t_{i}$. . . . .

3.6.2. Metodologia proposta por Eberhart

$\varepsilon$ Russel (1966) . . . . . . . .

4. RESULTAdOS E DISCUSSÃO . . . . . . . . . . .

4.1. Análise da Variância . . . . . . . . .

4.2. Desenvolvimento da distância de um híbrido em relação a um melhor genótipo . . . . .

4.2.1. Ano agrícola 1992/93.......

4.2.2. Ano agrícola 1993/94... . . .

4.2.3. Ano agrícola 1994/95.......

4.3. Adaptabilidade e Estabilidade pelo Método de Eberhart $\varepsilon$ Russel (1966) . . . . . .

4.3.1. Ano agrícola 1992/93......

4.3.2. Ano agrícola 1993/94... . . .

4.3.3. Ano agrícola 1994/95 . . . . .

4.4. Estudo de Simulação . . . . . . . . . 


\section{LISTA DE FIGURAS}

Figura

página

1 Ilustração de um gráfico, exemplificando o comportamento de dois híbridos em casos extremos. . . . . . . . . . . . . . . . .

2 Distância em o à produtividade máxima e ao tombamento mínimo para os dados obtidos de experimentos em 9 locais do Estado de São Paulo (ano agrícola 1992/93). . . . . . . . . . .

3 Distância em o à produtividade máxima e ao tombamento mínimo para os dados obtidos de experimentos em 3 locais do Estado de São Paulo, considerados desfavoráveis (ano agrícola $1992 / 931$. . . . . . . . . . . . . . . . . .

4 Distância em o à produtividade máxima e ao tombamento mínimo para os dados obtidos de experimentos em 6 locais do Estado de São Paulo, considerados favoráveis (ano agrícola 1992/93). 
Figura

5 Distância em o à produtividade máxima e ao tombamento mínimo para os dados obtidos de experimentos em 13 locais dos Estados de São Paulo e Minas Gerais (ano agrícola 1993/94). . . 100

6 Distância em $\frac{o}{2}$ à produtividade máxima e ao tombamento mínimo para os dados obtidos de experimentos em 5 locais do Estado de São Paulo, considerados desfavoráveis (ano agrícola $1993 / 94)$

7 Distância em \% à produtividade máxima e ao tombamento mínimo para os dados obtidos de experimentos em 8 locais dos Estados de São Paulo e Minas Gerais, considerados favoráveis (ano agrícola 1993/94).............. 
Eigura

Distância em o à produtividade máxima e ao tombamento mínimo para os dados obtidos de experimentos em 19 locais dos Estados de São Paulo e Minas Gerais (ano agrícola 1994/95). . .

9 Distância em o à produtividade máxima e ao tombamento mínimo para os dados obtidos de experimentos em 12 locais dos Estados de São Paulo e Minas Gerais (ano agrícola 1994/95), considerados desfavoráveis. . . . . . . . . . .

10 Distância em o à produtividade máxima e ao tombamento mínimo para os dados obtidos de experimentos em 7 locais dos Estados de São Paulo e Minas Gerais (ano agrícola 1994/95), considerados favoráveis. . . . . . . . . . 116

11 Regressão linear da produtividade de espigas do híbrido AG 514 e do máximo, em 9 ambientes do Estado de São Paulo, ano agrícola 1992/93. . . . 
Figura

Página

12 Regressão Iinear da produtividade de espigas do híbrido $A G 514$ e do máximo, em 9 ambientes do Estado de São Paulo, ano agrícola 1992/93. . . .

13 Regressão Iinear da produtividade de espigas do híbrido AG 519 e do máximo, em 9 ambientes do Estado de São Paulo, ano agrícola 1992/93. . . .

14 Regressão linear da produtividade de espigas do híbrido AG 6601 e do máximo, em 9 ambientes do Estado de São Paulo, ano agrícola 1992/93. . .

15 Regressão linear da produtividade de espigas do híbrido AG 951 e do máximo, em 13 ambientes dos Estados de São Paulo e Minas Gerais, ano agrícola 1993/94. . . . . . . . . . . .

16 Regressão Iinear da produtividade de espigas do híbrido AG 5011 e do máximo, em 13 ambientes dos Estados de São Paulo e Minas Gerais, ano agricola 1993/94. . . . . . . . . . . 
Eigura

17 Regressão linear da produtividade de espigas do híbrido BR 201 e do máximo, em 13 ambientes dos Estados de São Paulo e Minas Gerais, ano agrícola 1993/94. . . . . . . . . . .

18 Regressão linear da produtividade de espigas do híbrido AG 514 e do máximo, em 13 ambientes dos Estados de São Paulo e Minas Gerais, ano agrícola 1993/94. . . . . . . . . . . . . . .

19 Regressão Iinear da produtividade de espigas do híbrido $A G 122$ e do máximo, em 13 ambientes dos Estados de São Paulo e Minas Gerais, ano agrícola 1993/94. . . . . . . . . . . . .

20 Regressão Iinear da produtividade de espigas do híbrido AG 106 e do máximo, em 13 ambientes dos Estados de São Paulo e Minas Gerais, ano agrícola 1993/94. . . . . . . . . . . . 
Figura

21 Regressão Iinear da produtividade de espigas do híbrido AG 1051 e do máximo, em 13 ambientes dos Estados de São Paulo e Minas Gerais, ano agrícola 1993/94... . . . . . . . . . .

22 Regressão Iinear da produtividade de espigas do híbrido AG 1043 e do máximo, em 13 ambientes dos Estados de São Paulo e Minas Gerais, ano agrícola 1993/94. . . . . . . . . . . . . . .

23 Regressão linear da produtividade de espigas do híbrido AG 405 e do máximo, em 13 ambientes dos Estados de São Paulo e Minas Gerais, ano agrícola 1993/94. . . . . . . . . . . .

24 Regressão linear da produtividade de espigas do híbrido AG 5011 e do máximo, em 19 ambientes dos Estados de São Paulo e Minas Gerais, ano agrícola 1994/95. . . . . . . . . . . . 
Figura

25 Regressão linear da produtividade de espigas do híbrido AG 8012 e do máximo, em 19 ambientes dos Estados de São Paulo e Minas Gerais, ano agrícola 1994/95. . . . . . . . . . . .

26 Regressão linear da produtividade de espigas do híbrido AG 951 e do máximo, em 19 ambientes dos Estados de São Paulo e Minas Gerais, ano agrícola $1994 / 95$. . . . . . . . . . . .

27 Regressão Iinear da produtividade de espigas do híbrido AG 9012 e do máximo, em 19 ambientes dos Estados de São Paulo e Minas Gerais, ano agrícola 1994/95. . . . . . . . . . . . .

28 Regressão Iinear da produtividade de espigas do híbrido BR 201 e do máximo, em 19 ambientes dos Estados de São Paulo e Minas Gerais, ano agrícola 1994/95. . . . . . . . . . . . . . 
Figura

29 Regressão linear da produtividade de espigas do híbrido AG 405 e do máximo, em 19 ambientes dos Estados de São Paulo e Minas Gerais, ano agrícola 1994/95. . . . . . . . . . . . .

30 Regressão linear da produtividade de espigas do híbrido AG 4011 e do máximo, em 19 ambientes dos Estados de São Paulo e Minas Gerais, ano agrícola 1994/95. . . . . . . . . . . .

31 Regressão linear da produtividade de espigas do híbrido AG 106 e do máximo, em 19 ambientes dos Estados de São Paulo e Minas Gerais, ano agrícola 1994/95... . . . . . . . . . .

32 Regressão Iinear da produtividade de espigas do híbrido AG 122 e do máximo, em 19 ambientes dos Estados de São Paulo e Minas Gerais, ano agrícola 1994/95. . . . . . . . . . . . 
Figura

Página

33 Regressão Iinear da produtividade de espigas do híbrido AG 1043 e do máximo, em 19 ambientes dos Estados de São Paulo e Minas Gerais, ano agrícola 1994/95. . . . . . . . . . . . .

34 Regressão linear da produtividade de espigas do híbrido AG 514 e do máximo, em 19 ambientes dos Estados de São Paulo e Minas Gerais, ano agrícola 1994/95... . . . . . . . . . 160

35 Quantís da distribuição do máximo de uma distribuição normal com $\mu=10$ e $\sigma^{2}=25$ a partir de dados simulados de uma amostra de

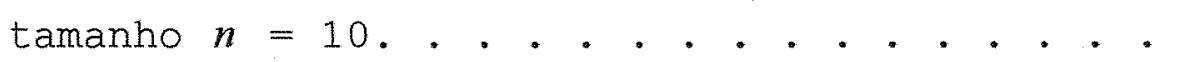

36 Quantís da distribuição do máximo de uma distribuição normal com $\mu=10$ e $\sigma^{2}=25$ a partir de dados simulados de uma amostra de tamanho $n=20$. . . . . . . . . . . . 
Figura

Página

37 Quantís da distribuição do máximo de uma distribuição normal com $\mu=10$ e $\sigma^{2}=25$ a partir de dados simulados de uma amostra de tamanho $n=50$. . . . . . . . . . .

38 Quantís da distribuição do máximo de uma distribuição normal com $\mu=10$ e $\sigma^{2}=25 \mathrm{a}$ partir de dados simulados de uma amostra de tamanho $n=100$............ . 
xVii

\section{LISTA DE TABELAS}

Tabela

Página

1 Classificação dos genótipos com base nos valores de $b_{i} \cdot$. . . . . . . . . . . . . . . . .

2 Esquema da análise da variância para um dado local. . . . . . . . . . . . . . . .

3 Quadro da análise conjunta de variância para um grupo de experimentos. . . . . . . . . .

4 Disposição dos dados obtidos de híbridos e blocos num dado local $\mathrm{k}$ para a variável produtividade. . . . . . . . . . . . . . .

5 Valores de distância $X_{i . k}$ para $I$ híbridos e $K$ locais. . . . . . . . . . . . . . .

6 Disposição dos dados obtidos de híbridos e blocos num dado local $\mathrm{k}$ para a variável : de tombamento. . . . . . . . . . . . . . . 
7 Valores de distância $Y_{i . k}$ para I híbridos e $\mathrm{K}$ locais. . . . . . . . . . . . . . . .

8 Quadro da Análise de Variância com os valores de $F$ para realizar testes e estimar os desvios de regressão linear de I cultivares, estudados em J repetições e $K$ locais. (Modelo proposto por EBERHART \& RUSSEL, 1966). . . . .

9 Produtividade média de espigas em t/ha e Quadrados Médios de Híbridos de milho e do Resíduo, obtidos nas análises da variância individuais de cada local no ano agrícola de 1992/93... . . . . . . . . . . . . .

10 Produtividade média de espigas em t/ha e Quadrados Médios de Híbridos de milho e do Resíduo, obtidos nas análises da variância individuais de cada local no ano agrícola de 1993/94................... 
Tabela

11 Produtividade média de espigas em t/ha e Quadrados Médios de Híbridos de milho e do Residuo, obtidos nas análises da variância individuais de cada local no ano agrícola de 1994/95. . . . . . . . . . . . . . .

12 Produtividade média de espigas, em t/ha e datas de semeadura de sete híbridos de milho, coeficientes de variação (C.V), médias em t/ha $\left(\bar{P}_{-k}\right)$ e indices ambientais $\left(I_{k}\right)$ dos ensaios realizados em 9 locais do Estado de São Paulo em 1992/93. . . . . . . . . . . . .

13 Produtividade média de espigas, em t/ha e datas de semeadura de dezessete híbridos de milho, coeficientes de variação (C.V), médias em $t$ ha $\left(\bar{P}_{. k}\right)$ e indices ambientais $\left(I_{k}\right)$ dos ensaios realizados em 13 locais dos Estados de São Paulo e Minas Gerais em 1993/94. . . . . . 
Tabela

Página

14 Produtividade média de espigas, em t/ha e datas de semeadura de dezoito híbridos de milho, coeficientes de variação (C.V), médias em $t$ ha $\left(\bar{P}_{. k}\right)$ e indices ambientais $\left(I_{k}\right)$ dos ensaios realizados em 19 locais dos Estados de São Paulo e Minas Gerais em 1994/95.

15 Análise conjunta da produtividade média do peso de espigas em t/ha, nos anos agrícolas de 1992/93, 1993/94 e 1994/95, respectivamente. .

16 Produtividade média de espigas, em $t /$ ha de sete híbridos de milho, valores máximos e mínimos $\quad\left[\bar{P}_{k}(\max )\right.$ e $\left.\bar{P}_{k}(\min )\right]$, amplitude $\left(X_{k}{ }^{-}\right)$e indices ambientais $\left(I_{k}\right)$ dos ensaios realizados em 9 locais do Estado de São Paulo em 1992/93. . • . . . . . . . . . . . • 
17 Distâncias em relação ao melhor genótipo para a produtividade de espigas, em t/ha de sete híbridos de milho, valores máximos e mínimos $\left[\bar{P}_{k}(\max ) \in \bar{P}_{k}(\min )\right], \quad$ amplitude $\left(X_{k}^{-}\right)$e indices ambientais $\left(I_{k}\right)$ dos ensaios realizados em 9 locais do Estado de São Paulo em 1992/93. . . .

18 Tombamentos médios, em percentagem, de sete híbridos de milho, valores mínimos e máximos $\left[\bar{T}_{k}(\min )\right.$ e $\left.\bar{T}_{k}(\max )\right]$ e amplitude $\left(Y_{k}^{-}\right)$dos ensaios realizados em 9 locais do Estado de São Paulo em 1992/93......................

19 Distâncias em relação ao melhor genótipo para a o de tombamento de sete híbridos de milho, valores mínimos e máximos $\left[\bar{T}_{k}(\min )\right.$ e $\left.\bar{T}_{k}(\max )\right]$ e amplitude $\left(Y_{k}^{-}\right)$dos ensaios realizados em 9 locais do Estado de São Paulo em 1992/93. . . 
20 Distância de sete híbridos de milho em relação ao melhor genótipo para a produtividade de espigas $\left(D p_{i}\right)$ e $\circ$ tombamento das plantas $\left(D t_{i}\right)$; grau de inferioridade dos híbridos em porcentagem da amplitude $\left(I p_{i} \%\right.$ e $\left.I t_{i} \%\right)$; média das amplitudes $\left(D p^{-}\right.$e $\left.D t^{-}\right)$; melhor e pior genótipo $(M g$ e $P g)$ para os resultados obtidos de experimentos em 9 locais do Estado de São Paulo (ano agrícola 1992/93). . . . . . . . . . .

21 Distância de sete híbridos de milho em relação ao melhor genótipo para a produtividade de espigas $\left(D p_{i}\right)$ e o tombamento das plantas $\left(D t_{i}\right)$; grau de inferioridade dos híbridos em porcentagem da amplitude $\left(I p_{i} \%\right.$ e $\left.I t_{i} \%\right) ;$ média das amplitudes $\left(D p^{-}\right.$e $\left.D t^{-}\right)$; melhor e pior genótipo $(M g$ e $P g)$ para os resultados obtidos de experimentos em 3 locais do Estado de São Paulo, considerados desfavoráveis (ano agrícola 1992/93) . . . . . . 
22 Distância de sete híbridos de milho em relação ao melhor genótipo para a produtividade de espigas $\left(D p_{i}\right)$ e o tombamento das plantas $\left(D t_{i}\right)$; grau de inferioridade dos híbridos em porcentagem da amplitude $\left(I p_{i} \%\right.$ e $\left.I t_{i} \%\right) ;$ média das amplitudes $\left(D p^{-}\right.$e $\left.D t^{-}\right)$; melhor e pior genótipo $(M g$ e $P g)$ para os resultados obtidos de experimentos em 6 locais do Estado de São Paulo, considerados favoráveis (ano agrícola 1992/93).

23 Produtividades médias de espigas, em t/ha de dezessete híbridos de milho, valores máximos e mínimos $\left[\bar{P}_{k}(\max )\right.$ e $\left.\bar{P}_{k}(\min )\right]$, amplitude $\left(X_{k}^{-}\right)$e indices ambientais $\left(I_{k}\right)$ dos ensaios realizados em 13 locais dos Estados de São Paulo e Minas Gerais no ano agrícola 1993/94. . 
24 Distâncias em relação ao melhor genótipo para a produtividade de espigas, em $t$ /ha de dezessete híbridos de milho, valores máximos e mínimos $\quad\left[\bar{P}_{k}(\max )\right.$ e $\left.\bar{P}_{k}(\min )\right]$, amplitude $\left(X_{k}{ }^{-}\right)$e indices ambientais $\left(I_{k}\right)$ dos ensaios realizados em 13 locais dos Estados de São Paulo e Minas Gerais no ano agrícola 1993/94. .

25 Tombamentos médios, em percentagem, de dezessete híbridos de milho, valores minimos e máximos $\left[\bar{T}_{k}(\min ) \in \bar{T}_{k}(\max )\right]$, amplitude $\left(Y_{k}^{-}\right)$dos ensaios realizados em 13 locais dos Estados de São Paulo e Minas Gerais no ano agrícola

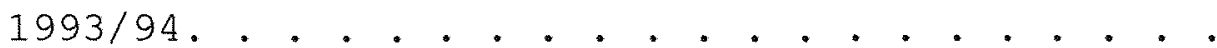


26 Distâncias em relação ao melhor genótipo para a \% de tombamento, de dezessete híbridos de milho, valores mínimos e máximos $\left[\bar{T}_{k}(\min )\right.$ e $\left.\bar{T}_{k}(\max )\right]$, amplitude $\left(Y_{k}^{-}\right)$dos ensaios realizados em 13 locais dos Estados de São Paulo e Minas Gerais no ano agrícola de 1993/94.

27 Distância de dezessete híbridos de milho em relação ao melhor genótipo para a produtividade de espigas $\left(D p_{i}\right)$ e o tombamento das plantas $\left(D t_{i}\right)$; grau de inferioridade dos híbridos em porcentagem da amplitude $\left(I p_{i} \%\right.$ e $\left.I t_{i} \%\right)$; amplitudes $\left(D p^{-}\right.$e $\left.D t^{-}\right)$; melhor e pior genótipo $(M g$ e $P g)$ para os resultados obtidos de experimentos em 13 locais dos Estados de São Paulo e Minas Gerais (ano agrícola 1993/94). . . . . . . . . . 
Tabela

28 Distância de dezessete híbridos de milho em relação ao melhor genótipo para a produtividade de espigas $\left(D p_{i}\right)$ e o tombamento das plantas $\left(D t_{i}\right)$; grau de inferioridade dos híbridos em porcentagem da amplitude $\left(I p_{i} \%\right.$ e $\left.I t_{i} \%\right) ;$ amplitudes $\left(D p^{-}\right.$e $\left.D t^{-}\right) ;$melhor e pior genótipo $(M g$ e $P g)$ para os resultados obtidos de experimentos em 5 locais do Estado de São Paulo, considerados desfavoráveis (ano agrícola 1993/94). . . . . .

29 Distância de dezessete híbridos de milho em relação ao melhor genótipo para a produtividade de espigas $\left(D p_{i}\right)$ e o tombamento das plantas $\left(D t_{i}\right)$; grau de inferioridade dos híbridos em porcentagem da amplitude $\left(I p_{i} \%\right.$ e $\left.I t_{i} \%\right)$; amplitudes $\left(D p^{-}\right.$e $\left.D t^{-}\right) ;$melhor e pior genótipo ( $M g$ e $P g$ ) para os resultados obtidos de experimentos em 8 locais dos Estados de São Paulo e Minas Gerais, considerados favoráveis (ano agrícola 1993/94). 
Tabela

Página

30 Produtividades médias de espigas, em $t / h a$, de dezoito híbridos de milho, valores máximos e minimos $\left[\bar{P}_{k}(m a x) \in \bar{P}_{k}(m i n)\right]$, amplitude $\left(X_{k}^{-}\right)$e indices ambientais $\left(I_{k}\right)$ dos ensaios realizados em 19 locais dos Estados de São Paulo e Minas Gerais no ano agrícola 1994/95. .

31 Distâncias em relação ao melhor genótipo para a produtividade de espigas, em $t / h a$, de dezoito híbridos de milho, valores máximos e mínimos $\left[\bar{P}_{k}(\max )\right.$ e $\left.\bar{P}_{k}(\min )\right]$, amplitude $\left(X_{k}{ }^{-}\right)$e índices ambientais $\left(I_{k}\right)$ dos ensaios realizados em 19 locais dos Estados de São Paulo e Minas Gerais no ano agrícola 1994/95. 
Tabela

Página

32 Tombamentos médios, em percentagem, de dezoito híbridos de milho, valores mínimos e máximos $\left[\bar{T}_{k}(\min )\right.$ e $\left.\bar{T}_{k}(\max )\right]$, amplitude $\left(Y_{k}^{-}\right)$dos ensaios realizados em 19 locais dos Estados de São Paulo e Minas Gerais no ano agrícola $1994 / 95$. . . . . . . . . . . . 109

33 Distâncias em relação ao melhor genótipo para a o de tombamento, de dezoito híbridos de milho, valores mínimos e máximos $\left[\bar{T}_{k}(\min )\right.$ e $\left.\bar{T}_{k}(\max )\right]$, amplitude $\left(Y_{k}^{-}\right)$dos ensaios realizados em 19 locais dos Estados de São Paulo e Minas Gerais no ano agrícola 1994/95. . 
34 Distância de dezoito híbridos de milho em relação ao melhor genótipo para a produtividade de espigas $\left(D p_{i}\right)$ e o tombamento das plantas $\left(D t_{i}\right)$; grau de inferioridade dos híbridos em porcentagem da amplitude $\left(I p_{i} \%\right.$ e $\left.I t_{i} \%\right)$, amplitudes $\left(D p^{-}\right.$e $\left.D t^{-}\right) ;$melhor e pior genótipo ( $M g$ e $\left.\mathrm{Pg}\right)$ para os resultados obtidos de experimentos em 19 locais dos Estados de São Paulo e de Minas Gerais (ano agrícola 1994/95). . . . . . . .

35 Distância de dezoito híbridos de milho em relação ao melhor genótipo para a produtividade de espigas $\left(D p_{i}\right)$ e o tombamento das plantas $\left(D t_{i}\right)$; grau de inferioridade dos híbridos em porcentagem da amplitude $\left(I p_{i} \%\right.$ e $\left.I t_{i} \%\right)$, amplitudes $\left(D p^{-}\right.$e $\left.D t^{-}\right)$; melhor e pior genótip $(M g$ e $P g)$ para os resultados obtidos de experimentos em 12 locais do Estado de São Paulo (ano agrícola 1994/95), considerados desfavoráveis. . . . . 
36 Distância de dezoito híbridos de milho em relação ao melhor genótipo para a produtividade de espigas $\left(D p_{i}\right)$ e o tombamento das plantas $\left(D t_{i}\right)$; grau de inferioridade dos híbridos em porcentagem da amplitude $\left(I p_{i} \%\right.$ e $\left.I t_{i} \%\right)$, amplitudes $\left(D p^{-}\right.$e $\left.D t^{-}\right) ;$melhor e pior genótipo $(M g$ e $P g)$ para os resultados obtidos de experimentos em 7 locais dos Estados de São Paulo e de Minas Gerais (ano agrícola 1994/95), considerados favoráveis. . . . . . . . . . . . . . . . .

37 Análise de variância da produtividade média de espigas de 7 híbridos de milho e do máximo ensaiados em 9 locais do Estado de São Paulo, no ano agrícola de 1992/93. (Modelo proposto por EBERHART $\varepsilon$ RUSSEL, 1966) . . . . . . . . . . 
Tabela

Página

38 Estimativa dos parâmetros da estabilidade fenotípica da produtividade de espigas de 7 híbridos de milho e do máximo estudados em 9 locais do Estado de São Paulo no ano agrícola de 1992/93. . . . . . . . . . . . . . . . . . .

39 Análise de variância da produtividade média de espigas de 17 híbridos de milho e do máximo ensaiados em 13 locais dos Estados de São Paulo e Minas Gerais, no ano agrícola de 1993/94. (Modelo proposto por EBERHART \& RUSSEL, 1966). .

40 Estimativas de parâmetros da estabilidade fenotípica da produtividade de espigas de 17 híbridos de milho e do máximo estudados em 13 locais dos Estados de São Paulo e Minas Gerais no ano agrícola de 1993/94. . . . . . . . . . 
41 Análise de variância da produtividade média de espigas de 18 hibridos de milho e do máximo ensaiados em 19 locais dos Estados de São Paulo e Minas Gerais, no ano agricola de 1994/95. (Modelo proposto por EBERHART \& RUSSEL, 1966).

42 Estimativas dos parâmetros da estabilidade fenotípica da produtividade de espigas de 18 híbridos de milho e do máximo estudados em 19 locais dos Estados de São Paulo e Minas Gerais no ano agrícola de 1994/95. . . . . . . . . . 
xxxiii

\section{DISTÂNCIA DE CULTIVARES EM RELAÇÃO AO MELHOR GENÓTIPO NA ANÁLISE DE GRUPOS DE EXPERIMENTOS}

Autora: VERA LÚCIA MONELLI Orientador: PROF. DR. ROLAND VENCOVSKY

\section{RESUMO}

A cada ano são avaliados novos cultivares, em diferentes condições de solo e clima, visando determinar seu desempenho em relação à produtividade e outras características importantes. $\mathrm{Na}$ avaliação da interação genótipos x ambientes, é de grande importância o uso de técnicas estatísticas que ajudem 0 pesquisador a determinar qual cultivar tem o melhor desempenho, de modo que, dada uma afirmação ela tenha o menor erro possível. Este trabalho então, fornece uma maneira alternativa para analisar grupos de experimentos, aplicando uma metodologia que determina a distância de cada cultivar em relação ao melhor genótipo. 
Foi proposta uma metodologia baseada na distância à produtividade máxima e ao tombamento mínimo. Ao analisar-se a variável produtividade, o melhor genótipo foi composto pela média geral das produtividades máximas obtidas em cada local. Por outro lado, analisando-se a segunda variável, o melhor genótipo foi composto pela média geral dos tombamentos mínimos obtidos em cada local. Deste modo, considerou-se como o melhor cultivar aquele que esteve mais próximo do melhor genótipo, alcançando o menor valor de distância à produtividade máxima e ao tombamento mínimo.

Para se ter uma idéia de como os cultivares próximos ou distantes do melhor genótipo se comportaram frente às variações ambientais, foi ainda aplicada a metodologia baseada na estabilidade fenotípica desenvolvida por EBERHART $\varepsilon$ RUSSEL (1966).

Para aplicação destas metodologias foram utilizados dados obtidos de 7 híbridos de milho em 9 locais no ano agricola de 1992/93, de 17 híbridos em 13 locais no ano agrícola de $1993 / 94 \mathrm{e}$, de 18 híbridos em 19 locais no ano agrícola de 1994/95.

A metodologia baseada na distância à produtividade máxima e ao tombamento mínimo, foí útil para 
quantificar o afastamento dos híbridos em relação ao melhor genótipo para todos os ambientes e para os ambientes desfavoráveis e favoráveis. Na comparação desta metodologia com a proposta por EBERHART $\varepsilon$ RUSSEL (1966), pôde-se verificar que a maioria dos híbridos que alcançaram valores de distância semelhantes, nos ambientes desfavoráveis e favoráveis, tiveram adaptabilidade geral.

Uma vez que a cada ano foram introduzidos novos híbridos para serem testados nos diversos locais, a metodologia da distância ao melhor genótipo permitiu, ainda, avaliar a performance destes frente aos já existentes. Pôde-se então verificar que os híbridos mais recentes possuem desempenho superior aos mais antigos em produtividade e tombamento, mostrando assim, a existência de ganhos nos programas de melhoramento.

Como exemplo, os híbridos AG 5011 e AG 4011 destacaram-se por terem ficado próximos ao melhor genótipo para a produtividade e o tombamento respectivamente.

Com a introdução do tratamento conceitual, considerado o melhor genótipo, ou de rendimento máximo ao longo dos ambientes, foi possivel conhecer o comportamento deste em relação à produtividade e estabilidade. Verificou- 
se que esse melhor genótipo apresentou adaptabilidade geral e alta estabilidade.

Através de simulações verificou-se a não existência de normalidade dos valores de distância em relação ao máximo, o que impossibilitou a realização de testes de hipóteses baseados na condição de normalidade dos erros. Também não foi desenvolvida expressão do erro experimental das estimativas de distância. Esses aspectos requerem investigações adicionais. 
xxxvii

\section{DISTANCE OF CULTIVARS TO THE BEST GENOTYPE IN THE ANALYSIS OF GROUPS OF EXPERIMENTS}

Author:

Adviser:
VERA LÚCIA MONELLI

Prof. Dr. ROLAND VENCOVSKY

\section{SUMMARY}

Each year new cultivars are evaluated under heterogeneous environmental conditions in order to check their performance for yield and other important agronomic traits. In the assessment of genotype $x$ environment interaction it is important to use statistical procedures that help the breeder to decide with the least chance of error which cultivar has the best performance. This work gives an alternative way to analyse groups of experiments, by using a methodology that calculates the distance of a cultivar to a conceptual best genotype.

The proposed methodology is based on the distance to maximum yield and minimum lodging. To represent the best conceptual genotype the following quantitative 
characters were considered: maximum yield averaged over enviroments and minimum lodging percentage, correspondingly. In this way the best cultivar was the one closest to the conceptual best genotype, having the lowest value of distance to maximum yield and minimum lodging.

To check the performance and distance of cultivars relative to the best genotype under diferent environmental conditions, the methodology of EBERHART and RUSSEL (1966), based on phenotypical stability, was used for comparison.

The data utilized were collected from maize hybrids yield trials conducted over a period of three years. Seven hybrids were evaluated in 9 locations in 1992/93, 17 hybrids in 13 locations in 1993/94, and 18 hybrids in 19 locations in 1994/95.

The methodology based on the distance to the maximum yield and minimum lodging was useful to quantify the hybrids distance to the best genotype in all environments, favorable and unfavorable. By comparing this methodology with that proposed by EBERHART and RUSSEL (1966) the majority of hybrids with similar distance values in the favorable and unfavorable environments had general adaptability. 
Since every year new hybrids were introduced to be tested across locations, the distance to the best genotype methodology allowed comparing the performance of these new materials in relation to the others. This provided an evidence of genetic gain in the breeding programs as the more recently developed hybrids were better in terms of yield and lodging. As an example, hybrids AG 5011 and AG 4011 appeared as being very close to the best genotype for yield and lodging.

In the analysis of stability for yield, the maximum value (that is the best conceptual genotype) was introduced, showing general adaptability and high stability. This procedure allowed a better understanding of the adaptability and stability of the best genotype.

Simulation studies indicated that the distribution of values of distance to the maximum is not normal. Consequently, tests of hypothesis requiring normality of errors were not made. Expression of the error of distance estimates were also not given. These aspects require additional investigations. 


\section{INTRODUÇÃO}

A cada ano são avaliadas novos cultivares de milho em diferentes regiões do Brasil, visando determinarIhes o desempenho em relação à produtividade e outras caracteristicas importantes, sendo estes testados em diferentes condições de solo e clima. Para isso, são instalados experimentos de avaliação que incluem os cultivares mais plantados pelos agricultores, cultivares novos, recém-lançados no mercado e cultivares que estão em fase experimental. Na maioria das vezes, usa-se como critério de seleção dos melhores cultivares, aqueles que apresentam os maiores rendimentos médios nos locais de teste. Porém, a indicação generalizada, sem considerar que existem ambientes favoráveis e desfavoráveis, pode beneficiar os cultivares que tiveram maiores produtividades nos ambientes favoráveis mas que podem ter produzido pouco nos ambientes desfavoráveis. Também pode ocorrer que um dos cultivares se destaque em certas localidades, enquanto, em outra um cultivar diferente o suplante. Essa diferença de comportamento dos cultivares 
nos diversos ambientes é explicada pela interação genótipos x ambientes.

Dada a importância desta interação, cabe ao pesquisador avaliar sua magnitude e significância, quantificar seus efeitos sobre as técnicas de melhoramento e estratégias de difusão do novo cultivar e fornecer subsidios que possibilitem adotar procedimentos para a sua minimização (CRUZ e REGAZZI, 1994).

$\mathrm{Na}$ avaliação da interação genótipos $\mathrm{x}$ ambientes, é de grande importância o uso de ferramentas estatísticas que ajudem o pesquisador a determinar qual cultivar tem o melhor desempenho de modo que, dada uma afirmação, ela tenha o menor erro possível.

Assim, o objetivo do presente trabalho, foi desenvolver uma metodologia que determine a distância de um cultivar em relação a um melhor genótipo. Um cultivar ideal seria aquele que produzisse o máximo em todos os locais e, se associado a uma outra característica como por exemplo a porcentagem de tombamento, seria aquele que além de produzir o máximo, tivesse a porcentagem de tombamento mínima em todos os locais testados. Além disso, objetivouse estudar como se comportam os cultivares de menor e maior distância ao melhor genótipo, frente às variações ambientais. Para tal realizaram-se análises de 
adaptabilidade e estabilidade, pelas quais foi possivel a identificação de cultivares de comportamento previsível e que responderam às variações ambientais, em condições específicas ou amplas. 


\section{REVISÃO DE LITERATURA}

\subsection{A Cultura do Milho}

Como serão usados para aplicação dados de milho híbrido, nesta revisão será dada maior ênfase ao milho.

MIRANDA FILHO \& VIÉGAS (1987) afirmam que a introdução do milho híbrido na década de 1920 deu um grande impulso à Agricultura moderna. Os estudos que sobrevieram à introdução do milho híbrido trouxeram ainda contribuições de importância, tanto prática quanto científica. A contribuição dos melhoristas de milho foi de importância extraordinária para os aumentos constantes na produtividade do milho híbrido.

MOURA $(1996)^{I}$ comenta que para o ano de 1995 - Brasil alcançou uma produção de 37,4 milhões de toneladas

\footnotetext{
1 MOURA, L. C. (Acessoria de Estudos Econômicos da Agroceres)
} comunicação pessoal, 1996. 
numa área de 14,2 milhões de hectares, com uma produtividade de $2631 \mathrm{~kg} / \mathrm{ha}$.

A data de plantio correta de um determinado híbrido é importante para que se tenha excelente produtividade. OLIVEIRA (1990) comenta que, no período de espigamento ao final da maturação fisiológica, o qual é caracterizado por um processo de enchimento dos grãos, a temperatura é um fator muito significativo no aumento do peso seco. Ocorre a necessidade de se ter temperatura adequada no amadurecimento fisiológico, pois, a planta de milho passa por um processo contínuo de perda de água, intensificado pelo sol e ventos, com ligeira queda do seu peso.

o autor comenta ainda que a fase de pendoamento à fertilização, apesar de curta duração, é sumamente importante para a produção, pois o aparecimento da inflorescência feminina e a sua polinização são processos que vão determinar o número de grãos na espiga. 


\subsection{Interação Genótipos x Ambientes.}

BRASIL (1990) comenta que as interações de genótipos com ambientes trazem aos melhoristas dificuldades na identificação de genótipos superiores, seja por ocasião da seleção, seja no momento da recomendação de cultivares. A presença de interações de genótipos com ambientes implica que o comportamento relativo dos genótipos nos testes depende, fundamentalmente, das condições ambientais às quais são submetidos. Desta forma, a resposta fenotípica de qualquer genótipo em relação a outros poderá ser inconsistente. Essa inconsistência se manifesta através da alteração da posição relativa dos genótipos de um ambiente para o outro ou em alterações na magnitude das diferenças absolutas entre seus fenótipos, sem que a ordem dos mesmos seja alterada.

RAMALHO et alIi (1989) enfatizam que o fenótipo é o resultado do genótipo + ambiente + interação genótipos por ambientes. Assim, tem-se: $F=G+A+G A . A$ interação genótipos por ambientes é um fenômeno amplamente disseminado entre as plantas e os animais, e inúmeros exemplos são conhecidos. Ela é o principal complicador do trabalho dos melhoristas, exigindo que o melhoramento seja conduzido nas condições em que o genótipo será utilizado. 
MIRANDA (1993) comenta que a interação genótipos $x$ ambientes pode ser definida como a inconsistência de comportamento dos genótipos quando submetidos a vários ambientes.

Allard $\varepsilon$ Bradshaw. $(1964)^{2}$, citados por MIRANDA (1993) dividiram a interação genótipos $\mathrm{x}$ ambientes em partes simples e complexa. A forma simples acontece quando os genótipos apresentam uma variabilidade de comportamento nos ambientes, sem, no entanto, alterar a posição relativa entre eles. Este tipo de interação não causa problema ao melhorista, uma vez que o genótipo superior é o mesmo em todos os ambientes. A interação em sua forma complexa, no entanto, ocorre quando os genótipos apresentam diferentes respostas com as variações dos ambientes, causando uma alteração na classificação deles, dificultando a seleção de um cultivar para os vários ambientes.

Robertson (1959) ${ }^{3}$, citado por BRASIL (1990) demonstra que o componente da variância devido à interação genótipo $x$ ambiente, pode ser desdobrado em duas partes, através da seguinte fórmula:

\footnotetext{
2 ALIARD, R.W $\varepsilon$ A.D. BRADSHAW (1964). Implications of genotype - enviromental interactions in applied plant breeding. Crop Sci., Madison, 4:503-508. 3 ROBERTSON, A. The Sampling Variance of the Genetic
Correlation 485,1959 .
} 
$\sigma_{g a}^{2}(1,2)=\frac{1}{2}\left(\sigma_{g 1}-\sigma_{g 2}\right)^{2}+\sigma_{g 1} \sigma_{g 2}\left(1-r_{1,2}\right)$

sendo :

$\sigma_{g 1}$ : a variância genética no ambiente 1 ;

$\sigma_{g 2}$ : a variância genética no ambiente 2;

$r_{1,2}$ : o coeficiente de correlação entre os ambientes 1 e 2. Por esta fórmula, pode-se atribuir a interação com ambientes a duas causas. A primeira parte da fórmula, ou componente $A$, se deve à diferença das variâncias genéticas entre os materiais nos locais 1 e 2. A segunda parte da fórmula, ou componente B, é atribuída à falta de correlação dos valores genotípicos dos tratamentos de um local para outro.

CRUZ $\varepsilon$ REGAZZI (1994) comentam que a avaliação da interação genótipos $x$ ambientes torna-se de grande importância no melhoramento, pois, no caso de sua existência, há possibilidades de o melhor genótipo em um ambiente não $\circ$ ser em outro. Este fato influencia o ganho de seleção e dificulta a recomendação de cultivares com ampla adaptabilidade. Pela importância desta interação, cabe ao melhorista avaliar sua magnitude e significância, quantificar seus efeitos sobre as técnicas de melhoramento e estratégias de difusão de tecnologia e fornecer subsídios 
que possibilitem adotar procedimentos para sua minimização e, ou, seu aproveitamento.

SANTOS (1980) comenta que, quando se testam genótipos em vários locais e anos, normalmente os seus comportamentos não são constantes nos diferentes ambientes. Esta oscilação de comportamento gera uma interação de genótipos por ambientes que, quando significativa, é uma indicação de que podem existir genótipos particulares para determinados tipos de ambientes e, possivelmente, genótipos menos influenciáveis pelas variações ambientais.

VENCOVSKY $\varepsilon$ BARRIGA (1992) comentam que é importante avaliar as magnitudes das interações do tipo genótipos $x$ locais, genótipos $x$ anos ou mesmo outras. Esse conhecimento orienta no planejamento e estratégias do melhoramento, na recomendação de cultivares além de ser determinante na questão da estabilidade fenotípica dos cultivares, para cada região.

SANTOS (1980) destaca a importância de se avaliar as magnitudes das interações genótipos $x$ locais, genótipos $x$ anos, e genótipos $x$ locais $x$ anos, para decidir se apenas locais, anos ou a combinação de locais e anos devem ser considerados, a fim de se determinar com melhor eficiência a estabilidade fenotípica dos cultivares para uma determinada região. 
Segundo Allard $\varepsilon$ Bradshaw $(1964)^{2}$, citados por VENCOVSKY $\varepsilon$ BARRIGA (1992), as condições ambientais, que contribuem para as interações com os genótipos, podem ser agrupadas em duas categorias a saber: as previsiveis e as imprevisíveis. Na primeira, incluem-se as variações de ambiente que ocorrem de região para região, dentro da área de distribuição da cultura. Enquadram-se aí as caracteristicas gerais de clima e solo e aquelas que flutuam de maneira sistemática, como o comprimento do dia, - grau de insolação e outras. Também incluem-se, neste grupo, os fatores de ambiente que estão sob controle do homem, como as práticas agronômicas, tais como a época de semeadura e colheita, etc. As variações imprevisiveis compreendem, por exemplo, as climáticas, no âmbito de uma mesma região, como a quantidade e distribuição de chuva, as oscilações de temperatura e outras que não podem prever com segurança.

EBERHART $\varepsilon$ RUSSEL (1966) comentam que a estratificação ambiental é usada efetivamente para reduzir a interação genótipos $x$ ambientes. A estratificação consiste em subdividir a região na qual o pesquisador está desenvolvendo variedades melhoradas em subregiões homogêneas. Essa estratificação é baseada normalmente em 
diferenças macroambientais, como gradientes de temperatura, distribuição de chuvas e tipos de solos.

OLIVEIRA (1976) comenta que com este refinamento da técnica, a interação de genótipos com locais dentro de uma sub-região e com ambientes no mesmo local em diferentes anos, frequentemente permanece também grande.

TAI (1971) concorda que a obtenção de cultivares com maior estabilidade fenotípica é uma medida mais eficiente, menos onerosa e mais fácil para diminuir a interação genótipos x ambientes.

\subsection{Adaptabilidade e Estabilidade.}

BRASIL (1990) comenta que os caminhos para o estudo das interações de genótipos com ambientes, baseados em medidas tomadas a partir do comportamento das plantas, podem ser classificados em dois grandes grupos. O primeiro grupo procura estudar a interação através do detalhamento do efeito de cultivares dentro de grupos de locais homogêneos; nesse grupo estão os métodos de zoneamento ecológico. Outra maneira de se estudar as interações de genótipos com ambientes seria através da determinação do comportamento de cada cultivar nos diversos ambientes, ou seja, detalhando-se os efeitos de ambientes dentro de 
cultivares. Esses métodos são conhecidos como métodos de determinação de estabilidade fenotípica de cultivares. STORCK (1989) comenta que as diferenças entre os cultivares, quanto à resposta à variação ambiental, são avaliadas através da interação de cultivares com ambientes obtida da análise de grupos de experimentos e - seu desdobramento em regressões, dentro de cada cultivar, em função do valor ambiental. Estes procedimentos estatísticos são conhecidos como análise de estabilidade de cultivares.

MARIOTTI et alii (1976) definem estabilidade como sendo a capacidade dos genótipos de exibirem um comportamento altamente constante em função da qualidade ambiental. Definem ainda a adaptabilidade como sendo a capacidade potencial dos genótipos de aproveitarem vantajosamente o estímulo ambiental.

Segundo ALLARD $\varepsilon$ BRADSHAW (1964), um cultivar estável é aquele que pode ajustar seu estado genotipico ou fenotípico às flutuações ambientais, de modo que forneça caminhos nos quais dão altos retornos econômicos, para um dado local e ano. BONATO (1978) comenta que a metodologia mais antiga para avaliar os genótipos, frente às variações ambientais, é a tradicional análise de grupos de 
experimentos. Através dessa análise, a magnitude das interações é avaliada pela variância dos efeitos dos genótipos $x$ anos, genótipos $x$ locais e genótipos $x$ anos $x$ locais.

CAMPOS (1984) considera que o agrupamento dos experimentos, para uma análise conjunta, poderá obedecer a diferentes critérios, dentre os quais, podem ser citados : a) por setores geográficos, b) por ano agrícola, c) por afinidade quanto a alguma característica de interesse, e d) pela ordem de grandeza dos quadrados médios dos resíduos (OMR) das análises individuais. Neste particular recomenda-se o agrupamento de ensaios cujos QMR não difiram além de uma relação de $4: 1$.

Stringfield $\varepsilon$ Salter $(1934)^{4}$ citados por BECKER $\varepsilon$ LEON (1988) devem ter sido, provavelmente, os primeiros a calcular o coeficiente de regressão linear para caracterizar a resposta especifica de genótipos às variações ambientais.

YATES $\&$ COCHRAN (1938) sugeriram desdobramento da interação genótipos $x$ ambientes, através do cálculo de uma regressão linear entre as produtividades

4 STRINGEIELD, G.H., \& SALTER, R.M. Differential response of corn varieties to fertility levels and to seasons. J.Agric.Res. 49: $991-100,1934$. 
de um dado genótipo, em diferentes ambientes, e as respectivas médias de todos os genótipos, em cada ambiente.

CRUZ $\varepsilon$ REGAZZI (1994) descrevem o método tradicional como sendo o método que consiste na análise conjunta dos experimentos, considerando todos os ambientes e o posterior desdobramento da soma de quadrados dos efeitos de ambientes e da interação genótipos $x$ ambientes, em efeitos de ambientes dentro de cada genótipo. A variação de ambientes dentro de cada genótipo é utilizada como estimativa da estabilidade, de tal forma que o genótipo que proporcionar menor quadrado médio, nos vários ambientes, será considerado o mais estável. Este método apresenta a vantagem de poder ser aplicado nas situações em que se dispõe de um número restrito de ambientes (por exemplo, um mínimo de três ambientes). Apresenta, entretanto, como desvantagens o fato de o parâmetro de estabilidade ser pouco preciso e de se fazer uso de um conceito de estabilidade que não é de grande interesse para o melhorista. O conceito de estabilidade de um genótipo, expresso pela variância mínima entre ambientes, tem sido pouco utilizado pelos melhoristas, possivelmente pelo fato de os genótipos que mantêm comportamento regular entre os ambientes serem, em geral, pouco produtivos. Além disso, esse conceito não é apropriado para avaliar o padrão de 
comportamento dos genótipos frente às variações ambientais. o estimador do parâmetro de estabilidade é descrito por:

$Q M\left(A / G_{I}\right)=\frac{r}{(a-1)}\left[\sum_{j} Y_{i j}-\frac{\left(Y_{i .}\right)^{2}}{a}\right]$

sendo:

$a$ : o número de ambientes

$Y_{i j}$ : a observação do $i$-ésimo tratamento no $j$-ésimo local

$Y_{i .}$ : total do $i$-ésimo genótipo

$r$ : é o número de repetições.

PLAISTED $\varepsilon$ PETERSON (1959) apresentaram um método para caracterizar a estabilidade de uma variável como a produtividade. O método possui os seguintes passos:

1) Eazer análise de variância para todas as variedades em todos os locais em um certo ano. Se a interação variedades x locais é significativa, os seguintes passos são seguidos:

2) As análises de variância são realizadas para todas as combinações de pares de variedades em todos os locais. Se há $n$ variedades, haverá $\frac{n(n-1)}{2}$ análises.

3) O conjunto de análises fornece uma estimativa de $\sigma_{v l}{ }^{2}$ (componente de variância da interação variedades x locais) para cada par de variedades. 
4) A média aritmética destas estimativas é obtida para cada variedade. A variedade que apresentar o menor valor médio é a que contribui menos para as interações variedades $x$ locais e, assim, é considerada a mais estável para o teste realizado.

Mais tarde, PLAISTED (1960) propôs uma modificação no método acima, que reduz a quantidade de cálculos e mantém a mesma interpretação. Considera a estabilidade, para determinado cultivar, como sendo a diferença entre a variância da interação obtida pela análise completa e a análise dos demais cultivares, em todos os ambientes.

BARRIGA (1980) comenta que vários trabalhos falham em fornecer uma medida da estabilidade, através da quantificação relativa e significância estatística do componente da variação da interação genótipos x ambientes. Entretanto, a partir do trabalho de FINLAY $\varepsilon$ WILKINSON (1963), é que tiveram início diferentes aproximações analiticas que permitem a avaliação e interpretação simples da resposta de diferentes genótipos à variação ambiental.

FINLAY $\varepsilon$ WILKINSON (1963) propuseram um método no qual é feito uma regressão linear para cada genótipo, em que a variável dependente é a produtividade de 
grãos e a independente é o índice ambiental (média de todos os genótipos no dado ambiente). Antes da análise de regressão, os dados de produtividade de grãos são transformadas para a escala logarítmica. Para os autores, esta transformação induz a um alto grau de linearidade nas regressões dos genótipos e também a um razoável grau de homogeneidade do erro experimental.

$$
\text { CRUZ } \varepsilon \text { REGAZZI (1994) descrevem as }
$$

características do método apresentado por FINLAY $\varepsilon$ WILKINSON (1963), adotando o seguinte modelo de regressão linear:

$$
Y_{i j}=\beta_{0 i}+\beta_{1 i} X_{j}+\delta_{i j}+\bar{\varepsilon}_{i j}
$$

em que:

$Y_{i j}$ : média do genótipo i, no ambiente j, obtida de dados preliminares transformados para a escala logaritmica; $\beta_{0 i}:$ constante da regressão;

$\beta_{1 i}$ : coeficiente da regressão;

$X_{j}$ : Indice ambiental definido por: $X_{i j}=\frac{1}{g} \sum_{i} Y_{i j}$, em que $g$ é - número de genótipos.

$\delta_{i j}:$ desvio da regressão;

$\bar{\varepsilon}_{i j}$ : é o erro experimental médio. 
Para maiores facilidades operacionais, utiliza-se o indice ambiental codificado $\left(I_{j}\right)$, dado por:

$I_{j}=\frac{1}{g} \sum_{i} Y_{i j}-\frac{1}{g a} Y_{.}$, em que $a$ é número de ambientes e $\sum_{j} I_{j}=0$ Com a utilização deste indice, tem-se:

$\hat{\beta}_{0 i}=\bar{Y}_{i .}=$ média do genótipo $i$.

Os autores comentam que as estimativas de $I_{j}$ são de grande utilidade, por serem indicativas da qualidade dos ambientes avaliados. Valores negativos de $I_{j}$ identificam os ambientes desfavoráveis, normalmente associados a regiões de condições climáticas, ou de solo, adversas ou a áreas de emprego de baixa tecnologia de produção, em razão do uso de quantidade e qualidade de insumos e/ou equipamentos agrícolas insuficientes. Valores positivos de $I_{j}$ identificam os ambientes favoráveis, considerados pelos melhoristas como sendo regiões com condições edáficas e climáticas apropriadas à aptidão da cultura ou, outras vezes, que evidenciam áreas de cultivo onde se emprega alta tecnologia de produção, caracterizada pelo uso de insumos adequados, por controles culturais rotineiros e pela mecanização agrícola.

$$
\text { WRICKE (1965), em seu trabalho na }
$$

determinação de estabilidade de cultivares, denominou de 
ecovalência o parâmetro que estima a contribuição de cada genótipo na interação total de genótipos com ambientes. A metodologia consiste em se calcular o efeito da interação em cada combinação de cultivares com ambientes. A soma de quadrados desses efeitos é dada através da formula:

$W_{i}=\sum_{j=1}^{J}\left(x_{i j}-\frac{x_{i .}}{J}-\frac{x_{. j}}{I}+\frac{x}{I J}\right)^{2}$

em que:

$I$ : é o número de genótipos;

$J$ : é o número de locais;

$x_{i j}$ : é a observação do genótipo $i$ no local $j$;

$x_{i .}$ : é o total do genótipo $i$;

$x_{. j}$ : é o total do local $j$;

$x_{.}$: é o total geral.

Com r repetições a contribuição de cada cultivar nas soma de quadrados da interação total é dada por r $W_{i}$, que corresponde à ecovalência.

EBERHART $\varepsilon$ RUSSEL (1966) propuseram um método semelhante ao de FINLAY $\varepsilon$ WILKINSON (1963). Difere deste porque a estabilidade de cada cultivar é determinada em função de produtividade média, coeficiente de regressão e desvio da regressão. 
Os autores descreveram o seguinte modelo:

$Y_{i j}=\mu_{i}+\beta_{1 i} I_{j}+\delta_{i j}$

em que:

$Y_{i j}$ é a média do i-ésimo cultivar no j-ésimo local $\mathrm{com} i=1,2, \ldots, \mathrm{v}$ e $j=1,2, \ldots, n$;

$\mu_{i}$ é a média do i-ésimo cultivar sobre todos os locais; $\beta_{i}$ é o coeficiente de regressão que mede a resposta da i-ésimo cultivar para diversos locais;

$\delta_{i j}$ é o desvio da regressão;

$I_{j}$ é o indice ambiental obtido como sendo a média de todas as variedades no j-ésimo local, menos a média geral.

$$
I_{j}=\frac{\sum_{i} Y_{i j}}{v}-\frac{\sum_{i} \sum_{j} Y_{i j}}{v n}, \sum_{j} I_{j}=0
$$

os parâmetros de estabilidade são conșiderados como sendo, o coeficiente de regressão $\left(b_{i}\right)$ e - estimador do componente de variância dos desvios da regressão linear $\left(S_{d i}{ }^{2}\right)$. O cultivar é definido como estável, quando $b_{i}=1,0$ e $S_{c t}{ }^{2}=0$. Quando $b_{i}<1,0$, o cultivar tem adaptabilidade específica para ambientes desfavoráveis, com $b_{i}>1,0$ tem adaptabilidade especifica para ambientes 
favoráveis e quando $b_{i}=1,0$ ○ cultivar tem adaptabilidade geral.

Quanto ao conceito de estabilidade, BONATO (1978) comenta as diferenças entre os métodos de FINLAY $\varepsilon$ WILKINSON (1963) e EBERHART $\varepsilon$ RUSSEL (1966). FINLAY $\varepsilon$ WILKINSON (1963) consideram como cultivar ideal aquele que apresenta maior potencial de produtividade na maioria dos ambientes e que tem coeficiente da regressão linear igual ou próximo de zero $(b \cong 0)$. Já EBERHART $\varepsilon$ RUSSEL (1966) classificam como desejável o cultivar que apresenta alta média de produtividade, coeficiente de regressão igual a unidade $(b=1)$ e variancia dos desvios igual a zero $\left(\sigma_{d_{i}}^{2}=0\right)$

Tai (1971) 5 citado por MIRANDA (1993), tomou por base os métodos de FINLAY $\varepsilon$ WILKINSON (1963) e EBERHART E RUSSEL (1966), desenvolvendo um processo para evitar a desvantagem da utilização dos índices ambientais como variável independente, uma vez que esses índices são estimados com base nos próprios genótipos estudados, estando portanto, sujeitos a erros. Demonstrou que o método dos mínimos quadrados não permite obter um estimador não

\footnotetext{
5 TAI, G.C.C. Genotypic stability analysis and its application to
} potato regional trials. Crop Science, Madison 11:184-90, 1971. 
viesado do coeficiente de regressão linear, quando a variável independente está associada a erros. Apresentou, então, os seguintes parâmetros de estabilidade:

$\widetilde{b}_{i}$ como a medida da resposta linear do i-ésimo genótipo sob os efeitos dos ambientes e $\lambda_{i}$ como o desvio da resposta linear em termos de magnitude de variância do erro, em relação ao erro associado à interação genótipos x ambientes. O genótipo ideal apresentaria $\tilde{b}=-1$ e $\lambda=1$.

SHUKLA (1972) sugeriu um estimador viesado da variância da estabilidade - Seja $\bar{Y}_{i j}$ a produção média comercial do $i$-ésimo genótipo $(i=1,2, \ldots, m)$ no $j$-ésimo experimento $(j=1,2, \ldots, n)$. A variância da estabilidade para a produtividade comercial do i-ésimo genótipo é estimada como:

$\hat{\sigma}_{i}^{2}=\frac{1}{(m-1)(n-1)(n-2)}\left[n(n-1) \sum_{j}\left(\bar{Y}_{i j}-\bar{Y}_{i .}-\bar{Y}_{. j}+\bar{Y}_{.}\right)^{2}-\sum_{i} \sum_{j}\left(\bar{Y}_{i j}-Y_{i .}-\bar{Y}_{. j}-\bar{Y}_{. j}\right)^{2}\right]$ A significância de $\hat{\sigma}_{i}{ }^{2}$ é testada por um teste $\mathrm{F}$ aproximado, $F^{*}=\frac{\hat{\sigma}_{i}^{2}}{\hat{\sigma}_{0}{ }^{2}} \operatorname{com}(\mathrm{m}-1)$ e $\mathrm{mn}(\mathrm{p}-1)$ graus de liberdade, no qual $\hat{\sigma}_{0}{ }^{2}$ é o quadrado médio do erro e p o número de repetições num experimento. Um genótipo cujo $\hat{\sigma}_{i}{ }^{2}$ não é significativamente maior que $\hat{\sigma}_{0}{ }^{2}$ é definido como estável. 
SILVA (1995) comenta sobre a crítica de que as variáveis preditoras da análise de regressão linear são funções do indice de ambiente. Para o autor e de acordo Com HARDWICK $\varepsilon$ WOOD (1972) e HILL (1975), a consequência da violação que origina esta crítica é a tendenciosidade das estimativas dos coeficientes de regressão. Entretanto, não resultará qualquer tendenciosidade séria, se o experimento incluir um número razoável de genótipos e a amplitude de ambientes for tal que o quadrado médio de ambientes seja significativamente maior que o quadrado médio do erro.

JOWETT (1972) estudou e comparou os métodos de FINLAY $\varepsilon$ WILKINSON (1963), WRICKE (1965) e EBERHART $\varepsilon$ RUSSEL (1966), aplicando-os a dados de produtividade de sorgo. Concluiu que o método de WRICKE (1965), que é baseado em apenas um parâmetro chamado de ecovalência, é o menos informativo. Concluiu ainda, que, quando os cultivares diferem muito em produtividade, 0 método de FINLAY \& WILKINSON (1963), que utiliza a transformação logarítmica dos dados, deve ser o preferido.

Pinthus (1973)6, citado por BECKER \& LEON (1988), propõe o uso do coeficiente de determinação $\left(r_{i}^{2}\right)$ no

6 PINThus, M. J. Estimate of genotypic value: A proposed method. Euphytica. Wageningen, 22:121-123, 1973. 
lugar do quadrado médio dos desvios de regressão, para estimar a estabilidade dos genótipos.

CRUZ $\varepsilon$ REGAZZI (1994) comentam que algumas vezes pode ocorrer que muitos genótipos, com rendimento médio superior, apresentam $\sigma_{d i}{ }^{2}$ estatisticamente diferente de zero. Porém, pode ser necessária a seleção de alguns genótipos do grupo em que a estabilidade lou previsibilidade) for baixa . Nesses casos, uma medida auxiliar de comparação entre estes genótipos é o coeficiente de determinação $R_{i}^{2}$.

BONATO (1978) em seu estudo com cultivares de soja, obteve similaridade entre os cultivares quanto ao seu comportamento Iinear, concluindo que a diferenciação da estabilidade só pôde ser feita através da magnitude dos desvios da Iinearidade.

BECKER $\varepsilon$ LEON (1988) comentam que ambas as estatísticas $r_{i}^{2}$ e $b_{i}$ possuem a vantagem de serem independentes da unidade de medida.

VERMA et alii (1978), definem um cultivar ideal quando este apresentar baixa resposta nos ambientes desfavoráveis e alta resposta nos ambientes favoráveis, aliados a uma alta produtividade. Os autores propõem uma metodologia que consiste no ajustamento de dois segmentos 
de reta, possibilitando descrever a resposta dos genótipos nos locais de baixa e nos de alta produtividade, buscando genótipos que tenham resposta constante em ambientes desfavoráveis e a mais elevada resposta em ambientes favoráveis.

BARRIGA (1980), em seu trabalho de caracterização de cultivares de mandioca com relação a produtividade e estabilidade, observou que os cultivares mais estáveis tenderam à menor produtividade. Já HUEHN (1990) considerou que o cultivar estável seria aquele que apresentasse a mesma classificação nos vários ambientes.

PHAM \& KANG (1988), comentam e classificam um genótipo em: (1) estável se nos locais testados teve variância pequena, (2) estável se sua resposta nos locais testados é paralela à média de todos os genótipos no experimento, (3) estável se o quadrado médio residual da análise de regressão dos locais for pequeno.

Verma et alii $(1978)^{7}$, citado por CROSSA (1988), classifica os genótipos baseado no estimador $b_{i}$, nos locais de baixa produtividade (LBP) e nos locais de alta produtividade (LAP), obtendo a seguinte tabela:

\footnotetext{
7 VERMA,M. M; G. S. CHAHAL e B. R. MURTY, 1978. Limitations of Conventional Regression Analysis a Proposed Modification. Theor. Apll. Genet., Berlim, 53:89-91.
} 
Tabela 1. Classificação dos genótipos com base nos valores de $b_{i}$.

\begin{tabular}{lll}
\hline \multicolumn{2}{c}{$b_{i}$} & \\
\hline LBP & LAP & \\
\hline$<1.0$ & $<1.0$ & melhor para LBP \\
$>1.0$ & $<1.0$ & melhor para LBP \\
$<1.0$ & $=1.0$ & Ideal \\
$<1.0$ & $>1.0$ & Ideal \\
$>1.0$ & $>1.0$ & melhor para LAP \\
\hline
\end{tabular}

$$
\text { STORCK (1989) comenta que alguns }
$$

pesquisadores usam a variância dentro de cada cultivar como estimativa da estabilidade, de modo que os cultivares com menores variâncias são mais estáveis. Estes são cultivares não sensiveis à variação ambiental e são, normalmente, acompanhados de médias baixas de rendimento, sendo o seu uso, atualmente, muito restrito. Também é desejável, para uma análise de estabilidade eficiente, uma boa amplitude de variação ambiental para instalar grupos de experimentos. Desse modo, dificilmente haverá cultivares estáveis por este conceito. o autor apresenta ainda metodologias baseadas unicamente em análises de variância, metodologias baseadas em análises de variância e de regressão e metodologias baseadas em regressões bissegmentadas.

As metodologias baseadas unicamente em análises de variância, são técnicas menos precisas, mas que podem ser aplicadas quando se dispõe de um número restrito 
de ambientes $(4$ e 5). Como exemplo citam-se o Método Tradicional e o proposto por PLAISTED \& PETERSON (1959).

As metodologias baseadas em análises de variância e de regressão, são técnicas mais precisas, que possibilitam uma avaliação mais detalhada do comportamento de cada cultivar e requerem, para a sua aplicação, um número não muito grande de ambientes (5 ou mais). Como exemplo citam-se as metodologias propostas por FINLAY $\varepsilon$ WILKINSON (1963); EBERHART $\varepsilon$ RUSSEL (1966) e TAI (1971).

As metodologias, baseadas em regressões bissegmentadas, são técnicas que permitem um detalhamento maior tanto do comportamento do cultivar quanto do conjunto de ambientes disponíveis. Para a sua aplicação é necessário um número relativamente grande de ambientes (maior que 8). Como exemplo citam-se as metodologias propostas por VERMA et alii (1978); SILVA $\varepsilon$ BARRETO (1985) e CRUZ et alii (1989) .

CRUZ et alii (1989) utilizaram, como parâmetros de adaptabilidade, a média e a resposta linear aos ambientes desfavoráveis e favoráveis $\left(\hat{\boldsymbol{\beta}}_{1 i}\right.$ e $\hat{\boldsymbol{\beta}}_{1 i}+\hat{\boldsymbol{\beta}}_{2 i}$ respectivamente) $e$, de estabilidade, os desvios da regressão de cada cultivar em função das variações ambientais, e também o coeficiente de determinação. o 
genótipo ideal é aquele com média alta, $\hat{\beta}_{1 i}\left\langle 1, \hat{\beta}_{1 i}+\hat{\beta}_{2 i}\right\rangle 1$ e $\hat{\sigma}_{d i}=0$.

$$
\text { Virk et alii }(1988)^{8} \text {, citados por GLAUCO }
$$

(1993) testaram os modelos linear, quadrático, cúbico e de regressão bi e tri-segmentada, em dados obtidos com híbridos de milheto (Pennisetum typhoides Burm). Concluíram que as regressões linear e bi-segmentada foram as mais eficientes e que $\circ$ modelo tri-segmentado apresentou uma desvantagem de difícil interpretação biológica, não sendo recomendado.

BRASIL (1990) propôs o seguinte modelo de regressão:

$Y_{i j}=\beta_{0 i}+\beta_{1 i} I_{j}+\beta_{2 i} I_{j}^{2}+\delta_{i j}$

em que : $Y_{i j}$ é o valor fenotípico do cultivar i no local j;

$\beta_{0 i}$ : é o valor fenotípico esperado do cultivar i no ponto correspondente ao local de índice ambiental zero $\left(I_{j}=0,00\right)$;

8 VIRK, D.S.; VIRK, P.S.; MANGAT, B.K. e HARINARAYANA, G., Linear and non linear regression analysis of genotype $x$ enviroment interactions in pearl millet. Theor. Appl. Genet., Berlim, 75 $736-40,1988$. 
$\beta_{1 i}$ : é o coeficiente de regressão de primeiro grau da resposta dos cultivares aos locais, correspondendo à inclinação da reta tangente à curva no ponto correspondente ao indice ambiental zero $\left(I_{j}=0,00\right)$;

$\beta_{2 i}$ : é o coeficiente de regressão que mede o efeito quadrático da resposta dos cultivares aos locais;

$I_{j}$ : é o índice ambiental, conforme definido para o modelo de EBERHART \& RUSSEL (1966).

$\delta_{i j}=$ desvio da regressão quadrática do cultivar i no local j.

- autor comparou este método com o método de regressão linear de EBERHART $\varepsilon$ RUSSEL (1966) e o de linear segmentada de SILVA $\varepsilon$ BARRETO (1985) modificada. Concluiu que as três metodologias se equivaleram no que se refere à explicação da variação observada; entretanto para casos particulares, os modelos linear segmentado e quadrático proporcionaram uma redução sensível no coeficiente de nãodeterminação em relação ao modelo linear. Os cultivares selecionados pelo modelo de regressão linear segmentada, 
coincidiram com aquelas selecionadas através do modelo quadrático. O modelo de regressão Iinear mostrou-se menos informativo por não medir, diferencialmente, a resposta de cultivares aos niveis de ambiente.

OLIVEIRA (1976) concluiu que os métodos de PLAISTED $\varepsilon$ PETERSON (1959), WRICKE (1965) e o Tradicional são pouco informativos. O autor comenta que, para estes métodos, não há um caminho para se estudar o comportamento de cada genótipo em relação às condições de cada ambiente, uma vez que seus parâmetros de estabilidade apenas informam a magnitude de variação dos genótipos para as condições ambientais médias.

Westcott (1987) ${ }^{9}$, citado por CROSSA (1988), propôs a seguinte equação para medir a similaridade entre dois tratamentos, a e b num dado local i:

$S_{i}(a, b)=\left[H_{i}-\left(a_{i}+b_{i}\right) / 2\right] /\left(H_{i}-L_{i}\right)$

em que :

$H_{i}$ : é a maior produtividade do tratamento no local i;

$L_{i}$ : é a menor produtividade do tratamento no local i;

$a_{i}$ : é a média de produtividade do tratamento a no local i;

$b_{i}$ : é a média de produtividade do tratamento b no local i.

9 WESTCOTT,B. A method of assessing the yield stability of crop genotypes. J. Agric: Sci. Cambridge, 108:267-274, 1987. 
Quando mais de um local é considerado, a similaridade entre os genótipos a e b é definida como a média de $S_{i}(a, b)$ dos locais envolvidos. Com este método fazse o agrupamento dos genótipos e observa-se a estabilidade de um genótipo quando se passa de um local a outro.

TOLER (1990), desenvolveu o seguinte modelo:

$Y_{i j}=\alpha_{i}+\left[Z_{j} \beta_{1 i}+\left(1-Z_{j}\right) \beta_{2 i}\right] \mu_{j}+\varepsilon_{i j}$

e classifica os genótipos em 5 grupos (A a E), a saber:

A: resposta convexa duplamente desejável $\left(\hat{\beta}_{1}<1<\hat{\beta}_{2}\right)$.

B: resposta linear simples e desejável somente para ambientes de alta qualidade $(\hat{\beta}>1)$.

C: resposta linear simples não desviando da resposta média $(\hat{\beta}=1)$.

D: resposta linear simples e desejável somente para ambientes de baixa qualidade $(\hat{\beta}<1)$.

E: resposta duplamente indesejável $\left(\hat{\beta}_{1}>1>\hat{\beta}_{2}\right)$.

Este modelo difere dos demais bissegmentados porque $u_{j}$ (índice ambiental), é estimado conjuntamente com os demais parâmetros através de quadrados mínimos não Iineares. 
2.4. Método de estimação da distância à produtividade máxima

IIN, C.S $\varepsilon$ BINNS, M.R., (1988), definiram como medida de superioridade geral de um cultivar, para dados do tipo cultivares $x$ locais, o quadrado médio da distância entre a resposta do cultivar e a resposta média máxima para todos os locais. Desde que a resposta máxima esteja no limite superior em cada local, o quadrado médio menor indicará uma superioridade geral do cultivar testado. Esta medida de superioridade é dada por :

$P_{i}=\frac{\sum_{j=1}^{n}\left(X_{i j}-M_{j}\right)^{2}}{2 n}$

tal que :

$X_{i j}$ : é a produtividade do i-ésimo cultivar no j-ésimo Iocal.

$M_{j}$ : é a resposta máxima observada entre todos os cultivares no local j.

$n$ : é o número de locais.

Segundo os autores a equação 1 pode ser escrita na seguinte forma: 
$P_{i}=\frac{\left[n\left(\bar{X}_{i .}-M_{j}\right)+\sum_{j=1}^{n}\left(X_{i j}-\bar{X}_{i .}-M_{j}+\bar{M}\right)^{2}\right]}{2 n}$.

sendo $\bar{X}_{i .}=\frac{\sum_{j=1}^{n} X_{i j}}{n}$ e $\bar{M}=\frac{\sum_{j=1}^{n} M_{j}}{n}$

Se $M_{j}$ representar variedades hipotéticas, então $1^{\circ}$ termo da Equação (2) é a soma de Quadrados (SQ) dos efeitos Genéticos $(G)$ e o segundo termo é a $S Q$ relativa à interação genótipos $x$ ambientes (GA), quando dois cultivares são comparados. Deste modo, $P_{i}$ pode ser considerado como QM do efeito conjunto de $G$ e GA.

Embora as propriedades de distribuição da estatistica $P_{i}$ e QM(GA), não sejam conhecidas, os autores fazem uma interpolação do teste $F$ baseado na análise de variância conjunta de locais para determinar, empiricamente, um ponto de corte para fornecer um possível nível de significância para os QM estimados. 


\subsection{Estatísticas de Ordem}

Como os valores da distância em relação à produtividade máxima ou outros caracteres, são variáveis envolvendo ordenação de dados, serão descritos alguns aspectos importantes das estatísticas de ordem.

Sejam as variáveis aleatórias $X_{1}, X_{2}, \ldots, X_{n}$ independentes, com função de densidade de probabilidade conjunta $f_{X, X_{2}, \ldots, X_{n}}\left(x_{1}, x_{2}, \ldots, x_{n}\right)=f\left(x_{1}\right) f\left(x_{2}\right) \ldots f\left(x_{n}\right)$ tal que $f($.$) é a$ função de densidade marginal de cada $X_{i}$. Desse modo, $X_{1}, X_{2}, \ldots, X_{n}$ é definida como amostra aleatória de tamanho $\mathrm{n}$ de uma população com densidade $f($.$) .$

Consideremos agora as variáveis aleatórias $X_{1}, X_{2}, \ldots, X_{n} \quad$ iid (identicamente e independentemente, distribuidas), com função de densidade de probabilidade dada por $f_{X_{i}}\left(x_{i}\right) I_{(a, b)}\left(x_{i}\right)$ com $a<x_{i}<b$. Seja $Y_{1}$ ○ menor dos $X_{i}^{\prime}$ 's, $Y_{2}$ o segundo menor em ordem crescente de magnitude e assim até $Y_{n}$ o maior dos $X_{i}^{\prime}$ 's. Temos então a amostra aleatória $X_{1}, X_{2}, \ldots, X_{n}$ ordenada na forma $a \leq Y_{1}<Y_{2}<\ldots<Y_{n} \leq b$. Assim, $Y_{j}$ representa a j-ésima estatística de ordem $(j=1,2, \ldots, n)$ da amostra aleatória $X_{1}, X_{2}, \ldots, X_{n}$. o processo de ordenação quebra a independência das variáveis. Portanto 
os valores $Y_{j}(j=1,2, \ldots \mathrm{n})$ são dependentes pois, se $Y_{j} \geq y$ tem-se que $Y_{j+1} \geq y$.

Logo, dada as estatísticas de ordem $Y_{1}, Y_{2}, \ldots Y_{n}$, ROUSSAS (1972) mostrou que a função de densidade conjunta das $Y_{j}$ 's é:

$g\left(y_{1}, \ldots, y_{n}\right)=\left\{\begin{array}{cc}n ! f_{x}\left(y_{1}\right) f_{x}\left(y_{2}\right) \ldots f_{x}\left(y_{n}\right) & a<y_{1}<y_{2}<\ldots<y_{n}<b \\ 0 & \text { caso contrario }\end{array}\right.$

Dada a função de densidade conjunta dos $Y_{j}^{\prime}$ 's, pode-se estar interessado em obter a função de densidade da j-ésima estatística de ordem. Para isso, basta integrar a função de densidade conjunta nas variáveis $y_{1}, y_{2}, \ldots, y_{j-1}, y_{j+1}, \ldots, y_{n}$. Assim a forma de densidade dada por ROUSSAS (1972) será:

$g\left(y_{j}\right)=\frac{n !}{(i-1) !(n-j) !}\left[F_{X}\left(y_{j}\right)\right]^{i-1}\left[1-F_{X}\left(y_{j}\right)\right]^{n-j} f_{X}\left(y_{j}\right) I_{(a, b)}\left(y_{j}\right)$

No caso particular em que $j=1$ tem-se que $Y_{1}=\min \left\{X_{1}, \ldots, X_{n}\right\}$ e sua densidade será dada por :

$$
g\left(y_{1}\right)=n\left[1-F_{X}\left(y_{1}\right)\right]^{n-1} f_{X}\left(y_{1}\right) \quad I_{(a, b)}\left(y_{1}\right)
$$


Analogamente, para $j=n$, tem-se que $Y_{n}=\max \left\{X_{1}, \ldots, X_{n}\right\}$ e sua densidade será:

$g\left(y_{n}\right)=n\left[F_{X}\left(y_{n}\right)\right]^{n-1} f_{X}\left(y_{n}\right) \quad I_{(a, b)}\left(y_{n}\right)$

Desse modo, percebe-se que a função de densidade de uma estatística de ordem qualquer depende da função de distribuição acumulada da variável original. Isso acarreta alguns problemas, porque a função de distribuição acumulada pode não ter forma explícita, como é o caso da distribuição normal.

Assim, considerando uma amostra aleatória $X_{1}, X_{2}, \ldots, X_{n}$ com distribuição normal de parâmetros $\mu$ e $\sigma^{2}$, não é possível obter a densidade da j-ésima estatística de ordem de forma explícita. Estudos de simulação podem ser realizados para verificar se a distribuição da j-ésima estatística de ordem se preserva, neste caso.

Para a $1^{\text {a }}$ e a n-ésima estatística de ordem, TIPPET (1925) verificou que, quanto maior o tamanho da amostra, mais e mais a distribuição diverge da forma normal.

KENDALL $\varepsilon$ STUART (1963) fizeram um estudo detalhado do cálculo dos momentos, da distribuição da $1^{a}$ e 
da n-ésima estatística de ordem e a distribuição da amplitude para o caso normal. Fornecem resultados assintóticos para estes problemas, que são em geral, de difícil aplicação prática. 


\section{MATERIAL E MÉTODO}

\subsection{Análise Individual}

Foram utilizados dados de produtividade de espigas obtidos dos ensaios de avaliação de milho híbrido conduzidos pelo Departamento de Pesquisa da Agroceres de Santa Cruz das Palmeiras, Estado de São Paulo, durante os anos agrícolas de 1992/93, $1993 / 94$ e 1994/95.

Os locais, onde foram instalados os experimentos, estão no Estado de São Paulo e Sul de Minas Gerais. No ano agricola de $1992 / 93$ foram realizados experimentos em 9 locais com 7 híbridos, em 1993/94 foram 13 locais com 17 híbridos e em 1994/95, 19 locais com 18 híbridos. Para este estudo foram considerados somente híbridos comerciais que foram os seguintes :

AG 1043, duplo, normal

AG 1051, duplo, normal

AG 106, duplo, normal

AG 122, duplo, precoce

AG 4011, triplo, normal 
AG 405, duplo, precoce

AG 5011, triplo, precoce

AG 5012, triplo, normal

AG 510, triplo, precoce

AG 514, triplo, precoce

AG 519, duplo, precoce

AG 6012, triplo, super precoce

AG 612, triplo, precoce

AG 6601, duplo, normal

AG 672, triplo, precoce

AG 8010, simples, precoce

AG 8012, simples, precoce

AG 9010, simples, super precoce

AG 9012, simples, super precoce

AG 9014, simples, super precoce

AG 951, triplo, normal

BR 201, duplo, precoce

Nos três anos, utilizou-se o delineamento em blocos ao acaso, com área total das parcelas de 4 fileiras de 5 metros espaçadas de $0,90 \mathrm{~m}$, sendo a área útil correspondente às duas fileiras centrais.

Em todos os ensaios foram realizadas correção do solo e adubação, segundo recomendação feita através de análise do solo. Todas as técnicas de manejo, 
recomendadas para a cultura, foram empregadas na condução dos testes de campo.

Nas análises individuais, avaliou-se o caráter produtividade de espigas em $t /$ ha envolvendo I híbridos, segundo um delineamento em blocos casualizados. Cada observação fenotípica pôde ser descrita pelo seguinte modelo matemático:

$Y_{i j}=\mu+t_{j}+b_{j}+e_{i j}$

Neste modelo:

$\mu$ : é a média geral do experimento ou uma constante inerente a todas as observações $Y_{i j}$

$t_{i}$ : é o efeito fixo do i-ésimo tratamento $(i=1,2, \ldots, I)$, considerado fixo.

$b_{j}$ : é o efeito do j-ésimo bloco, $(j=1,2, \ldots J)$, considerado aleatório, $\operatorname{com} b_{i} \sim \operatorname{NID}\left(0, \sigma_{b}{ }^{2}\right)$

$e_{i j}$ : é o erro experimental correspondente à observação $Y_{i j}$ supondo-se que $e_{i j} \sim \operatorname{NID}\left(0, \sigma^{2}\right)$.

Hipótese a ser testada:

$H_{0}: t_{1}=t_{2}=\ldots t_{I}=0$ vs $H_{a}: t_{i} \neq 0$ para algum $i$

\section{Esperança Matemática:}

Para a composição do teste $F$, foram deduzidos os componentes de variância pelo método de Hicks, 
considerando-se apenas os efeitos de tratamentos como fixos.

$$
\text { Considerando o modelo: } Y_{i j}=\mu+t_{i}+b_{j}+e_{i j}
$$

e admitindo-se :

$E\left(b_{j}\right)=0 ; E\left(b_{j}^{2}\right)=\sigma_{b}^{2}$

$E\left(e_{i j}\right)=0 ; E\left(e_{i j}^{2}\right)=\sigma^{2}$

tem-se o esquema da análise de variância que é mostrado na Tabela 2 .

Tabela 2. Esquema da análise da variância para um dado local.

\begin{tabular}{llllll}
\hline C.V & G.L & SQ & $Q M$ & $E(Q M)$ & F \\
\hline Trat. & $I-1$ & $S_{1}$ & $Q_{1}$ & $\sigma^{2}+J c \sum_{i=1}^{I} t_{i}^{2}$ & $Q_{1} / Q_{3}$
\end{tabular}

BIOC. J-1 $\quad S_{2} \quad Q_{2} \quad \sigma^{2}+I \sigma_{b}{ }^{2}$

\begin{tabular}{lllll} 
Residuo & $(I-I)(j-1)$ & $S_{3}$ & $Q_{3}$ & $\sigma^{2}$ \\
\hline Total & $I J-I$ & $S_{4}$ & & \\
\hline
\end{tabular}

onde $c=\frac{1}{I-1}$

Decisão:

Rejeita-se $H_{0}: t_{1}=t_{2}=\ldots=t_{I}=0$

ao nivel $\alpha$ de significância se :

$\frac{Q_{1}}{Q_{3}} \geq F_{[\alpha ;(I-1) ;(I-1)(J-1)]}$ 


\subsection{Análise Conjunta}

Para proceder à análise conjunta houve a necessidade de verificar a existência da homogeneidade entre variancias residuais dos $K$ experimentos (1ocais). Isto não ocorrendo, dever-se-ia ajustar os graus de liberdade das fontes de variação que seriam utilizadas como denominadores nos testes $F$ da análise de variância conjunta.

Foram realizadas análises conjuntas com os locais que representam diversas regiões de são Paulo e Sul de Minas Gerais, sendo realizada uma análise para cada ano, num total de três anos.

Teste de homogeneidade de variâncias dos experimentos:

$H_{0}: \sigma_{1}^{2}=\sigma_{2}^{2}=\ldots=\sigma_{k}^{2} \quad$ vs $H_{a}: \sigma_{k}^{2} \neq \sigma_{k^{\prime}}^{2},\left(k \neq k^{\prime}\right)$

onde $K$ é o número de locais

Teste:

$F_{\max }=\frac{\hat{\sigma}_{k}{ }^{2}(\max )}{\hat{\sigma}_{k^{\prime}}{ }^{2}(\min )}$

Rejeita-se $H_{0}: \sigma_{1}^{2}=\sigma_{2}^{2}=\ldots=\sigma_{k}^{2}$ se $F_{\max } \geq H_{[\alpha, k, G L R(k)]}$

em que :

$H$ : é obtido em tabela de teste de Hartley

$\alpha$ : é o nível de significância 
$K$ : é o número de experimentos (locais)

GLR $(k)$ : é o número de graus de liberdade do resíduo dos experimentos individuais, logo, $\operatorname{GLR}(k)=(\mathrm{I}-1)(\mathrm{J}-1)$.

\section{Modelo Matemático para a análise conjunta}

Para uma análise conjunta de $K$ experimentos (locais) com I Tratamentos (híbridos de milho) e J repetições (blocos), adotou-se o seguinte modelo:

$Y_{i j k}=\mu+t_{i}+\ell_{k}+(t \ell)_{i k}+b_{j(k)}+e_{i j k}$

onde :

$Y_{i j k}$ é a resposta observada da variável y na

$$
\begin{array}{ll}
\text { repetição } j, & j=1,2, \ldots, \mathrm{J} . \\
\text { do tratamento } i, & i=1,2, \ldots, \mathrm{I} . \\
\text { no local } k, & k=1,2, \ldots, \mathrm{K} .
\end{array}
$$

$\mu$ :média geral; constante inerente a todas as

observações.

$t_{i}$ : efeito do $i$-ésimo tratamento $(i=1,2, \ldots I)$, considerado Eixo:

$\ell_{k}$ :efeito do $k$-ésimo local $(k=1,2, \ldots, \mathrm{K})$, considerado aleatório.

$(t \ell)_{i k}$ : efeito da interação do $i$-ésimo tratamento com $0 k-$ ésimo local, considerado aleatório; 
$b_{j(k)}$ :efeito do $j$-ésimo bloco dentro do $k$-ésimo local

$$
(j=1,2, \ldots, J), \text { considerado aleatório; }
$$

$e_{i j k}$ :erro experimental correspondente à observação $Y_{i j k}$, sendo que os $e_{i j k}$ são independentes e $e_{j j k} \sim N\left(0, \sigma^{2}\right)$.

Considerou-se, ainda, que :

$\ell_{k} \cap N\left(0, \sigma_{\ell}^{2}\right) ; \quad(t \ell)_{i k} \cap N\left(0, \sigma_{t \ell}^{2}\right) ; \quad b_{k(j)} \cap N\left(0, \sigma_{b}^{2}\right)$

\section{Hipóteses que foram testadas}

(1) $H_{0}: \sigma_{\ell}^{2}=0 \quad$ vs $H_{a}: \sigma_{\ell}^{2} \neq 0$

(2) $H_{0}: t_{i}=0$ para todo valor de $i$ vs $H_{a}: t_{i} \neq 0$ para algum $i$.

(3) $H_{0}: \sigma_{t \ell}^{2}=0 \quad$ vs $H_{a}: \sigma_{t \ell}^{2} \neq 0$

\section{Esperança Matemática}

Para composição do teste $F$, foram obtidos os componentes de variância pelo método de Hicks, considerando apenas os tratamentos como de efeito fixo e:
$E\left(\ell_{k}\right)=0$
e $\quad E\left(\ell_{k}^{2}\right)=\sigma_{\ell}^{2}$
$E\left(b_{j(k)}\right)=0$
e $\quad E\left(b_{j(k)}{ }^{2}\right)=\sigma_{b}^{2}$
$E\left[(t \ell)_{i k}\right]=0$
e $E\left[(t \ell)_{i k}{ }^{2}\right]=\sigma_{t \ell}{ }^{2}$ 
$E\left(e_{i j k}\right)=0 \quad$ e $\quad E\left(e_{i j k}^{2}\right)=\sigma^{2}$

As estimativas dos parâmetros do modelo

foram obtidas pelo método dos mínimos quadrados, usando-se as restrições usuais dadas por:

$\sum_{i=1}^{I} \hat{t}_{i}=0 ; \quad \sum_{k=1}^{K} \hat{\ell}_{k}=0 ; \quad \sum_{i=1}^{I}(t \hat{\ell})_{i k}=\sum_{k=1}^{K}(t \hat{\ell})_{i k}=\sum_{i=1}^{I} \sum_{k=1}^{K}(t \hat{\ell})_{i k}=0 ;$

$\sum_{j=1}^{J} \hat{b}_{j(k)}=0, \forall \forall_{k}$

o sistema de equações normais obtido foi:

$I J K \hat{\mu}$

$I J \hat{\mu}+I J \hat{\ell}_{k}$

$I \hat{\mu}+I \hat{\ell}_{k}+I \hat{b}_{j(k)}$

$J K \hat{\mu}+$

$J \hat{\mu}+j \hat{\ell}_{k}$

cuja solução

$+J K \hat{t}_{i}$

$+\hat{t}_{i}+J(\hat{t} \hat{\ell})_{i k}$

$=y_{i . k}$ $=y_{\ldots}$

$=y_{-k}$

$=y_{. j k}$

$=y_{i}$

respectivos parâmetros :

$\hat{\mu}=\frac{y_{\ldots}}{I J K} \quad ;$

$\hat{\ell}_{k}=\frac{y_{. . k}}{I J}-\hat{\mu}=\hat{\mu}_{. . k}-\hat{\mu} \quad ;$ 


$$
\begin{aligned}
& \hat{b}_{j(k)}=\frac{y_{. j k}}{I}-\hat{\ell}_{k}-\hat{\mu}=\hat{\mu}_{. j k}-\hat{\mu}_{. . k} ; \\
& \hat{t}_{i}=\frac{y_{i . .}}{J K}-\hat{\mu}=\hat{\mu}_{i . .}-\hat{\mu} \quad ; \\
& (\hat{t} \hat{\ell})_{i k}=\frac{y_{i . k}}{J}-\hat{\mu}-\hat{\ell}_{k}-\hat{t}_{i}=\hat{\mu}_{i . k}-\hat{\mu}-\hat{\mu}_{. . k}+\hat{\mu}-\hat{\mu}_{i . .}+\hat{\mu}=\hat{\mu}_{i . k}-\hat{\mu}_{\cdot \cdot_{k}}-\hat{\mu}_{i . .}+\hat{\mu}
\end{aligned}
$$

As somas de quadrados são dadas por:

SQ Média $=$ Correção $=\mathrm{C}=\hat{\mu} y_{.}=\frac{y \ldots{ }^{2}}{I J K}$

SQ de Locais $=$ SQL $=\sum_{k=1}^{K} \hat{\ell}_{k}\left(y_{. . k}\right)$

$$
\begin{aligned}
& =\sum_{k=1}^{K}\left(\frac{Y_{. k}}{I J}-\hat{\mu}\right) y_{. . k}=\frac{1}{I J} \sum_{k=1}^{K} y_{. . k}^{2}-\hat{\mu} \sum_{k=1}^{K} y_{. . k}= \\
& \frac{1}{I J} \sum_{k=1}^{K} y_{. . k}^{2}-\frac{y_{\ldots}^{2}}{I J K}
\end{aligned}
$$

$\mathrm{SQ}$ Blocos dentro de Locais $=\mathrm{SQB} \mid \mathrm{L}=\sum_{j k} \hat{b}_{j(k)}\left(y_{. j k}\right)$

$$
=\sum_{j k}\left(\frac{y_{. j k}}{I}-\hat{\mu}-\hat{\ell}_{k}\right) y_{. j k}
$$




$$
\begin{aligned}
& =\frac{1}{I} \sum_{j k} y_{. j k}{ }^{2}-\hat{\mu} \sum_{j k} y_{. j k}-\sum_{k=1}^{K} \hat{\ell}_{k} \sum_{j=1}^{J} y_{. j k} \\
& =\left(\frac{1}{I} \sum_{j k} y_{. j k}{ }^{2}-\frac{y_{\ldots}^{2}}{I J K}\right)-\sum_{k=1}^{K} \hat{\ell}_{k}\left(y_{. k}\right) \\
& =\text { SQ BIOCOS }- \text { SQ Locais }
\end{aligned}
$$

$\mathrm{SQ}$ de Tratamentos $=\mathrm{SQT}=\sum_{i=1}^{I} \hat{t}_{i}\left(y_{i . .}\right)$

$$
\begin{aligned}
& =\sum_{i=1}^{I}\left(\frac{y_{i . .}}{J K}-\hat{\mu}\right) y_{i . .}=\frac{1}{J K} \sum_{i=1}^{I} y_{i . .}{ }^{2}-\hat{\mu} \sum_{i=1}^{I} y_{i . .} \\
& =\frac{1}{J K} \sum_{i=1}^{I} y_{i_{. .}}{ }^{2}-\frac{y_{. .}{ }^{2}}{I J K}
\end{aligned}
$$

SQ da Interação $\mathrm{T} \times \mathrm{L}=\mathrm{SQTL}=\sum_{i k}(\hat{t} \hat{\ell})_{i k}\left(y_{i . k}\right)$

$$
\begin{aligned}
& =\sum_{i k}\left(\frac{y_{i . k}}{J}-\hat{\mu}-\hat{t}_{i}-\hat{\ell}_{k}\right) y_{i . k} \\
& =\frac{1}{J} \sum_{i k} y_{i . k}^{2}-\hat{\mu} \sum_{i k} y_{i . k}-\sum_{i=1}^{I} \hat{t}_{i} \sum_{k=1}^{K} y_{i . k}-\sum_{k=1}^{K} \hat{\ell}_{k} \sum_{i=1}^{I} y_{i . k} \\
& =\left(\frac{1}{J} \sum_{i k} y_{i . k}^{2}-\frac{y_{. .2}^{2}}{I J K}\right)-\sum_{i=1}^{I} \hat{t}_{i}\left(y_{i . .}\right)-\sum_{k=1}^{K} \hat{\ell}_{k}\left(y_{. . k}\right) \\
& =\mathrm{SQT}, \mathrm{L}-\mathrm{SQT}-\mathrm{SQL}
\end{aligned}
$$

SQResiduo $=S Q R=\sum_{i j k} y_{i j k}{ }^{2}-S Q\left[\mu, t_{i}, \ell_{k}, b_{j(k)},(t \ell)_{i k}\right]$ 


$$
\begin{aligned}
& =\sum_{i j k} y_{i j k}^{2}-\left[\hat{\mu} y_{. . .}+\sum_{i=1}^{I} \hat{t}_{i} y_{i .}+\sum_{k=1}^{K} \hat{\ell}_{k} y_{. . k}+\sum_{j k} \hat{b}_{j(k)} y_{. j k}+\sum_{i k}(\hat{t} \hat{\ell})_{i k} y_{i . k}\right] \\
& =\left(\sum_{i j k} y_{i j k}^{2}-\frac{y_{\ldots}^{2}}{I J K}\right)-\mathrm{SQL}-\mathrm{SQB} \mid \mathrm{L}-\mathrm{SQT}-\mathrm{SQTL} \\
& =\text { SQTOTAL - SQL - (SQB-SQL }) \text { SQT - (SQT, L - SQT - SQL) } \\
& =\mathrm{SQTOTAL}-\mathrm{SQB}-\mathrm{SQT}, \mathrm{I}+\mathrm{SQL} \\
& \mathrm{SQR}=\left(\sum_{i j k} y_{i j k}{ }^{2}-\frac{y_{\ldots}{ }^{2}}{I J K}\right)-\left(\frac{1}{I} \sum_{j k} y_{. j k}{ }^{2}-\frac{y_{\ldots . .}{ }^{2}}{I J K}\right)-\left(\frac{1}{J} \sum_{i k} y_{i . k}{ }^{2}-\frac{y_{\ldots .}{ }^{2}}{I J K}\right)+\left(\frac{1}{I J} \sum_{k=1}^{K} y_{. . .}{ }^{2}-\frac{y_{\ldots . .}{ }^{2}}{I J K}\right) \\
& =\sum_{i j k} y_{i j k}^{2}-\frac{1}{I} \sum_{j k} y_{. j k}^{2}-\frac{1}{J} \sum_{i k} y_{i . k}^{2}+\frac{1}{I J} \sum_{k=1}^{K} y_{. . k}^{2} \\
& =\sum_{k=1}^{K}\left(\sum_{i j} y_{i j k}^{2}-\frac{1}{I} \sum_{j=1}^{J} y_{. j k}^{2}-\frac{1}{J} \sum_{i=1}^{I} y_{i . k}^{2}+\frac{1}{I J} y_{. . k}^{2}\right) \\
& =\sum_{k=1}^{K}\left[\left(\sum_{i j} y_{i j k}^{2}-\frac{1}{I J} y_{. . k}^{2}\right)-\left(\frac{1}{I} \sum_{j=1}^{J} y_{. j k}^{2}-\frac{1}{I J} y_{. . k}^{2}\right)-\left(\frac{1}{J} \sum_{i=1}^{I} y_{i . k}^{2}-\frac{1}{I J} y_{. . k}^{2}\right)\right] \\
& =\sum_{k=1}^{K}\left(S Q \text { Total }_{k}-S Q B_{k}-S Q T_{k}\right)
\end{aligned}
$$

$\mathrm{SQR}=\sum_{k=1}^{K} S Q R_{k} \quad$ ou seja, a soma de quadrados do resíduo para a análise conjunta é obtida somando-se as $K$ somas de quadrados do resíduo das análises individuais. o esquema da análise conjunta é dado na Tabela 3. 
Tabela 3. Quadro da análise conjunta de variância para um grupo de experimentos.

\begin{tabular}{|c|c|c|c|}
\hline F.V & GL & SQ $\quad \mathrm{QM}$ & $E(Q M)$ \\
\hline Blocos/local & $\bar{K}(\mathrm{~J}-1)$ & $\begin{array}{ll}S_{1} & Q_{1}\end{array}$ & $\sigma^{2}+I \sigma_{b}^{2}$ \\
\hline Tratamentos $(\mathrm{T})$ & $I-1$ & $Q_{2}$ & $\sigma^{2}+J \phi \sigma_{t \ell}^{2}+J K \phi_{t}$ \\
\hline Locais (L) & $\mathrm{K}-1$ & $S_{3}$ & $\sigma^{2}+J \phi \sigma_{t \ell}^{2}+I \sigma_{b}^{2}+I J \sigma_{\ell}^{2}$ \\
\hline$T \times L$ & $(I-1)(K-1)$ & $Q_{4}$ & $\sigma^{2}+J \phi \sigma_{t \ell}^{2}$ \\
\hline Resíduo & $K(I-1)(J-1)$ & $S_{5}$ & $\sigma^{2}$ \\
\hline Total & IJK-1 & $S_{6}$ & \\
\hline
\end{tabular}

onde : $\quad \phi=\frac{I}{I-1} \quad$ e $\quad \phi_{t}=\frac{1}{I-1} \sum_{i} t_{i}^{2}$

\section{Decisão sobre o Teste $F$}

Utilizaram-se os critérios seguintes:

(1) Rejeita-se $H_{o}: \sigma_{\ell}^{2}=0$, ao nível $\alpha$ de significância se:

$\frac{Q M \operatorname{Re} s+Q M L}{Q M B / L+Q M T x L} \geq F_{\left(\alpha, n_{1}, n_{2}\right)}$

sendo :

$$
n_{1}=\frac{(Q M \operatorname{Re} s+Q M L)^{2}}{\frac{(Q M \operatorname{Re} s)^{2}}{K(I-1)(J-1)}+\frac{(Q M L)^{2}}{K-1}} \quad \text { e } \quad n_{2}=\frac{(Q M B / L+Q M T x L)^{2}}{\frac{(Q M B / L)^{2}}{K(J-1)}+\frac{(Q M T x L)^{2}}{(J-1)(K-1)}}
$$

(2) Rejeita-se $H_{0}: t_{i}=0$ para todo $i$, ao nivel $\alpha$ de significância se :

$\frac{Q M T}{Q M T x L} \geq F_{[\alpha,(I-1),(I-1)(k-1)]}$ 
(3) Rejeita-se $H_{0}: \sigma_{t \ell}{ }^{2}=0$, ao nível $\alpha$ de significância se: $\frac{Q M T x L}{Q M \operatorname{Re} s} \geq F_{[\alpha,(I-1)(K-1) ; K(I-1)(J-1)]}$

3.3. Desenvolvimento da distância de um tratamento em relação a um melhor genótipo

\subsubsection{Variável produtividade}

Os dados obtidos da variável produtividade, foram dispostos em tabelas de dupla entrada para cada local, cuja disposição é mostrada na Tabela 4.

Tabela 4. Disposição dos dados obtidos de híbridos e blocos num dado local $\mathrm{k}$ para a variável produtividade.

\begin{tabular}{|c|c|c|c|c|c|c|c|}
\hline \multirow[b]{2}{*}{ Híbrido } & \multicolumn{6}{|c|}{ BIocos } & \multirow[b]{2}{*}{ média } \\
\hline & 1 & 2 & $\cdot$ &. &. & $\mathrm{J}$ & \\
\hline 1 & $p_{11 k}$ & $p_{12 k}$ & $\cdot$ & $\cdot$ & $\cdot$ & $p_{1 J k}$ & $\bar{P}_{1 . k}$ \\
\hline 2 & $p_{21 k}$ & $p_{22 k}$ & $\cdot$ & $\cdot$ & $\cdot$ & $p_{2 J k}$ & $\bar{P}_{2 . k}$ \\
\hline - & - & • & & & & - & . \\
\hline • & $\cdot$ & • & & & & - & - \\
\hline - & - & - & & & & - & - \\
\hline$I$ & $p_{I 1 k}$ & $p_{I 2 k}$ & $\cdot$ & - & . & $p_{l J k}$ & $\bar{P}_{I . k}$ \\
\hline
\end{tabular}

Para este estudo foi definido como sendo o melhor genótipo a média geral dos valores médios máximos obtidos em cada 1ocal. Deste modo definiu-se $X_{i . k}$ como a 
distância da média $\bar{P}_{i . k}$ em relação ao melhor genótipo, para $i=1,2, \ldots, I$, no $k$-ésimo local, isto é:

$X_{i, k}=\bar{P}_{i, k}-\bar{P}_{k}(\max )$ para $i=1,2, \ldots, \mathrm{I} ; k=1,2, \ldots$ K; $\quad \bar{P}_{k}(\max )$ é o maior valor médio, de modo que quando $\bar{P}_{i . k}=\bar{P}_{k}(\max ), X_{i . k}$ será igual a zero, para todo $i=1,2, \ldots, I$.

A fim de se obter uma amplitude dos valores de $\bar{P}_{i . k}$, para $i=1,2, \ldots, I$, no $k$-ésimo local, calculou-se a distância do mínimo em relação ao máximo como sendo :

$$
X_{k}^{\cdots}=\bar{P}_{k}(\max )-\bar{P}_{k}(\min )
$$

Para se obter o valor do melhor genótipo $(M g)$, calculou-se o valor médio dos valores médios máximos de locais:

$M g=\frac{\sum_{k} \bar{P}_{k}(\max )}{K}=\bar{P}(\max )$

Analogamente, para se obter o valor do pior genótipo $(P g)$, calculou-se o valor médio dos valores médios mínimos de locais:

$$
P g=\frac{\sum_{k} \bar{P}_{k}(\mathrm{~min})}{K}=\bar{P}(\mathrm{~min})
$$


Os valores de distância $X_{i . k}$ para todos os locais foram dispostos numa tabela de dupla entrada, onde I é o número de híbridos e $K$ representa o número de locais, conforme a Tabela 5 .

Tabela 5. Valores de distância $X_{i . k}$ para I híbridos e K locais.

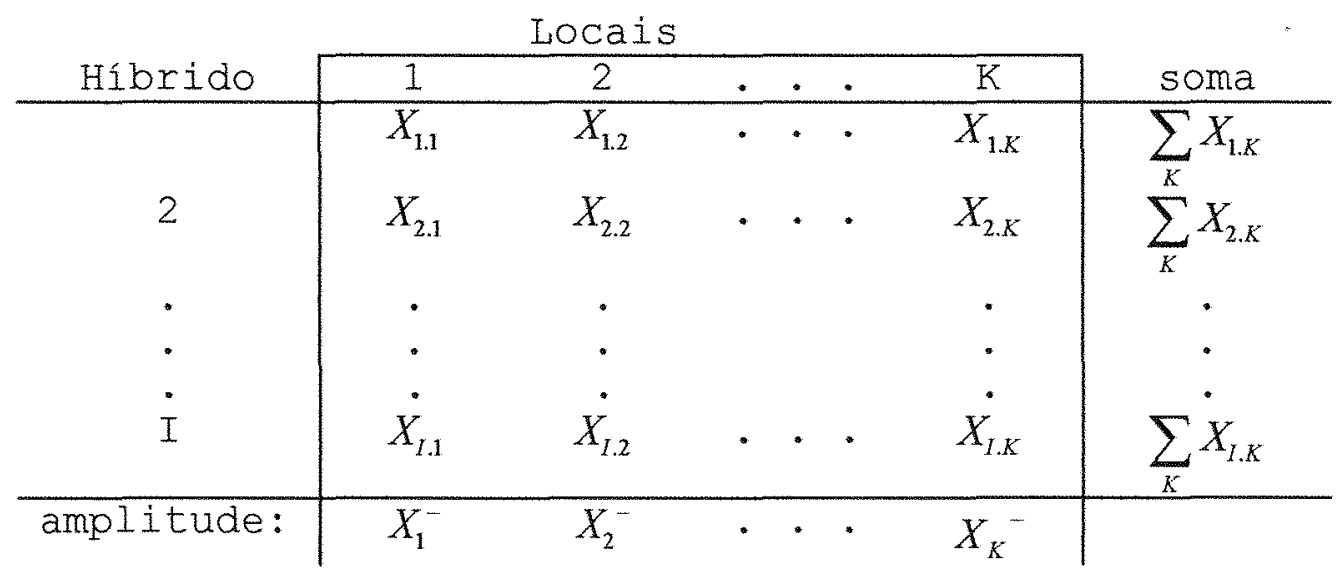

Definiu-se a quantidade $D p_{i}$ de distância ao melhor genótipo para o híbrido $i$, como sendo:

$D p_{i}=-\left[\frac{\sum_{k} X_{i . k}}{K}\right]=\bar{X}_{i . .}$

lembrando-se que $X_{i . k}=\bar{P}_{i . k}-\bar{P}_{k}(\max )$

Quanto menor for o valor de $D p_{i}$ mais próximo do melhor genótipo para produtividade estará o $i$-ésimo híbrido. 
Da mesma forma, definiu-se também o valor de distância ao pior genótipo como sendo:

$D p^{-}=\frac{\sum_{k} X_{k}^{-}}{k}=\bar{X}^{-}$

onde $X_{k}{ }^{-}=\bar{P}_{k}(\max )-\bar{P}_{k}(\min )$, no $k$-ésimo local.

Para se ter uma idéia de quanto um híbrido $i$ esta distante do melhor genótipo, calculou-se o grau de inferioridade deste híbrido através do seguinte indice : $I p_{i}=\frac{D p_{i}}{D p^{-}}$

de modo que, quanto mais próximo $I p_{i}$ estiver de zero mais próximo do melhor genótipo estará o híbrido, e quanto mais próximo $I p_{i}$ estiver de 1 , mais próximo do pior genótipo estará o híbrido.

\subsubsection{Variável \% de tombamento}

Os dados obtidos da variável $\frac{\circ}{0}$ de tombamento, foram dispostos em tabelas de dupla entrada para cada local, cuja disposição é mostrada na Tabela 6 . 
Tabela 6. Disposição dos dados obtidos de híbridos e blocos num dado local k para a variável o de tombamento.

\begin{tabular}{|c|c|c|c|c|c|c|c|}
\hline \multirow[b]{2}{*}{ Híbrido } & \multicolumn{6}{|c|}{ Blocos } & \multirow[b]{2}{*}{ média } \\
\hline & $I$ & 2 & . & $\dot{-}$ & . & $\mathrm{J}$ & \\
\hline 1 & $t_{11 k}$ & $t_{12 k}$ & ${ }^{\circ}$ & • & • & $t_{1 J k}$ & ${\overline{T_{1 . k}}}$ \\
\hline 2 & $t_{21 k}$ & $t_{22 k}$ & - & $\cdot$ & • & $t_{2 J k}$ & $\bar{T}_{2 . k}$ \\
\hline - & · & - & & & & - & - \\
\hline • & $\cdot$ & ${ }^{\circ}$ & & & & - & - \\
\hline • & • & • & & & & - & - \\
\hline$I$ & $t_{I 1 k}$ & $t_{I 2 \mathrm{k}}$ & - & - & • & $t_{I J k}$ & $\bar{T}_{l . k}$ \\
\hline
\end{tabular}

Para este estudo foi definido como sendo o melhor genótipo a média geral dos valores médios mínimos obtidos em cada local.

Definiu-se $Y_{i . k}$ como a distância da média $\bar{T}_{i}$ em relação ao melhor genótipo, para $i=1,2, \ldots, I$ no $k$-ésimo local, isto é:

$Y_{i . k}=\bar{T}_{i, k}-\bar{T}_{k}(\min )$,para $i=1,2, \ldots, I_{i} \bar{T}_{k}(\min )$ é o menor valor médio, de modo que quando $\bar{T}_{i . k}=\bar{T}_{k}(\min ), Y_{i . k}$ será igual a zero. A fim de se obter uma amplitude dos valores de $\bar{T}_{i . k}$ no $k$-ésimo local, calculou-se a distância do máximo em relação ao mínimo como sendo $Y_{k}^{-}=\bar{T}_{k}(\max )-\bar{T}_{k}(\min )$

Para se obter o valor do melhor genótipo $(M g)$, calculou-se o valor médio dos valores médios mínimos de locais: 
$M g=\frac{\sum_{k} \bar{T}_{k}(\min )}{K}=\bar{T}(\min )$

Análogamente, para se obter o valor do pior genótipo $(P g)$, calculou-se o valor médio dos valores médios máximos de locais:

$$
P g=\frac{\sum_{k} \bar{T}_{k}(\max )}{K}=\bar{T}(\max )
$$

Os valores de distância $Y_{i . k}$ para todos os locais foram dispostos numa tabela de dupla entrada, conforme Tabela 7 .

Tabela 7. Valores de distância $Y_{i, k}$ para I híbridos e K locais.

\begin{tabular}{|c|c|c|c|c|c|c|c|}
\hline \multirow[b]{2}{*}{ Híbrido } & \multicolumn{5}{|c|}{ Locais } & & \multirow[b]{2}{*}{ soma } \\
\hline & 1 & 2 & . &. &. & $\mathrm{K}$ & \\
\hline 1 & $Y_{1.1}$ & $Y_{1.2}$ & . & . & $\cdot$ & $Y_{1 . K}$ & $\sum_{x} Y_{1 . K}$ \\
\hline 2 & $Y_{2.1}$ & $Y_{2.2}$ & - & $\cdot$ & 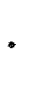 & $Y_{2 . K}$ & $\sum_{K}^{K} Y_{2 . K}$ \\
\hline • & - & - & & & & - & - \\
\hline - & - & - & & & & - & - \\
\hline * & : & - & & & & - & • \\
\hline$I$ & $Y_{I .1}$ & $Y_{I .2}$ & . & " & • & $Y_{I . K}$ & $\sum_{K} Y_{I . K}$ \\
\hline amplitude: & $\overline{Y_{1}^{-}}$ & $\overline{Y_{2}}$ & . & - & $\cdot$ & $Y_{K}^{-}$ & \\
\hline
\end{tabular}

Definiu-se a quantidade $D t_{i}$ de distância ao melhor genótipo, para o híbrido $i$, como sendo: 
$D t_{i}=\frac{\sum_{k} Y_{i . k}}{K}=\bar{Y}_{i . .}$

lembrando-se que $Y_{i . k}=\bar{T}_{i . k}-\bar{T}_{k}(\mathrm{~min})$

Percebe-se que, quanto menor for o valor de $D t_{i}$, mais próximo do melhor genótipo para o de tombamento estará o $i$-ésimo híbrido.

Da mesma forma, definiu-se também o valor de distância em relação ao pior genótipo como sendo :

$D t^{-}=\frac{\sum_{k} Y_{k}^{-}}{K}=\bar{Y}^{-}$

sendo $Y_{k}^{-}=\bar{T}_{k}(\max )-\bar{T}_{k}(\min )$, no $k$-ésimo local

Para se ter uma idéia de quanto um híbrido $i$ está distante do melhor genótipo, calculou-se o grau de inferioridade deste híbrido através do seguinte índice:

$I t_{i}=\frac{D t_{i}}{D t^{-}}$

de modo que quanto mais próximo de zero $I_{i}$ estiver, mais próximo do melhor genótipo estará o híbrido, e quanto mais próximo $I_{i}$ estiver de 1 , mais próximo do pior genótipo estará o híbrido. 


\subsection{Análise Gráfica}

Com base nas distâncias calculadas construiu-se um gráfico para cada ano, baseado no grau de inferioridade expresso em porcentagem, calculados para a variável produtividade e para a variável o de tombamento $\left(\% I p_{i}\right.$ e $\left.\% I t_{i}\right)$.

para a variável produtividade: $I p_{i}=\frac{D p_{i}}{D p^{-}} \rightarrow \% I p_{i}=\left(\frac{D p_{i}}{D p^{-}}\right) \times 100$

para a variável o tombamento: $I t_{i}=\frac{D t_{i}}{D t^{-}} \rightarrow \% I t_{i}=\left(\frac{D t_{i}}{D t^{-}}\right) x 100$ - gráfico está representado na Figura 1.

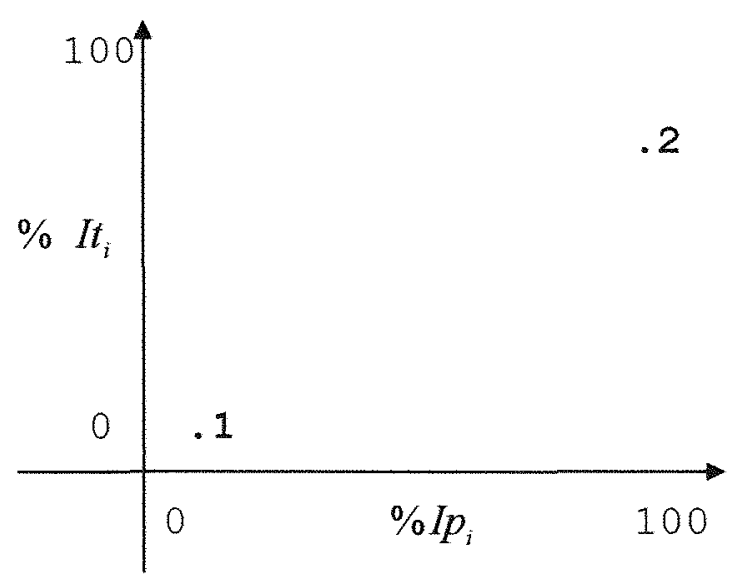

Figura 1. Ilustração de um gráfico, exemplificando o comportamento de dois híbridos em casos extremos.

Assim, pode-se dizer que o híbrido 1 é o que esteve mais próximo do melhor genótipo, pois obteve uma 
distância mínima tanto para a produtividade quanto para o tombamento. O híbrido 2 foi o híbrido de pior desempenho, pois obteve a distância máxima ao melhor genótipo tanto para produtividade quanto para o tombamento. A construção deste gráfico teve o propósito de agrupar os híbridos e associá-los a uma medida de estabilidade, podendo-se desta maneira, estabelecer níveis tecnológicos para os cultivares avaliados. 


\subsection{Estudos de Simulação para a Distribuição Normal}

Dada uma amostra aleatória da distribuição normal com parâmetros $\mu$ e $\sigma^{2}$, TIPPET (1925) verificou que a distribuição da $1^{a}$ e da n-ésima estatística de ordem se afasta da distribuição normal quando se aumenta o tamanho da amostra.

Utilizando-se o programa S-PLUS e a função de geração de números aleatórios para a distribuição normal, criou-se amostras de diversos tamanhos para $\mu$ e $\sigma^{2}$ fixados, tomando-se o máximo e o mínimo valor para cada amostra gerada. Este procedimento foi executado 1000 vezes. De posse desses dados, construiu-se o gráfico QONORM (gráfico de probabilidade normal), especifico do programa S-PLUS, cuja figura mostra os quantis da distribuição gerada versus os quantis da distribuição normal. Isto foi feito em função de se obter uma possivel distribuição para as distâncias de produtividade em relação ao máximo e ao mínimo, já que a distribuição original dos dados pode ser considerada normal.

Caso as diferenças de produtividade em relação ao máximo e ao mínimo viessem a seguir uma 
distribuição normal, poder-se-ia proceder a uma análise de variância conjunta para as distâncias obtidas e assim encontrar uma distribuição do residuo especifico para esses casos.

\subsection{Análise da Estabilidade e Adaptabilidade}

Realizou-se análise conjunta de locais e análise de regressão, visando estimar parâmetros de estabilidade e adaptabilidade, pelos quais tornou-se possivel a identificação de híbridos que fossem responsivos às variações ambientais, em condições específicas ou amplas, bem como o comportamento previsivel do híbrido. Deste modo pôde-se estudar como se comportam os cultivares de menor e maior distância ao melhor genótipo frente às variações ambientais.

\subsubsection{Análise da Estabilidade com base nas distâncias $D p_{i}$} e $D t_{i}$

Para este tipo de análise, os ambientes (locais) foram separados em desfavoráveis e favoráveis. Esta separação realizou-se com base no cálculo do índice ambiental $I_{k}$, em que $I_{k}=\bar{P}_{. k}-\bar{P}_{\ldots}$ em que $\mathrm{P}$ é a variável produtividade em t/ha e $k$ refere-se a locais. 
aqueles com $I_{k}\left\langle 0\right.$, e ambientes favoráveis com $\left.I_{k}\right\rangle 0$, para todo $k$.

Dada a separação dos ambientes, calcularamse as distancias $D p_{i}$ e $D t_{i}$ para os ambientes desfavoráveis e analogamente para os favoráveis, de modo que o cultivar que obtivesse valor pequeno de distância nos ambientes favoráveis e também nos desfavoráveis, seria um cultivar que, além de estar próximo do melhor genótipo teria adaptabilidade geral e alta estabilidade para o conjunto de ambientes testados.

\subsubsection{Metodologia proposta por Eberhart $\varepsilon$ Russel (1966)}

Além de calcular a estabilidade e a
adaptabilidade com base nas distâncias, estimou-se a
estabilidade através do coeficiente de regressão linear
da produtividade média de cada hibrido em relação à
produtividade média de todos os cultivares em cada local, e
pelos seus respectivos desvios, seguindo-se o modelo
proposto por EBERHART $\varepsilon$ RUSSEL (1966):
$Y_{i k}=\mu_{i}+\beta_{1 i} I_{k}+\delta_{i k}+\bar{\varepsilon}_{i j}$


sendo:

$Y_{i k}$ : é a média observada do tratamento $i$ no local $k$; $\mu_{i}$ : é a média geral do tratamento $i, i=1,2, \ldots$, ;

$\beta_{1 i}$ : é o coeficiente de regressão linear que mede a reposta do $i$-ésimo tratamento à variação ambiental;

$\delta_{i k}$ : é o desvio da regressão do tratamento $i$ no local $k$; $I_{k}$ : é o indice ambiental dado por,

$$
I_{k}=\frac{1}{I} \sum_{i=1}^{I} Y_{i k}-\frac{1}{I K} Y_{.} \quad, \quad \sum_{k=1}^{K} I_{k}=0, k=1,2, \ldots, \mathrm{K}
$$

$\bar{\varepsilon}_{i k}$ : é o erro experimental médio.

os cálculos da Soma de Quadrados da análise de variância do modelo proposto por EBERHART $\varepsilon$ RUSSEL (1966), são dados a seguir

SQ tratamentos $=S Q_{1}=\frac{1}{K}\left(\sum_{i=1}^{I} Y_{i .}^{2}\right)-\frac{1}{I K} Y$

$\mathrm{SQ}$ Ambientes dentro de tratamentos $=S Q_{2}=\sum_{i=1}^{I}\left[\left(\sum_{k=1}^{K} Y_{i k}^{2}\right)-\frac{1}{K}\left(Y_{i .}\right)^{2}\right]$

$S Q$ Ambientes (Iinear) $=S Q_{3}=\frac{1}{I}\left(\sum_{k=1}^{K} Y_{. k} I_{k}\right)^{2} / \sum_{k=1}^{K} I_{k}^{2}$

$\mathrm{SQ}$ Ambientes (Iinear) $\times$ tratamentos $=S Q_{4}=$ 
$=\sum_{i=1}^{I}\left[\left(\sum_{k=1}^{K} Y_{i k} I_{k}\right)^{2} / \sum_{k=1}^{K} I_{k}^{2}\right]-S Q A m b .(\operatorname{lin}$.

$S Q$ Desvios da regressão $=S Q_{5}=\sum_{i=1}^{I}\left(\sum_{k=1}^{K} \hat{\delta}_{i k}{ }^{2}\right)$

SQ Efeito Linear de Cada tratamento $=S Q \ell_{i}=$ $=\left(\sum_{k=1}^{K} Y_{i k} I_{k}\right)^{2} / \sum_{k=1}^{K} I_{k}^{2}$

SQ Desvios da Regressão de Cada tratamento $=S Q D_{i}=$

$=\sum_{k=1}^{K} Y_{i k}^{2}-\frac{Y_{i .}^{2}}{K}-\frac{\left(\sum_{k=1}^{K} Y_{i k} I_{k}\right)^{2}}{\sum_{k=1}^{K} I_{k}{ }^{2}}=\sum_{k=1}^{K} \hat{\delta}_{i k}^{2}$

Na tabela 8 é mostrado o esquema da análise de variância desenvolvida a partir do modelo proposto por EBERHART $\varepsilon$ RUSSEL (1966). Dos quadrados médios mostrados nessa tabela, destaca-se $\circ Q_{4}$, o qual é adequado para se testar as diferenças entre os coeficientes da regressão Iinear dos tratamentos. Os quadrados médios $Q \ell_{1}, Q \ell_{2}, \ldots, Q \ell_{i,}$ $Q D_{1}, Q D_{2}, \ldots, Q D_{i}$, permitem um estudo detalhado de cada tratamento, respectivamente, quanto à linearidade ou não de seu comportamento frente às variações ambientais. 
Tabela 8. Quadro da Análise de Variancia com os valores de F para realizar testes e estimar os desvios de regressão linear de I cultivares, estudados em J repetições e $K$ locais. (Modelo proposto por EBERHART \& RUSSEL, 1966).

\begin{tabular}{|c|c|c|c|c|}
\hline Causas de Variação & G.I & $\mathrm{SQ}$ & $\mathrm{QM}$ & $\mathrm{E}$ \\
\hline Híbridos & $I-1$ & $S Q_{1}$ & $Q_{1}$ & $Q_{1} / Q_{6}$ \\
\hline $\begin{array}{l}\text { Ambientes dentro de } \\
\text { cultivares }\end{array}$ & $I(K-1)$ & $S Q_{2}$ & $Q_{2}$ & $Q_{2} / Q_{6}$ \\
\hline Ambientes (linear) & 1 & $S Q_{3}$ & $Q_{3}$ & $Q_{3} / Q_{6}$ \\
\hline $\begin{array}{l}\text { Ambientes (linear)x } \\
\text { híbridos }\end{array}$ & $I-1$ & $S Q_{4}$ & $Q_{4}$ & $Q_{4} / Q_{6}$ \\
\hline Desvios da regressão & $I(K-2)$ & $S Q_{5}$ & $Q_{5}$ & $Q_{5} / Q_{6}$ \\
\hline $\begin{array}{l}\text { Ambientes dentro de } \\
\text { cultivares } \\
\text { Efeito linear: }\end{array}$ & $I(K-1)$ & $S Q_{2}$ & $Q_{2}$ & \\
\hline Híbrido 1 & 1 & $S Q \ell_{1}$ & $Q \ell_{1}$ & $Q \ell_{1} / Q D_{1}$ \\
\hline Híbrido 2 & 1 & $\mathrm{SQ \ell}_{2}$ & $Q \ell_{2}$ & $Q \ell_{2} / Q D_{2}$ \\
\hline$:$ & : & : & : & $:$ \\
\hline . & . & . & . & . \\
\hline Híbrido I & 1 & $S Q \ell_{1}$ & $Q \ell_{I}$ & $Q \ell_{I} / Q D_{I}$ \\
\hline Desvios da regressão: & & & & \\
\hline cultivar 1 & $K-2$ & $S Q D_{1}$ & $Q D_{1}$ & $Q D_{1} / Q_{6}$ \\
\hline cultivar 2 & $K-2$ & $\mathrm{SQD}_{2}$ & $Q D_{2}$ & $Q D_{2} / Q_{6}$ \\
\hline$:$ & : & : & $:$ & \\
\hline . & * & . & 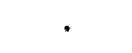 & \\
\hline cultivar I & $K-2$ & $S Q D_{I}$ & $Q D_{I}$ & $Q D_{I} / Q_{6}$ \\
\hline Residuo Médio & $K(J-1)(I-1)$ & & $Q_{6}$ & \\
\hline
\end{tabular}

- coeficiente da regressão linear de cada cultivar, foi estimado por:

$\hat{\beta}_{1 i}=\frac{\sum_{k=1}^{K} Y_{i k} I_{k}}{\sum_{k=1}^{K} I_{k}{ }^{2}}$

e $\hat{V}\left(\hat{\beta}_{1 i}\right)=\frac{1}{\sum_{k=1}^{K} I_{k}{ }^{2}} \hat{\sigma}_{s}{ }^{2} \quad$, sendo: $\hat{\sigma}_{s}{ }^{2}=\frac{1}{J} \hat{\sigma}^{2}=\frac{Q M R}{J}$

em que QMR é Resíduo médio e J é o número de repetições 
Foi introduzido na análise o valor do máximo, que é um tratamento idealizado, composto pelos valores dos cultivares de maior produtividade em cada local. Como isso implicou em repetições de dados, optou-se por utilizar o residuo da análise conjunta sem o valor do máximo, pois caso contrário, este resíduo seria tendencioso.

A hipótese $H_{0}: \beta_{1 i}=1$ versus $H_{a}: \beta_{1 i} \neq 1$ foi avaliada pela estatistica $t$ a 50, dada por:

$t=\frac{\hat{\beta}_{1 i}-1}{\sqrt{\hat{V}\left(\hat{\beta}_{1 i}\right)}}$

o parâmetro de estabilidade $\left(\sigma_{d i}{ }^{2}\right)$ foi estimado, pelo método da análise de variância, a partir do quadrado médio dos desvios da regressão de cada tratamento $\left(Q M D_{i}\right)$ e do quadrado médio do residuo (QMR), isto é:

$\hat{\sigma}_{d i}{ }^{2}=\frac{\sum_{k=1}^{K} \hat{\delta}_{i k}{ }^{2}}{K-2}=\frac{Q M D_{i}-Q M R}{J}$

sendo

$Q M D_{i}=\frac{J}{K-2}\left[\sum_{k=1}^{K} Y_{i k}{ }^{2}-\frac{Y_{i .}{ }^{2}}{K}-\frac{\left(\sum_{k=1}^{K} Y_{i k} I_{k}\right)^{2}}{\sum_{k=1}^{K} I_{k}{ }^{2}}\right]$ 
Para obtenção das análises de variância, parâmetros de estabilidade e gráficos de cada híbrido, utilizou-se os programas MSTAT, GENES da Universidade Federal de Viçosa e o HARVARD GRAPHICS, respectivamente. 


\section{RESULTADOS E DISCUSSÃO}

\subsection{Análise da Variância}

No ano agrícola de $1992 / 93$ a média de produtividade dos ensaios variou de 3,17 t/ha em Candido Mota, SP, a $12,55 \mathrm{t} / \mathrm{ha}$ em Ituverava $\mathrm{SP}$. No ano de 1993/94 esta variou de $6,50 \mathrm{t} / \mathrm{ha}$ em Caraguatatuba, SP a $12,08 \mathrm{t} / \mathrm{ha}$ em Guaxupé, MG e no ano agrícola de $1994 / 95$ de 4,60 t/ha em Pirassununga, $\mathrm{SP}$ a $13,72 \mathrm{t} / \mathrm{ha}$ em Guaxupé, MG. Esses Iimites mostram uma ampla faixa de ambientes, indispensável para o cálculo das distâncias em relação ao melhor genótipo e para o estudo da estabilidade.

A produtividade média e o quadrado médio do resíduo de cada local no respectivo ano, encontram-se nas tabelas 9, 10 e 11 . Verificou-se através do teste ... a existência de homogeneidade de variâncias dos experimentos dentro de cada ano.

Os rendimentos médios dos híbridos comerciais em cada local encontram-se nas tabelas 12,13 e 
14. Pode-se observar que no ano agrícola de 1992/93, o híbrido AG 514 se destacou, pois, dos 6 ambientes considerados favoráveis, em 4 destes ele obteve a maior produtividade. No ano seguinte o híbrido AG 951 obteve as maiores produtividades em 4 dos 13 locais testados. Já no ano de 1994/95, o destaque ficou com o híbrido AG 5011, que obteve produtividades elevadas em 9 dos 19 locais testados. As análises da variância conjunta dos dados, realizada para cada ano, revelaram efeito significativo dos híbridos, locais e da interação híbridos x locais (Tabela 15). 
Tabela 9. Produtividade média de espigas em t/ha e Quadrados Médios de Híbridos de milho e do Resíduo, obtidos nas análises da variância individuais de cada local no ano agricola de $1992 / 93$.

\begin{tabular}{lccc}
\hline Locais & média & $\begin{array}{c}\text { Q.M.Híbridos } \\
6 \mathrm{~g} .1)\end{array}$ & $\begin{array}{c}\text { Q.M.Resíduo } \\
(18 \mathrm{~g} .1)\end{array}$ \\
\hline 1. Candio Mota & 3.18 & $3,876 \star \star$ & 0,296 \\
2. Palmital & 5,28 & $1,004 \mathrm{n.s}$. & 1,415 \\
3. S.C. das Palmeiras & 8,04 & $2,926 \star$ & 0,642 \\
4. Paulo de Farias & 8,99 & $3,635 \star$ & 1,004 \\
5. Paulínia & 9,14 & $0,675 \mathrm{n} . \mathrm{s}$. & 0,549 \\
6. Rio Claro & 9,26 & $2,012 \star \star$ & 0,230 \\
7. Holamora & 9,30 & $1,503 \star$ & 0,527 \\
8. Novo Horizonte & 11,01 & $0,911 *$ & 0,221 \\
9. Ituverava & 12,55 & $1,872 \star *$ & 0,245 \\
\hline média geral & 8,53 & & \\
\hline
\end{tabular}

* - significativo a 5\% de probabilidade pelo teste F. ** - significativo a 1\% de probabilidade pelo teste F. n.s - não significativo. 
Tabela 10. Produtividade média de espigas em t/ha e Quadrados Médios de Híbridos de milho e do Residuo, obtidos nas análises da variância individuais de cada local no ano agrícola de $1993 / 94$.

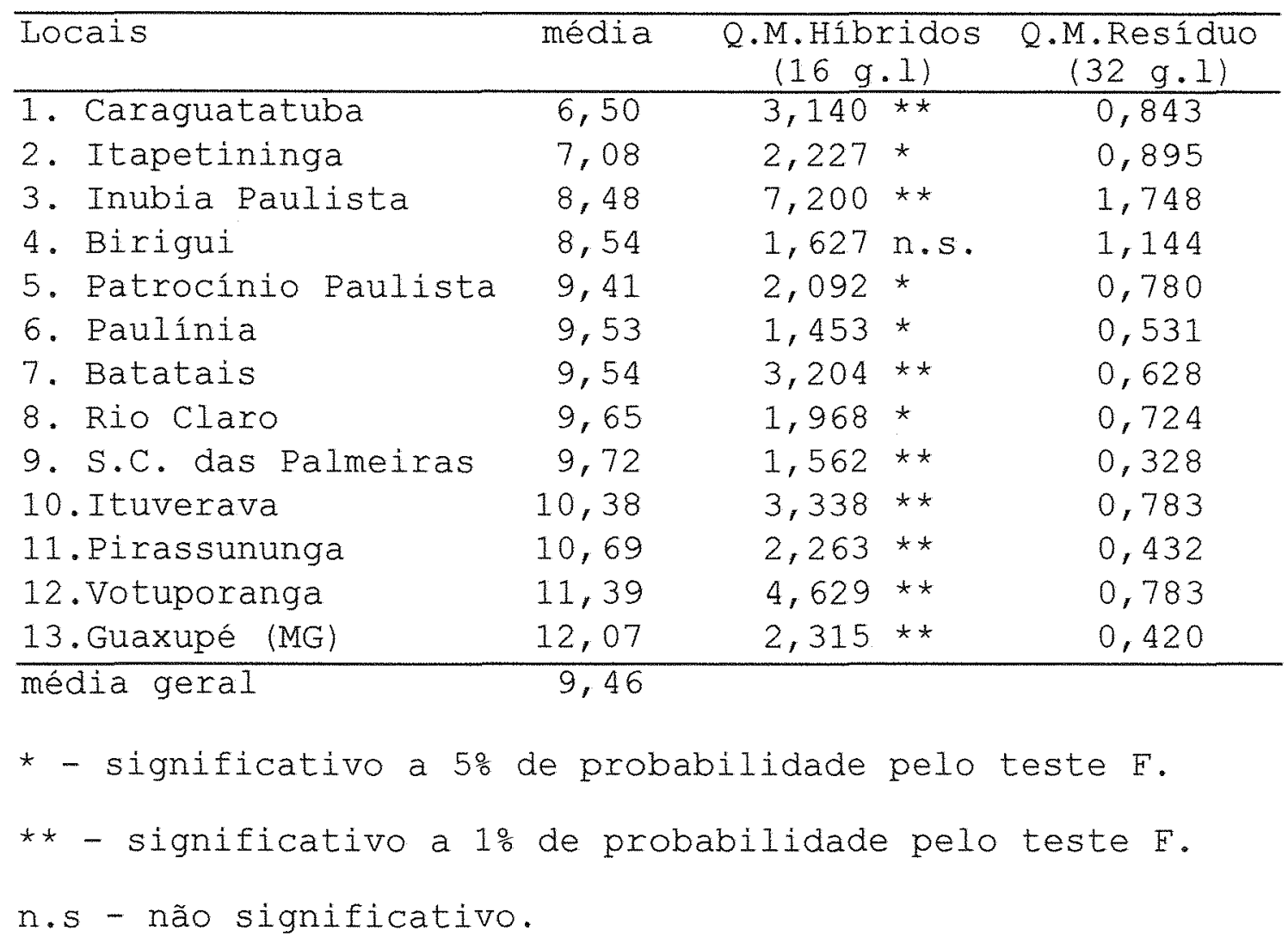


Tabela 11. Produtividade média de espigas em t/ha e Quadrados Médios de Híbridos de milho e do Resíduo, obtidos nas análises da variância individuais de cada local no ano agrícola de $1994 / 95$.

\begin{tabular}{|c|c|c|c|c|}
\hline Locais & média & \multicolumn{2}{|c|}{$\begin{array}{c}\text { Q.M.Híbridos } \\
(17 \mathrm{~g} \cdot 1)\end{array}$} & $\begin{array}{l}\text { Q.M.Residu } \\
0 \\
\quad(34 \mathrm{~g} \cdot 1)\end{array}$ \\
\hline 1. Pirassununga & 4,60 & 2,847 & $\star \star$ & 0,429 \\
\hline 2. Pindorama & 5,22 & 1,932 & $n \cdot s$ & 1,791 \\
\hline 3. Estrela D'Oeste & 5,98 & 0,614 & n.s & 0,657 \\
\hline 4. Américo De Campos & 6,36 & 6,951 & $\star *$ & 1,820 \\
\hline 5. Rio Claro & 6,37 & 1,408 & n.s & 0,834 \\
\hline 6. Batatais & 6,68 & 3,231 & * & 1,341 \\
\hline 7. Guaraci & 7,08 & 2,503 & * & 1,027 \\
\hline 8. Birigui & 7,43 & 2,762 & $* *$ & 0,817 \\
\hline 9. Bariri & 7,74 & 3,765 & $\star \star$ & 1,112 \\
\hline 10. Carmo do Rio Claro (MG) & 7,90 & 2,732 & $\mathrm{n} \cdot \mathrm{s}$ & 1,885 \\
\hline 11. Capão Bonito & 8,05 & 2,453 & * & 0,790 \\
\hline 12. Icem & 8,07 & 1,023 & * & 0,482 \\
\hline 13.S.C. das Palmeiras 2 & 8,64 & 1,180 & * & 0,575 \\
\hline 14.Andradas (MG) & 9,71 & 6,093 & $* \star$ & 1,419 \\
\hline 15.Paulínia & 10,28 & 2,429 & * & 0,865 \\
\hline 16. Tatui & 10,51 & 4,070 & * & 1,759 \\
\hline 17.S.C das Palmeiras 1 & 10,83 & 4,426 & $\star \star$ & 0,663 \\
\hline 18. Guaratinguetá & 11,42 & 4,161 & $\star \star \star$ & 0,892 \\
\hline 19. Guaxupé (MG) & 13,72 & 4,120 & * & 1,469 \\
\hline média geral & 8,24 & & & \\
\hline
\end{tabular}

* - significativo a 5\% de probabilidade pelo teste F. ** - significativo a 1을 de probabilidade pelo teste F. n.s - não significativo. 
Tabela 12. Produtividade média de espigas, em t/ha e datas de semeadura de sete híbridos de milho, coeficientes de variação (C.V), médias em t/ha $\left(\bar{P}_{. k}\right)$ e indices ambientais $\left(I_{k}\right)$ dos ensaios realizados em 9 locais do Estado de São Paulo em 1992/93.

\begin{tabular}{|c|c|c|c|c|c|c|c|c|c|c|}
\hline \multirow[b]{3}{*}{ híbridos } & ambientes & $I$ & 2 & 3 & 4 & 5 & 6 & 7 & 8 & 9 \\
\hline & locais & $\begin{array}{l}\text { Candido } \\
\text { Mota }\end{array}$ & $\begin{array}{c}\text { Palmi } \\
\text { tal }\end{array}$ & $\begin{array}{c}\text { S.C. } \\
\text { Palmei } \\
\text { ras }\end{array}$ & $\begin{array}{c}\text { Paulo } \\
\text { de } \\
\text { Farias }\end{array}$ & $\begin{array}{c}\text { Pauli } \\
\text { nia }\end{array}$ & $\begin{array}{l}\text { Rio } \\
\text { Claro }\end{array}$ & $\begin{array}{c}\text { Holam } \\
\text { bra }\end{array}$ & $\begin{array}{l}\text { Novo Ho } \\
\text { rizonte }\end{array}$ & $\begin{array}{c}\text { Ituvera } \\
\text { va }\end{array}$ \\
\hline & $\begin{array}{l}\text { datas de } \\
\text { semeadura }\end{array}$ & $20 / 10$ & $01 / 10$ & $10 / 11$ & $23 / 09$ & $18 / 11$ & $22 / 12$ & $03 / 11$ & $22 / 10$ & $09 / 10$ \\
\hline $\begin{array}{ll}A G 106 \\
\end{array}$ & & 2,20 & 4,82 & 7.76 & 8,34 & 8,38 & 9,00 & 8,69 & 11,18 & 12,49 \\
\hline AG 122 & & 2,93 & 6,06 & 9,34 & 8,80 & 8,92 & 8,58 & 9,62 & 11,22 & 12,37 \\
\hline AG 510 & & 4,25 & 5,58 & 7,77 & 10,09 & 9.11 & 9,26 & 9,58 & 10,66 & 12,70 \\
\hline AG 514 & & 3,47 & 5,36 & 7,91 & 9,90 & 9,60 & 10,76 & 10,20 & 11,32 & 13,62 \\
\hline AG 519 & & 3,62 & 5,48 & 8,85 & 8,19 & 9.54 & 9,05 & 8,39 & 10,23 & 11,52 \\
\hline AG 612 & & 4,15 & 4,55 & 6,68 & 9,88 & 9,13 & 8,80 & 9,50 & 10,78 & 12,06 \\
\hline AG 6601 & & 1,62 & 5,11 & 7,98 & 7,75 & 9,30 & 9,34 & 9,14 & 11,65 & 13,11 \\
\hline$\overline{\bar{P}}_{k}$ & & 3,18 & 5,28 & 8,04 & 8,99 & 9,14 & 9,26 & 9,30 & 11,01 & 12,55 \\
\hline$\overline{c . v . \frac{g}{2}}$ & & 17,1 & 22,5 & 9,9 & 11,1 & 8,1 & $\overline{5,2}$ & 7,8 & 4,3 & 3,9 \\
\hline$\overline{I_{k}}$ & & $-5,35$ & $-3,25$ & $-0,49$ & 0,46 & 0,61 & 0,73 & 0,78 & 2,48 & 4,02 \\
\hline
\end{tabular}


Tabela 13. Produtividade média de espigas, em tha e datas de semeadura de dezessete hibridos de milho, coeficientes de variaça (C.V), médias en tha $\left(\bar{P}_{k}\right)$ e irdices ambientais $\left(I_{k}\right)$ dos ensaios realizados em 13 locais dos Estados de São Paulo e Minas Gerais em $1993 / 94$.

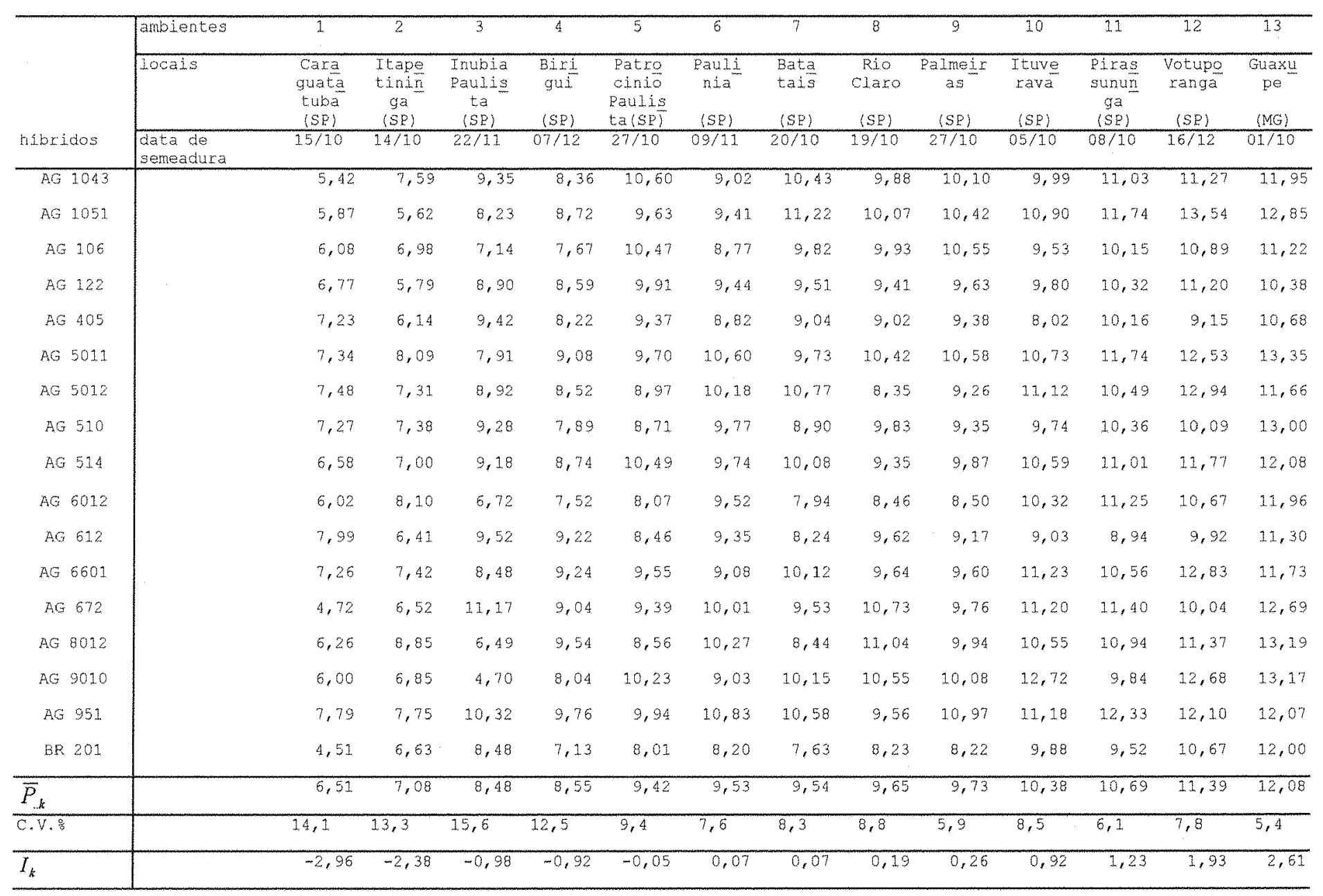


Tabela 14. Produtividade média de espigas, en t/ha e datas de semeadura de dezoito híbridos de milho, cceficientes de variaça (C.V), médias em tha $\left(\bar{P}_{k}\right)$ e indices ambientais $\left(I_{k}\right)$ dos ensaios realizados em 19 locais dos Estados de Säo paulo e Miras Gerais em $1994 / 95$.

\begin{tabular}{|c|c|c|c|c|c|c|c|c|c|c|c|c|c|c|c|c|c|c|c|c|}
\hline & mibientes & 1 & 2 & 3 & 4 & 5 & 6 & 7 & 8 & 9 & 10 & 11 & 12 & 13 & 14 & 15 & 16 & 17 & 18 & $\sqrt{19}$ \\
\hline & Locais & $\begin{array}{c}\text { Pira } \\
\text { sunun } \\
99 \\
(S P)\end{array}$ & $\begin{array}{l}\text { Pindo } \\
\text { rama } \\
(\mathrm{SP})\end{array}$ & $\begin{array}{l}\text { Estre } \\
\text { la D. } \\
\text { Oeste } \\
\text { (SP) }\end{array}$ & $\begin{array}{l}\text { A.de } \\
\text { Cam } \\
\text { pos } \\
\langle\mathrm{SP}\rangle\end{array}$ & $\begin{array}{c}\text { Rio } \\
\text { Claro } \\
\text { (SP) }\end{array}$ & $\begin{array}{l}\text { Bata } \\
\text { tais } \\
\text { (SP) }\end{array}$ & $\begin{array}{c}\text { Gura } \\
c 1 \\
(S P)\end{array}$ & $\begin{array}{l}\text { Biri } \\
\text { guí } \\
\text { (SP) }\end{array}$ & $\begin{array}{c}\text { Bari } \\
r i \\
(S P) \\
\end{array}$ & $\begin{array}{l}\text { C.do } \\
\text { Rio } \\
\text { Claro } \\
\text { (SP) }\end{array}$ & $\begin{array}{c}\text { Capzo } \\
\text { Boni } \\
\text { to } \\
\text { (SP) } \\
\end{array}$ & Icem & $\begin{array}{l}\text { S.C. } \\
\text { palme } \\
\text { iras } \\
2 \text { (SP) }\end{array}$ & $\begin{array}{c}\text { Andra } \\
\text { des } \\
(M G) \\
\text { (MG) }\end{array}$ & $\begin{array}{c}\text { Paulí } \\
\text { nia } \\
\text { (SP) }\end{array}$ & Tatui & $\begin{array}{l}\text { S.C. } \\
\text { Palme } \\
\text { i.tas } \\
\text { 1(SP }\end{array}$ & $\begin{array}{l}\text { Gura } \\
\text { tinf } \\
\text { gueta } \\
\text { (SP) }\end{array}$ & $\begin{array}{c}\text { Guaxu } \\
\text { pe } \\
\text { (MG) }\end{array}$ \\
\hline bridos & $\begin{array}{l}\text { datas de } \\
\text { semeadura }\end{array}$ & $09 / 12$ & $14 / 11$ & $10 / 11$ & $02 / 11$ & $11 / 10$ & $06 / 11$ & $22 / 11$ & $03 / 12$ & $16 / 11$ & $02 / 12$ & $02 / 11$ & $09 / 11$ & $10 / 11$ & $07 / 11$ & $8 / 11$ & $02 / 11$ & $10 / 10$ & $01 / 12$ & $01 / 11$ \\
\hline AG 1043 & & 3,70 & 6.07 & 5,66 & 5,03 & 5,38 & 6,27 & 7,03 & 6,22 & 8,96 & 7,20 & 8,89 & 8,49 & 7,69 & 10,77 & 10,04 & 11,12 & 10,41 & 11,56 & 13,09 \\
\hline AG 106 & & 5,12 & 4.38 & 5,58 & 5.91 & 6.85 & 6,54 & 6,56 & 6,28 & 7,68 & 8,49 & 9,15 & 7,56 & 8,96 & 7,93 & 10,23 & 10,60 & 10,40 & 12,09 & 12,39 \\
\hline AG 122 & & 5.09 & 3,65 & 6,47 & 6,26 & 5,67 & 5.65 & 7,49 & 7,72 & 7,71 & 8,16 & 8,34 & 8,43 & 8,68 & 11,23 & 9,93 & 10,96 & 13,40 & 12,19 & 13,50 \\
\hline$A G 4011$ & & 6,22 & 5,83 & 6,38 & 4.65 & 7,29 & 7,61 & 7,33 & 6,78 & 6,95 & 9,41 & 7,28 & 8,40 & 8,90 & 11,08 & 10,71 & 9,05 & 9.14 & 10,19 & 13.66 \\
\hline AG 405 & & 3,85 & 4,68 & 5,97 & 5,10 & 6,68 & 5,75 & 5,94 & 5,41 & 6,25 & 7,51 & 6,31 & 7,78 & 7,85 & 8,05 & 9,35 & 8,47 & 9,42 & 9,22 & 12,20 \\
\hline AG 5011 & & 5,95 & 6,15 & 6,85 & 7,53 & 7,03 & 7,42 & 8,57 & 9,01 & 9,92 & 9,90 & 9,45 & 9,28 & 9,72 & 12,30 & 12,14 & 12,04 & 12,00 & 13,85 & 13,62 \\
\hline AG 5012 & & 4,80 & 4,85 & 5,74 & 4,66 & 6,68 & 7,48 & 7,33 & 6,80 & 7,45 & 7,77 & 8,74 & 7,06 & 9,36 & 9,19 & 10,62 & 10,86 & 9,03 & 17,35 & 14,88 \\
\hline$A G \$ 10$ & & 3,34 & 4,08 & 5,68 & 5,22 & 5,70 & 7,12 & 6,82 & 6,58 & 7.14 & 8,15 & 7,49 & 7,76 & 8,80 & 8,55 & 11,76 & 10,70 & 3.1 .07 & 11,36 & 15,07 \\
\hline AG 514 & & 4,71 & 5,32 & 5,47 & 5,18 & 6,22 & 5,01 & 5,07 & 5,82 & 6,80 & 7,48 & 8,36 & 7,25 & 8,77 & 8,18 & 9,62 & 9,59 & 9,72 & 11,58 & 13,74 \\
\hline AG 5 & & 4,83 & 5,55 & 6,12 & 5,05 & 5,53 & 5,59 & 7,25 & 7,66 & 7,84 & 7.94 & 8,21 & 8,52 & 8,51 & 9,71 & 9,94 & 39 & .55 & 11,26 & 13,39 \\
\hline AG 612 & & 3,09 & 4,83 & 5,81 & 8,06 & 6.17 & 5,56 & 7,28 & 7,53 & 8,28 & 7,71 & 6.58 & 7,39 & 8,59 & 8,68 & 8,79 & 10,66 & 12,29 & 12,41 & 15,04 \\
\hline AG 6 & & 4,18 & 5,91 & 5,86 & 6.71 & 5,40 & 5,87 & 7,08 & 8,53 & 7,92 & 8,74 & 8,34 & 8,78 & 8,64 & 8,08 & 10 & 10 & 12.62 & 11,85 & 15,25 \\
\hline AG 8010 & & 6,16 & 5,65 & 5,03 & 5,75 & 6,43 & 6,74 & 5,90 & 8,02 & 7,01 & 6,46 & 8,86 & 8,31 & 8,08 & 8,73 & 9,29 & 9,21 & 11,72 & 9,81 & 14.25 \\
\hline$A G 8012$ & & 3,75 & 4,17 & 5,57 & 9,1 & 6,82 & 2 & 7,72 & 9,26 & 10,20 & 7.47 & 6,56 & 7,87 & 7,63 & 08 & 11,72 & 12,69 & 12,16 & 12,07 & 14,32 \\
\hline AE 9012 & & 4,73 & 5,73 & 5,51 & 9,34 & 7.59 & 7,88 & 7.70 & 7.88 & 7,91 & 6.46 & 7,80 & 8.24 & 9,09 & 11,52 & 10,76 & 11,00 & 12,41 & 11,99 & 12,94 \\
\hline AG 9014 & & 4,03 & 5,89 & 6,05 & 8,23 & 6,37 & 7,69 & 5,26 & 7,78 & 6,31 & 6.84 & 8,07 & 7,72 & 9,58 & 10,89 & 9,56 & 21,60 & 10.27 & 11,20 & 12,67 \\
\hline AG 951 & & 5,65 & 6,32 & 6,66 & 5,72 & 7,14 & 5,68 & 8,11 & 8,20 & 8,39 & 3,12 & 8,47 & 8.61 & 8,90 & 10,17 & 10,60 & 11,18 & 11,49 & 12,30 & 15,62 \\
\hline BR 201 & & 3,58 & 4,91 & 5,23 & 5,87 & 5,78 & 5,27 & 7,94 & 5,23 & 6,51 & 7,46 & 8,02 & 7,79 & 7,77 & 8,60 & 10,06 & 8,39 & 9,89 & 9,22 & 11,39 \\
\hline$\overline{P_{. k}}$ & & 4,60 & 5,22 & 5,98 & 6,36 & 6,37 & 6,68 & 7.08 & 7,43 & 7.74 & 7,90 & 8,05 & 8.07 & 8,64 & 9.71 & 10,29 & 10,51 & 10,83 & 11,42 & $\overline{13,72}$ \\
\hline$\overline{c . v}$ & & 14,2 & 25.6 & 13,5 & 21,2 & 14,3 & 27,3 & 14,3 & 12,2 & 13,6 & 17,4 & 11.0 & 8,6 & 8,8 & 12,3 & 9.0 & 12,6 & 7,5 & 8,3 & $\overline{8,8}$ \\
\hline$I_{k}$ & & $-3,64$ & $-3,02$ & $-2,26$ & 1,89 & $-1,87$ & $-1,56$ & $-1,17$ & $-0,81$ & $-0,51$ & $-0,34$ & $-0,19$ & $-0,17$ & 0,40 & 1.47 & 2,05 & 2,27 & 2,59 & 3,17 & 5,48 \\
\hline
\end{tabular}


Tabela 15. Análise conjunta da produtividade média do peso de espigas em tha, nos anos agrícolas de $1992 / 93,1993 / 94$ e $1994 / 95$, respectivamente.

\begin{tabular}{|c|c|c|c|c|c|c|c|}
\hline \multirow[t]{2}{*}{ Causas de Variação } & \multicolumn{2}{|c|}{$1992 / 93$} & \multicolumn{2}{|c|}{$1993 / 94$} & \multicolumn{3}{|c|}{$1994 / 95$} \\
\hline & G.I & $Q . M$ & G.I & $Q \cdot M$ & G.L & Q.M & \\
\hline Total & 251 & & 662 & & 1025 & & \\
\hline Locais & 8 & $222,163^{* *}$ & 12 & $124,256 * *$ & 18 & 293,759 & $\star \star$ \\
\hline blocos (locais) & 27 & 4,905 & 26 & 12,242 & 38 & 7,057 & \\
\hline Híbridos & 6 & $4,306 * *$ & 16 & $10,045 * *$ & 17 & 18,362 & $\star \star$ \\
\hline Locais $x$ Híbridos & 48 & $1,763 * *$ & 192 & $2,248 * \star$ & 306 & 2,241 & $* *$ \\
\hline Residuo Médio & 162 & 0,570 & 416 & 0,772 & 646 & 1,086 & \\
\hline$\overline{C . V} 8$ & & 8,8 & & 9,3 & & 12,6 & \\
\hline
\end{tabular}

* significância ao nivel de is de probabilidade. 
grupo 1 : AG 514

grupo 2 : AG 510 e AG 122

grupo 3 : AG 612, AG 6601, AG 519 e AG 106

Ao se considerar os ambientes desfavoráveis, - híbrido AG 122 destacou-se em produtividade, com 19,4 \% de distância ao melhor genótipo, porém com um comportamento médio em relação ao tombamento com $38,2 \%$ de distância. O híbrido AG 514 continuou com $O$ menor tombamento $(4,6 \%)$. O híbrido com baixa produtividade foi 0 AG 6601 com valor de $72,6 \%$ embora tenha mostrado baixo valor de distância para o tombamento (16,7\%). Verifica-se, através da figura 3, que os hibridos não formaram grupos, estando estes bem distantes um do outro, não havendo híbrido que se destacasse por estar próximo do melhor genótipo, ao se levar em conta as duas variáveis (produtividade e tombamento).

Considerando-se os ambientes favoráveis, o híbrido AG 514 destacou-se pelo seu excelente desempenho. Mostrou em produtividade um valor de distância $4,7 \%$, e um valor zero de distância quanto ao tombamento. O AG 510 foi - segundo melhor (Figura 4). O híbrido AG 519 foi considerado de pior desempenho para aquelas condições, pois foi o que ficou mais distante do melhor genótipo. Pode-se também formar três grupos, que foram: 


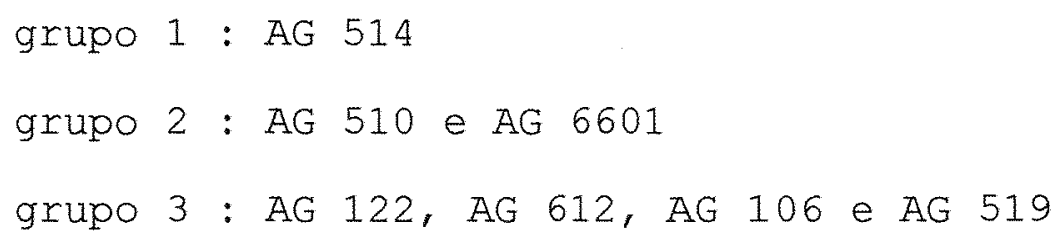




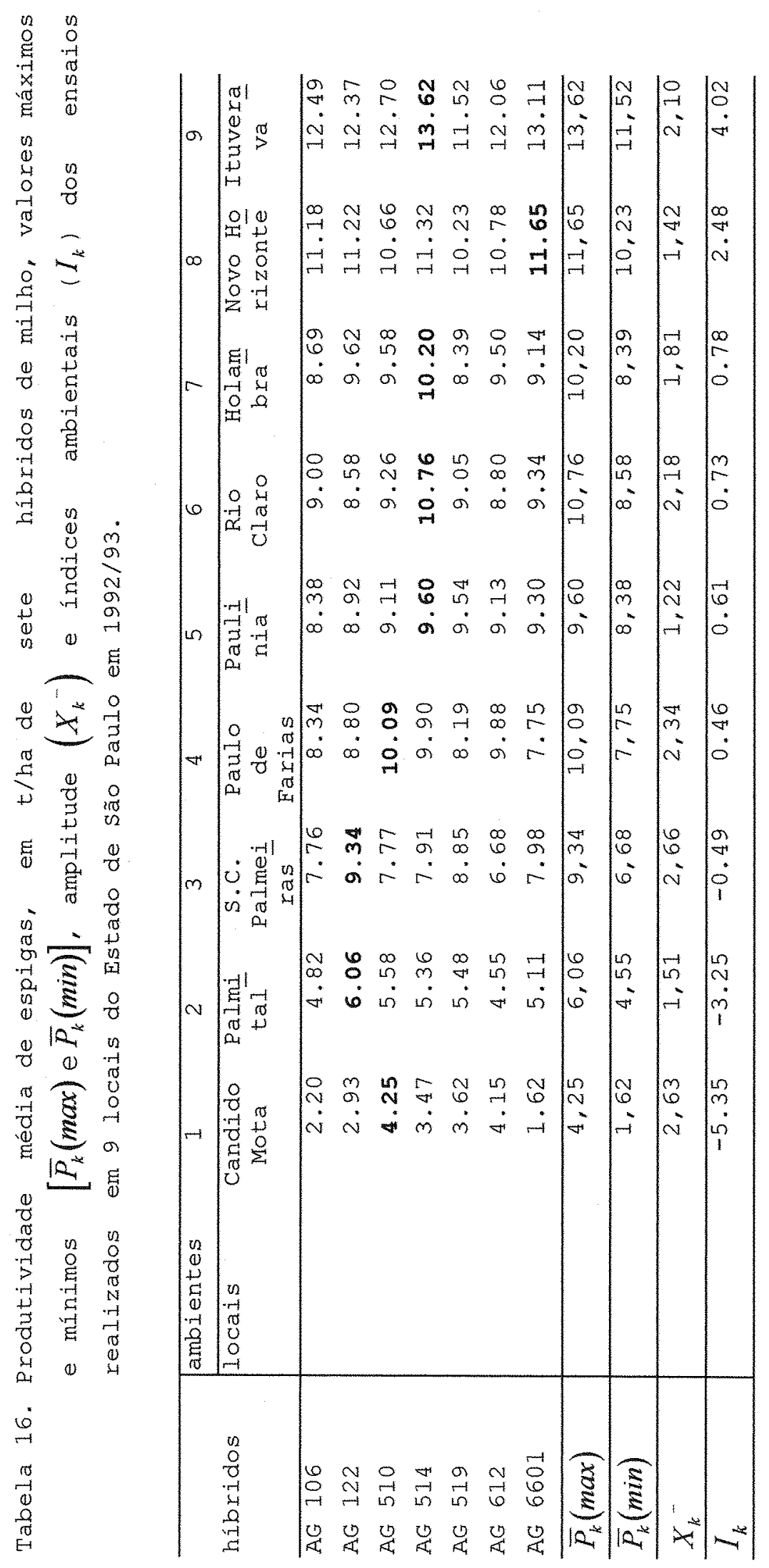




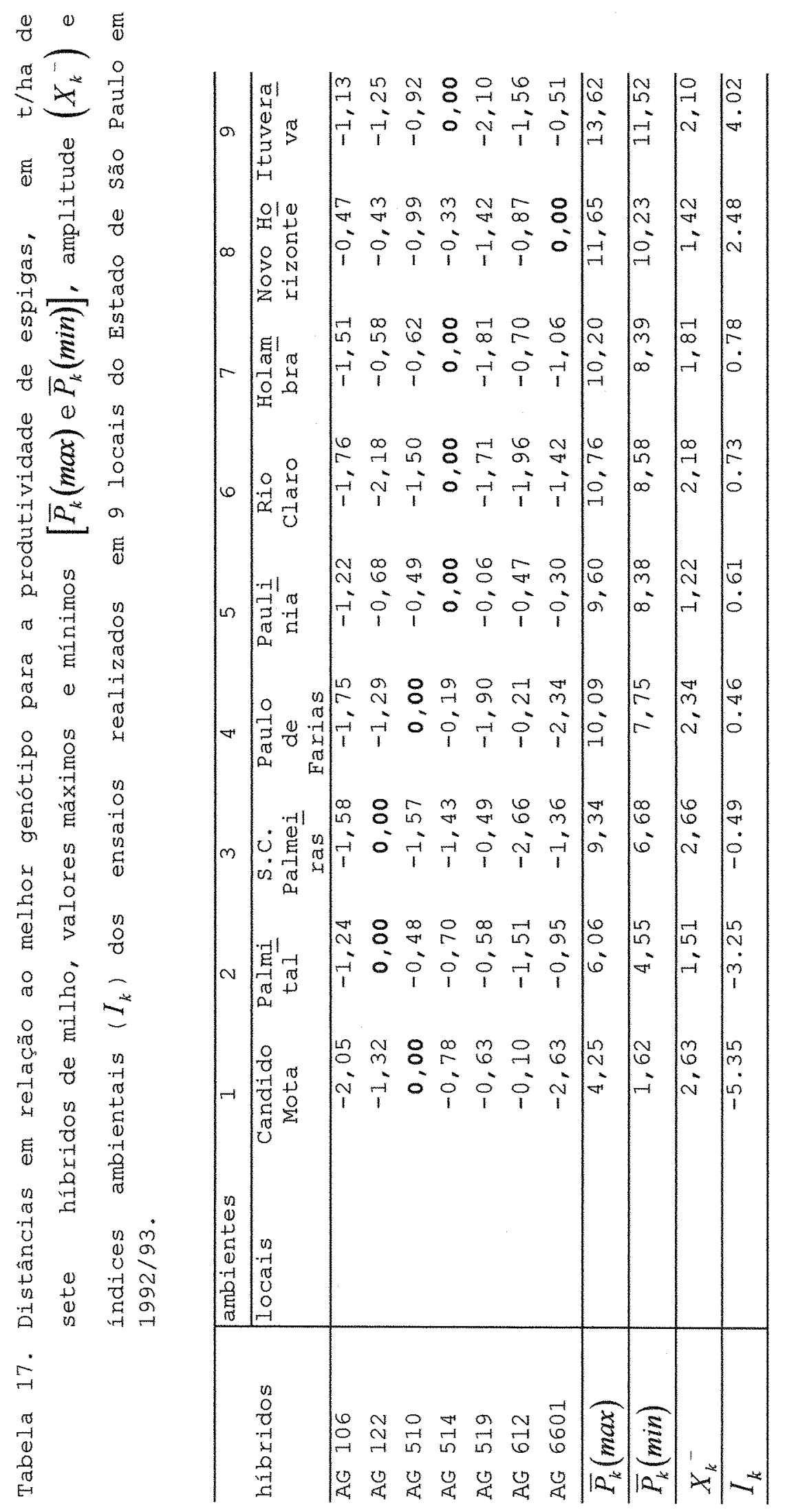




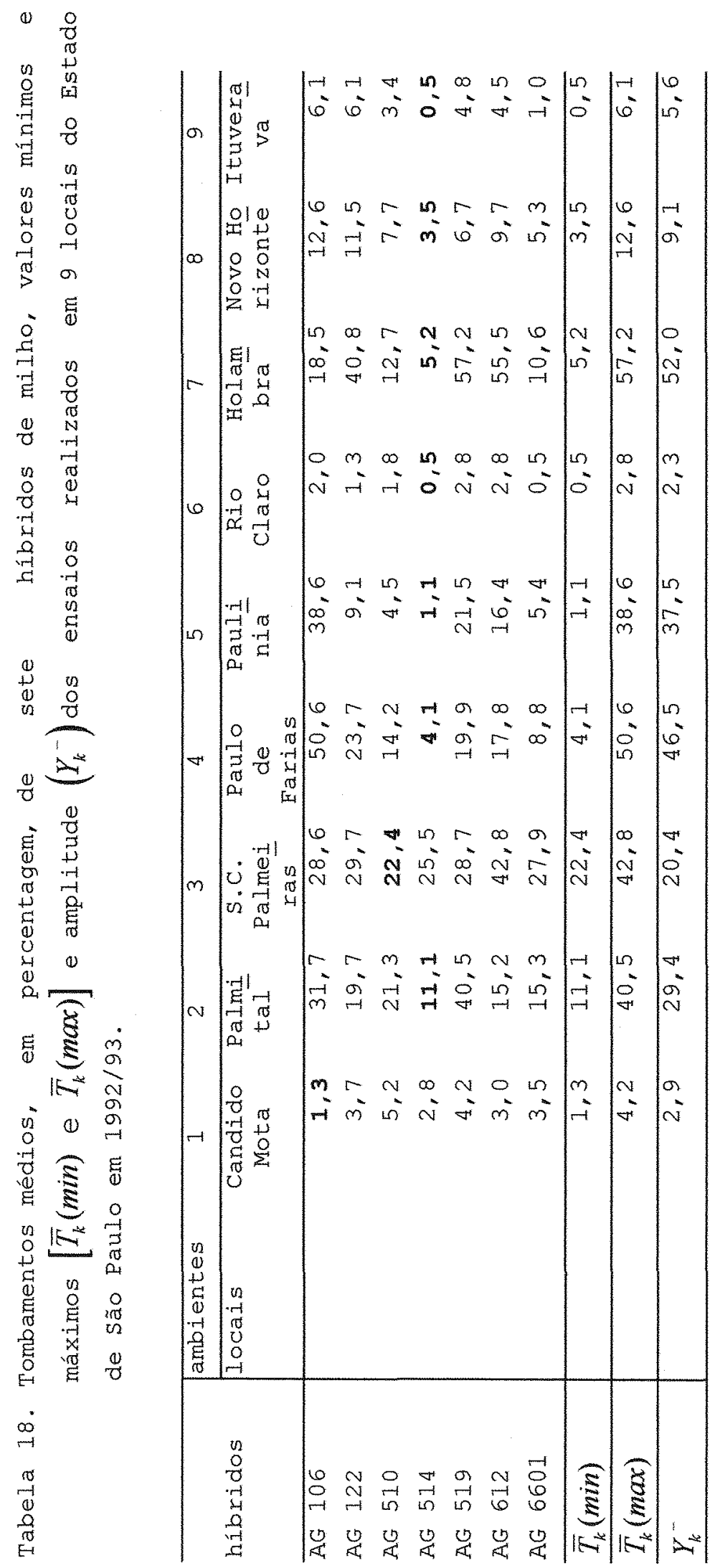




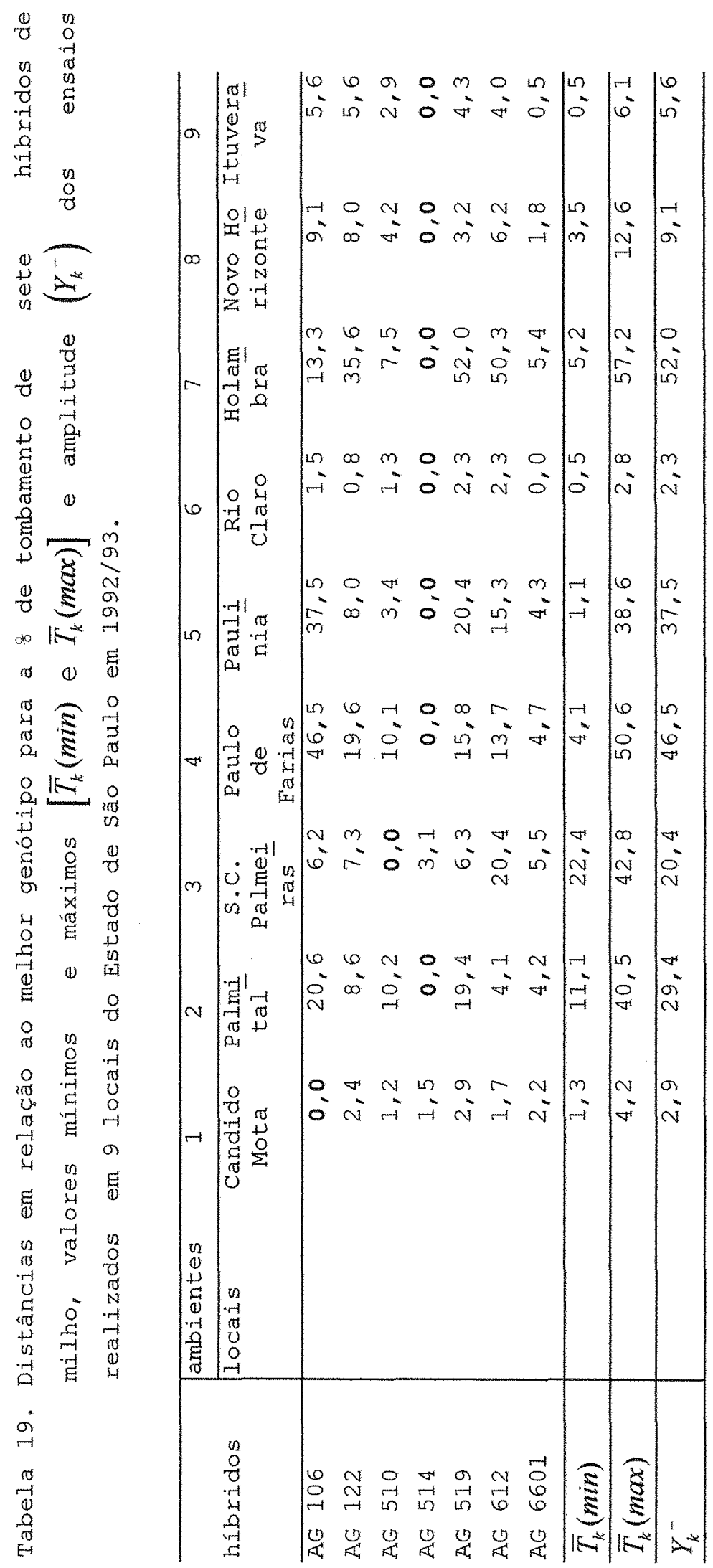


Tabela 20. Distância de sete híbridos de milho em relação ao melhor genótipo para a produtividade de espigas $\left(D p_{i}\right)$ e o tombamento das plantas $\left(D t_{i}\right)$; grau de inferioridade dos híbridos em porcentagem da amplitude $\left(I p_{i} \%\right.$ e $\left.I t_{i} \%\right)$; média das amplitudes $\left(D p^{-}\right.$e $\left.D t^{-}\right)$; melhor e pior genótipo ( $M g$ e $P g$ ) para os resultados obtidos de experimentos em 9 locais do Estado de São Paulo (ano agrícola 1992/93).

Produtividade

\begin{tabular}{|c|c|c|c|c|c|}
\hline Híbridos & $D p_{i}$ & $I P_{i} \%$ & Híbridos & $D t_{i}$ & $I t_{i} \%$ \\
\hline$\overline{A G \quad 514}$ & 0,38 & 19,2 & $\overline{A G \quad 514}$ & 0,5 & 2,2 \\
\hline AG 510 & 0,73 & 36,8 & AG 6601 & 3,2 & 13,9 \\
\hline AG $\quad 122$ & 0,86 & 43,3 & AG 510 & 4,5 & 19,8 \\
\hline AG $\quad 612$ & 1,12 & 56,2 & AG 122 & 10,7 & 46,6 \\
\hline AG 6601 & 1,17 & 59,1 & AG 612 & 13,1 & 57,4 \\
\hline AG 519 & 1,19 & 59,9 & AG 519 & 15,2 & 66,4 \\
\hline $\mathrm{AG} 106$ & 1,41 & 71,1 & AG 106 & 15,6 & 68,2 \\
\hline$D p^{-}$ & \multicolumn{2}{|c|}{1,99} & $D t^{-}$ & \multicolumn{2}{|c|}{22,9} \\
\hline$\overline{M g}$ & \multicolumn{2}{|c|}{9,51} & $M g$ & \multicolumn{2}{|c|}{5,5} \\
\hline$P g$ & \multicolumn{2}{|c|}{7,52} & $P g$ & \multicolumn{2}{|c|}{28,4} \\
\hline
\end{tabular}

응 Tombamento 
Tabela 21. Distância de sete híbridos de milho em relação ao melhor genótipo para a produtividade de espigas $\left(D p_{i}\right)$ e o tombamento das plantas $\left(D t_{i}\right)$ i grau de inferioridade dos híbridos em porcentagem da amplitude $\left(I p_{i} \%\right.$ e $\left.I t_{i} \%\right)$; média das amplitudes $\left(D p^{-}\right.$e $\left.D t^{-}\right)$; melhor e pior genótipo ( $M g$ e $P g$ ) para os resultados obtidos de experimentos em 3 locais do Estado de são Paulo, considerados desfavoráveis (ano agrícola 1992/93).

\begin{tabular}{|c|c|c|c|c|c|}
\hline \multirow[b]{2}{*}{ Híbridos } & \multicolumn{2}{|c|}{ Produtividade } & \multicolumn{3}{|c|}{ iombamento } \\
\hline & $\overline{D p_{i}}$ & $I P_{i} \%$ & Híbridos & $\overline{D t_{i}}$ & $I t_{i} \%$ \\
\hline AG 122 & 0,44 & 19,4 & $\overline{A G \quad 514}$ & 1,2 & 4,6 \\
\hline AG 519 & 0,57 & 25,0 & AG 6601 & 4,2 & 16,7 \\
\hline AG 510 & 0,68 & 30,1 & AG 510 & 5,4 & 21,7 \\
\hline AG 514 & 0,97 & 42,8 & AG 122 & 9,5 & 38,2 \\
\hline AG 612 & 1,42 & 62,8 & AG 612 & 10,0 & 40,2 \\
\hline AG 106 & 1,62 & 71,6 & AG 519 & 13,6 & 54,8 \\
\hline AG 6601 & 1,65 & 72,6 & AG 106 & 18,3 & 73,9 \\
\hline$D p^{-}$ & \multicolumn{2}{|c|}{2,27} & $D t^{-}$ & \multicolumn{2}{|c|}{24,8} \\
\hline$\overline{M g}$ & \multicolumn{2}{|c|}{6,55} & $M g$ & \multicolumn{2}{|c|}{9,7} \\
\hline$\overline{P g}$ & \multicolumn{2}{|c|}{4,28} & $P g$ & \multicolumn{2}{|c|}{34,5} \\
\hline
\end{tabular}


Tabela 22. Distância de sete híbridos de milho em relação ao melhor genótipo para a produtividade de espigas $\left(D p_{i}\right)$ e o tombamento das plantas $\left(D t_{i}\right)$; grau de inferioridade dos híbridos em porcentagem da amplitude $\left(I p_{i} \%\right.$ e $\left.I t_{i} \%\right)$; média das amplitudes $\left(D p^{-}\right.$e $\left.D t^{-}\right)$; melhor e pior genótipo ( $M g$ e $P g$ ) para os resultados obtidos de experimentos em 6 locais do Estado de São Paulo, considerados favoráveis (ano agrícola 1992/93).

\begin{tabular}{|c|c|c|c|c|c|}
\hline & \multicolumn{2}{|c|}{ Produtividade } & \multicolumn{3}{|c|}{ Tombamento } \\
\hline Híbridos & $\overline{D p_{i}}$ & $I P_{i} \%$ & Híbridos & $\overline{D t_{i}}$ & $I t_{i} \%$ \\
\hline$\overline{A G \quad 514}$ & 0,09 & 4,7 & $\overline{A G ~} 514$ & 0,0 & 0,0 \\
\hline$A G 510$ & 0,75 & 40,8 & AG 6601 & 2,4 & 11,3 \\
\hline AG 6601 & 0,94 & 50,9 & AG 510 & 3,9 & 18,1 \\
\hline $\mathrm{AG} \quad 612$ & 0,96 & 52,1 & AG 122 & 11,6 & 54,5 \\
\hline AG 122 & 1,07 & 57,9 & AG 106 & 13,4 & 62,9 \\
\hline AG 106 & 1,31 & 70,8 & $\mathrm{AG} \quad 612$ & 15,6 & 73,3 \\
\hline AG 519 & 1,50 & 81,3 & AG 519 & 16,4 & 77,2 \\
\hline$D p^{-}$ & \multicolumn{2}{|c|}{1,85} & $D t^{-}$ & \multicolumn{2}{|c|}{21,3} \\
\hline$\overline{M g}$ & \multicolumn{2}{|c|}{10,89} & $M g$ & \multicolumn{2}{|c|}{2,2} \\
\hline$\overline{P g}$ & \multicolumn{2}{|c|}{9,14} & $P g$ & \multicolumn{2}{|c|}{23,5} \\
\hline
\end{tabular}




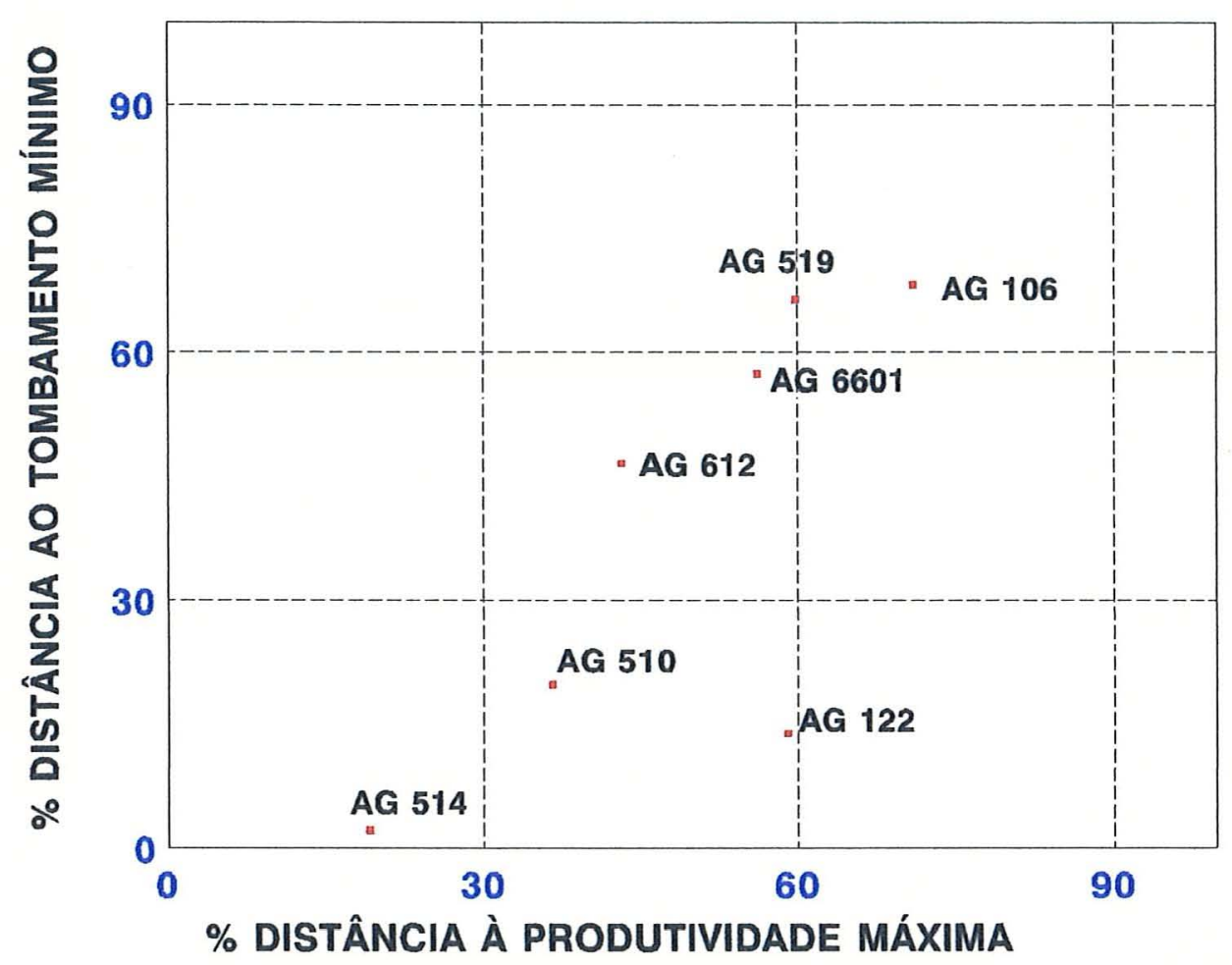

Figura 2. Distância em o à produtividade máxima e ao tombamento mínimo para os dados obtidos de experimentos em 9 locais do Estado de São Paulo (ano agrícola 1992/93). 


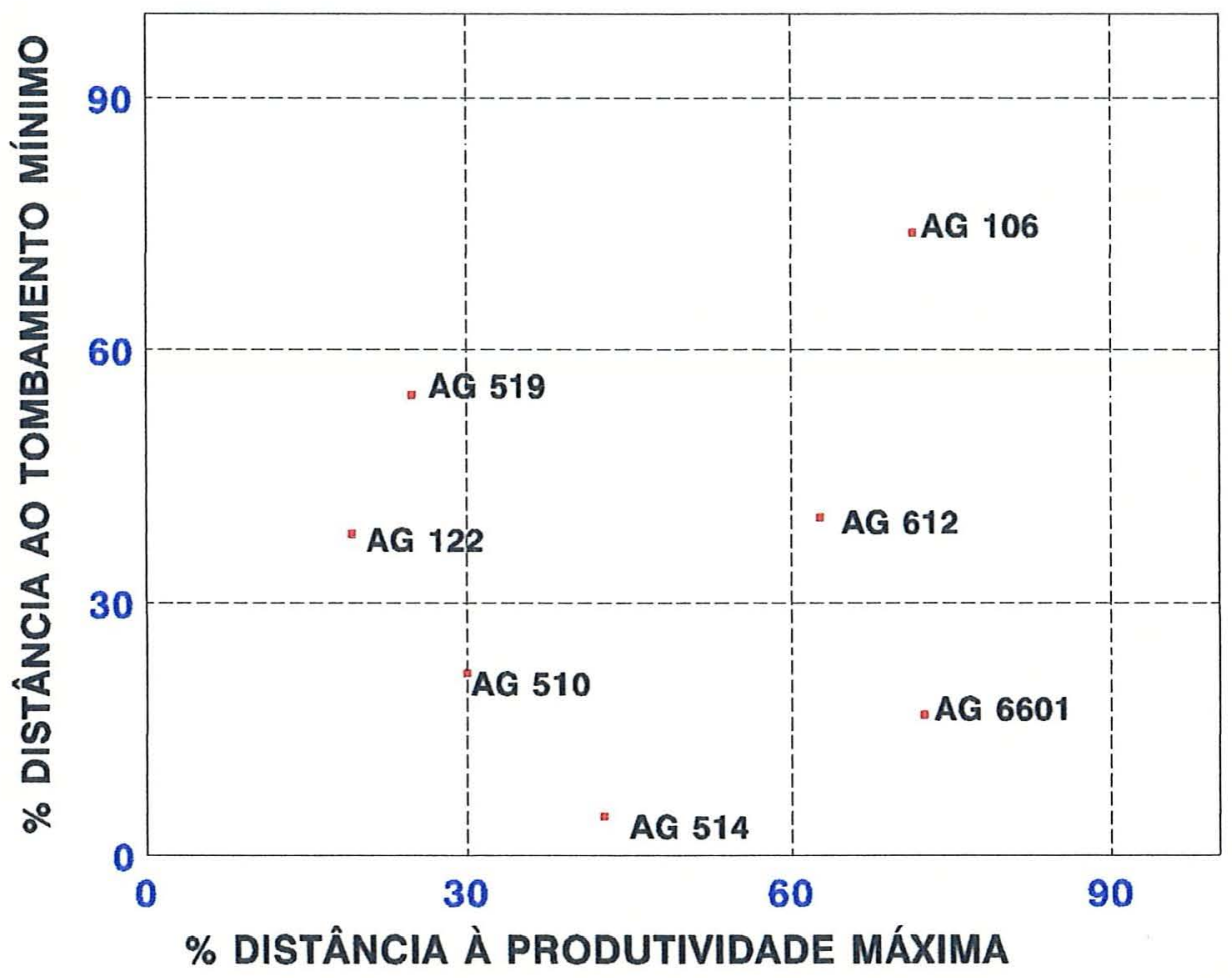

Figura 3. Distância em ò à produtividade máxima e ao tombamento mínimo para os dados obtidos de experimentos em 3 locais do Estado de São Paulo, considerados desfavoráveis (ano agrícola $1992 / 93)$. 


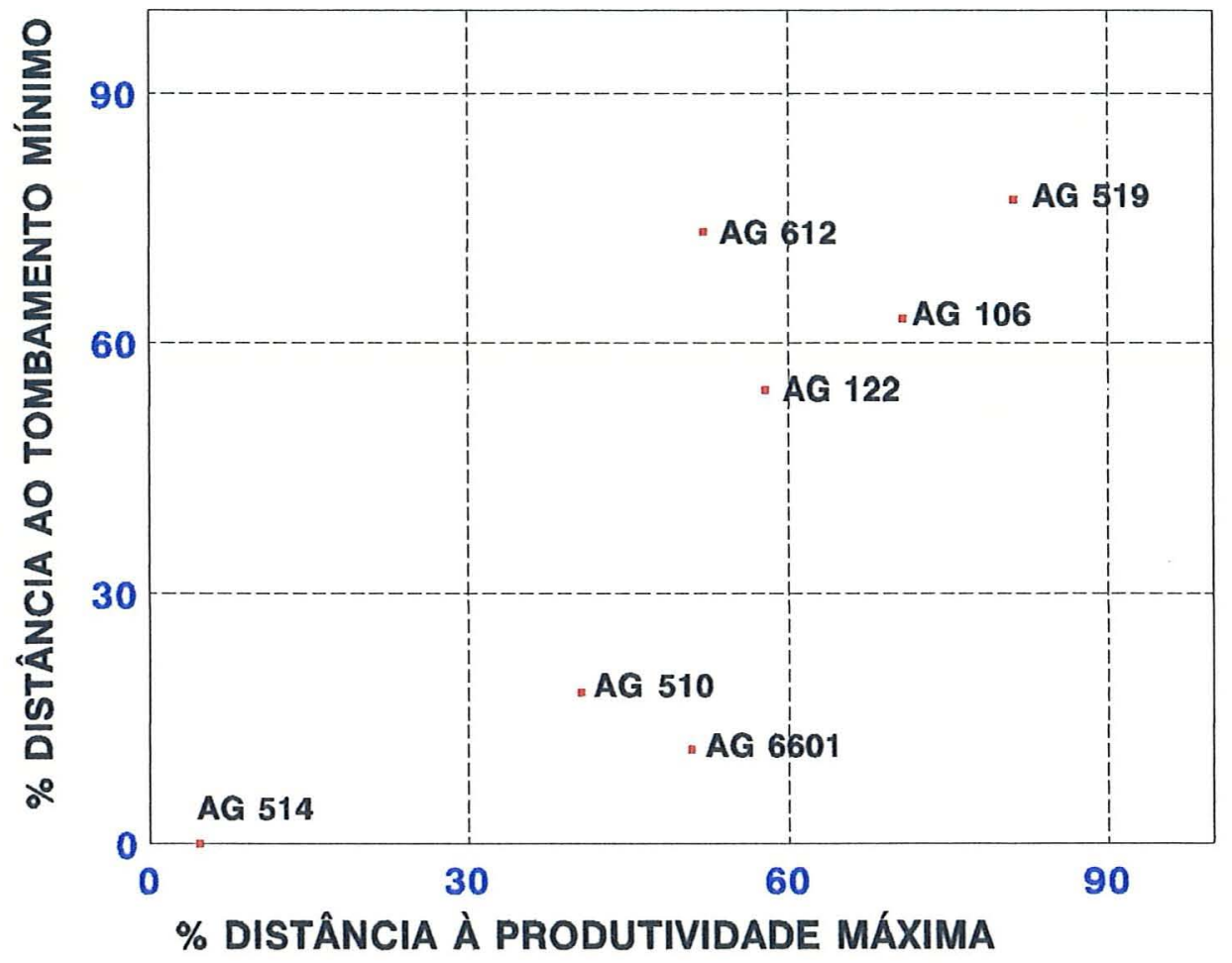

Figura 4. Distância em o à produtividade máxima e ao tombamento mínimo para os dados obtidos de experimentos em 6 locais do Estado de São Paulo, considerados favoráveis (ano agrícola $1992 / 93)$. 


\subsubsection{Ano agrícola 1993/94}

Para o ano agrícola de 1993/94, foram introduzidos novos híbridos nos experimentos e pode-se observar pelas tabelas 23 e 24 que a maioria desses se destacaram em produtividade. O híbrido AG 951 mostrou produtividades elevadas em quatro dos treze locais testados. Em relação ao tombamento das plantas, o híbrido AG 514 repetiu seu ótimo desempenho obtido no ano anterior, e híbridos novos mostraram terem excelente colmo, como foi o caso dos híbridos AG 5011 e AG 5012 (tabela 25 e 26).

Considerando-se todos os locais (tabela $27 \mathrm{e}$ figura 5), o híbrido AG 951 foi o que esteve mais próximo do melhor genótipo para produtividade, com um valor de distância de 20,10 ; alcançou porém um valor de $28,0 \%$ para a variável tombamento. Já o híbrido AG 5011 obteve o segundo lugar em produtividade, com um valor de 27,5\%, e terceiro lugar em tombamento com 10,7\%, de modo que, no conjunto das duas variáveis, este foi o híbrido que mais se aproximou do melhor genótipo. O híbrido de pior desempenho foi o BR 201 com valores de distância à produtividade máxima e ao 
tombamento mínimo de $77,3 \%$ e $81,1 \%$ respectivamente, como pode-se observar na figura 5.

Com base nos valores de distâncias e na figura 5, foi possivel formar os seguintes grupos de híbridos:

grupo 1 : AG 951

grupo 2 : AG 5011, AG 1051, AG 514, AG 5012, AG 6601, AG 1043, AG 9010 e AG 510.

grupo 3 : AG 122 e AG 106

grupo 4 : $A G 405$

grupo 5 : AG 672 e $A G 8012$

grupo 6 : AG 612 e AG 6012

grupo 7 : BR 201

Conforme a tabela 28 e a figura 6, referente a ambientes desfavoráveis, verificou-se que o híbrido AG 951 esteve mais próximo do melhor genótipo com uma distância de $15,3 \frac{0}{0}$ considerando-se a produtividade de espigas. Em relação ao tombamento, todavia, essa distância foi de $40,8 \%$

O híbrido com bom desempenho foi o AG 5011, pois sua distância em relação ao melhor genótipo foi de 34, 0 을 para a produtividade e de 21,5 응 para o tombamento.

o material de pior desempenho foi considerado o cultivar BR 201 com distâncias à 
produtividade máxima e ao tombamento mínimo, de 74,0\% e $74,1 \%$, respectivamente.

Nos ambientes desfavoráveis não houve híbridos que se destacassem por estar próximo do melhor genótipo. Com base na tabela 28 e na figura 6, pode-se construir os seguintes grupos:

grupo 1 : AG 951

grupo 2 : $A G$ 5011, AG 514, AG 5012, AG 1043, AG 510, $A G$ 405, AG 6601 e AG 405

grupo 3: AG 1051

grupo 4: AG 9010

grupo 5: AG 106

grupo 6: AG 672 e AG 612

grupo 7: AG 122 e AG 8012

grupo 8: AG 6012 e BR 201

Considerando-se os ambientes favoráveis, cujos resultados constam da tabela 29 e figura 7, destacaram-se os híbridos AG 1051 e AG 5011 por estarem mais próximos do melhor genótipo. A distância em relação à produtividade máxima e ao tombamento mínimo foi de $21,5 \%$ e $11,4 \%$ para o híbrido $A G 1051$ respectivamente. O híbrido AG 5011, por sua vez, atingiu os valores $23,2 \%$ e $6,9 \%$, respectivamente. 
os híbridos que apresentaram excelente colmo foram $\circ$ AG 5012 e $\circ$ AG 514, pois, obtiveram valores de distância ao tombamento mínimo de 5,5\% e 5,9\% respectivamente.

o cultivar BR 201, por sua vez, teve o pior desempenho, pois as distâncias em relação ao melhor genótipo foram de $79,5 \frac{0}{\circ}$ e $83,6 \%$, respectivamente.

Com esses resultados, pôde-se formar os seguintes grupos:

grupo 1 : AG 1051 e AG 5011

grupo 2 : AG 951 e AG 9010

grupo 3 : AG 5012, AG 514, AG 1043 e AG 6501

grupo 4 : $A G$ 510, $A G 122$ e $A G 106$

grupo 5 : AG 405

grupo 6 : AG 8012 e $\mathrm{AG} 672$

grupo 7 : AG 6012 e AG 612

grupo 8 : BR 201 


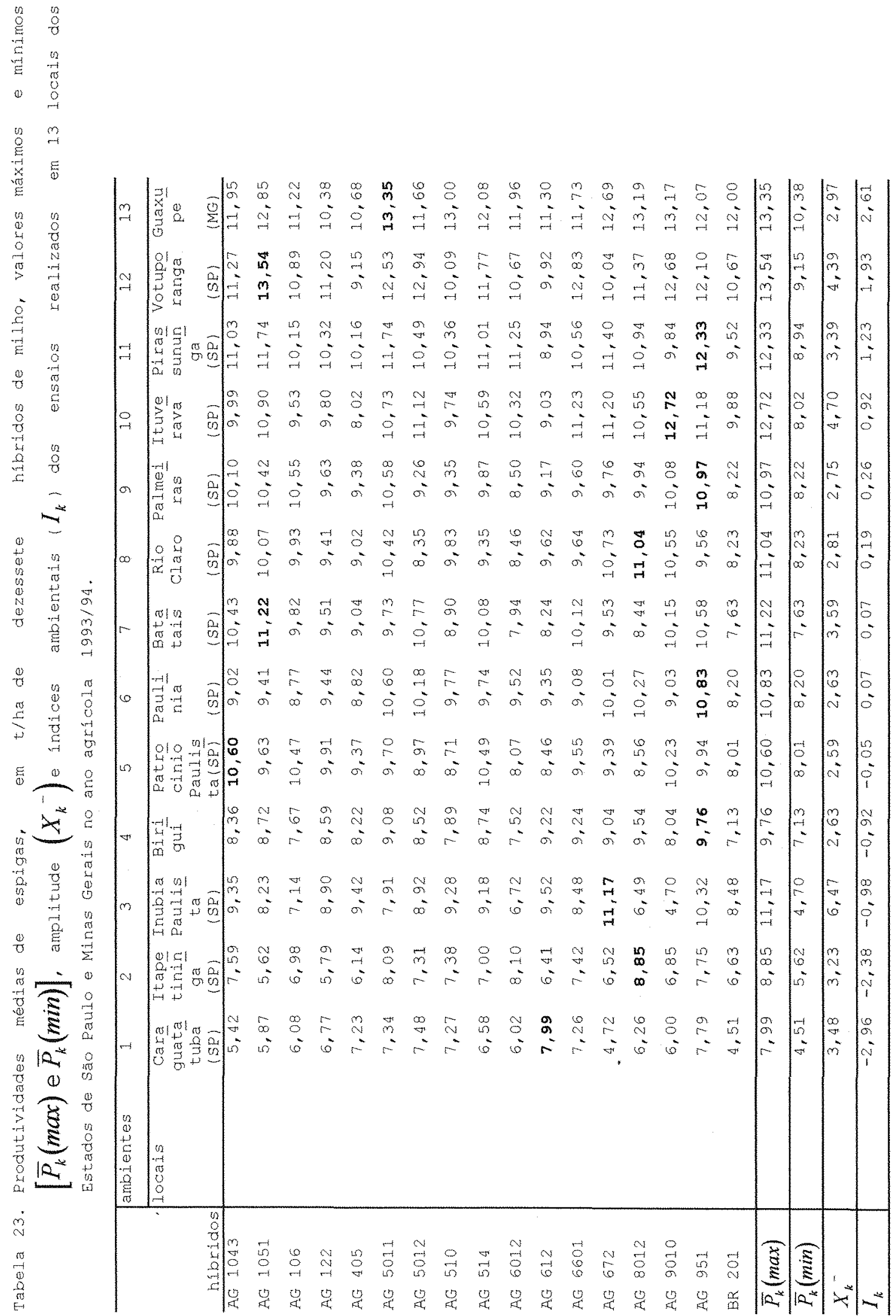




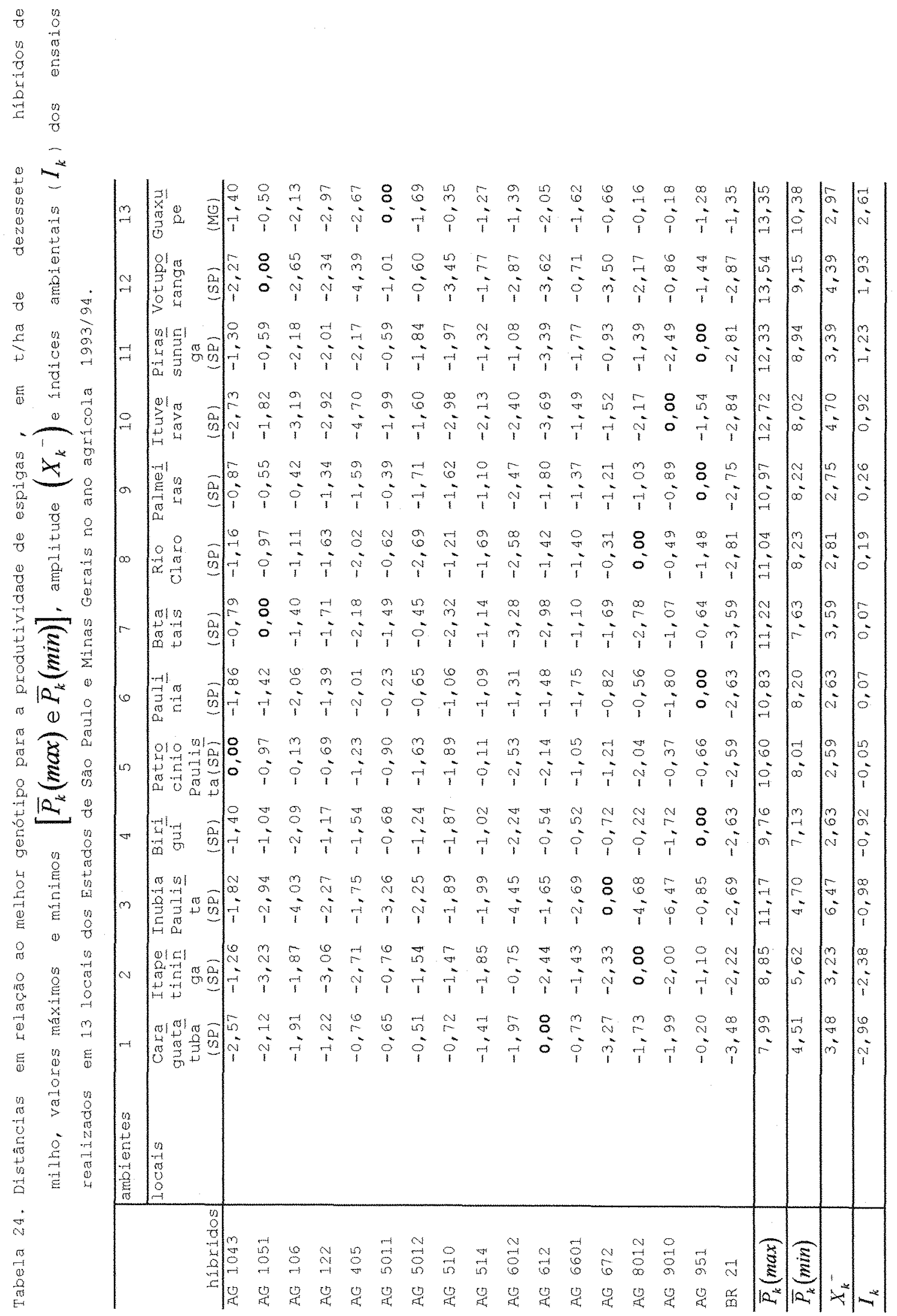




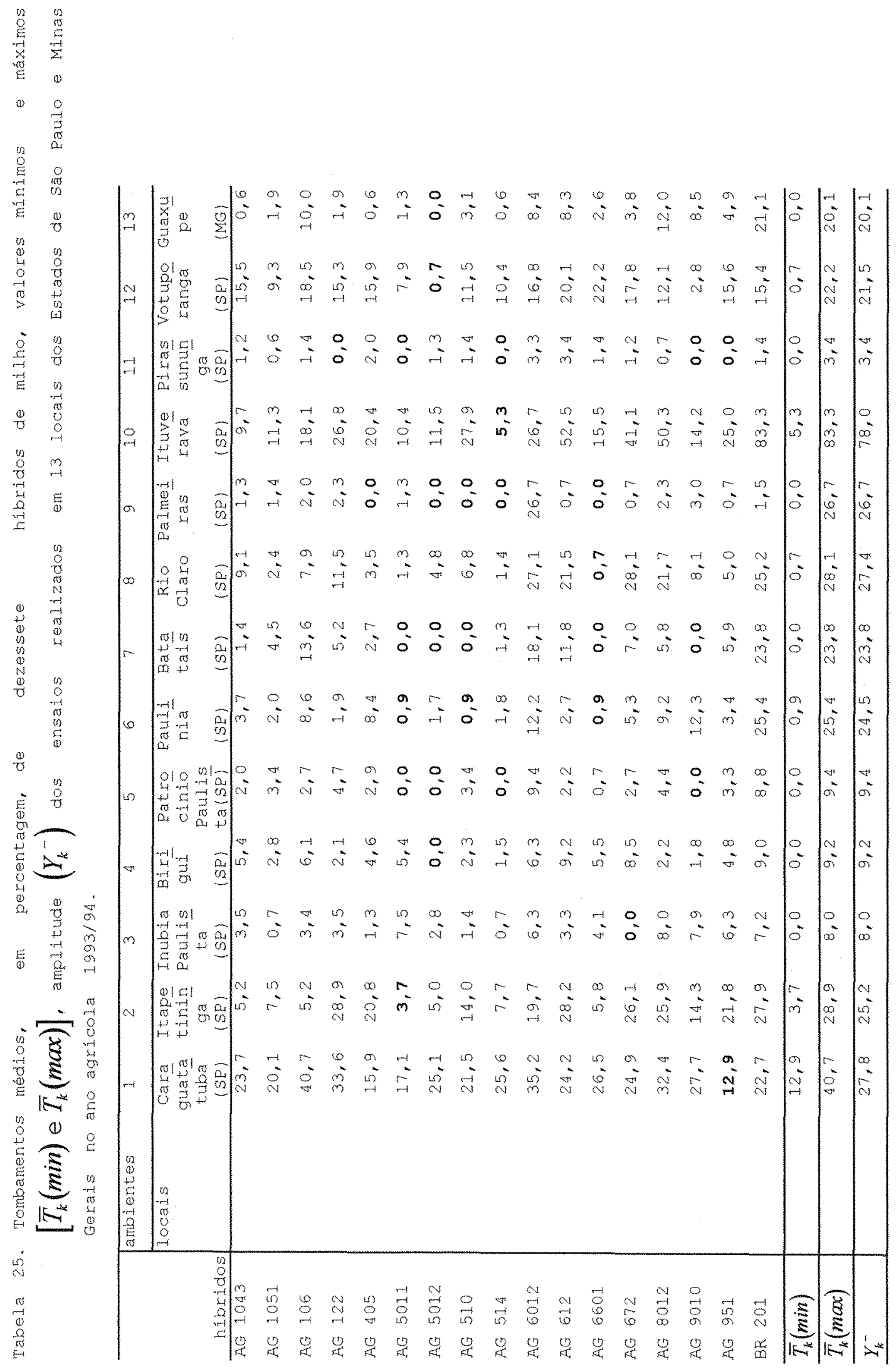




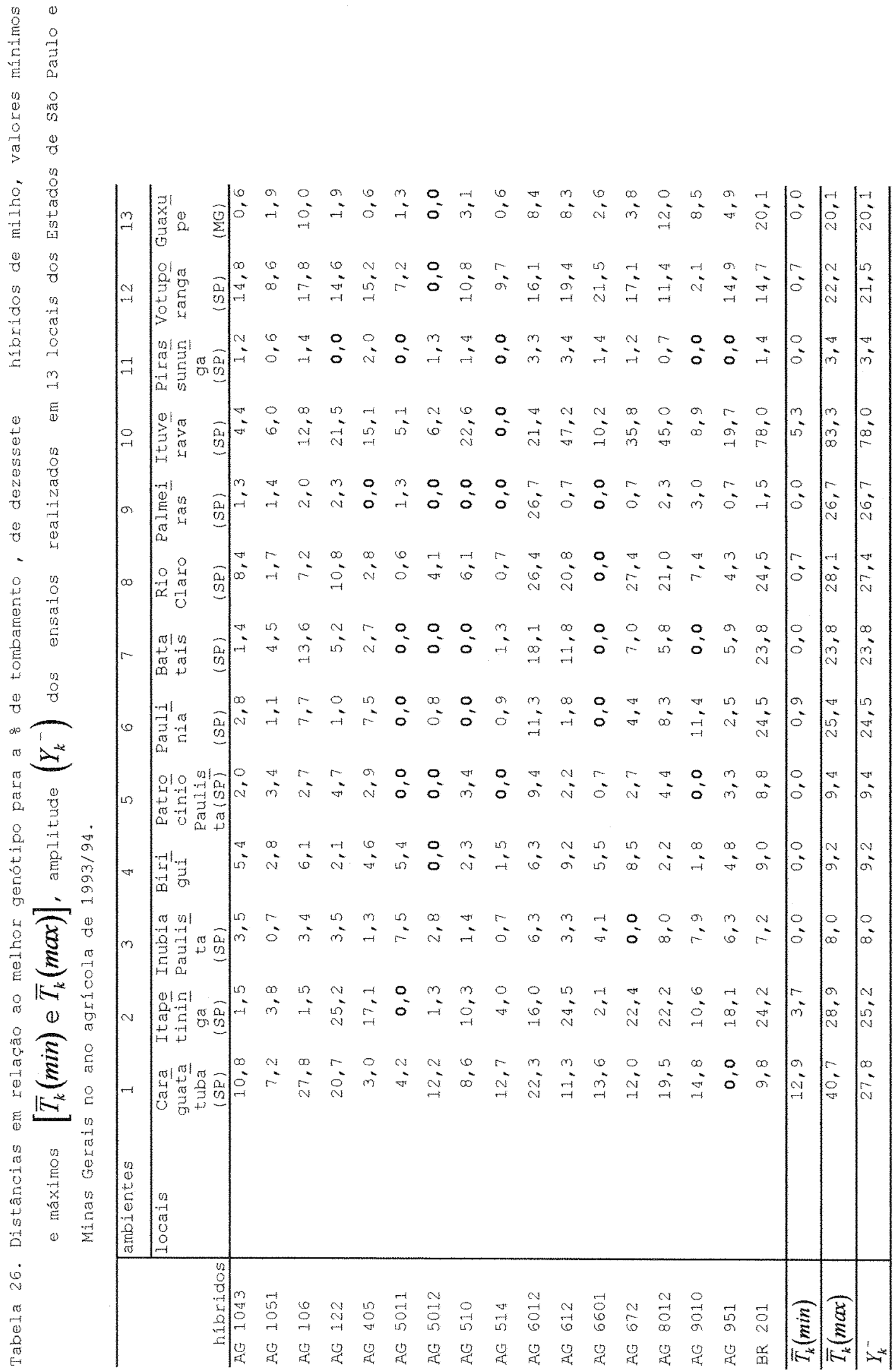


Tabela 27. Distância de dezessete híbridos de milho em relação ao melhor genótipo para a produtividade de espigas $\left(D p_{i}\right)$ e o tombamento das plantas $\left(D t_{i}\right)$; grau de inferioridade dos híbridos em porcentagem da amplitude $\left(I p_{i} \%\right.$ e $\left.I t_{i} \%\right)$; amplitudes $\left(D p^{-}\right.$e $\left.D t^{-}\right)$; melhor e pior genótipo $(\mathrm{Mge} P g)$ para os resultados obtidos de experimentos em 13 locais dos Estados de São Paulo e Minas Gerais (ano agrícola 1993/94).

\begin{tabular}{|c|c|c|c|c|c|}
\hline \multicolumn{3}{|c|}{ Produtividade } & \multicolumn{3}{|c|}{ \% Tombamento } \\
\hline Híbridos & $D p_{i}$ & $I P_{i} \%$ & Híbridos & $D t_{i}$ & $I t_{i} \%$ \\
\hline$\overline{\mathrm{AG}} 951$ & 0,71 & 20,1 & $\overline{A G \quad 5012}$ & 2,2 & 9,4 \\
\hline AG 5011 & 0,97 & 27,5 & AG 514 & 2,5 & 10,5 \\
\hline AG 1051 & 1,24 & 35,4 & AG 5011 & 2,5 & 10,7 \\
\hline AG 6601 & 1,36 & 38,6 & AG 1051 & 3,4 & 14,3 \\
\hline AG 514 & 1,38 & 39,2 & AG 1043 & 4,5 & 19,0 \\
\hline AG 672 & 1,40 & 39,8 & AG 6601 & 4,7 & 20,2 \\
\hline AG 5012 & 1,42 & 40,3 & AG 510 & 5,4 & 23,0 \\
\hline AG 8012 & 1,46 & 41,5 & AG 405 & 5,8 & 24,5 \\
\hline AG 1043 & 1,49 & 42,5 & AG 9010 & 5,9 & 25,0 \\
\hline AG 9010 & 1,56 & 44,6 & AG 951 & 6,6 & 28,0 \\
\hline AG 510 & 1,75 & 50,0 & $\mathrm{AG} \quad 122$ & 8,7 & 37,2 \\
\hline AG 122 & 1,90 & 54,2 & AG 106 & 8,8 & 37,4 \\
\hline AG 106 & 1,94 & 55,2 & AG $\quad 672$ & 11,0 & 46,9 \\
\hline AG 612 & 2,09 & 59,6 & AG 8012 & 12,5 & 53,4 \\
\hline AG 6012 & 2,26 & 64,3 & AG 612 & 12,6 & 53,7 \\
\hline AG 405 & 2,29 & 65,1 & AG 6012 & 14,8 & 63,0 \\
\hline BR 201 & 2,71 & 77,3 & BR 201 & 19,0 & 81,1 \\
\hline$D p^{-}$ & \multicolumn{2}{|c|}{3,51} & $D t^{-}$ & \multicolumn{2}{|c|}{23,4} \\
\hline$M g$ & \multicolumn{2}{|c|}{11,11} & $M g$ & \multicolumn{2}{|c|}{1,8} \\
\hline$P g$ & \multicolumn{2}{|c|}{7,60} & $P g$ & \multicolumn{2}{|c|}{25,3} \\
\hline
\end{tabular}


Tabela 28. Distância de dezessete híbridos de milho em relação ao melhor genótipo para a produtividade de espigas $\left(D p_{i}\right)$ e o tombamento das plantas $\left(D t_{i}\right)$; grau de inferioridade dos híbridos em porcentagem da amplitude $\left(I p_{i} \%\right.$ e $\left.I t_{i} \%\right)$; amplitudes $\left(D p^{-}\right.$e $\left.D t^{-}\right)$; melhor e pior genótipo $(M g$ e $P g)$ para os resultados obtidos de experimentos em 5 locais do Estado de São Paulo, considerados desfavoráveis (ano agrícola 1993/94).

\begin{tabular}{|c|c|c|c|c|c|}
\hline \multicolumn{3}{|c|}{ Produtividade } & \multicolumn{3}{|c|}{$\therefore$ Tombamento } \\
\hline Híbridos & $\overline{D p}$ & $I P_{i} \%$ & Híbridos & $D t_{i}$ & It. $\%$ \\
\hline$\overline{A G} 951$ & 0,56 & 15,3 & $\overline{\mathrm{AG} 5012}$ & 3,3 & 20,5 \\
\hline AG 5011 & 1,25 & 34,0 & AG 5011 & 3,4 & 21,5 \\
\hline AG 514 & 1,28 & 34,7 & AG 1051 & 3,6 & 22,5 \\
\hline AG 6601 & 1,28 & 34,9 & AG 514 & 3,8 & 23,7 \\
\hline AG 612 & 1,35 & 36,8 & AG 1043 & 4,6 & 29,1 \\
\hline AG 1043 & 1,41 & 38,3 & AG 510 & 5,2 & 32,7 \\
\hline AG 5012 & 1,43 & 39,0 & AG 6601 & 5,2 & 32,7 \\
\hline AG 672 & 1,51 & 40,9 & AG 405 & 5,8 & 36,3 \\
\hline $\mathrm{AG} \quad 510$ & 1,57 & 42,6 & AG 951 & 6,5 & 40,8 \\
\hline AG 405 & 1,60 & 43,4 & AG 9010 & 7,0 & 44,1 \\
\hline AG 122 & 1,68 & 45,7 & AG 106 & 8,3 & 52,1 \\
\hline AG 8012 & 1,73 & 47,1 & AG 672 & 9,1 & 57,3 \\
\hline AG 106 & 2,01 & 54,5 & AG 612 & 10,1 & 63,4 \\
\hline AG 1051 & 2,06 & 56,0 & AG 122 & 11,2 & 70,6 \\
\hline AG 6012 & 2,39 & 64,9 & AG 8012 & 11,3 & 70,7 \\
\hline AG 9010 & 2,51 & 68,2 & BR 201 & 11,8 & 74,1 \\
\hline BR 201 & 2,72 & 74,0 & AG $\quad 6012$ & 12,1 & 75,8 \\
\hline$D p^{-}$ & 3 & & $D t^{-}$ & 15 & \\
\hline$\overline{M g}$ & 9, & & $M g$ & & \\
\hline$P g$ & 5, & & $P g$ & 19 & \\
\hline
\end{tabular}


Tabela 29. Distância de dezessete híbridos de milho em relação ao melhor genótipo para a produtividade de espigas $\left(D p_{i}\right)$ e o tombamento das plantas $\left(D t_{i}\right)$; grau de inferioridade dos híbridos em porcentagem da amplitude $\left(I p_{i} \%\right.$ e $\left.I t_{i} \%\right)$; amplitudes $\left(D p^{-}\right.$e $\left.D t^{-}\right)$; melhor e pior genótipo $(M g$ e $P g)$ para os resultados obtidos de experimentos em 8 locais dos Estados de São Paulo e Minas Gerais, considerados favoráveis (ano agrícola 1993/94).

\begin{tabular}{|c|c|c|c|c|c|}
\hline \multicolumn{3}{|c|}{ Produtividade } & \multicolumn{3}{|c|}{ Tombamento } \\
\hline Híbridos & $D p_{i}$ & $I P_{i} \%$ & Híbridos & $D t_{i}$ & $I t_{i} \%$ \\
\hline$\overline{A G} 1051$ & 0,73 & 21,5 & $\overline{A G} 5012$ & 1,6 & 5,5 \\
\hline AG 5011 & 0,79 & 23,2 & AG 514 & 1,7 & 5,9 \\
\hline AG 951 & 0,80 & 23,4 & AG 5011 & 1,9 & 6,9 \\
\hline AG 9010 & 0,97 & 28,6 & AG 1051 & 3,2 & 11,4 \\
\hline AG 8012 & 1,28 & 37,7 & AG 1043 & 4,4 & 15,5 \\
\hline AG 672 & 1,33 & 39,1 & AG 6601 & 4,5 & 15,8 \\
\hline AG 6601 & 1,40 & 41,2 & AG 9010 & 5,2 & 18,3 \\
\hline AG 5012 & 1,40 & 41,2 & AG 510 & 5,5 & 19,5 \\
\hline AG 514 & 1,44 & 42,3 & AG 405 & 5,7 & 20,4 \\
\hline AG 1043 & 1,54 & 45,3 & AG 951 & 6,6 & 23,5 \\
\hline AG 510 & 1,87 & 54,9 & AG 122 & 7,2 & 25,4 \\
\hline $\mathrm{AG} 106$ & 1,89 & 55,6 & AG 106 & 9,1 & 32,2 \\
\hline $\mathrm{AG} \quad 122$ & 2,04 & 59,9 & AG $\quad 672$ & 12,2 & 43,2 \\
\hline AG 6012 & 2,17 & 63,8 & AG 8012 & 13,3 & 47,2 \\
\hline AG 612 & 2,55 & 75,0 & AG 612 & 14,2 & 50,3 \\
\hline $\mathrm{BR} 201$ & 2,71 & 79,5 & $\mathrm{AG} \quad 6012$ & 16,5 & 58,4 \\
\hline AG 405 & 2,72 & 79,8 & BR 201 & 23,6 & 83,6 \\
\hline$D p^{-}$ & \multicolumn{2}{|c|}{3,40} & $D t^{-}$ & \multicolumn{2}{|c|}{28,2} \\
\hline$M g$ & \multicolumn{2}{|c|}{12,00} & $M g$ & \multicolumn{2}{|c|}{0,9} \\
\hline $\mathrm{Pg}$ & \multicolumn{2}{|c|}{8,60} & $P g$ & \multicolumn{2}{|c|}{29,1} \\
\hline
\end{tabular}




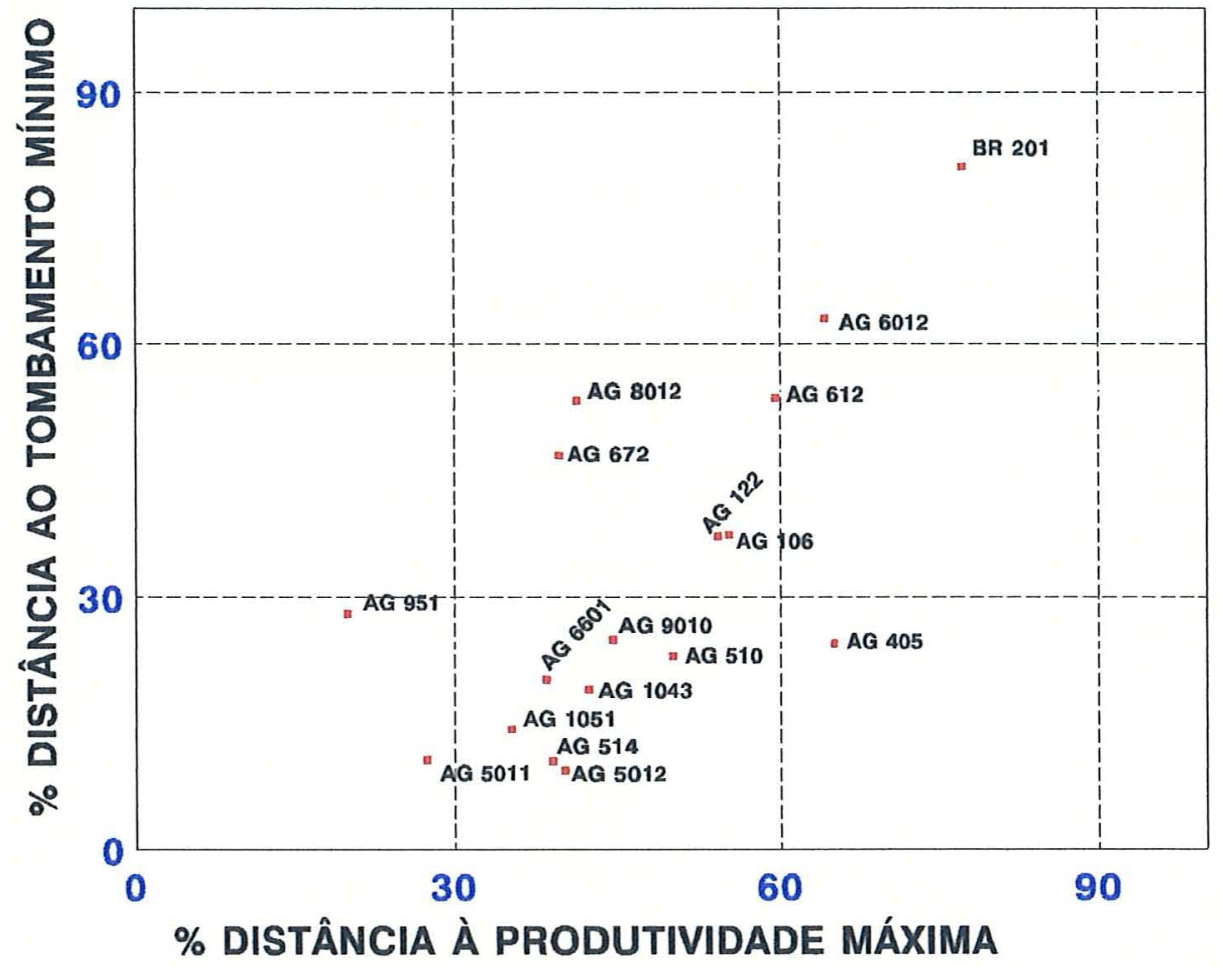

Figura 5. Distância em o à produtividade máxima e ao tombamento mínimo para os dados obtidos de experimentos em 13 locais dos Estados de São Paulo e Minas Gerais (ano agrícola 1993/94). 


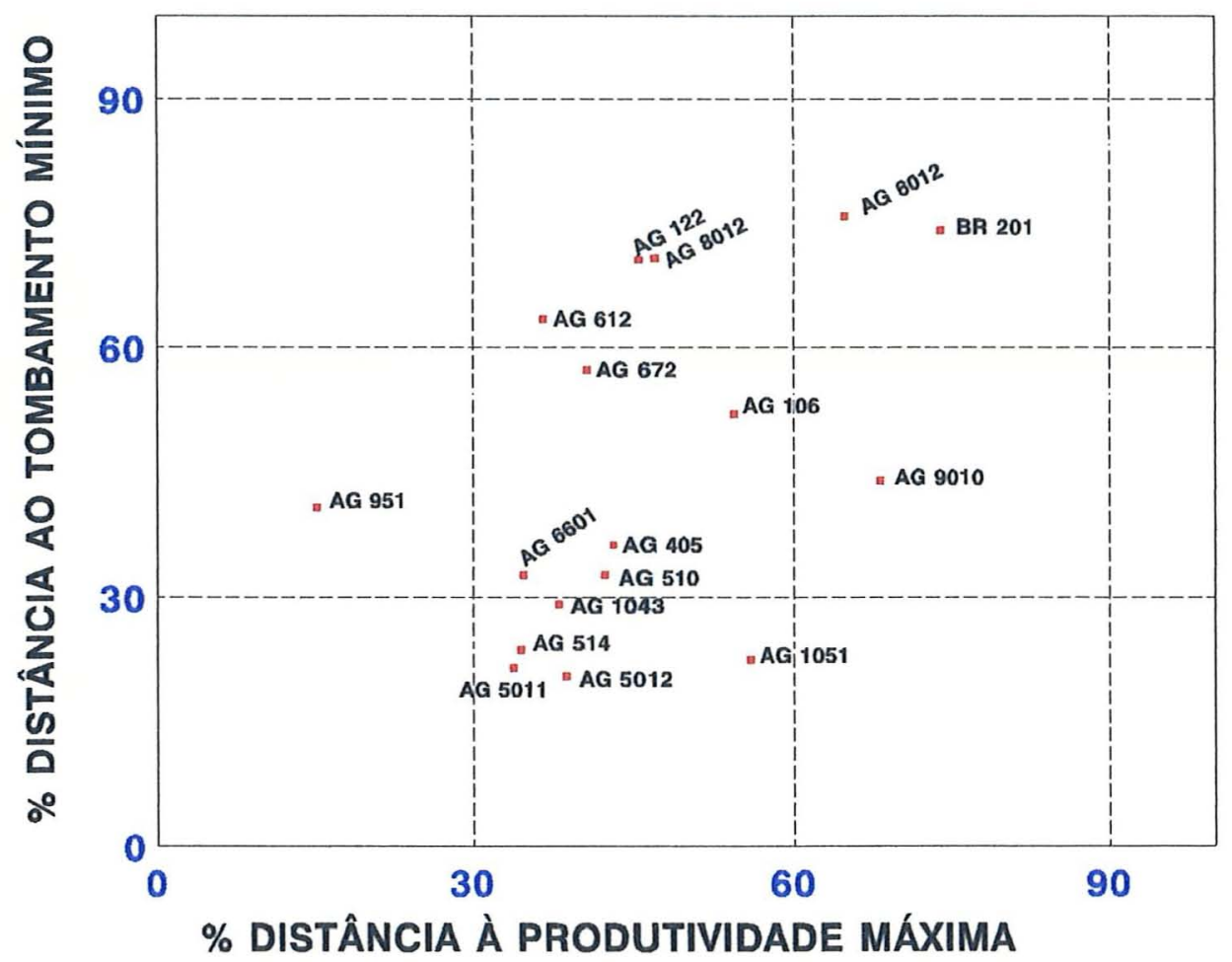

Figura 6. Distância em ò à produtividade máxima e ao tombamento mínimo para os dados obtidos de experimentos em 5 locais do Estado de São Paulo, considerados desfavoráveis (ano agrícola $1993 / 94)$. 


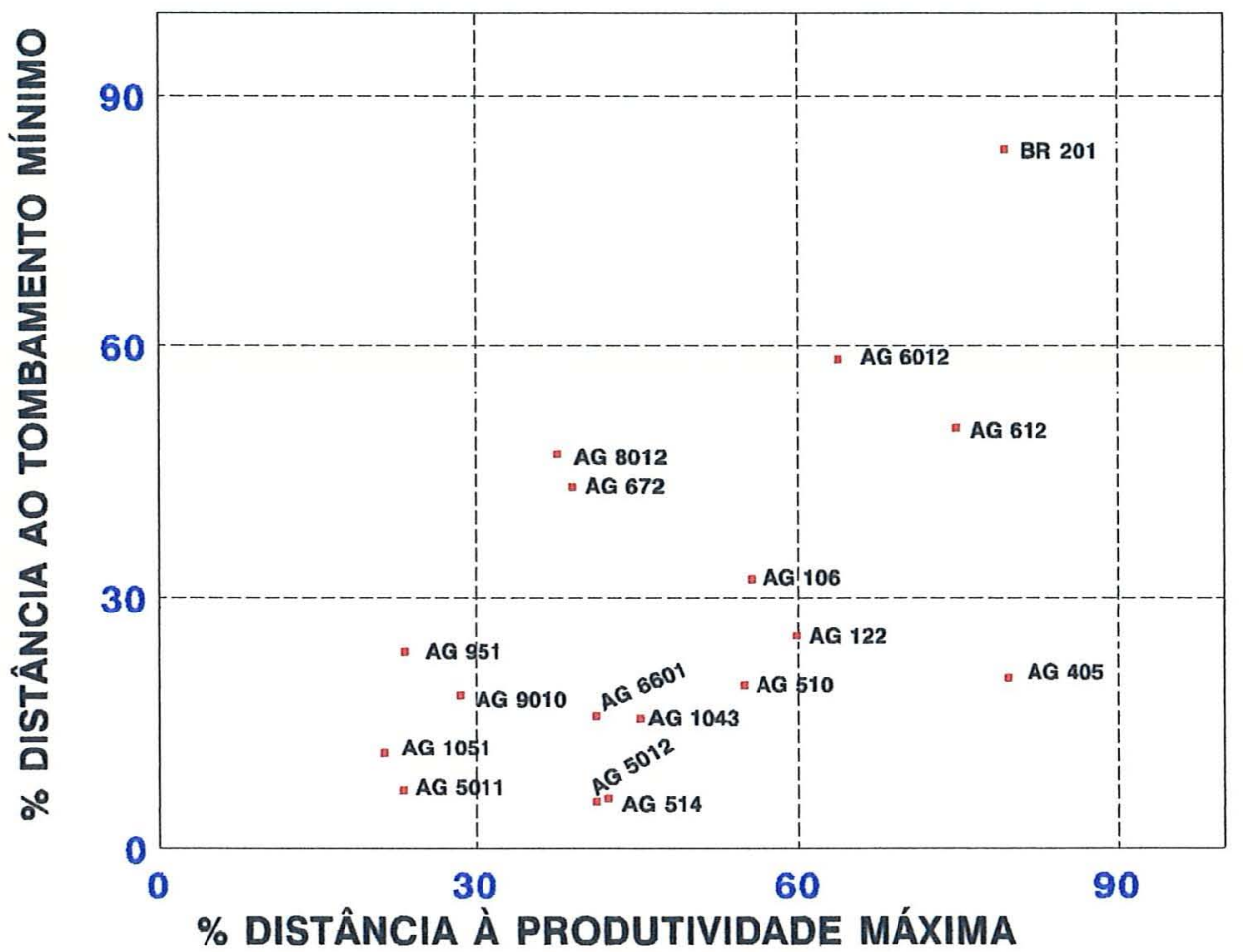

Figura 7. Distância em o à produtividade máxima e ao tombamento mínimo para os dados obtidos de experimentos em 8 locais dos Estados de São Paulo e Minas Gerais, considerados favoráveis (ano agrícola 1993/94). 


\subsubsection{Ano agrícola 1994/95}

Para o ano agrícola $1994 / 95$ foram introduzidos quatro novos híbridos, ou seja, AG 8010 , AG 9012, $A G 9014$ e 9 AG 4011. Este último mostrou produtividade em torno da média (tabela 30) e apresentou excelente qualidade de colmo (tabela 31 e 33). Pode-se observar ainda, nas tabelas 30 e 31 , que o híbrido AG 5011 repetiu seu excelente desempenho do ano anterior, em 9 dos 19 locais testados, com elevadas produtividades.

Considerando-se todos os locais (tabela $34 \mathrm{e}$ figura 8), o híbrido AG 5011 destacou-se dos demais, por estar mais próximo do melhor genótipo, com valores de distância à produtividade máxima e ao tombamento mínimo de $13,0 \%$ e $12,8 \%$ respectivamente. Observa-se ainda que os híbridos que apresentaram excelente qualidade de colmo (AG 4011, AG 5012 e AG 514), ficaram agrupados com valores de distância de $2,9 \%, 5,9 \%$ e $7,8 \%$ respectivamente. O híbrido AG 514, pelo terceiro ano consecutivo, mostrou seu excelente desempenho para esta característica. Por outro lado, o híbrido BR 201 foi o de pior comportamento, com 88, $8 \circ$ de distância ao tombamento mínimo.

Com esses resultados pôde-se formar os seguintes grupos: 


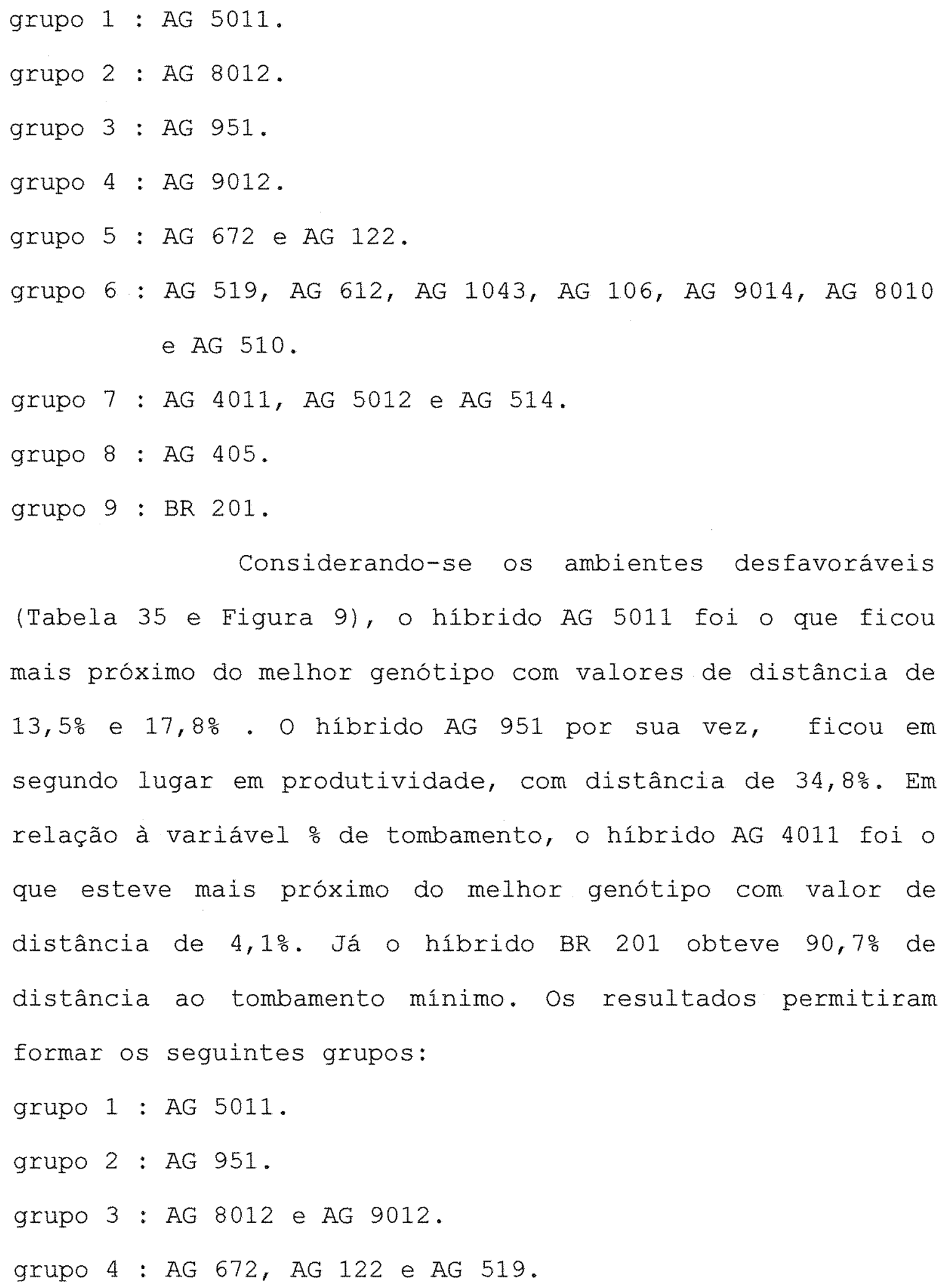

Considerando-se os ambientes desfavoráveis (Tabela 35 e Eigura 9), o híbrido AG 5011 foi o que ficou mais próximo do melhor genótipo com valores de distância de $13,5 \%$ e 17,8\% . O híbrido AG 951 por sua vez, ficou em segundo lugar em produtividade, com distância de 34,8\%. Em relação à variável o de tombamento, o híbrido AG 4011 foi o que esteve mais próximo do melhor genótipo com valor de distância de $4,1 \%$. Já o híbrido BR 201 obteve 90,70 de distância ao tombamento mínimo. Os resultados permitiram formar os seguintes grupos:

grupo 1 : AG 5011.

grupo 2 : AG 951.

grupo 3 : AG 8012 e AG 9012.

grupo 4: AG 672, AG 122 e $A G 519$. 
grupo 5: AG 9014, AG 8010, AG 612, AG 106 e AG 1043.

grupo 6 : AG 4011 e AG 5012 .

grupo 7 : AG 510, AG 514 e AG 405.

grupo 8 : BR 201.

Considerando-se apenas os ambientes favoráveis (Tabela 36 e Figura 10), novamente o híbrido AG 5011 foi o que mais se aproximou do melhor genótipo para a produtividade e $\frac{\circ}{0}$ de tombamento. O híbrido AG 4011 apresentou excelente colmo, alcançando apenas o valor de 2,1\% de distância do tombamento mínimo. Já o híbrido AG 8012 alcançou um valor de distância de 82,90 para esta característica.

O híbrido BR 201 mostrou seu pior desempenho com valor de distância à produtividade máxima e ao tombamento mínimo de $88,9 \%$ e $87,4 \%$, respectivamente.

O híbrido AG 5011 foi considerado com adaptabilidade geral pois alcançou classificação similar nos ambientes desfavoráveis e favoráveis para a variável produtividade.

Com base nos resultados da Tabela 36 e Figura 10 foi possivel formar os seguintes grupos:

grupo 1: $\mathrm{AG} 5011$.

grupo 2 : AG 8012 . 
grupo 3 : AG 951, AG 672, AG 122, AG 612, AG 1043, AG 519. grupo 4 : AG 106 .

grupo 5 : AG 9012, AG 510 e $A G 9014$.

grupo 6 : AG 5012, AG 4011 e AG 514.

grupo 7 : AG 8010 .

grupo 8 : AG 405 .

grupo $9:$ BR 201 . 


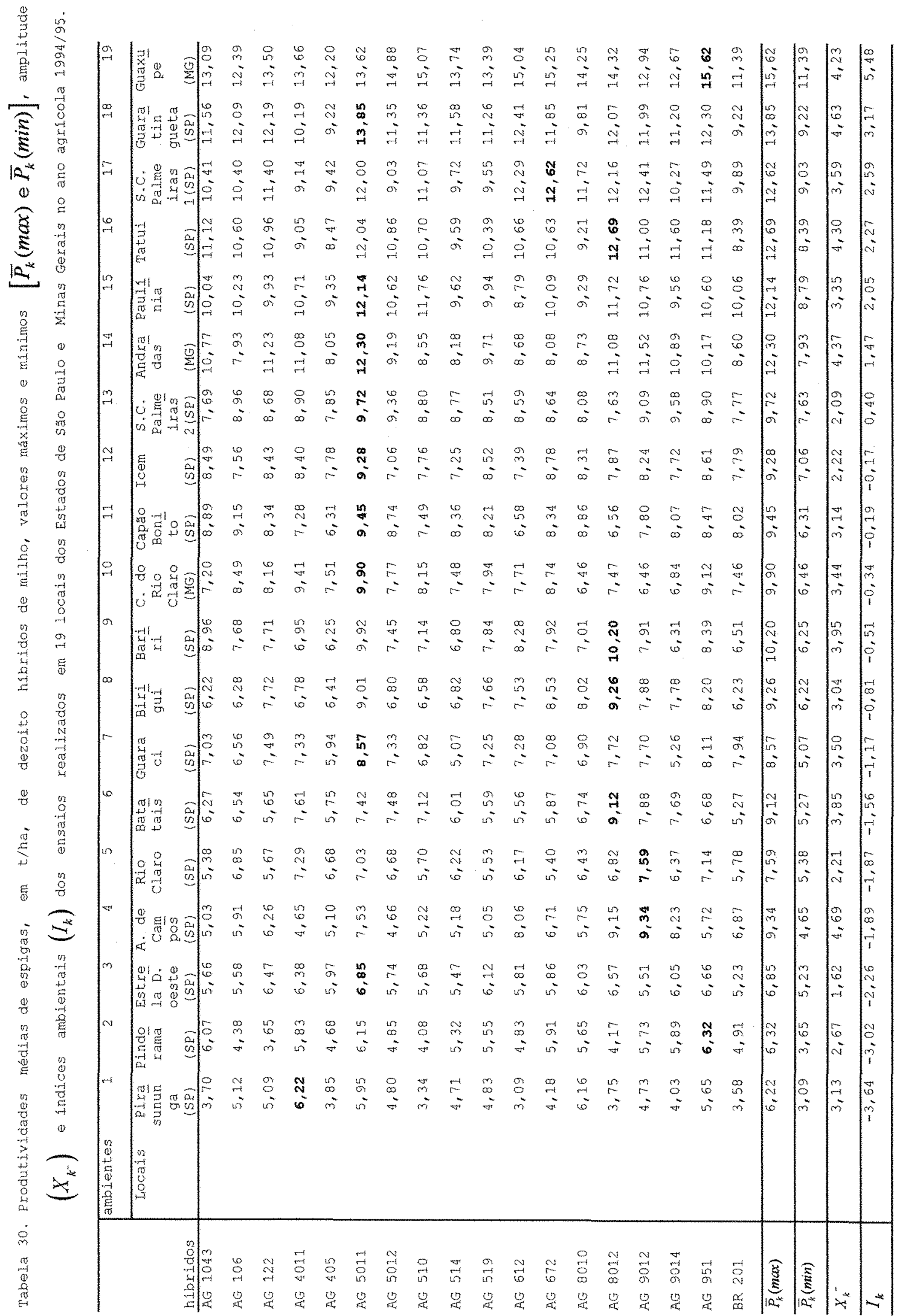




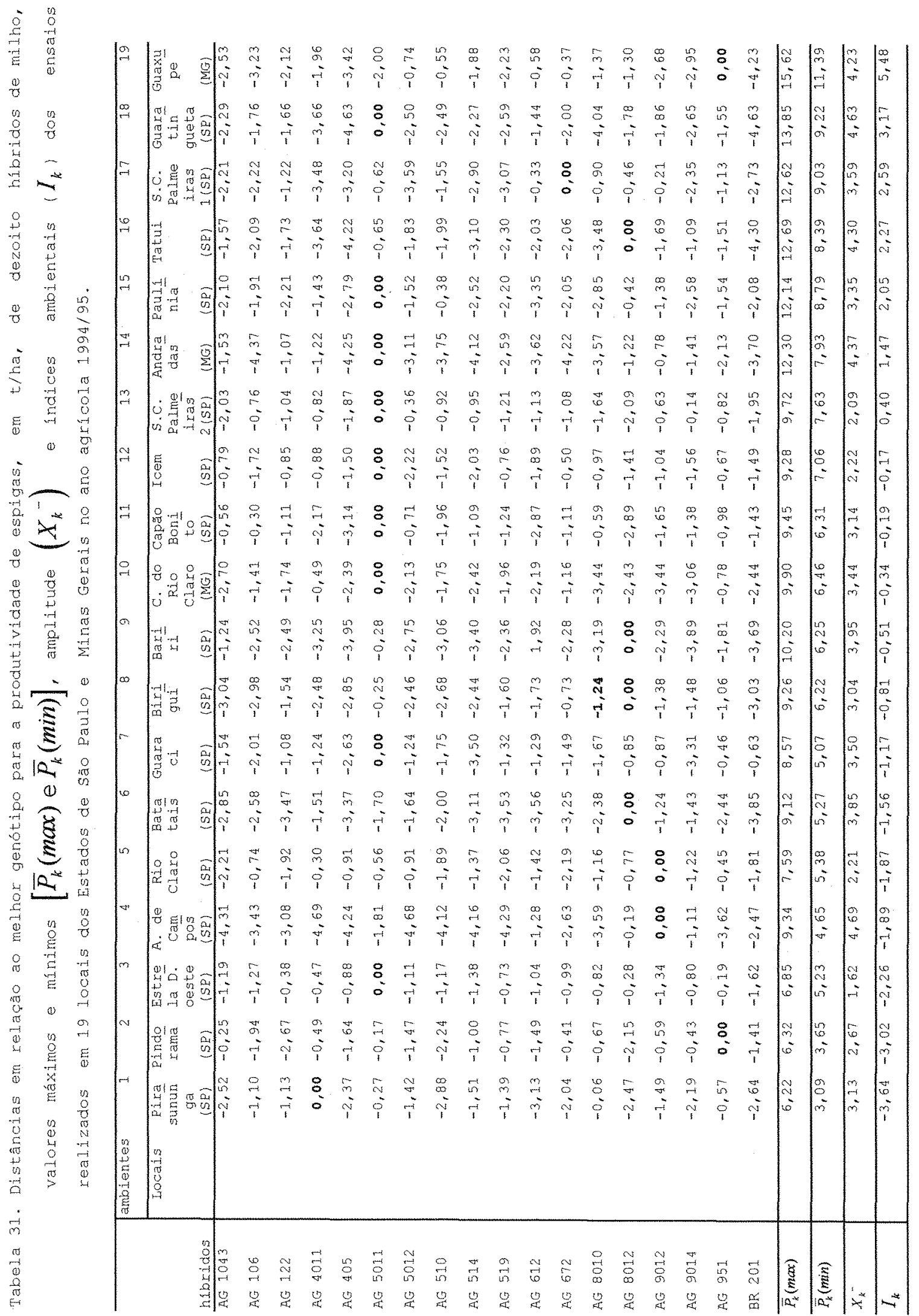




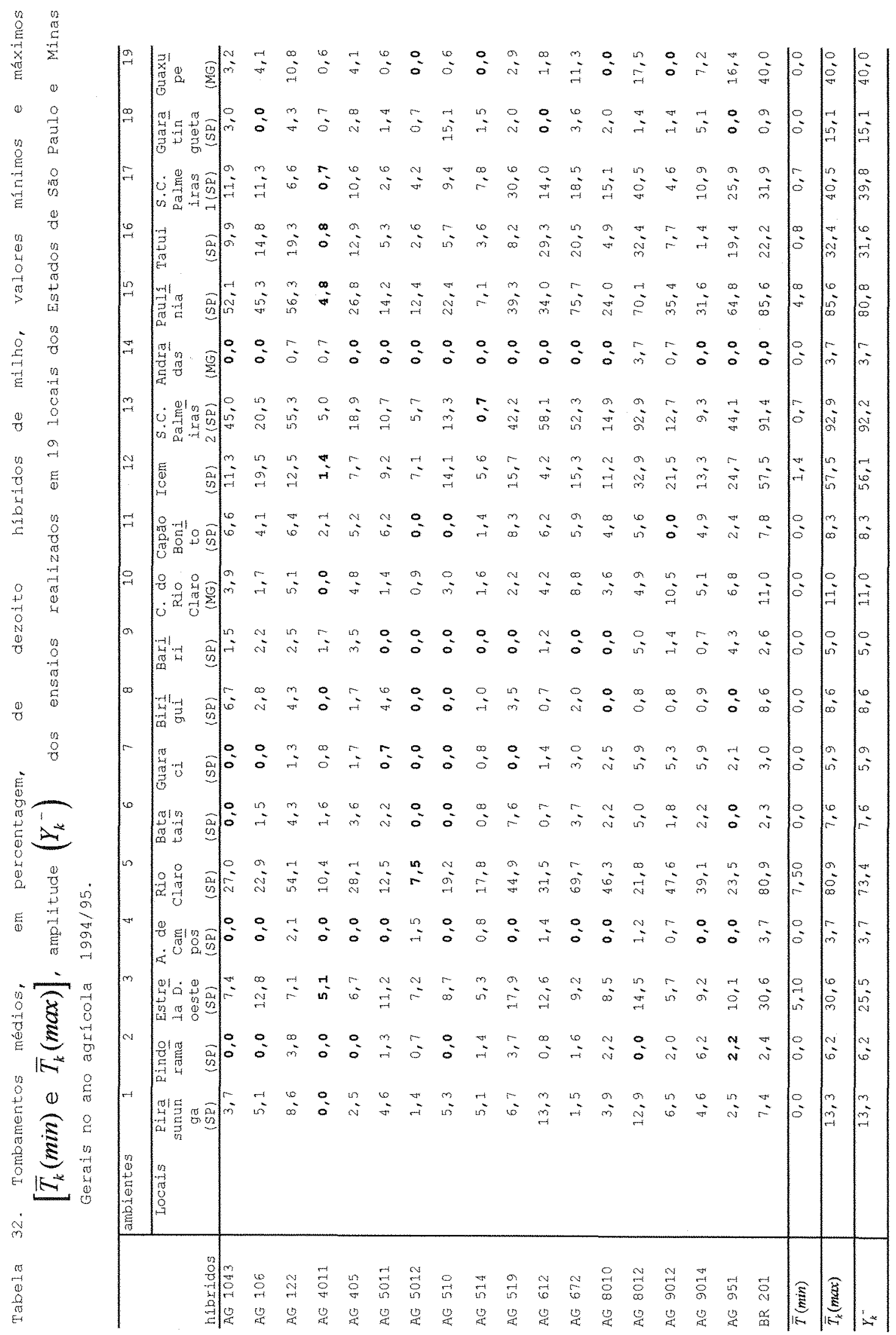




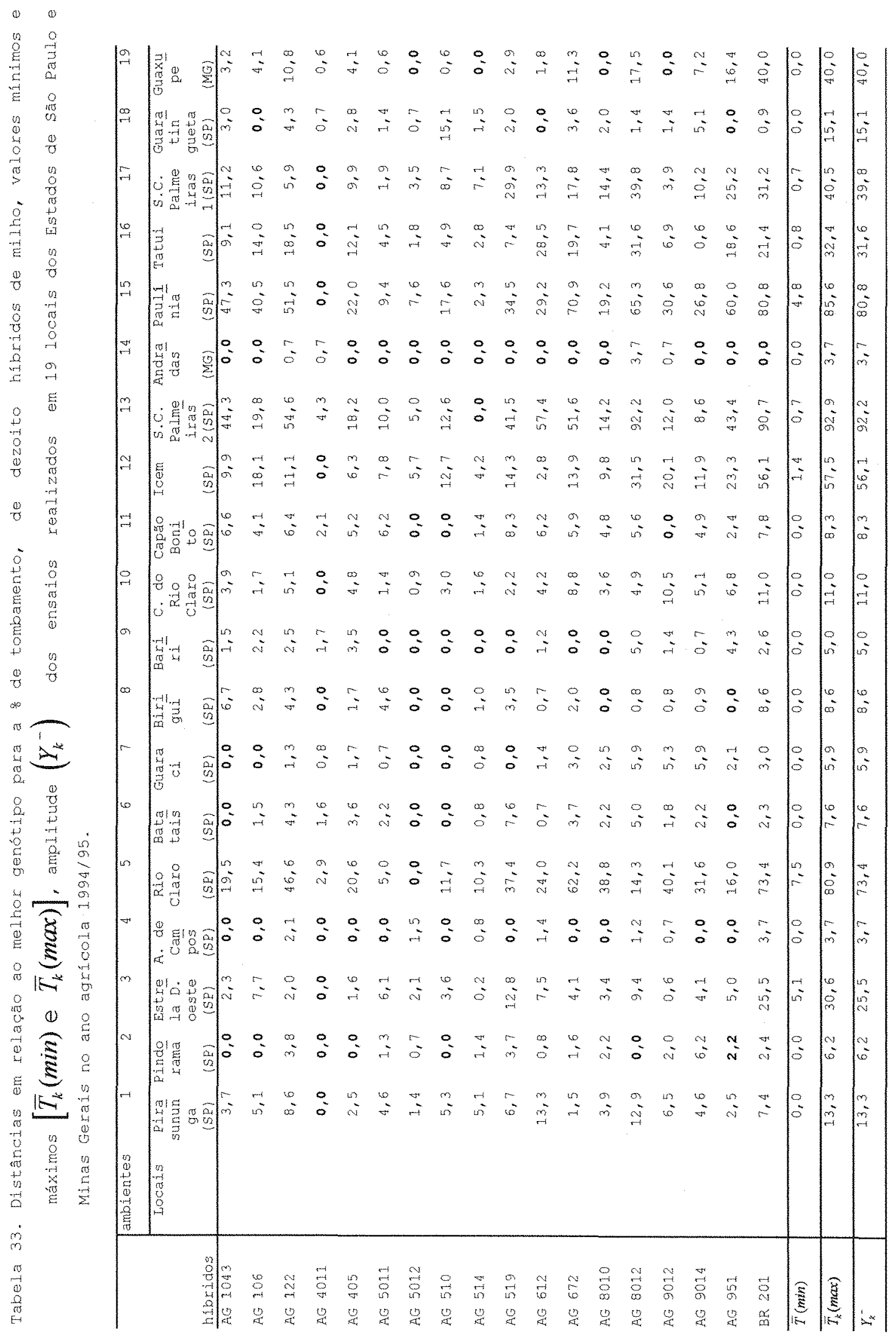


Tabela 34. Distância de dezoito híbridos de milho em relação ao melhor genótipo para a produtividade de espigas $\left(D p_{i}\right)$ e o tombamento das plantas $\left(D t_{i}\right)$; grau de inferioridade dos híbridos em porcentagem da amplitude $\left(I p_{i} \%\right.$ e $\left.I t_{i} \%\right)$, amplitudes $\left(D p^{-}\right.$e $\left.D t^{-}\right) ;$melhor e pior genótipo $(M g$ e $P g)$ para os resultados obtidos de experimentos em 19 locais dos Estados de São Paulo e de Minas Gerais lano agrícola 1994/95).

Produtividade

\begin{tabular}{|c|c|c|c|c|c|}
\hline Híbridos & $D p_{i}$ & $I P_{i} \%$ & Híbridos & $D t_{i}$ & $I t \%$ \\
\hline$\overline{A G 5011}$ & 0,44 & 13,0 & $\overline{A G} 4011$ & 0,8 & 2,9 \\
\hline AG 8012 & 1,09 & 32,3 & AG 5012 & 1,6 & 5,9 \\
\hline AG 951 & 1,14 & 33,9 & AG 514 & 2,2 & 7,8 \\
\hline AG 9012 & 1,29 & 38,4 & AG 5011 & 3,6 & 12,8 \\
\hline AG 672 & 1,61 & 47,7 & AG 510 & 5,0 & 18,2 \\
\hline $\mathrm{AG} \quad 122$ & 1,71 & 50,8 & AG 405 & 6,3 & 22,8 \\
\hline AG 4011 & 1,80 & 53,4 & AG 8010 & 6,6 & 23,7 \\
\hline AG 9014 & 1,84 & 54,7 & AG 9014 & 7,2 & 25,9 \\
\hline AG 612 & 1,91 & 56,7 & AG 9012 & 7,6 & 27,5 \\
\hline AG 5012 & 1,92 & 56,8 & AG 106 & 7,8 & 28,0 \\
\hline AG 1043 & 1,97 & 58,5 & AG 1043 & 9,1 & 32,6 \\
\hline AG 8010 & 1,98 & 58,8 & AG. 612 & 10,2 & 36,8 \\
\hline AG 519 & 2,01 & 59,7 & $A G \quad 519$ & 11,3 & 40,7 \\
\hline AG 106 & 2,02 & 59,9 & AG 951 & 12,0 & 43,2 \\
\hline AG 510 & 2,03 & 60,4 & AG 122 & 12,9 & 46,3 \\
\hline AG 514 & 2,38 & 70,5 & AG 672 & 14,8 & 53,4 \\
\hline BR 201 & 2,64 & 78,3 & AG 8012 & 18,3 & 65,9 \\
\hline AG 405 & 2,86 & 84,7 & BR 201 & 24,7 & 88,8 \\
\hline$D p^{-}$ & \multicolumn{2}{|c|}{3,37} & $D t^{-}$ & \multicolumn{2}{|c|}{27,8} \\
\hline$M g$ & \multicolumn{2}{|c|}{10,05} & $M g$ & \multicolumn{2}{|c|}{1,1} \\
\hline$\overline{P g}$ & \multicolumn{2}{|c|}{6,69} & $P g$ & \multicolumn{2}{|c|}{28,8} \\
\hline
\end{tabular}

\% Tombamento 
Tabela 35. Distância de dezoito híbridos de milho em relação ao melhor genótipo para a produtividade de espigas $\left(D p_{i}\right)$ e o tombamento das plantas $\left(D t_{i}\right)$; grau de inferioridade dos híbridos em porcentagem da amplitude $\left(I p_{i} \%\right.$ e $\left.I t_{i} \%\right)$, amplitudes $\left(D p^{-} \in D t^{-}\right)$; melhor e pior genótipo ( $M g$ e $P g$ ) para os resultados obtidos de experimentos em 12 locais do Estado de São Paulo (ano agrícola 1994/95), considerados desfavoráveis.

\begin{tabular}{|c|c|c|c|c|c|}
\hline \multicolumn{3}{|c|}{ Produtividade } & \multicolumn{3}{|c|}{$\%$ Tombamento } \\
\hline Híbridos & $D p_{i}$ & $I P_{i} \%$ & Híbridos & $D t_{i}$ & $I t_{i} \%$ \\
\hline AG 5011 & 0,42 & 13,5 & $\overline{\mathrm{AG}} 4011$ & 0,8 & 4,1 \\
\hline AG 951 & 1,09 & 34,8 & AG 5012 & 1,0 & 5,5 \\
\hline AG 8012 & 1,12 & 35,9 & AG 514 & 2,3 & 12,3 \\
\hline AG 9012 & 1,28 & 40,9 & $\mathrm{AG} \quad 510$ & 3,0 & 16,2 \\
\hline AG 4011 & 1,50 & 48,0 & AG 5011 & 3,3 & 17,8 \\
\hline AG 672 & 1,57 & 50,1 & $\mathrm{AG} \quad 405$ & 4,3 & 22,9 \\
\hline AG 8010 & 1,65 & 52,8 & AG 1043 & 4,5 & 24,1 \\
\hline $\mathrm{AG} \quad 122$ & 1,79 & 57,3 & AG 106 & 4,9 & 26,1 \\
\hline AG 9014 & 1,82 & 58,4 & AG 612 & 5,4 & 28,6 \\
\hline AG 106 & 1,83 & 58,7 & AG 951 & 5,4 & 28,8 \\
\hline AG 519 & 1,83 & 58,8 & AG 8010 & 5,9 & 31,7 \\
\hline AG 5012 & 1,90 & 60,7 & AG 9014 & 6,5 & 34,8 \\
\hline AG 1043 & 1,93 & 61,9 & AG 9012 & 7,5 & 40,0 \\
\hline AG $\quad 612$ & 1,98 & 63,6 & AG 519 & 8,0 & 43,0 \\
\hline BR 201 & 2,21 & 70,8 & AG 8012 & 8,0 & 43,0 \\
\hline AG 510 & 2,25 & 72,1 & $\mathrm{AG} \quad 122$ & 8,2 & 43,7 \\
\hline AG 514 & 2,28 & 73,2 & AG 672 & 8,9 & 47,5 \\
\hline$A G \quad 405$ & 2,49 & 79,7 & BR 201 & 17,0 & 90,7 \\
\hline$D p^{-}$ & \multicolumn{2}{|c|}{3,11} & $D t^{-}$ & \multicolumn{2}{|c|}{18,7} \\
\hline$M g$ & \multicolumn{2}{|c|}{8,51} & $M g$ & \multicolumn{2}{|c|}{1,2} \\
\hline$P g$ & \multicolumn{2}{|c|}{5,39} & $P g$ & \multicolumn{2}{|c|}{19,8} \\
\hline
\end{tabular}


Tabela 36. Distância de dezoito híbridos de milho em relação ao melhor genótipo para a produtividade de espigas $\left(D p_{i}\right)$ e o tombamento das plantas $\left(D t_{i}\right)$; grau de inferioridade dos híbridos em porcentagem da amplitude $\left(I p_{i} \%\right.$ e $\left.I t_{i} \%\right)$, amplitudes $\left(D p^{-}\right.$e $\left.D t^{-}\right)$; melhor e pior genótipo $(M g \in P g)$ para os resultados obtidos de experimentos em 7 locais dos Estados de São Paulo e de Minas Gerais (ano agrícola 1994/95), considerados favoráveis.

Produtividade

\begin{tabular}{|c|c|c|c|c|c|}
\hline \multicolumn{3}{|c|}{ Produtividade } & \multicolumn{3}{|c|}{ \% Tombamento } \\
\hline Híbridos & $\overline{D p_{i}}$ & $I P_{i} \%$ & Híbridos & $D t_{i}$ & $I t_{i} \%$ \\
\hline$\overline{A G ~} 5011$ & 0,47 & 12,3 & $\overline{\mathrm{AG} 4011}$ & 0,9 & 2,1 \\
\hline AG 8012 & 1,04 & 27,4 & AG 514 & 2,0 & 4,5 \\
\hline AG 951 & 1,24 & 32,7 & $A G \quad 5012$ & 2,7 & 6,1 \\
\hline AG 9012 & 1,32 & 34,8 & AG 5011 & 4,0 & 9,2 \\
\hline AG 122 & 1,58 & 41,6 & AG 8010 & 7,7 & 17,8 \\
\hline AG 510 & 1,66 & 43,8 & AG 9012 & 7,9 & 18,3 \\
\hline AG $\quad 672$ & 1,68 & 44,4 & AG 9014 & 8,4 & 19,3 \\
\hline AG 612 & 1,78 & 47,0 & AG 510 & 8,5 & 19,6 \\
\hline AG 9014 & 1,88 & 49,6 & AG 405 & 9,9 & 22,8 \\
\hline AG 5012 & 1,95 & 51,4 & AG 106 & 12,7 & 29,4 \\
\hline AG 1043 & 2,04 & 53,7 & AG 1043 & 16,9 & 39,0 \\
\hline AG 519 & 2,31 & 61,0 & AG 519 & 16,9 & 39,0 \\
\hline AG 4011 & 2,32 & 61,0 & AG 612 & 18,6 & 42,9 \\
\hline AG 106 & 2,33 & 61,5 & AG 122 & 20,9 & 48,3 \\
\hline AG 514 & 2,53 & 66,8 & AG 951 & 23,4 & 54,0 \\
\hline AG 8010 & 2,55 & 67,2 & AG 672 & 25,0 & 57,7 \\
\hline BR 201 & 3,37 & 88,9 & AG 8012 & 35,9 & 82,9 \\
\hline AG 405 & 3,48 & 91,8 & BR 201 & 37,9 & 87,4 \\
\hline$D p^{-}$ & \multicolumn{2}{|c|}{3,80} & $D t^{-}$ & \multicolumn{2}{|c|}{43,3} \\
\hline$M g$ & \multicolumn{2}{|c|}{12,71} & $M g$ & \multicolumn{2}{|c|}{1,0} \\
\hline$P g$ & \multicolumn{2}{|c|}{8,91} & $P g$ & \multicolumn{2}{|c|}{44,3} \\
\hline
\end{tabular}

\% Tombamento 


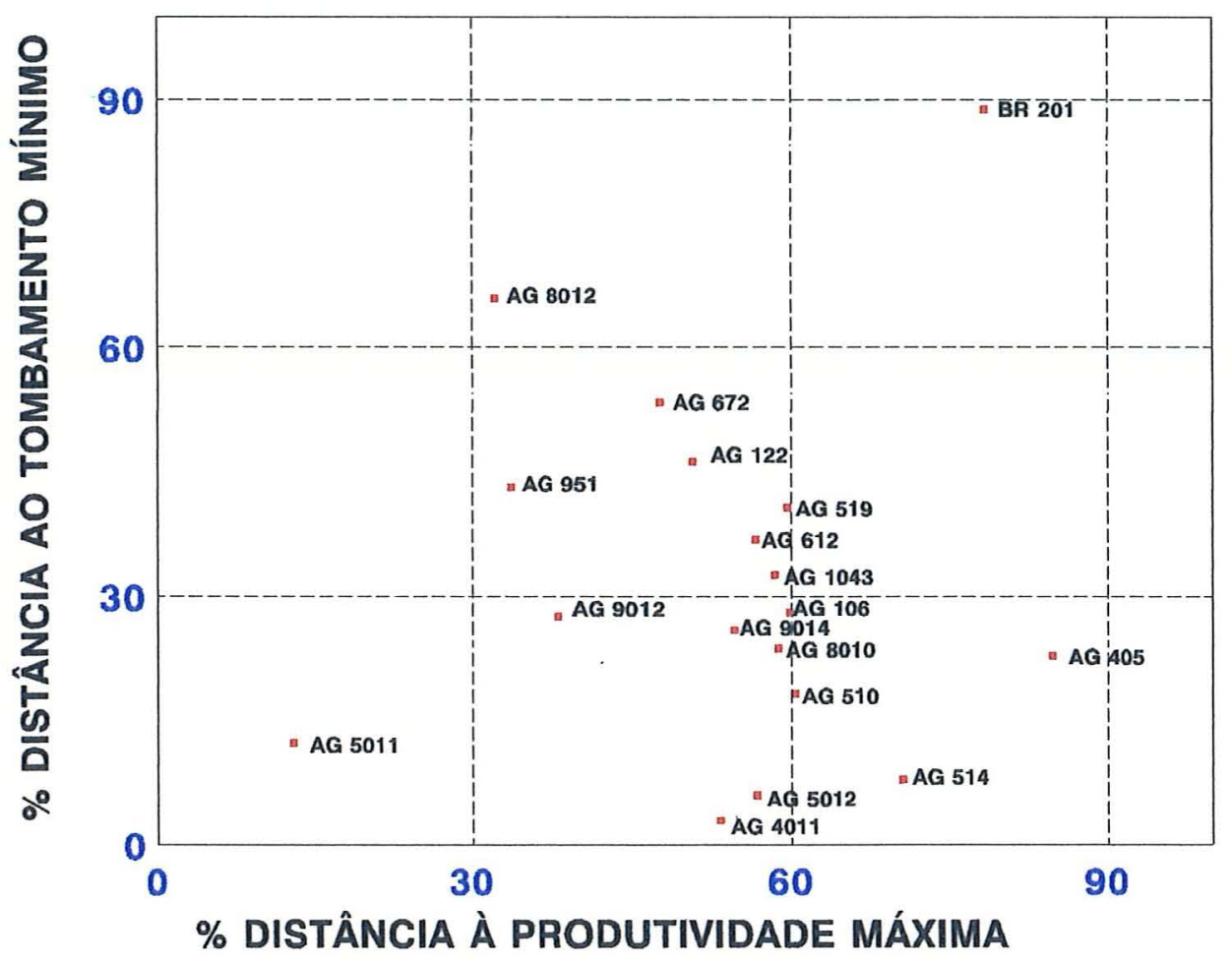

Figura 8. Distância em o à produtividade máxima e ao tombamento mínimo para os dados obtidos de experimentos em 19 locais dos Estados de São Paulo e Minas Gerais (ano agrícola 1994/95). 


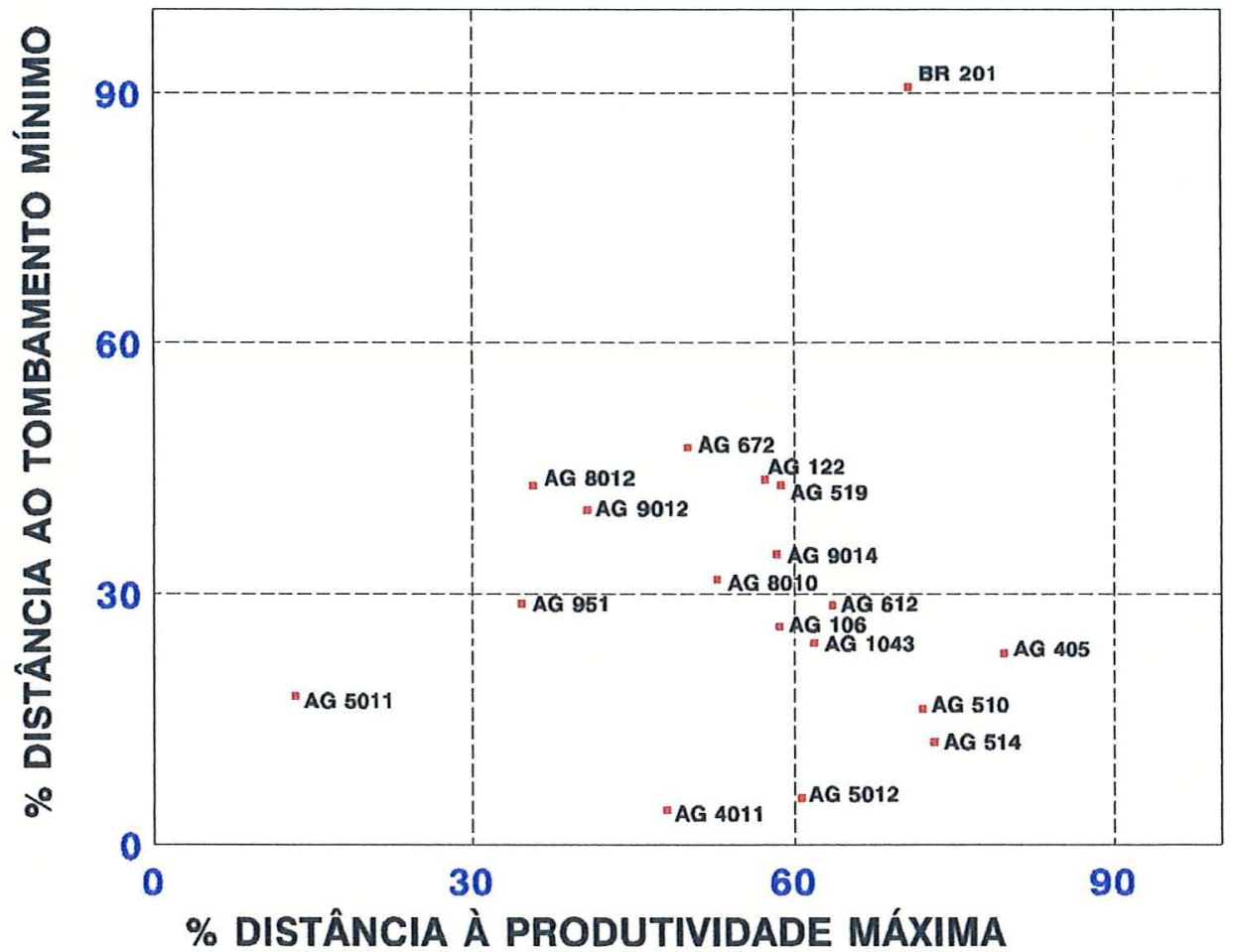

Figura 9. Distância em o à produtividade máxima e ao tombamento mínimo para os dados obtidos de experimentos em 12 locais dos Estados de São Paulo e Minas Gerais (ano agrícola 1994/95), considerados desfavoráveis. 


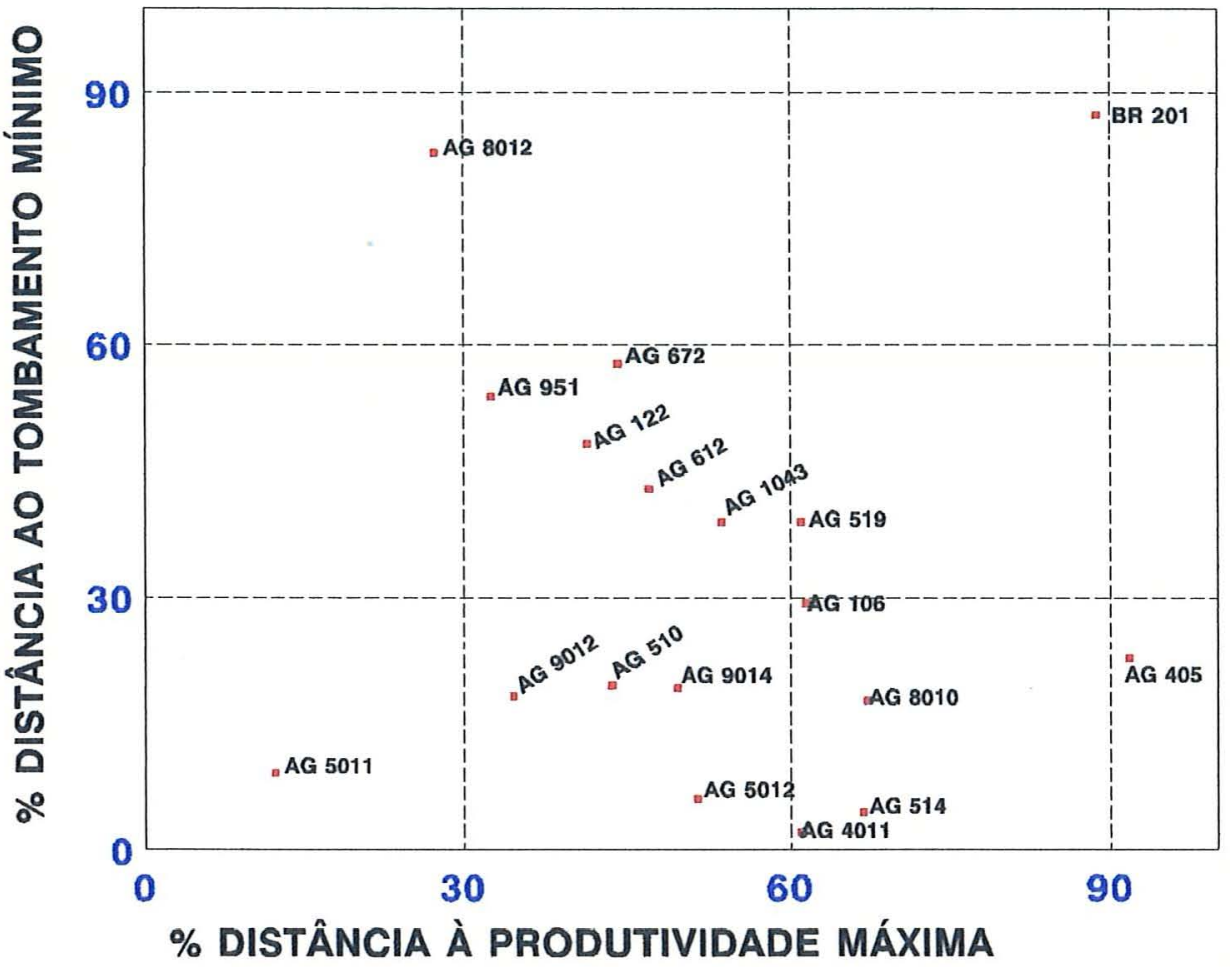

Figura 10. Distância em o à produtividade máxima e ao tombamento mínimo para os dados obtidos de experimentos em 7 locais dos Estados de São Paulo e Minas Gerais (ano agrícola 1994/95), considerados favoráveis. 


\subsection{Adaptabilidade e Estabilidade pelo Método de Eberhart E Russel (1966)}

\subsubsection{Ano agrícola 1992/93}

A tabela 37 apresenta os resultados, para o ano de 1992/93, da análise de variância de acordo com o modelo proposto por EBERHART $\varepsilon$ RUSSEL (1966). Observa-se, pela significância do quadrado médio do efeito linear da interação genótipos com ambientes, que os híbridos mostraram diferenças significativas no que se refere ao coeficiente de regressão linear. O máximo introduzido na análise, foi comparado com todos os híbridos.

Os híbridos AG 106, AG 510, AG 514 e o máximo, não apresentaram significância em relação aos desvios da regressão. De acordo com a Tabela 38, estes híbridos foram os que apresentaram valores baixos de $\hat{\sigma}_{d}^{2}$ (componente de variancia atribuido aos desvios de regressão) sendo então, os de maior estabilidade e previsibilidade.

o híbrido AG 122 apresentou valor do coeficiente de regressão igual a $0,96\left(\hat{\beta}_{1}=0,96\right.$, Tabela 38) e não foi significativamente diferente de 1,0 pela estatistica t. Este híbrido apresentou portanto 
adaptabilidade geral para a variável produtividade. Pode-se observar na Figura 11 que, na comparação do AG 122 com o máximo, as retas ficaram paralelas confirmando a adaptabilidade geral do híbrido. Este híbrido, porém, apresentou um valor significativo de $\hat{\sigma}_{d}{ }^{2}=0,271$, o que caracteriza instabilidade. Já o híbrido AG 106 foi o mais estável com um valor de $\hat{\sigma}_{d}{ }^{2}=0$.

O híbrido AG 514, com base nos valores de distância, foi o que esteve mais próximo do melhor genótipo. 0 valor obtido de $\hat{\beta}_{1}=1,09$ foi significativamente diferente de $1,00 \mathrm{e}$, conforme a Figura 12, as retas aproximaram-se nos ambientes favoráveis, tornando-o com adaptabilidade especifica para ambientes favoráveis; além disso, este híbrido mostrou-se estável conforme indicado pelo valor não significativo de $\hat{\sigma}_{d}{ }^{2}=$ 0,078. Os valores de distâncias nos ambientes desfavoráveis e favoráveis, para este híbrido, foram de $42,8 \%$ e 4,7\% respectivamente. Esses valores contrastantes confirmam a adaptabilidade do híbrido para melhores condições ambientais.

Na Figura 13, foi feita a comparação do híbrido AG 519 com o máximo. Pode-se observar que as retas tenderam a se juntar nos ambientes desfavoráveis, o que 
confirma o valor significativo de $\hat{\beta}_{1}=0,84$. Isso mostra, sua adaptabilidade específica para ambientes desfavoráveis. Este híbrido foi considerado instável pelo valor significativo de $\hat{\sigma}_{d}^{2}=0,162$.

Em relação à adaptabilidade específica para ambientes favoráveis, o híbrido AG 6601 mostrou valor significativo de $\hat{\beta}_{1}=1,19$ e na comparação com o máximo (Figura 14), as retas tenderam a se juntar nos ambientes favoráveis. Este híbrido, porém, apresentou valor significativo de $\hat{\sigma}_{d}{ }^{2}=0,173$, indicando tratar-se de material instável.

Na Tabela 38, nota-se que o híbrido conceitual formado pelos rendimentos máximos mostrou valor de $\hat{\beta}_{1}=1,0$ e de $\hat{\sigma}_{d}{ }^{2}=0$. Tem-se então, que este material apresentou adaptabilidade geral e alta estabilidade. 
Tabela 37. Análise de variância da produtividade média de espigas de 7 híbridos de milho e do máximo ensaiados em 9 locais do Estado de São Paulo, no ano agrícola de 1992/93. (Modelo proposto por EBERHART $\varepsilon$ RUSSEL, 1966).

\begin{tabular}{|c|c|c|c|}
\hline Causas de Variação & G.L & $Q \cdot M$ & \\
\hline Híbridos & 7 & 8,007 & $\star \star$ \\
\hline Ambientes dentro de híbridos & 64 & 33,056 & $\star \star$ \\
\hline Ambiente (Iinear) & 1 & 2027,959 & $\star \star$ \\
\hline Ambiente (linear) x híbridos & 7 & 3,496 & $\star \star$ \\
\hline Desvios da regressão reunidos & 56 & 1,127 & $\mathrm{n} \cdot \mathrm{s}$ \\
\hline \multicolumn{4}{|l|}{ Efeito Linear dos híbridos : } \\
\hline AG 106 & 1 & 300,640 & $\star *$ \\
\hline AG 122 & 1 & 233,967 & $\star \star$ \\
\hline AG 510 & 1 & 207,115 & $\star \star$ \\
\hline AG 514 & 1 & 303,055 & $\star \star$ \\
\hline AG 519 & 1 & 176,962 & $\star \star$ \\
\hline AG 612 & 1 & 218,961 & $\star \star$ \\
\hline AG 6601 & 1 & 360,464 & $\star \star$ \\
\hline MÁX IMO & 1 & 251,262 & $\star \star$ \\
\hline \multicolumn{4}{|l|}{ Desvios da Regressão dos híbridos: } \\
\hline AG 106 & 7 & 0,302 & $\mathrm{n} \cdot \mathrm{s}$ \\
\hline AG 122 & 7 & 1,654 & $\star \star$ \\
\hline AG 510 & 7 & 0,892 & $\mathrm{n} \cdot \mathrm{s}$ \\
\hline AG 514 & 7 & 0,883 & n.s \\
\hline AG 519 & 7 & 1,222 & * \\
\hline AG 612 & 7 & 2,437 & $\star \star$ \\
\hline AG 6601 & 7 & 1,264 & * \\
\hline MÁXIMO & 7 & 0,364 & $n .5$ \\
\hline Resíduo Médio & 189 & 0,570 & \\
\hline
\end{tabular}

* - significativo a 5\% pelo teste $F$ ** - significativo a 1\% pelo teste $F$

n.s - não significativo 
Tabela 38. Estimativa dos parâmetros da estabilidade fenotipica da produtividade de espigas de 7 híbridos de milho e do máximo estudados em 9 locais do Estado de São Paulo no ano agricola de $1992 / 93$.

\begin{tabular}{lccllll}
\hline híbridos & $\hat{\beta}_{o i}$ & $\hat{\beta}_{1 i}$ & & $\hat{\sigma}_{d i}{ }^{2}$ & & $R_{2 i}(\%)$ \\
\hline AG 106 & 8,10 & 1,08 & n.s & 0,000 & n.s & 99,30 \\
AG 122 & 8,65 & 0,96 & n.s & 0,271 & $\star \star$ & 95,28 \\
AG 510 & 8,78 & 0,90 & + & 0,080 & n.s & 97,07 \\
AG 514 & 9,13 & 1,09 & + & 0,078 & n.s & 98,00 \\
AG 519 & 8,32 & 0,84 & ++ & 0,162 & $\star$ & 95,39 \\
AG 612 & 8,39 & 0,93 & n.s & 0,466 & $\star \star$ & 92,77 \\
AG 6601 & 8,33 & 1,19 & ++ & 0,173 & $\star$ & 97,60 \\
MÁXIMO & 9,51 & 1,00 & n.s & 0,000 & n.s & 98,99 \\
\hline
\end{tabular}

$+\quad$ - significativo a 5\% pelo teste $t$

++ - significativo a 1\% pelo teste $t$

* - significativo a 5\% pelo teste $F$

* - significativo a 1\% pelo teste $F$

n.s - não significativo 


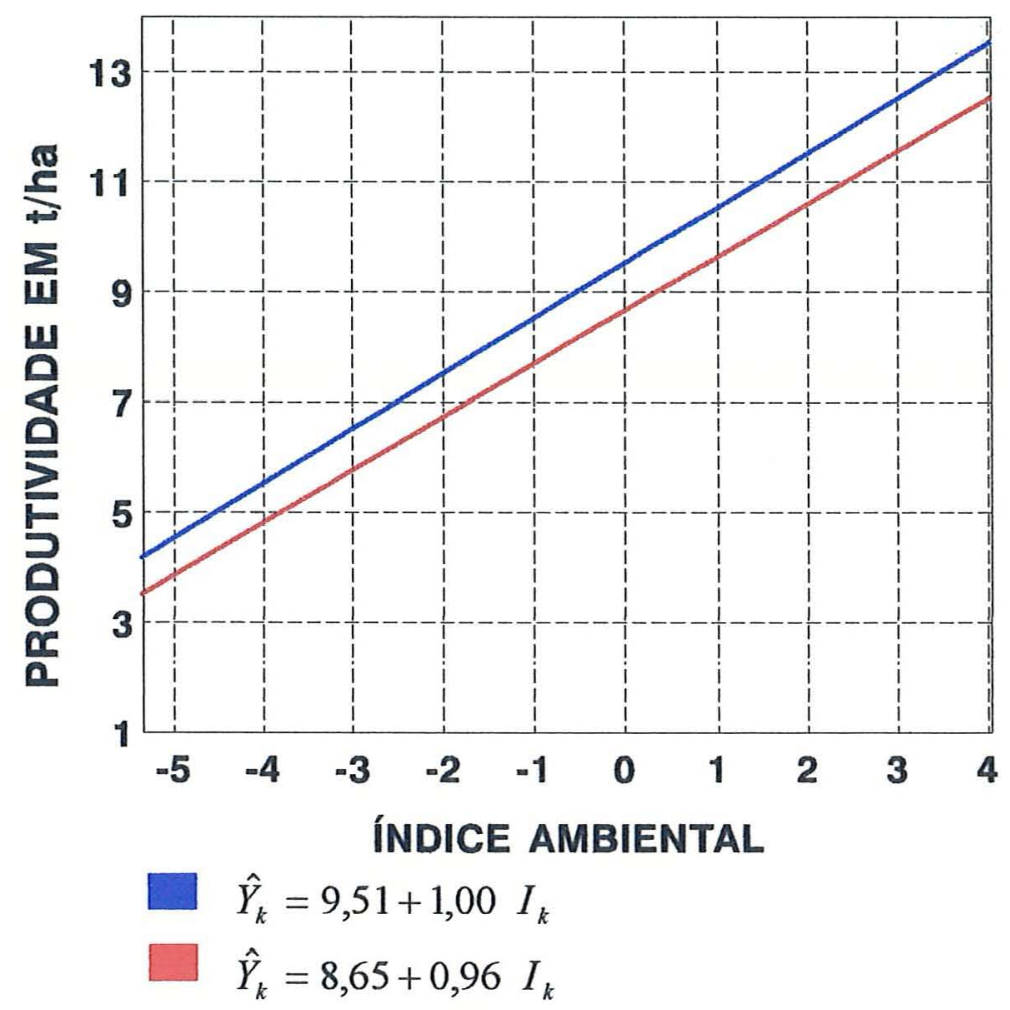

- AG 122

- máximo

Figura 11. Regressão linear da produtividade de espigas do híbrido AG 122 e do máximo, em 9 ambientes do Estado de São Paulo, ano agrícola 1992/93. 


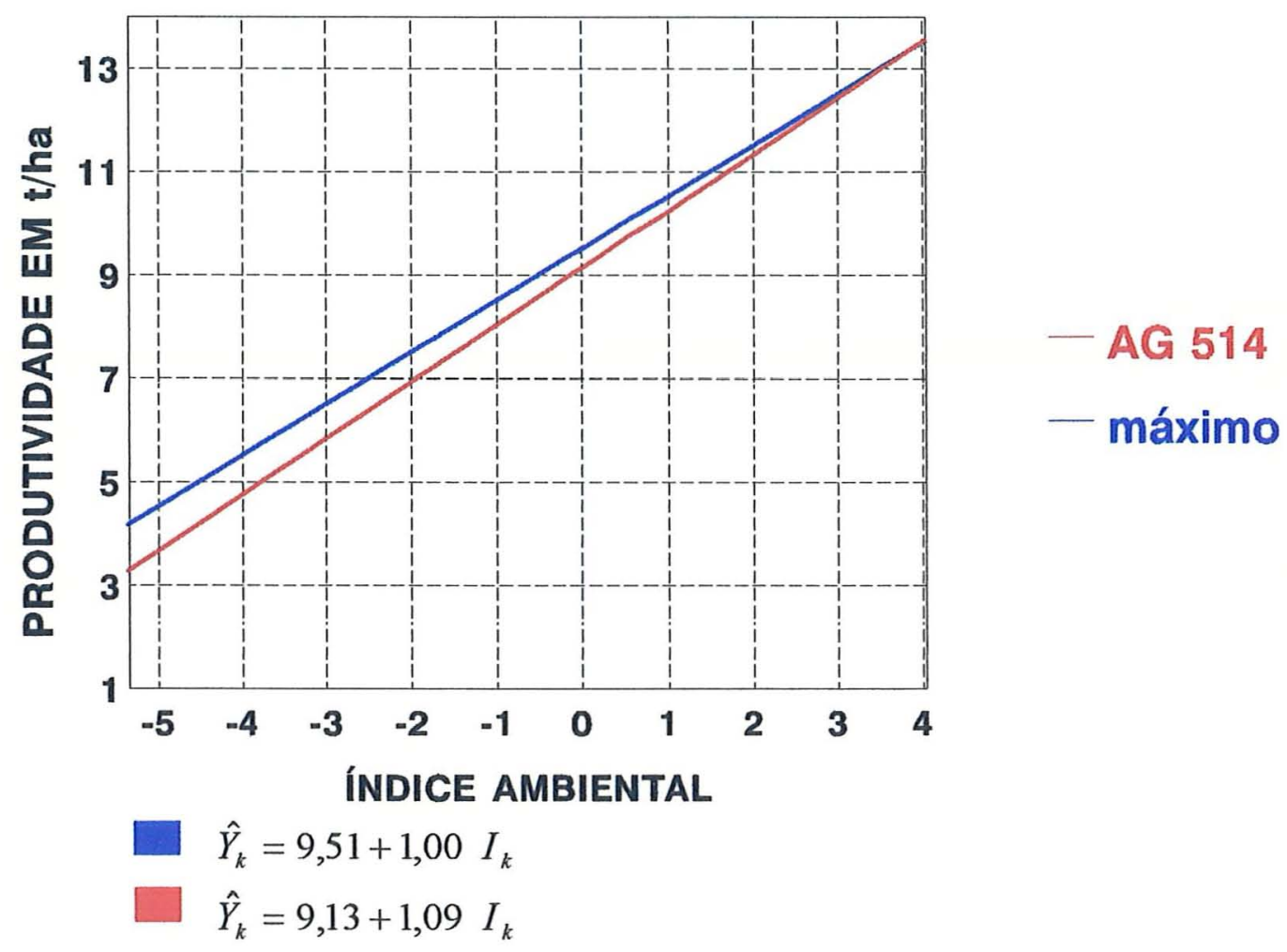

Figura 12. Regressão linear da produtividade de espigas do híbrido AG 514 e do máximo, em 9 ambientes do Estado de São Paulo, ano agrícola 1992/93. 


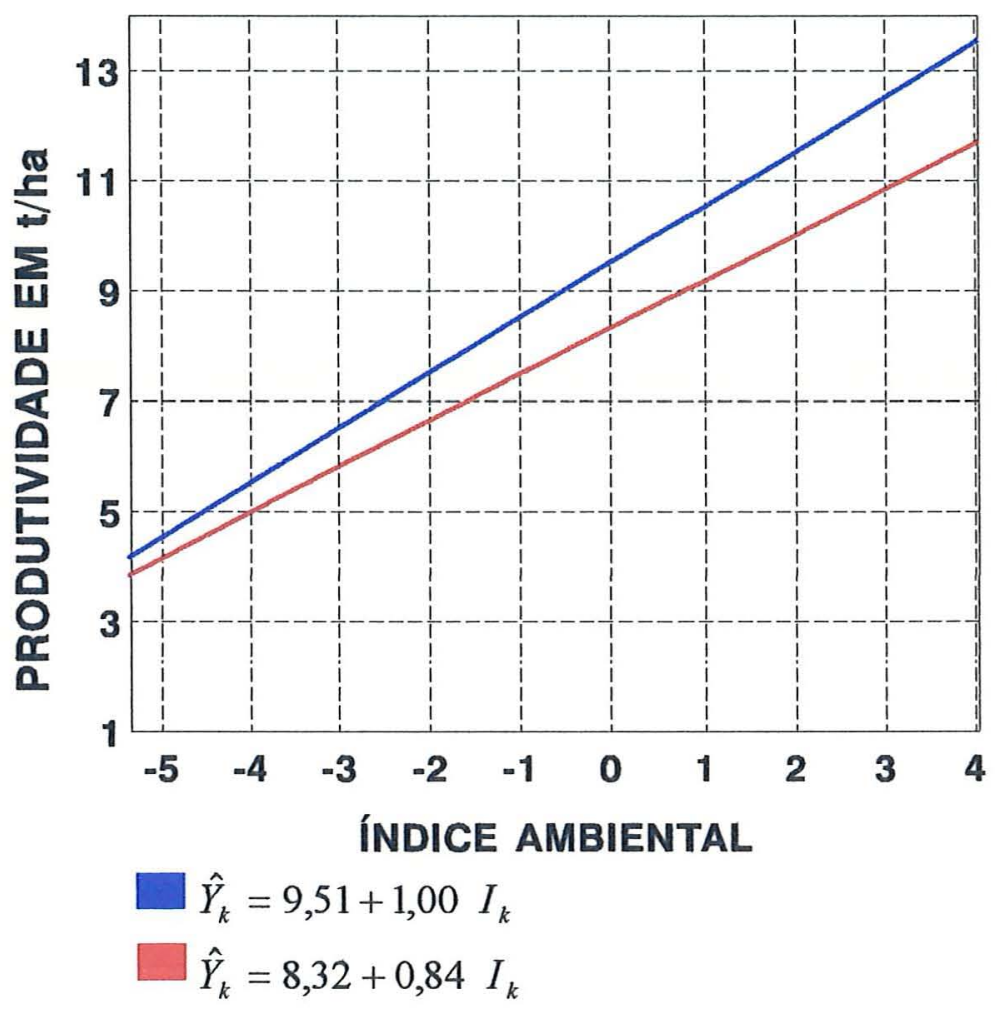

$-\mathrm{AG} 519$ máximo

Figura 13. Regressão linear da produtividade de espigas do híbrido AG 519 e do máximo, em 9 ambientes do Estado de São Paulo, ano agrícola 1992/93. 


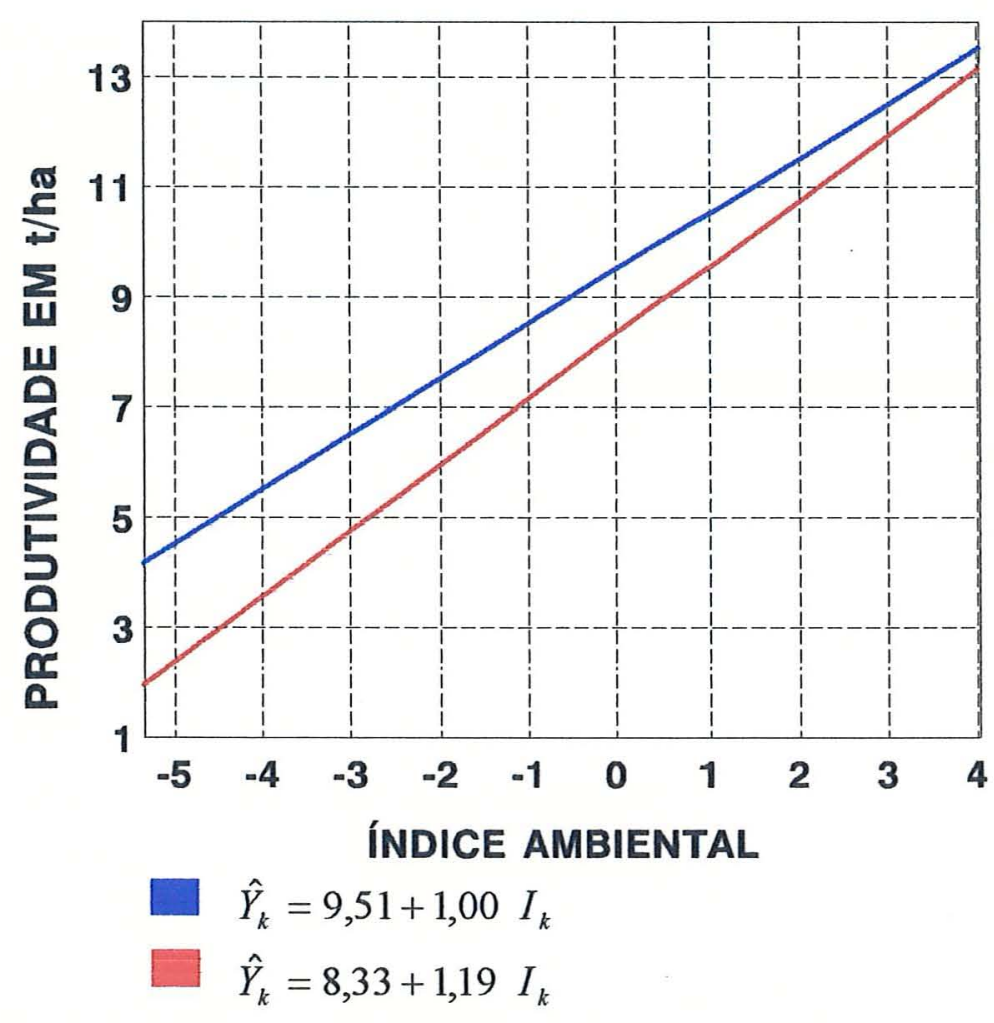

- AG 6601

- máximo

Figura 14. Regressão linear da produtividade de espigas do híbrido AG 6601 e do máximo, em 9 ambientes do Estado de São Paulo, ano agrícola 1992/93. 


\subsubsection{Ano agrícola 1993/94}

Na Tabela 39 tem-se a significância da interação de híbridos $x$ ambientes (linear), mostrando diferenças genéticas entre os materiais estudados, quanto ao seu comportamento linear frente aos ambientes. Desta maneira, os coeficientes de regressão linear foram úteis para diferenciar a adaptação desses materiais a algum ambiente em particular. Os efeitos devidos ao ambiente (Iinear) e à interação de híbridos $x$ ambientes (linear) foram decompostos em efeito linear para cada híbrido. Essa decomposição foi realizada com o objetivo de evidenciar quanto da variação de cada cultivar pode ser explicada pela reta da regressão.

Na Tabela 39 observa-se, ainda, a não significância dos desvios de regressão linear nos híbridos AG 1043, AG 1051, AG 122, AG 5011, AG 514, AG 6601, AG 951, BR 201 e no máximo. O híbrido AG 510 apresentou desvio intermediário, sendo significativo apenas ao nível de 5\% de probabilidade. Os demais mostraram grandes desvios da regressão.

os coeficientes de regressão linear dos dezessete híbridos e do máximo variaram de 0,56 a 1,47 (Tabela 40). Os híbridos cujo valor de $\hat{\beta}_{1 i}$ diferiu de 1,00 , 
segundo o teste $t$ a $1 \frac{\circ}{0}$ foram $\circ \mathrm{AG} 1051, \mathrm{Ag} 405, \mathrm{AG} 612$ e 0 , AG 9010.

O híbrido AG 951 que esteve mais próximo do melhor genótipo para a produtividade, mostrou valor não significativo de $\hat{\beta}_{1}=0,87$ e valor não significativo de $\hat{\sigma}_{d}{ }^{2}=0,054 \quad($ Tabela 40$)$, expressando assim sua adaptabilidade geral e estabilidade. Pode-se verificar na Eigura 15 que, na comparação do híbrido AG 951 com o máximo, as retas estiveram bem próximas com uma leve tendência de se unirem nos ambientes desfavoráveis. Deve-se lembrar que os valores obtidos de distância à produtividade máxima, para os ambientes desfavoráveis e favoráveis foram de $15,3 \%$ e $23,4 \%$ respectivamente.

- híbrido AG 5011, que também esteve bem próximo do melhor genótipo, foi considerado com adaptabilidade geral e altamente estável devido aos valores não significativos de $\hat{\beta}_{1}=1,09$ e de $\hat{\sigma}_{d}{ }^{2}=0,019$. Na Figura 16 pode-se observar que as retas ficaram paralelas indicando adaptabilidade geral. Os valores de distância em relação à produtividade máxima nos ambientes desfavoráveis e favoráveis foram de $34,0 \%$ e $23,2 \%$ respectivamente.

o híbrido BR 201 que foi considerado o de pior desempenho para a variável produtividade, foi 
comparado com o máximo na Figura 17. A retas paralelas, mostraram adaptabilidade geral com um valor não significativo de $\hat{\beta}_{1}=1,14$. Este híbrido mostrou ainda, ser estável com um valor não significativo de $\hat{\sigma}_{d}{ }^{2}=0,137$. Seus valores de distância ao melhor genótipo, para os ambientes desfavoráveis e favoráveis, foram de 74,0\% e 83,6\% respectivamente.

o híbrido $\mathrm{AG}$ 514, pelo segundo ano consecutivo, foi considerado estável com valor de $\hat{\sigma}_{d}{ }^{2}=0 \mathrm{e}$ valor não significativo de $\hat{\beta}_{1}=1,02$. Isso evidênciou adaptabilidade geral. Pode-se observar na Figura 18 que as retas ficaram paralelas.

Pelo segundo ano consecutivo, o híbrido AG 122 exibiu adaptabilidade geral com um valor não significativo de $\hat{\beta}_{1}=0,86$. Na Figura 19 a reta deste híbrido ficou paralela com a do máximo, sendo ainda considerado estável com um valor não significativo de $\hat{\sigma}_{d}{ }^{2}$ $=0,120$.

O híbrido AG 106 repetiu sua tendência a uma adaptabilidade geral com um valor não significativo de $\hat{\beta}_{1}=$ 0,97. Apresentou-se porém como instável, com um valor significativo de $\hat{\sigma}_{d}{ }^{2}=0,322$. 
O híbrido AG 1051 foi considerado com adaptabilidade específica para condições favoráveis. Podese observar na Figura 21 que as retas juntaram-se nos ambientes favoráveis. Este híbrido exibiu valor significativo de $\hat{\beta}_{1}=1,47$ e foi considerado estável com valor não significativo de $\hat{\sigma}_{d}{ }^{2}=0,125$. Seus valores de distância em relação à produtividade máxima nos ambientes desfavoráveis e favoráveis, foram de 56,0\% e 21,5\%, respectivamente.

O híbrido AG 1043 foi considerado com adaptabilidade geral e estável com valores não significativos de $\hat{\beta}_{1}=1,03 \mathrm{e} \hat{\sigma}_{d}^{2}=0,182$ respectivamente. Pode-se observar na comparação com o máximo (Figura 22), que as retas foram paralelas. Já o híbrido AG 405 mostrou valores significativos de $\hat{\beta}_{1}=0,60$ e de $\hat{\sigma}_{d}{ }^{2}=0,340$. Podese concluir, assim, que se trata de material com adaptabilidade específica para ambientes desfavoráveis e instável. Pode-se observar na Figura 23 que as retas tenderam a se unir nos ambientes desfavoráveis. Seus valores de distância à produtividade máxima para os ambientes desfavoráveis e favoráveis foram de 43,4\% e 79,8 respectivamente. 
O máximo por sua vez, pôde ser considerado com adaptabilidade geral devido ao valor não significativo de $\hat{\beta}_{1}=1,01$. Pôde também ser considerado como estável, pelo valor não significativo de $\hat{\sigma}_{d}{ }^{2}=0$. 
Tabela 39. Análise de variância da produtividade média de espigas de 17 híbridos de milho e do máximo ensaiados em 13 locais dos Estados de São paulo e Minas Gerais, no ano agrícola de 1993/94. (Modelo proposto por EBERHART \& RUSSEL, 1966).

\begin{tabular}{|c|c|c|c|}
\hline Causas de Variação & G.L & $Q . M$ & \\
\hline Híbridos & 17 & 15,316 & *夫 \\
\hline Ambientes dentro de híbridos & 216 & 9,344 & $\star \star$ \\
\hline Ambiente (Iinear) & 1 & 1579,320 & $* *$ \\
\hline Ambiente (linear) $x$ híbridos & 17 & 4,556 & $\star \star$ \\
\hline Desvios da regressão reunidos & 198 & 1,826 & $\star \star$ \\
\hline \multicolumn{4}{|l|}{ Efeito Linear dos híbridos: } \\
\hline AG 1043 & 1 & 93,481 & $\star \star$ \\
\hline AG 1051 & 1 & 189,560 & $\star \star$ \\
\hline AG 106 & 1 & 82,037 & $\star *$ \\
\hline AG 122 & 1 & 65,185 & $\star \star$ \\
\hline AG 405 & 1 & 31,742 & $\star \star$ \\
\hline AG 5011 & 1 & 104,713 & $* *$ \\
\hline AG 5012 & 1 & 78,332 & $\star \star$ \\
\hline$A G \quad 510$ & 1 & 63,653 & $\star \star$ \\
\hline AG 514 & 1 & 90,393 & $\star \star$ \\
\hline AG 6012 & 1 & 87,615 & $\star \star$ \\
\hline AG 612 & 1 & 27,315 & $\star \star$ \\
\hline $\mathrm{AG} \quad 6601$ & 1 & 80,971 & $\star \star$ \\
\hline AG 672 & 1 & 116,978 & $\star \star$ \\
\hline AG 8012 & 1 & 94,041 & $\star \star$ \\
\hline AG 9010 & 1 & 181,120 & $\star \star$ \\
\hline AG 951 & 1 & 66,900 & $\star \star$ \\
\hline BR 201 & 1 & 113,791 & $\star \star$ \\
\hline \multirow[t]{2}{*}{ MÁX IMO } & 1 & 88,945 & $\star \star$ \\
\hline & & \multicolumn{2}{|c|}{ continua } \\
\hline
\end{tabular}


Tabela 39. Análise de variância da produtividade média de espigas de 17 híbridos de milho e do máximo ensaiados em 13 locais dos Estados de São Paulo e Minas Gerais, no ano agrícola de 1993/94. (Modelo proposto por EBERHART $\varepsilon$ RUSSEL, 1966).

... continuação,

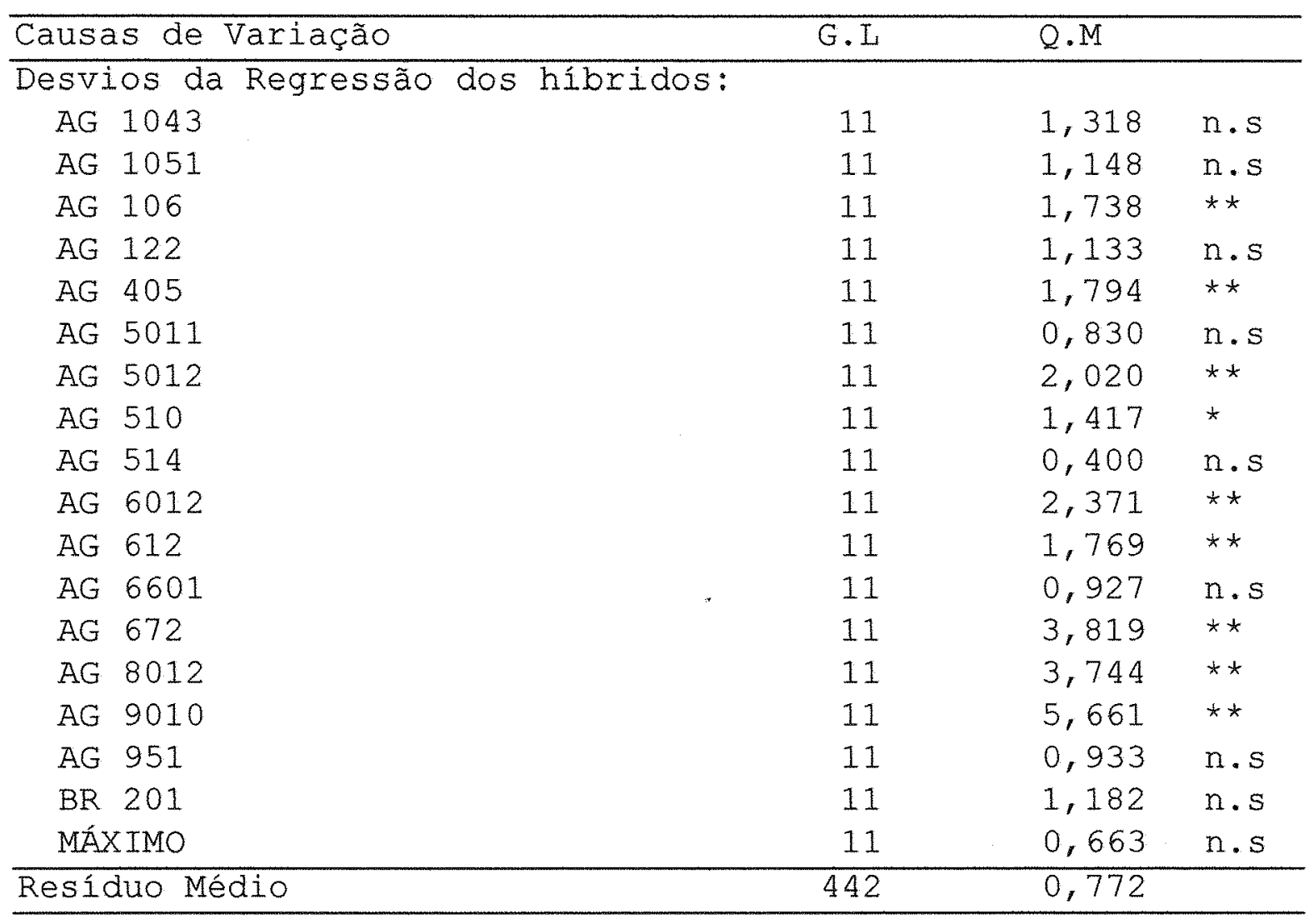

* - significativo a 5\% pelo teste $\mathrm{F}$

* - significativo a $1 \%$ pelo teste F

n.s - não significativo 
Tabela 40. Estimativas de parâmetros da estabilidade fenotípica da produtividade de espigas de 17 híbridos de milho e do máximo estudados em 13 locais dos Estados de São Paulo e Minas Gerais no ano agrícola de 1993/94.

\begin{tabular}{|c|c|c|c|c|c|c|}
\hline híbridos & $\hat{\beta}_{o i}$ & $\hat{\beta}_{1 i}$ & & $\hat{\sigma}_{d i}^{2}$ & & $R_{2 i}(\%)$ \\
\hline AG 1043 & 9,61 & 1,03 & $n \cdot s$ & 0,182 & $n \cdot s$ & 86,57 \\
\hline AG 1051 & 9,86 & 1,47 & ++ & 0,125 & $n \cdot s$ & 93,75 \\
\hline AG 106 & 9,17 & 0,97 & n.s & 0,322 & $\star \star$ & 81,10 \\
\hline AG 122 & 9,20 & 0,86 & n.s & 0,120 & $n \cdot s$ & 83,94 \\
\hline AG 405 & 8,82 & 0,60 & ++ & 0,340 & $\star \star$ & 61,65 \\
\hline AG 5011 & 10,14 & 1,09 & $n \cdot s$ & 0,019 & $n \cdot s$ & 91,98 \\
\hline AG 5012 & 9,69 & 0,94 & $n \cdot s$ & 0,416 & $\star \star$ & 77,90 \\
\hline$A G \quad 510$ & 9,35 & 0,85 & $\mathrm{n} \cdot \mathrm{s}$ & 0,215 & * & 80,32 \\
\hline AG 514 & 9,73 & 1,02 & $\mathrm{n} \cdot \mathrm{s}$ & 0,000 & n.s & 95,36 \\
\hline AG 6012 & 8,85 & 1,00 & $\mathrm{n} \cdot \mathrm{s}$ & 0,533 & $\star \star$ & 77,06 \\
\hline$A G \quad 612$ & 9,01 & 0,56 & ++ & 0,332 & $\star \star$ & 58,40 \\
\hline AG 6601 & 9,75 & 0,96 & $n \cdot s$ & 0,052 & $n \cdot s$ & 88,81 \\
\hline AG 672 & 9,71 & 1,15 & $\mathrm{n} \cdot \mathrm{s}$ & 1,015 & $* \star$ & 73,58 \\
\hline AG 8012 & 9,65 & 1,04 & $\mathrm{n} \cdot \mathrm{s}$ & 0,990 & $\star \star$ & 69,54 \\
\hline AG 9010 & 9,54 & 1,44 & ++ & 1,630 & $\star \star$ & 74,41 \\
\hline AG 951 & 10,40 & 0,87 & $\mathrm{n} \cdot \mathrm{s}$ & 0,054 & n.s & 86,70 \\
\hline BR 201 & 8,39 & 1,14 & n.s & 0,137 & $n \cdot s$ & 89,74 \\
\hline MÁXIMO & 11,11 & 1,01 & $\mathrm{n} . \mathrm{s}$ & 0,000 & $n \cdot s$ & 92,42 \\
\hline
\end{tabular}

$+\quad$ - significativo a 5\% pelo teste $t$

+ + - significativo a $1 \%$ pelo teste $t$

* - significativo a 5\% pelo teste $F$

** - significativo a 1\% pelo teste $F$

n.s - não significativo 


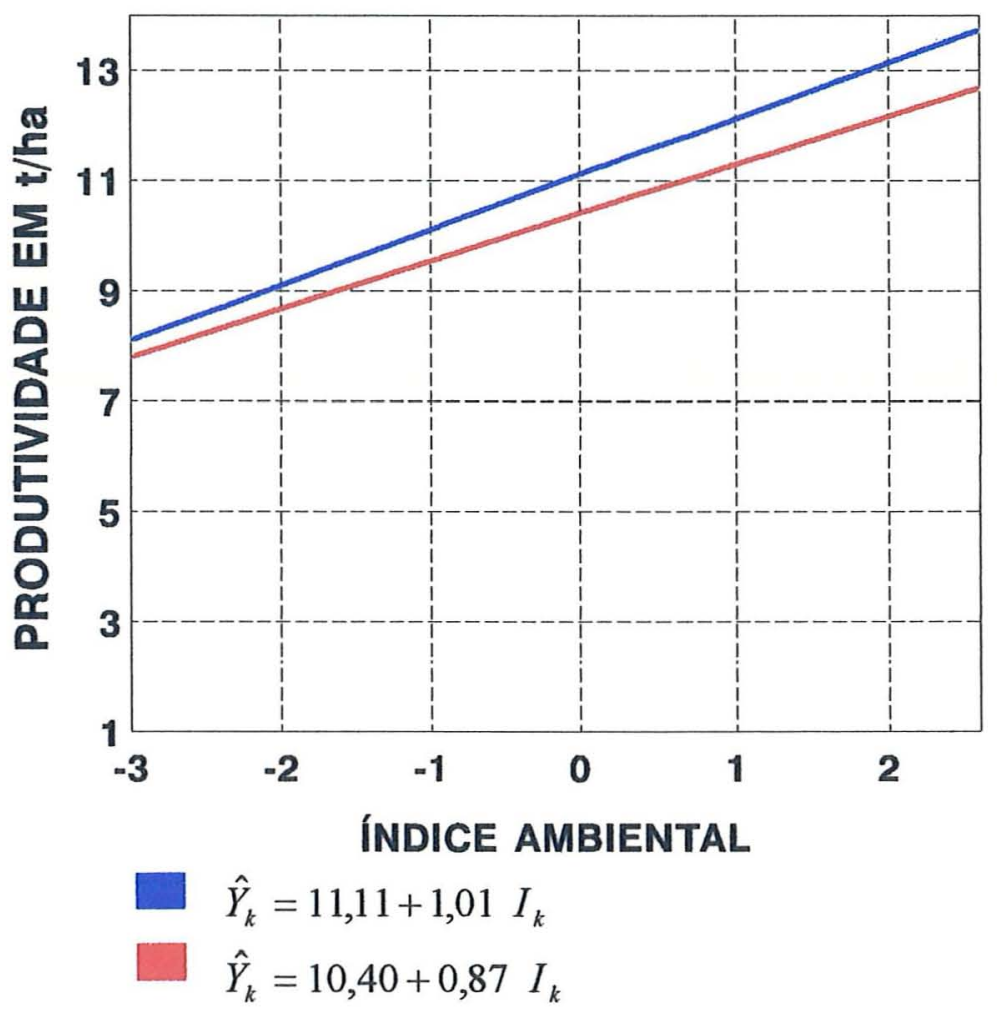

\section{- AG 951 \\ - máximo}

Figura 15. Regressão linear da produtividade de espigas do híbrido AG 951 e do máximo, em 13 ambientes dos Estados de São Paulo e Minas Gerais, ano agrícola 1993/94. 


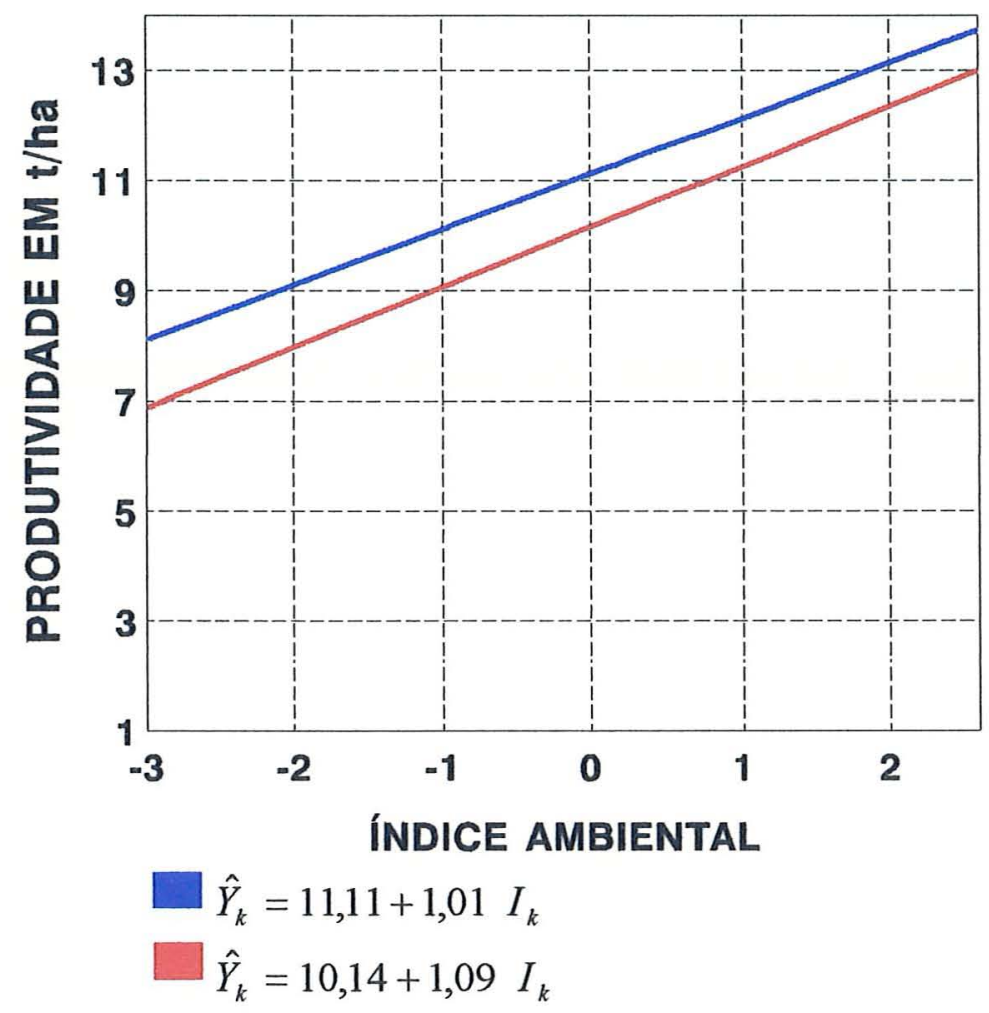

- AG 5011

- máximo

Figura 16. Regressão linear da produtividade de espigas do híbrido AG 5011 e do máximo, em 13 ambientes dos Estados de São Paulo e Minas Gerais, ano agrícola 1993/94. 


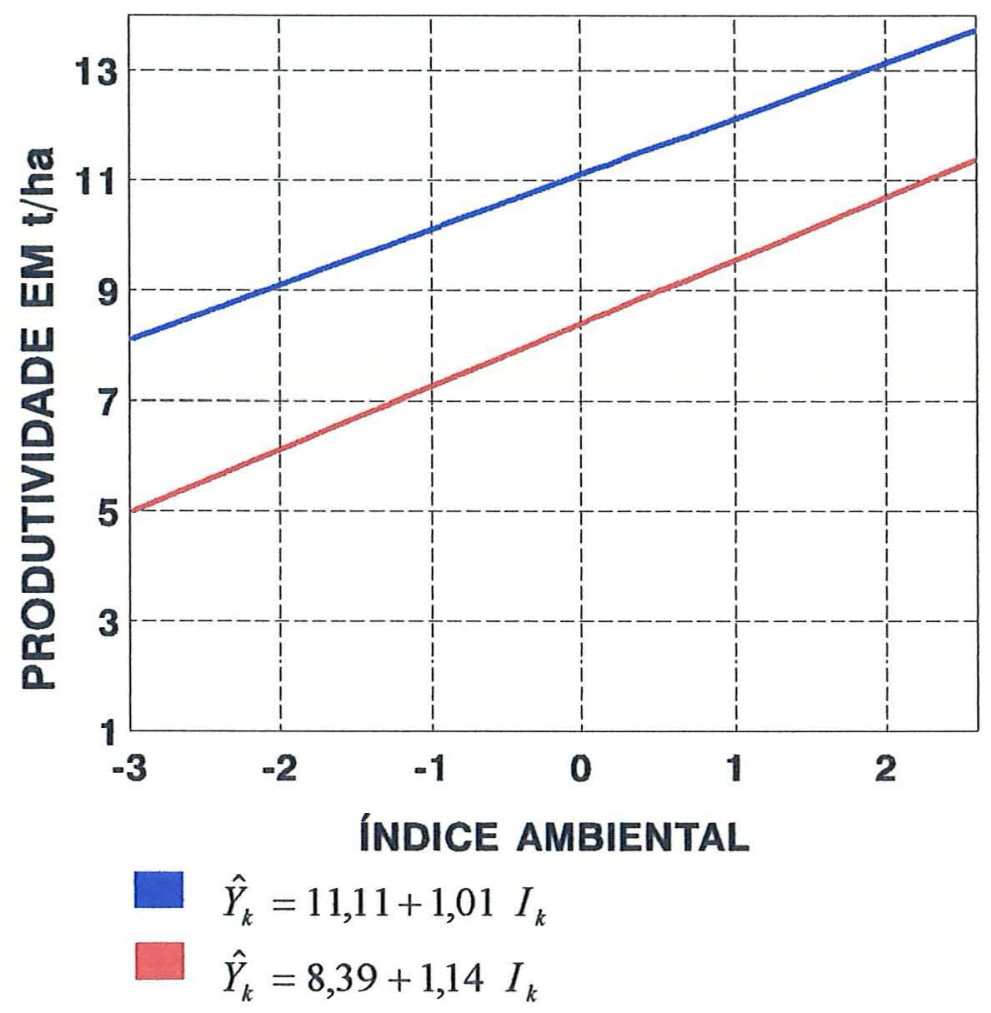

\section{- BR 201 \\ - máximo}

Figura 17. Regressão linear da produtividade de espigas do híbrido BR 201 e do máximo, em 13 ambientes dos Estados de São Paulo e Minas Gerais, ano agrícola 1993/94. 


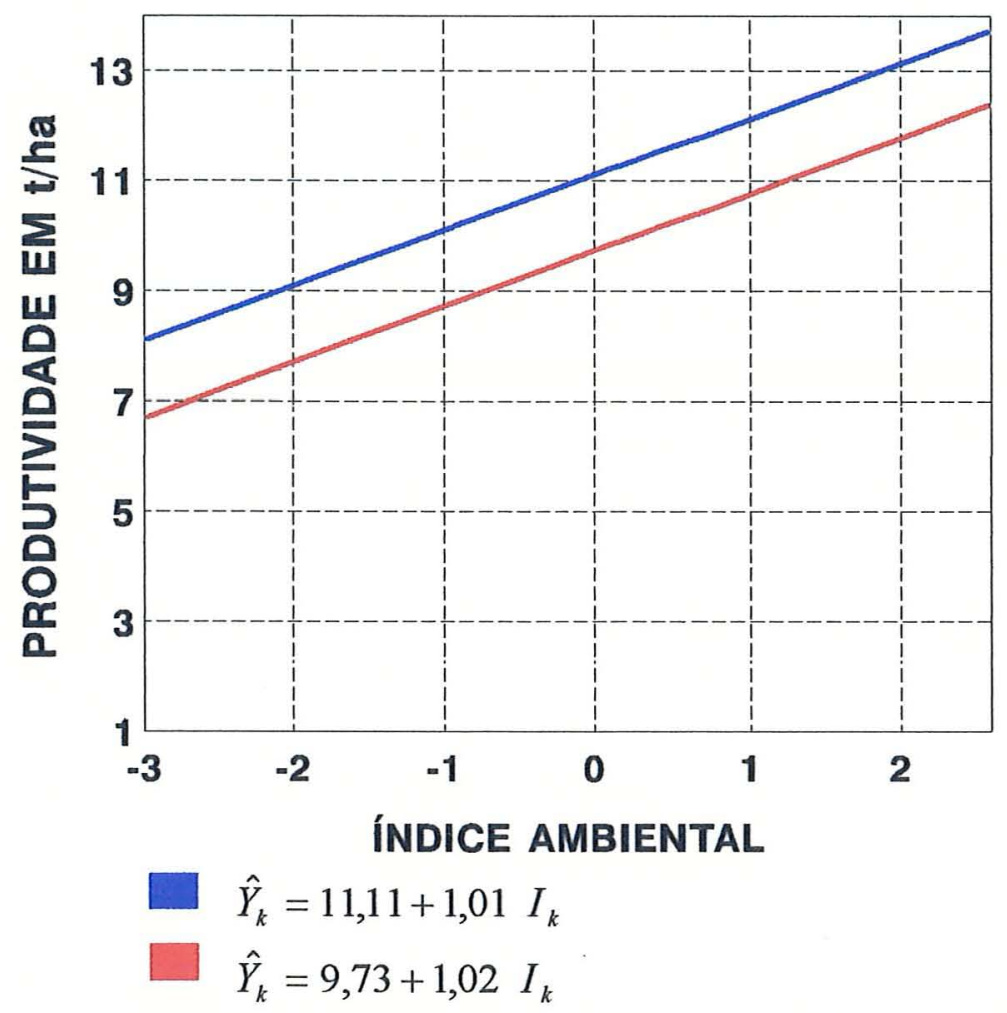

- $\mathrm{AG} 514$

- máximo

Figura 18. Regressão linear da produtividade de espigas do híbrido AG 514 e do máximo, em 13 ambientes dos Estados de São Paulo e Minas Gerais, ano agrícola 1993/94. 


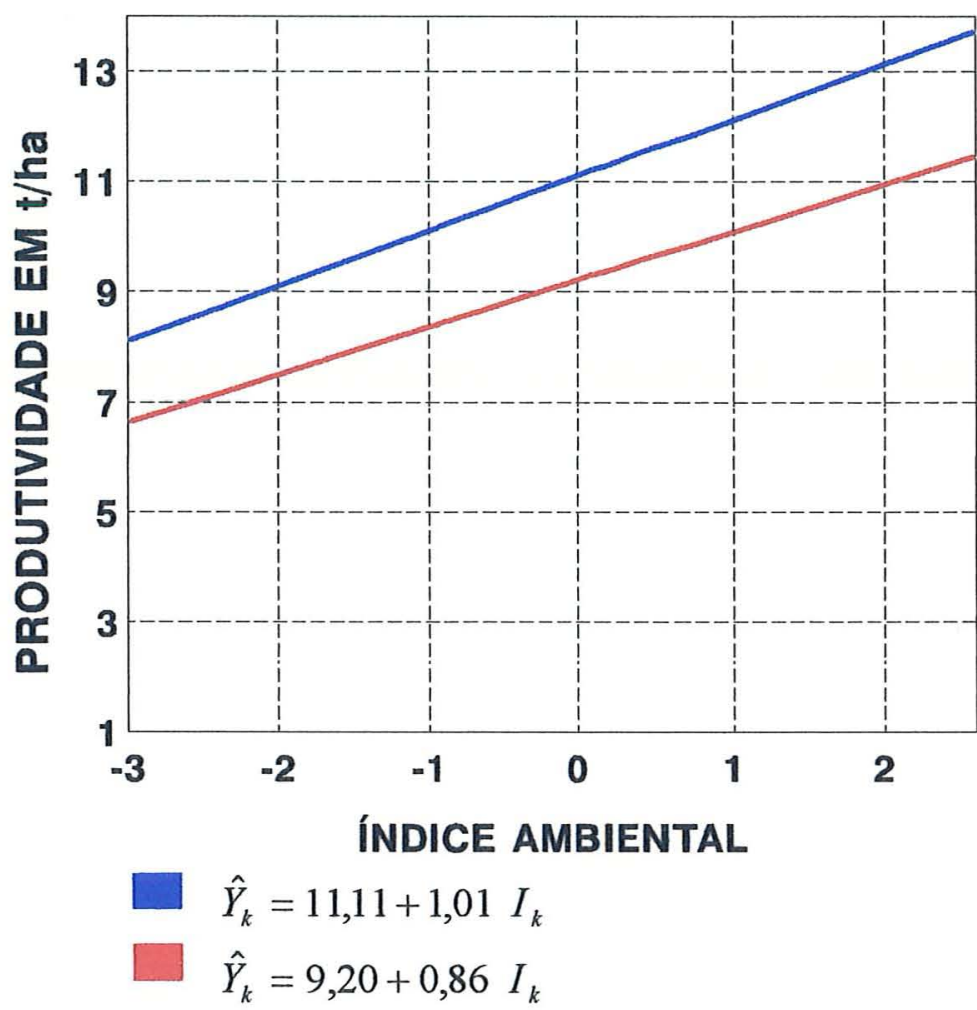

- $\mathrm{AG} 122$

- máximo

Figura 19. Regressão linear da produtividade de espigas do híbrido AG 122 e do máximo, em 13 ambientes dos Estados de São Paulo e Minas Gerais, ano agrícola 1993/94. 


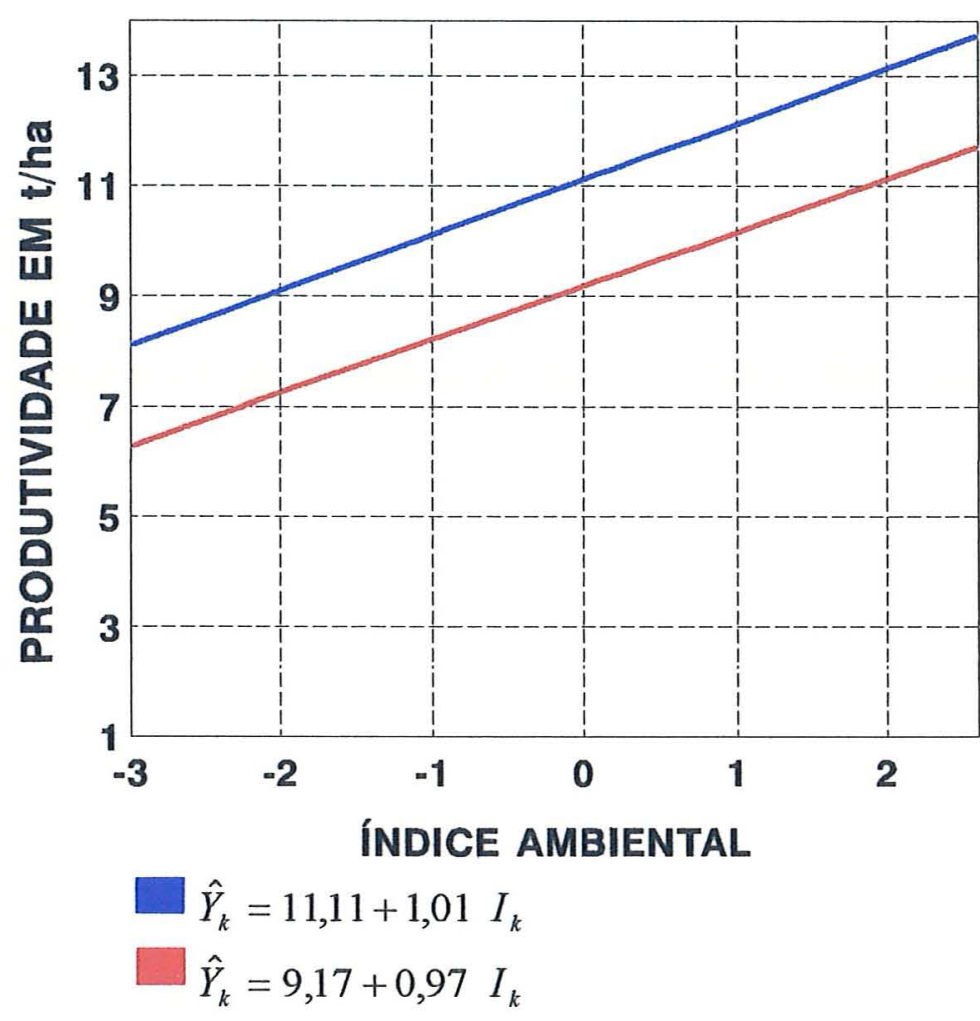

- $\mathrm{AG} 106$ - máximo

Figura 20. Regressão linear da produtividade de espigas do híbrido AG 106 e do máximo, em 13 ambientes dos Estados de São Paulo e Minas Gerais, ano agrícola 1993/94. 


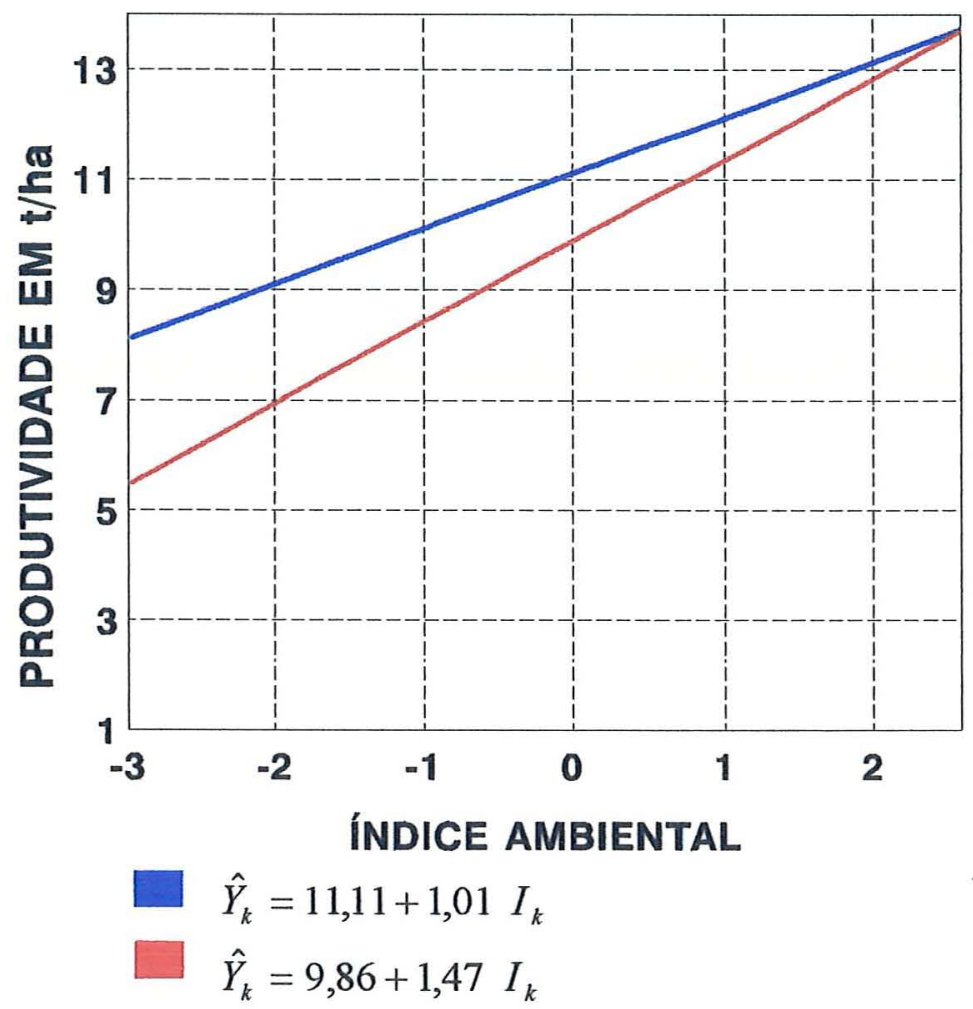

- $\mathrm{G} 1051$

- máximo

Figura 21. Regressão linear da produtividade de espigas do híbrido AG 1051 e do máximo, em 13 ambientes dos Estados de São Paulo e Minas Gerais, ano agrícola $1993 / 94$. 


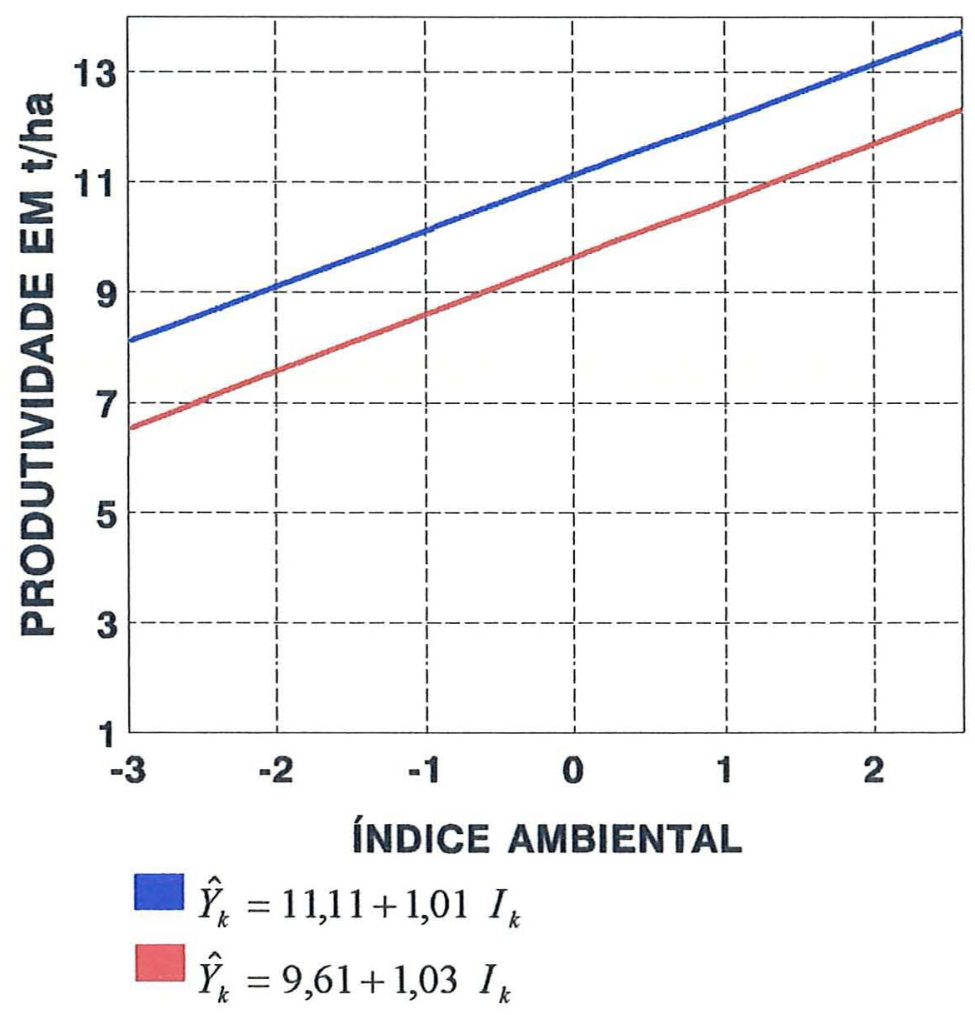

- AG 1043

- máximo

Figura 22. Regressão linear da produtividade de espigas do híbrido AG 1043 e do máximo, em 13 ambientes dos Estados de São Paulo e Minas Gerais, ano agrícola 1993/94. 


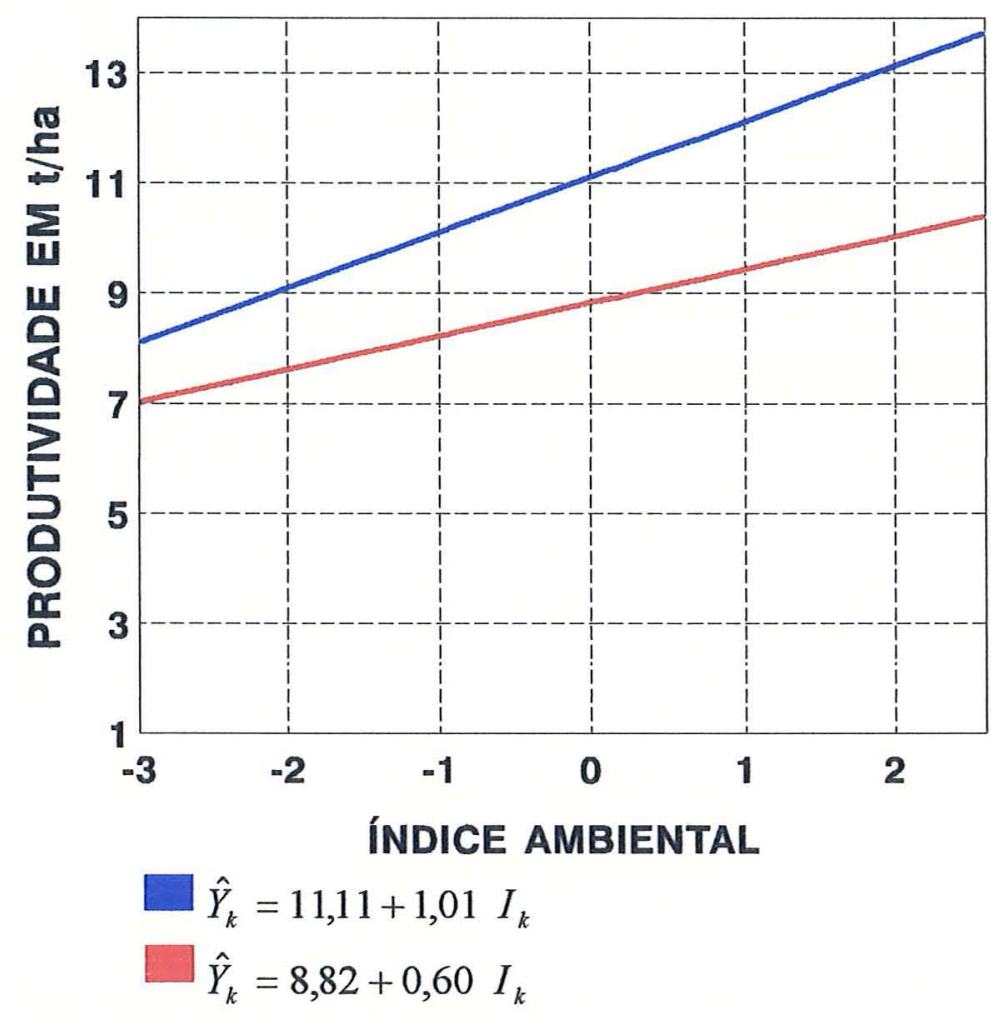

- AG 405

- máximo

Figura 23. Regressão linear da produtividade de espigas do híbrido AG 405 e do máximo, em 13 ambientes dos Estados de São Paulo e Minas Gerais, ano agrícola 1993/94. 


\subsubsection{Ano agrícola 1994/95}

Na tabela 41, é mostrada a significância da interação Ambiente (linear) x híbridos, que indica haver pronunciadas diferenças genéticas entre os 18 materiais testados, quanto ao seu comportamento linear frente aos ambientes. Observa-se, ainda, a não significância dos desvios da regressão linear nos híbridos AG 106, AG 122, AG 405, AG 5011, AG 510, AG 514, AG 519, AG 951, BR 201 e no máximo. Os híbridos AG 1043, AG 5012, AG 672 apresentaram desvios intermediários, sendo significativos apenas ao nível de 5\% de probabilidade. Os demais apresentaram desvios significativos a $1 \%$

Os coeficientes de regressão linear dos 10 materiais variaram de 0,79 a 1,22 (Tabela 42). Os híbridos AG 4011, AG 405, AG 510, AG 612, AG 672, AG 8010 e BR 201 tiveram coeficientes de regressão que diferiram de 1,00, segundo $o$ teste $t$.

O híbrido AG 5011 que esteve mais próximo do melhor genótipo para produtividade, teve valores não significativos de $\hat{\beta}_{1}=1,02$ e $\hat{\sigma}_{d}^{2}=0,070$ mostrando assim, pelo segundo ano consecutivo, adaptabilidade geral e alta estabilidade. Pode-se observar na Figura 24 que as retas estão bem próximas pois, como já foi visto, os valores de 
đistância à produtividade máxima para os ambientes desfavoráveis e favoráveis foram de apenas 13,5\% e 12,3\% respectivamente.

Os híbridos AG 8012 e AG 9012, que foram considerados produtivos apresentaram adaptabilidade geral com valores não significativos de $\hat{\beta}_{1}=1,11$ e $\hat{\beta}_{1}=0,95$, respectivamente. Estes híbrido porém foram considerados instáveis com valores significativos de $\hat{\sigma}_{d}{ }^{2}=1,322$ e $\hat{\sigma}_{d}{ }^{2}=$ 0,615 respectivamente. Pode-se observar nas Figuras 25 e 27 que as retas desses híbridos comparadas com a do máximo estiveram paralelas, sendo que a reta do AG 9012 apresentou uma leve tendência a se juntar com a do máximo nos ambientes desfavoráveis.

O híbrido AG 951, que foi o terceiro híbrido mais produtivo, também apresentou adaptabilidade geral com um valor não significativo de $\hat{\beta}_{1}=1,06$, podendo ser considerado altamente estável, com um valor de $\hat{\sigma}_{d}{ }^{2}=0$. Quando comparado com o máximo (Figura 26) as retas mostraram-se paralelas confirmando assim, sua adaptabilidade geral.

Foram considerados de baixa produtividade os híbridos BR 201 e AG 405. Estes apresentaram adaptabilidade especifica para ambientes desfavoráveis com valores 
significativos de $\hat{\beta}_{1}=0,79$ e $\hat{\beta}_{1}=0,82$, respectivamente. Ambos os híbridos foram estáveis pois, tiveram valores não significativos de $\hat{\sigma}_{d}^{2}$. Pode-se observar nas Figuras 28 e 29 que as retas tenderam a se juntar nos ambientes desfavoráveis.

Foi introduzido neste ano o híbrido AG 4011, que também apresentou adaptabilidade específica para ambientes desfavoráveis com um valor significativo de $\hat{\beta}_{1}=$ 0,82. Pode-se observar na Eigura 30, que as retas tenderam a se juntar nos ambientes desfavoráveis.

Pelo terceiro ano consecutivo os híbridos AG 106 e AG 122 apresentaram adaptabilidade geral com valores não significativos de $\hat{\beta}_{1}=0,94$ e $\hat{\beta}_{1}=1,09$, respectivamente. Isto pôde ser confirmado nas Figuras 31 e 32, pois as retas dos híbridos comparadas com a do máximo ficaram paralelas. Além disso, estes hibridos foram considerados estáveis com valores não significativos de $\hat{\sigma}_{d}^{2}$

o híbrido AG 1043 apresentou, também pelo segundo ano consecutivo, adaptabilidade geral com valor não significativo de $\hat{\beta}_{1}=1,04$. Pode-se observar na comparação com o máximo (Figura 33) que a retas estiveram paralelas. 
Pelo terceiro ano consecutivo o híbrido AG 514 apresentou-se estável com valor não significativo de $\hat{\sigma}_{d}{ }^{2}=0,082$. Além disso, foi considerado com adaptabilidade geral com um valor não significativo de $\hat{\beta}_{1}=0,99$. Pode-se observar na Eigura 34 que as retas ficaram paralelas.

o máximo repetiu pelo terceiro ano, sua adaptabilidade geral com um valor não significativo de $\hat{\beta}_{1}=$ 1,07 e também foi novamente considerado altamente estável com um valor de $\hat{\sigma}_{d}{ }^{2}=0$. 
Tabela 41. Análise de variância da produtividade média de espigas de 18 híbridos de milho e do máximo ensaiados em 19 locais dos Estados de São Paulo e Minas Gerais, no ano agrícola de 1994/95. (Modelo proposto por EBERHART \& RUSSEL, 1966).

\begin{tabular}{|c|c|c|c|}
\hline Causas de Variação & G.L & $Q \cdot M$ & \\
\hline$\overline{\text { Híbridos }}$ & $17 \%$ & 27,174 & $\star \star$ \\
\hline Ambientes dentro de híbridos & 342 & 18,507 & ** \\
\hline Ambiente (Iinear) & 1 & 5625,943 & $\star \star$ \\
\hline Ambiente (linear) $x$ híbridos & $18 \%$ & 4,313 & $\star \star$ \\
\hline Desvios da regressão reunidos & 323 & 1,938 & * * \\
\hline \multicolumn{4}{|l|}{ Efeito Linear dos híbridos : } \\
\hline AG 1043 & 1 & 90,546 & $* *$ \\
\hline AG 106 & 1 & 89,982 & $\star \star$ \\
\hline AG 122 & 1 & 93,987 & ** \\
\hline AG 4011 & 1 & 78,943 & ** \\
\hline AG 405 & 1 & 92,489 & $\star \star$ \\
\hline AG 5011 & 1 & 93,306 & $* *$ \\
\hline AG 5012 & 1 & 90,558 & $\star *$ \\
\hline $\mathrm{AG} \quad 510$ & 1 & 96,004 & $\star \star$ \\
\hline AG 514 & 1 & 92,771 & $\star \star$ \\
\hline AG 519 & 1 & 94,348 & $\star \star$ \\
\hline AG 612 & 1 & 89,872 & $\star \star$ \\
\hline AG 672 & 1 & 91,764 & $\star *$ \\
\hline AG 8010 & 1 & 85,597 & $\star \star$ \\
\hline AG 8012 & 1 & 80,814 & $\star \star$ \\
\hline AG 9012 & 1 & 84,283 & $\star \star$ \\
\hline AG 9014 & 1 & 83,512 & $\star \star$ \\
\hline AG 951 & 1 & 95,845 & $\star \star$ \\
\hline BR 201 & 1 & 87,310 & $\star \star$ \\
\hline MÁX IMO & 1 & 95,648 & $\star \star$ \\
\hline
\end{tabular}


Tabela 41. Análise de variância da produtividade média de espigas de 18 híbridos de milho e do máximo ensaiados em 19 locais dos Estados de São Paulo e Minas Gerais, no ano agrícola de 1994/95. (Modelo proposto por EBERHART $\varepsilon$ RUSSEL, 1966).

\begin{tabular}{|c|c|c|c|}
\hline Causas de Variação & G.L & Q.M & \\
\hline \multicolumn{4}{|l|}{ Desvios da Regressão dos híbridos: } \\
\hline AG 1043 & 17 & 1,985 & * \\
\hline AG 106 & 17 & 1,703 & n.s \\
\hline AG 122 & 17 & 1,326 & n.s \\
\hline AG 4011 & 17 & 3,106 & $\star \star$ \\
\hline AG 405 & 17 & 0,949 & n.s \\
\hline AG 5011 & 17 & 1,296 & n.s \\
\hline AG 5012 & 17 & 1,996 & * \\
\hline AG 510 & 17 & 1,085 & n.s \\
\hline$A G 514$ & 17 & 1,333 & n.s \\
\hline AG 519 & 17 & 0,956 & n.s \\
\hline AG 612 & 17 & 2,628 & $* \star$ \\
\hline AG 672 & 17 & 1,970 & * \\
\hline AG 8010 & 17 & 2,215 & $\star \star$ \\
\hline AG 8012 & 17 & 5,052 & $* \star$ \\
\hline AG 9012 & 17 & 2,931 & $\star \star$ \\
\hline AG 9014 & 17 & 2,946 & $\star \star$ \\
\hline AG 951 & 17 & 0,845 & n.s \\
\hline BR 201 & 17 & 1,590 & n.s \\
\hline MÁXIMO & 17 & 0,911 & n.s \\
\hline Resíduo Médio & 684 & 1,086 & \\
\hline
\end{tabular}

\footnotetext{
* - significativo a 5\% pelo teste $F$ ** - significativo a $1 \%$ pelo teste $F$

n.s - não significativo
} 
Tabela 42. Estimativas dos parâmetros da estabilidade fenotípica da produtividade de espigas de 18 híbridos de milho e do máximo estudados em 19 locais dos Estados de São Paulo e Minas Gerais no ano agrícola de 1994/95.

\begin{tabular}{lcclcll}
\hline híbridos & $\hat{\beta}_{\text {oi }}$ & $\hat{\beta}_{1 i}$ & & $\hat{\sigma}_{d i}{ }^{2}$ & & $R_{2 i}(\%)$ \\
\hline AG 1043 & 8,08 & 1,04 & n.s & 0,300 & $\star$ & 90,55 \\
AG 106 & 8,04 & 0,94 & n.s & 0,206 & n.s & 89,98 \\
AG 122 & 8,34 & 1,09 & n.s & 0,080 & n.s & 93,90 \\
AG 4011 & 8,26 & 0,82 & ++ & 0,673 & $\star \star$ & 78,94 \\
AG 405 & 7,20 & 0,82 & ++ & 0,000 & n.s & 92,49 \\
AG 5011 & 9,62 & 1,02 & n.s & 0,070 & n.s & 93,31 \\
AG 5012 & 8,14 & 1,05 & n.s & 0,303 & $\star$ & 90,56 \\
AG 510 & 8,02 & 1,22 & ++ & 0,000 & n.s & 96,00 \\
AG 514 & 7,68 & 0,99 & n.s & 0,082 & n.s & 92,77 \\
AG 519 & 8,05 & 0,96 & n.s & 0,000 & n.s & 94,35 \\
AG 612 & 8,15 & 1,16 & ++ & 0,514 & $\star \star$ & 89,87 \\
AG 672 & 8,45 & 1,12 & + & 0,295 & $\star$ & 91,76 \\
AG 8010 & 8,08 & 0,87 & + & 0,376 & $\star \star$ & 85,60 \\
AG 8012 & 8,96 & 1,11 & n.s & 1,322 & $\star \star$ & 80,81 \\
AG 9012 & 8,76 & 0,95 & n.s & 0,615 & $\star \star$ & 84,28 \\
AG 9014 & 8,21 & 0,93 & n.s & 0,620 & $\star \star$ & 83,51 \\
AG 951 & 8,91 & 1,06 & n.s & 0,000 & n.s & 95,85 \\
BR 201 & 7,42 & 0,79 & ++ & 0,168 & n.s & 87,31 \\
MAX IMO & 10,05 & 1,07 & n.s & 0,000 & n.s & 95,65 \\
\hline
\end{tabular}

$+\quad$ - significativo a 5\% pelo teste $t$

++ - significativo a $1 \%$ pelo teste $t$

* - significativo a 5\% pelo teste F

** - significativo a $1 \frac{0}{\sigma}$ pelo teste $F$

n.s - não significativo 


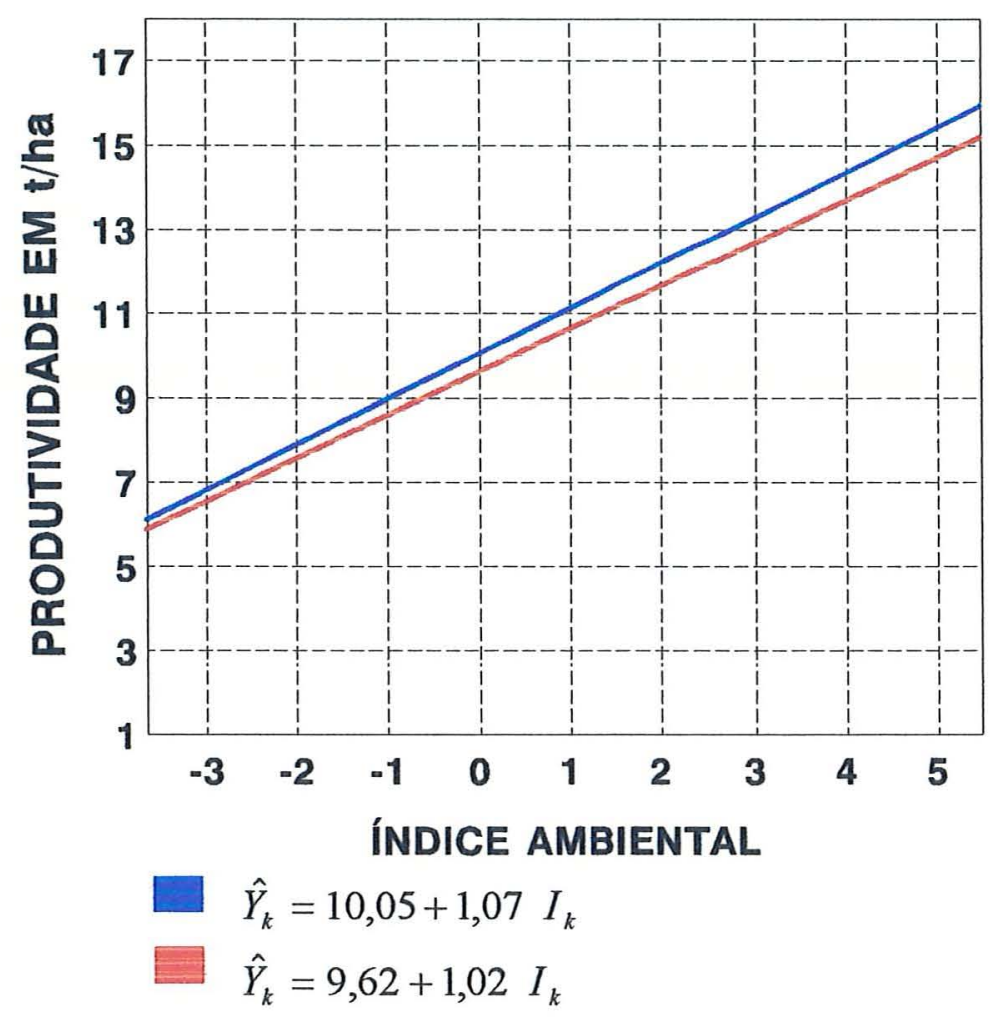

\section{- AG 5011 \\ - máximo}

Figura 24. Regressão linear da produtividade de espigas do híbrido AG 5011 e do máximo, em 19 ambientes dos Estados de São Paulo e Minas Gerais, ano agrícola 1994/95. 


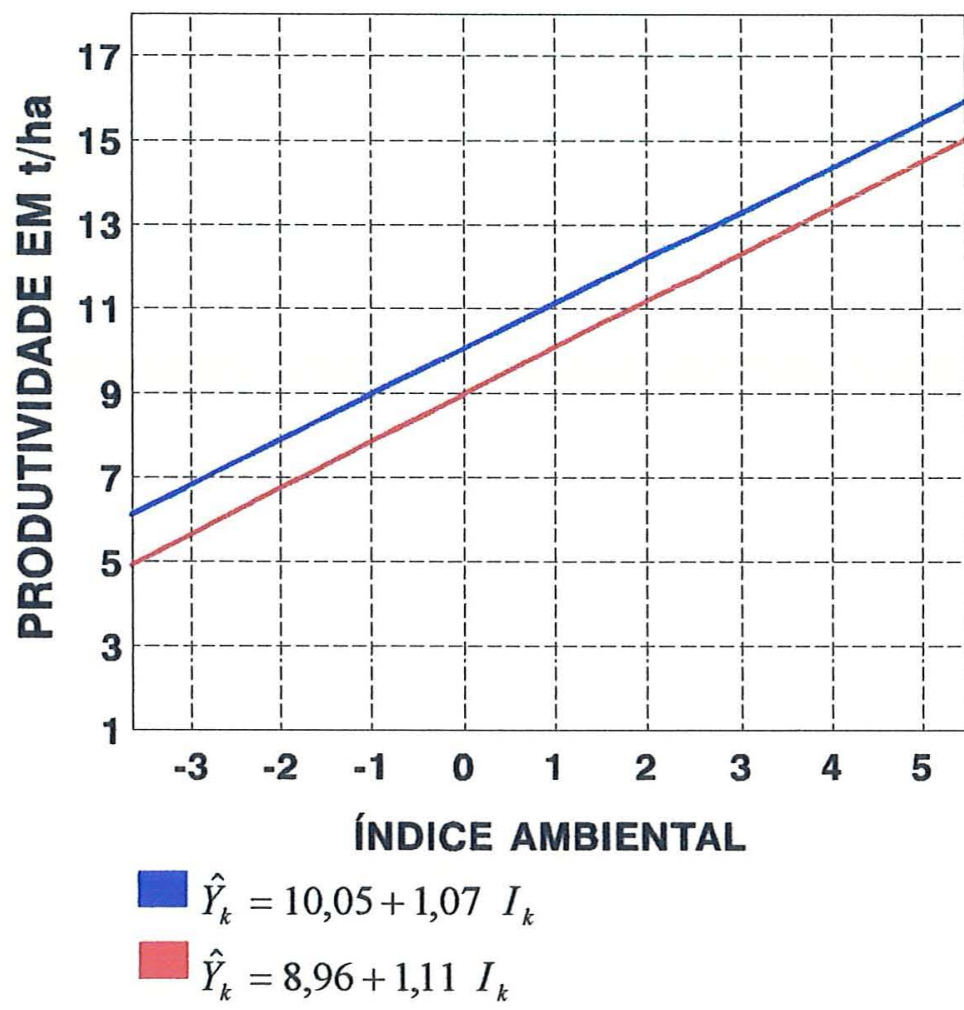

- AG 8012

- máximo

Figura 25. Regressão linear da produtividade de espigas do híbrido AG 8012 e do máximo, em 19 ambientes dos Estados de São Paulo e Minas Gerais, ano agrícola 1994/95. 


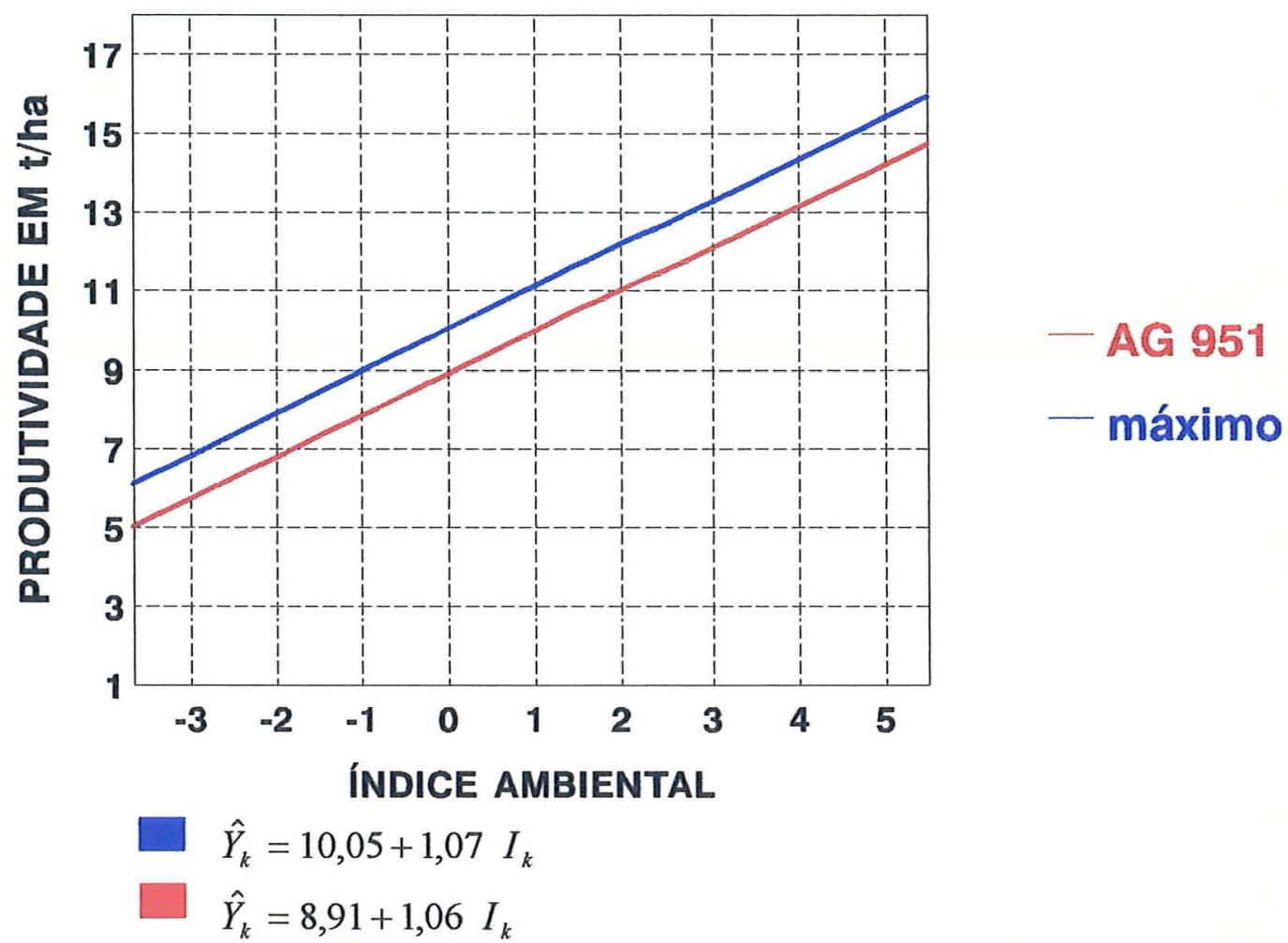

Figura 26. Regressão linear da produtividade de espigas do híbrido AG 951 e do máximo, em 19 ambientes dos Estados de São Paulo e Minas Gerais, ano agrícola $1994 / 95$. 


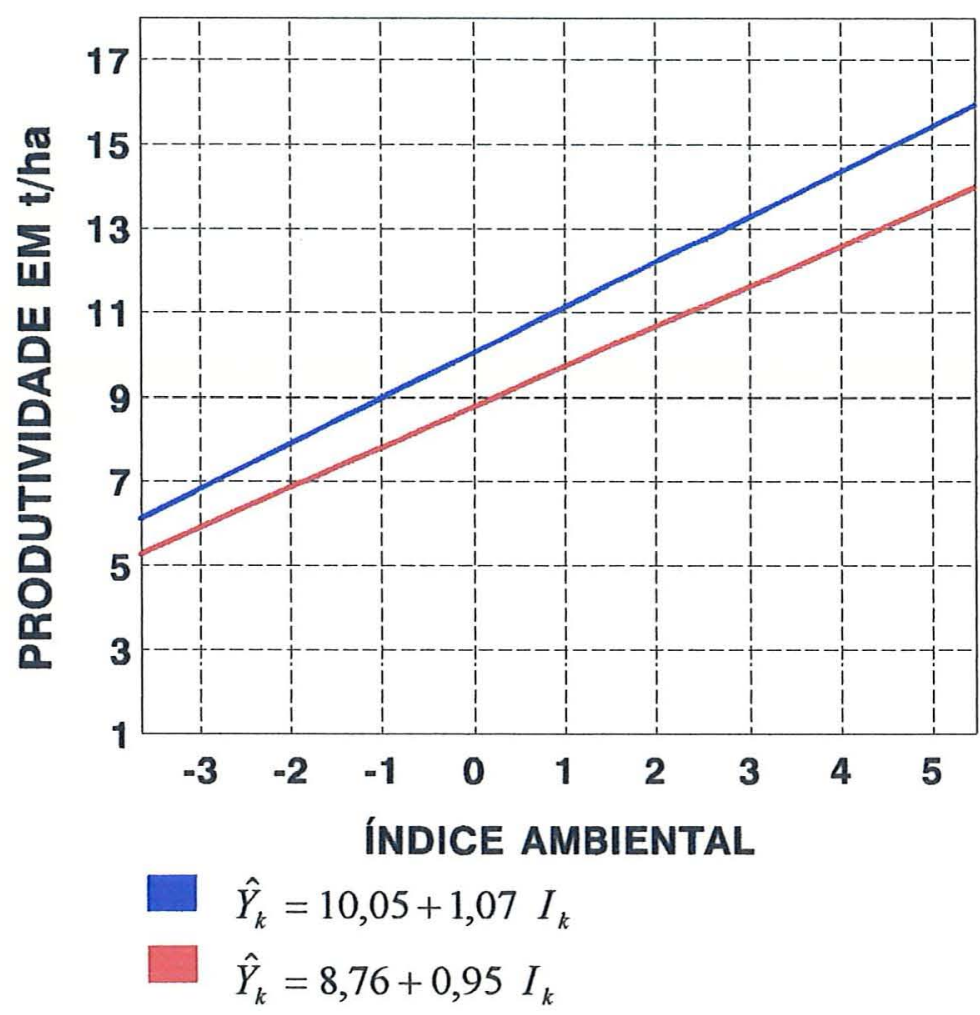

- AG 9012

- máximo

Figura 27. Regressão linear da produtividade de espigas do híbrido AG 9012 e do máximo, em 19 ambientes dos Estados de São Paulo e Minas Gerais, ano agrícola 1994/95. 


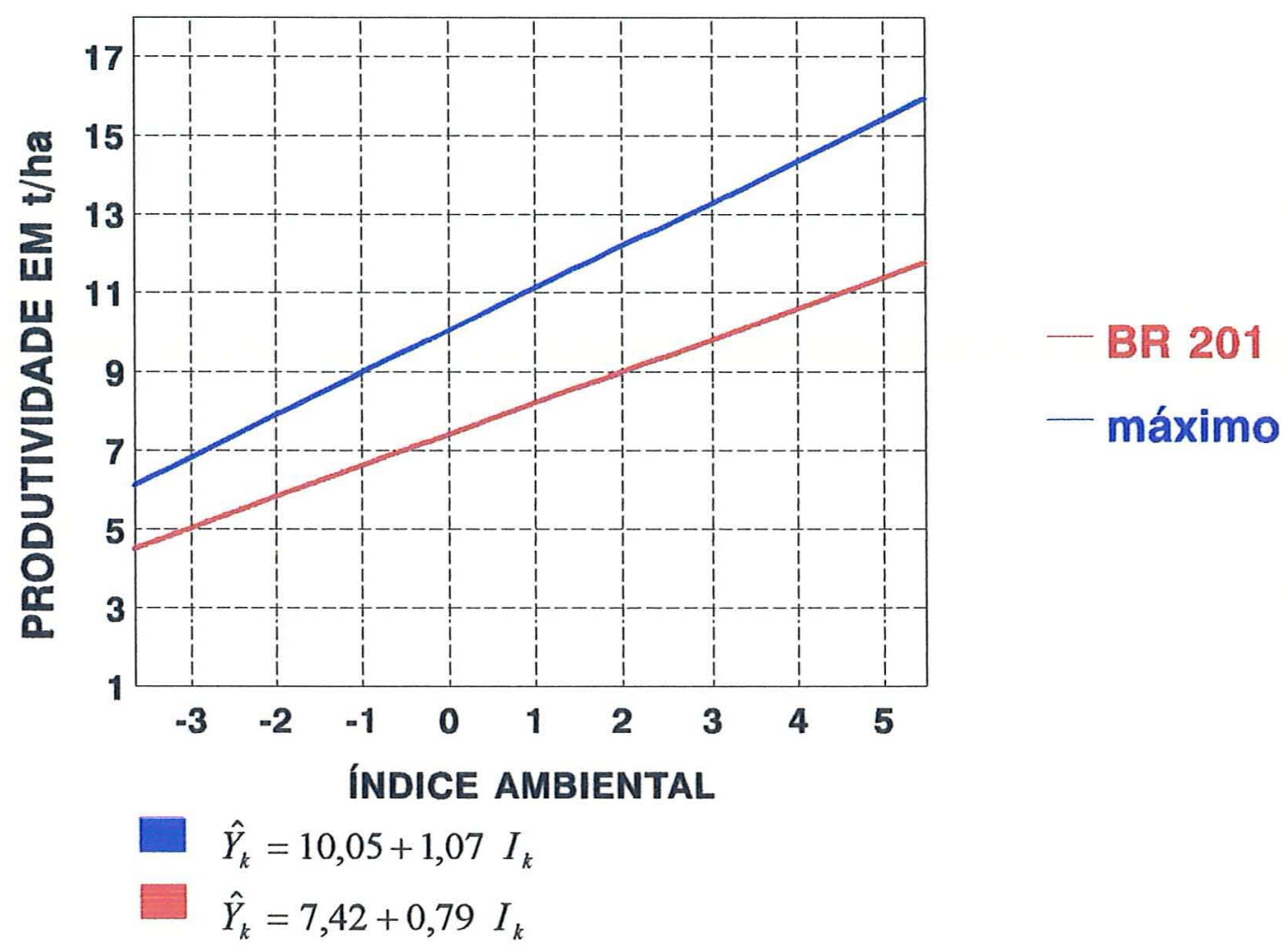

Figura 28. Regressão linear da produtividade de espigas do híbrido BR 201 e do máximo, em 19 ambientes dos Estados de São Paulo e Minas Gerais, ano agrícola $1994 / 95$. 


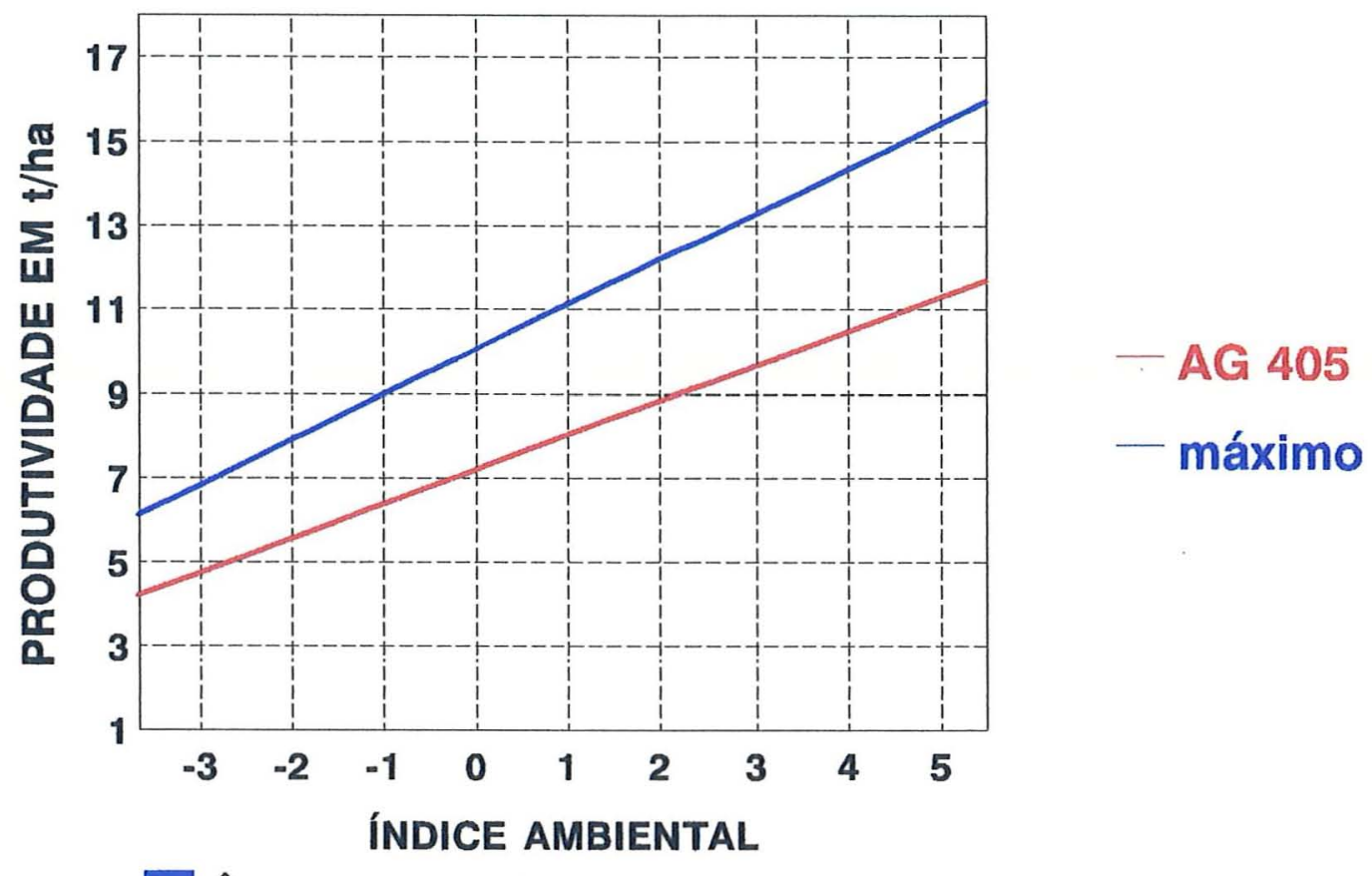

$\square \hat{Y}_{k}=10,05+1,07 I_{k}$

$\hat{Y}_{k}=7,20+0,82 I_{k}$

Figura 29. Regressão linear da produtividade de espigas do híbrido AG 405 e do máximo, em 19 ambientes dos Estados de São Paulo e Minas Gerais, ano agrícola $1994 / 95$. 


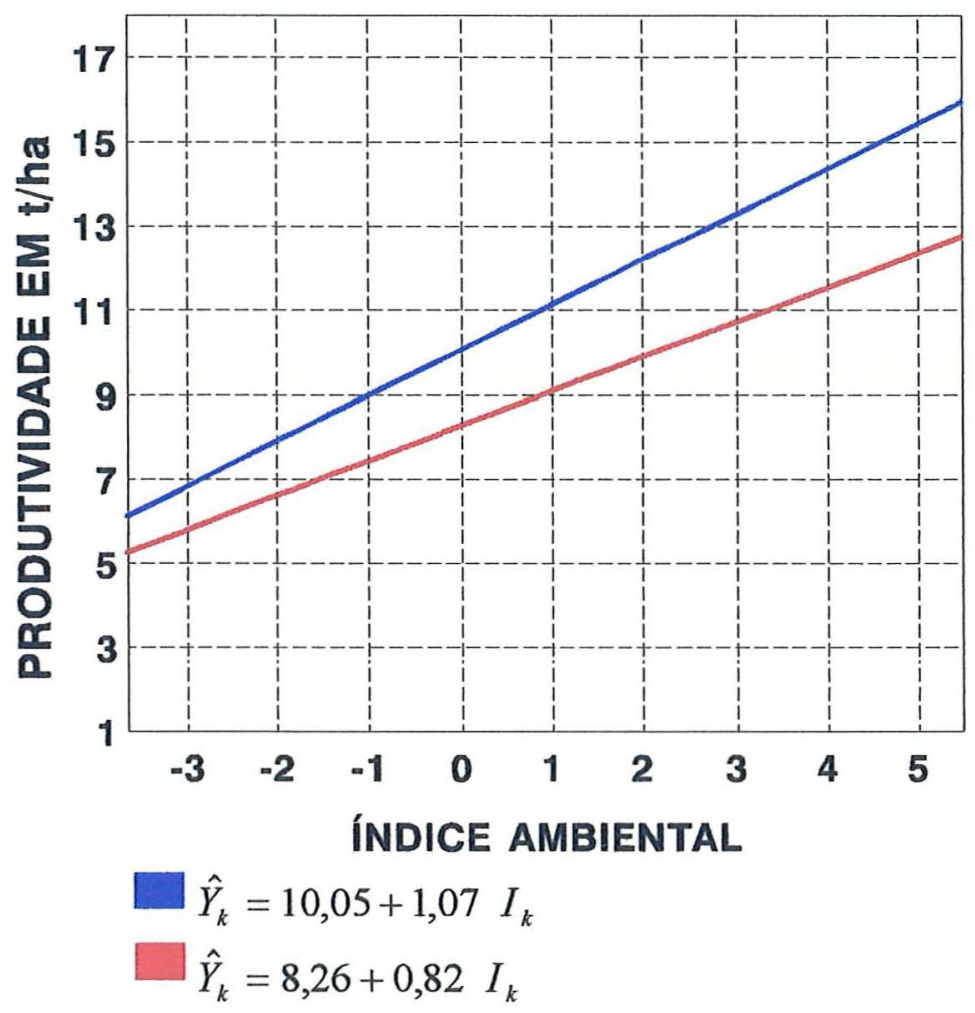

- AG 4011

- máximo

Figura 30. Regressão linear da produtividade de espigas do híbrido AG 4011 e do máximo, em 19 ambientes dos Estados de São Paulo e Minas Gerais, ano agrícola $1994 / 95$. 


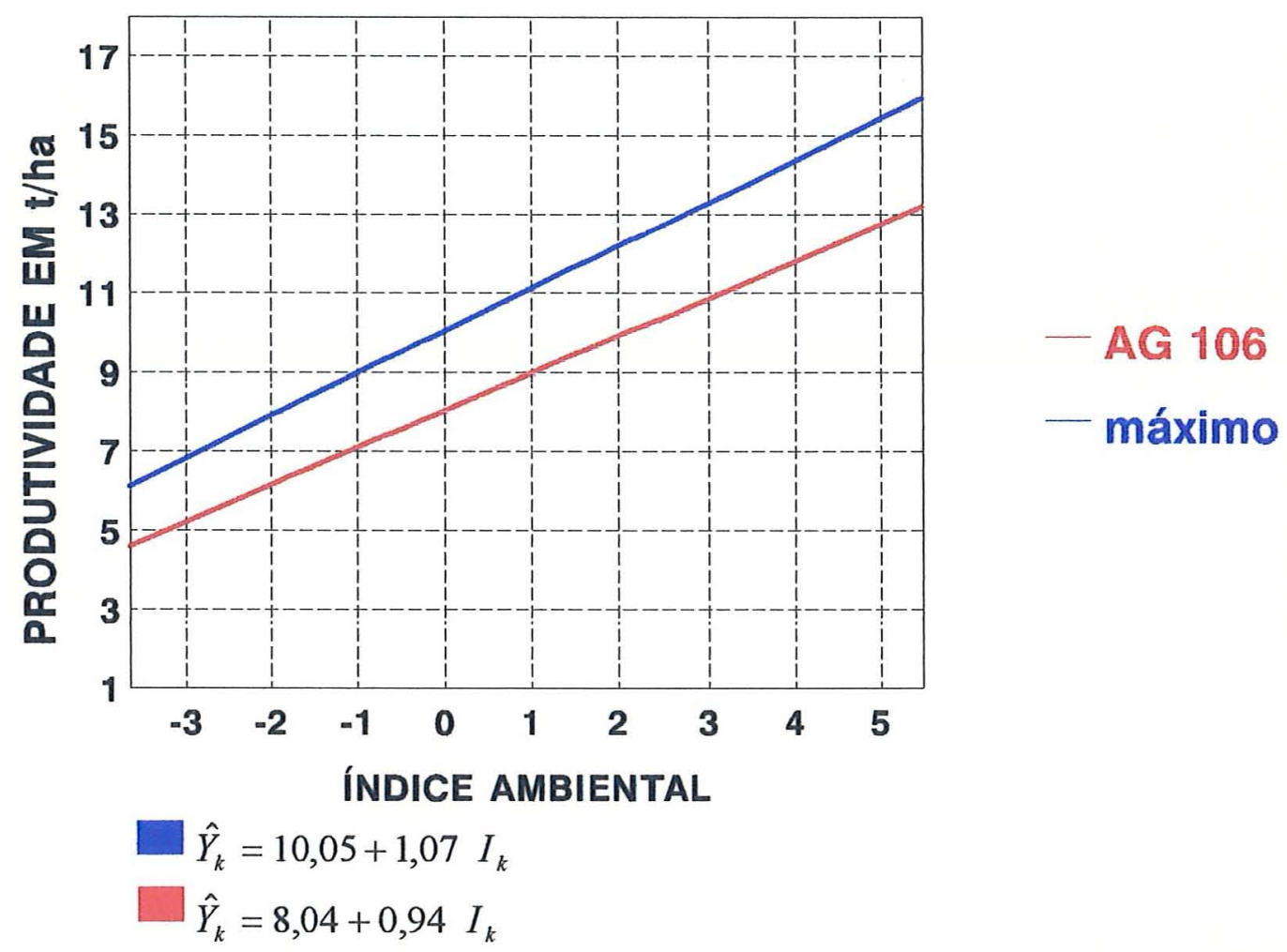

Figura 31. Regressão linear da produtividade de espigas do híbrido AG 106 e do máximo, em 19 ambientes dos Estados de São Paulo e Minas Gerais, ano agrícola $1994 / 95$. 


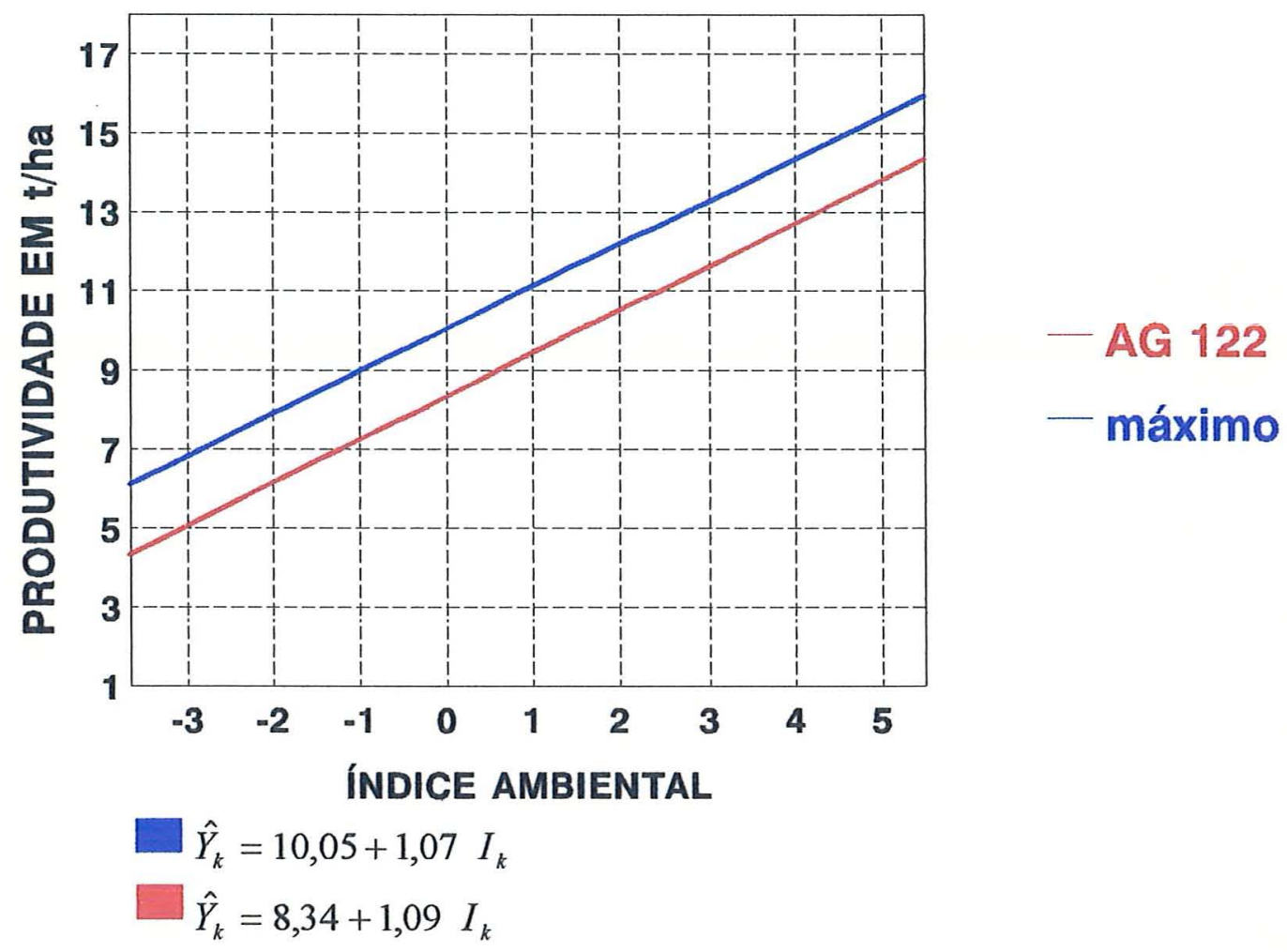

Figura 32. Regressão linear da produtividade de espigas do híbrido AG 122 e do máximo, em 19 ambientes dos Estados de São Paulo e Minas Gerais, ano agrícola 1994/95. 


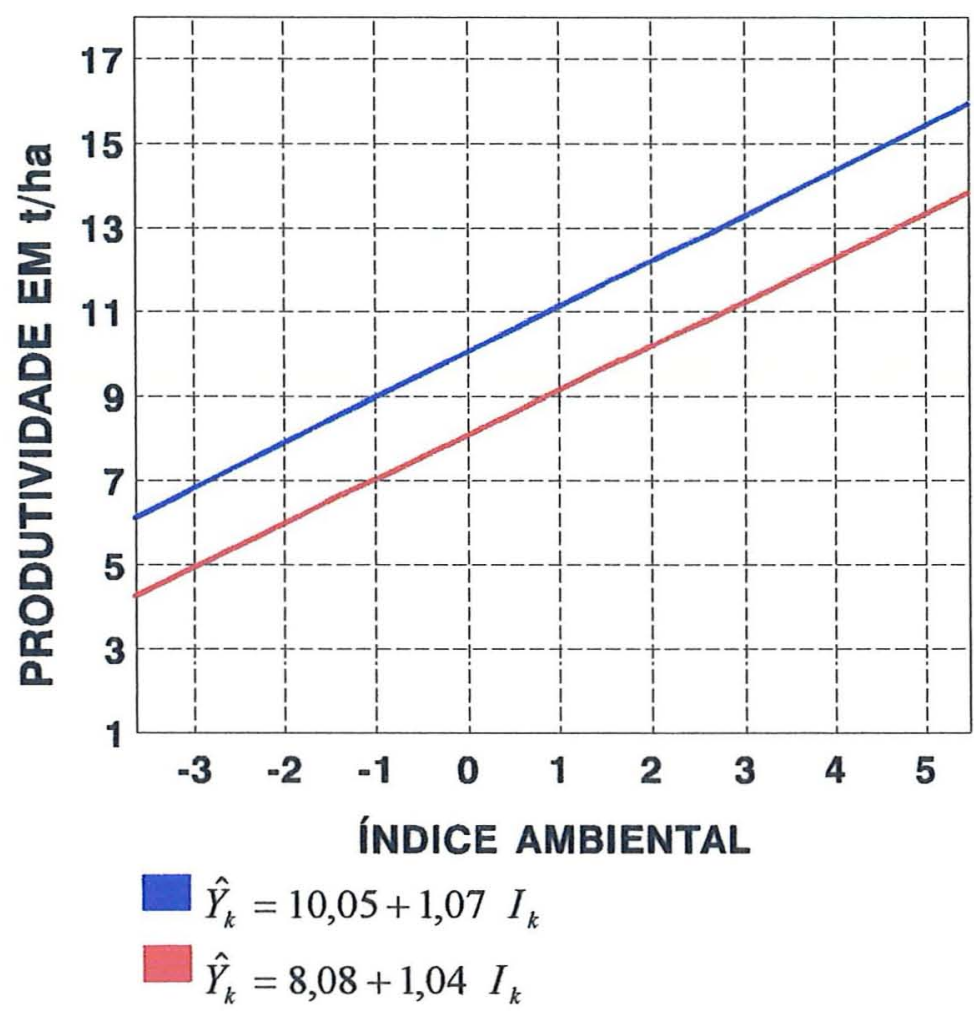

- AG 1043

- máximo

Figura 33. Regressão linear da produtividade de espigas do híbrido AG 1043 e do máximo, em 19 ambientes dos Estados de São Paulo e Minas Gerais, ano agrícola 1994/95. 


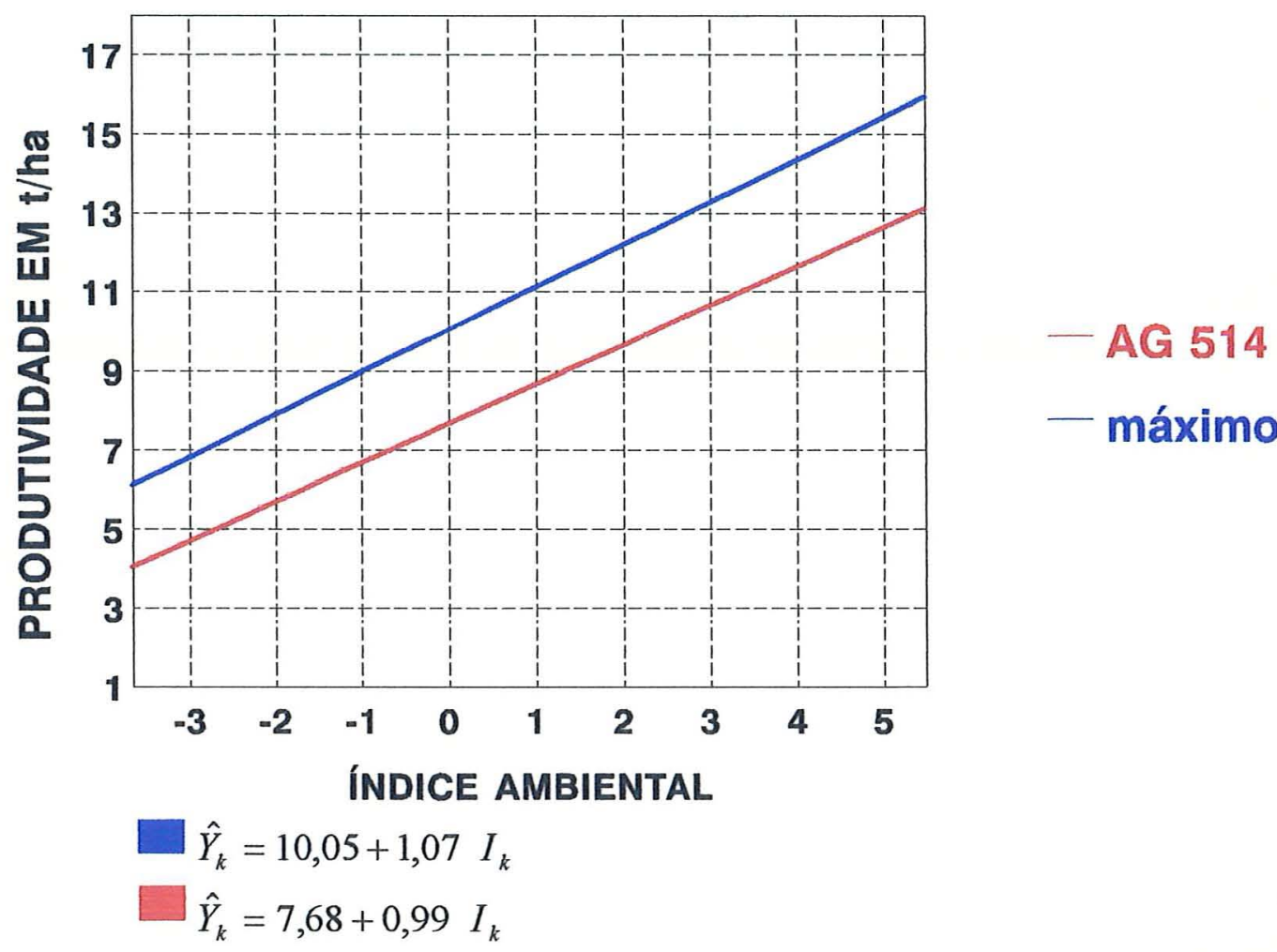

Figura 34. Regressão linear da produtividade de espigas do híbrido AG 514 e do máximo, em 19 ambientes dos Estados de São Paulo e Minas Gerais, ano agrícola 1994/95. 


\subsection{Estudo de Simulação}

De acordo como o que foi proposto, verificou-se a normalidade da n-ésima estatística de ordem de dados gerados a partir de uma distribuição normal com média $\mu$ e variância $\sigma^{2}$.

Com $\circ$ programa S-PLUS e considerando $\mu=10$ e $\sigma^{2}=25$, para valores de $n=10,20,50$ e 100, em que $n$ é tamanho da amostra, obtiveram-se os QQ-Norm (gráfico de probabilidade normal), que são mostrados nas Figuras 35, 36,37 e 38 .

Pode-se observar que a distribuição do máximo de valores obtidos de uma distribuição normal, afasta-se da distribuição normal, concordando com os resultados obtidos por TIPPET (1925). Desse modo, estudos mais detalhados serão necessários a fim de se construir um resíduo específico para uma análise conjunta entre híbridos e locais, quando a variável sob estudo for distância em relação ao máximo e ao mínimo. 


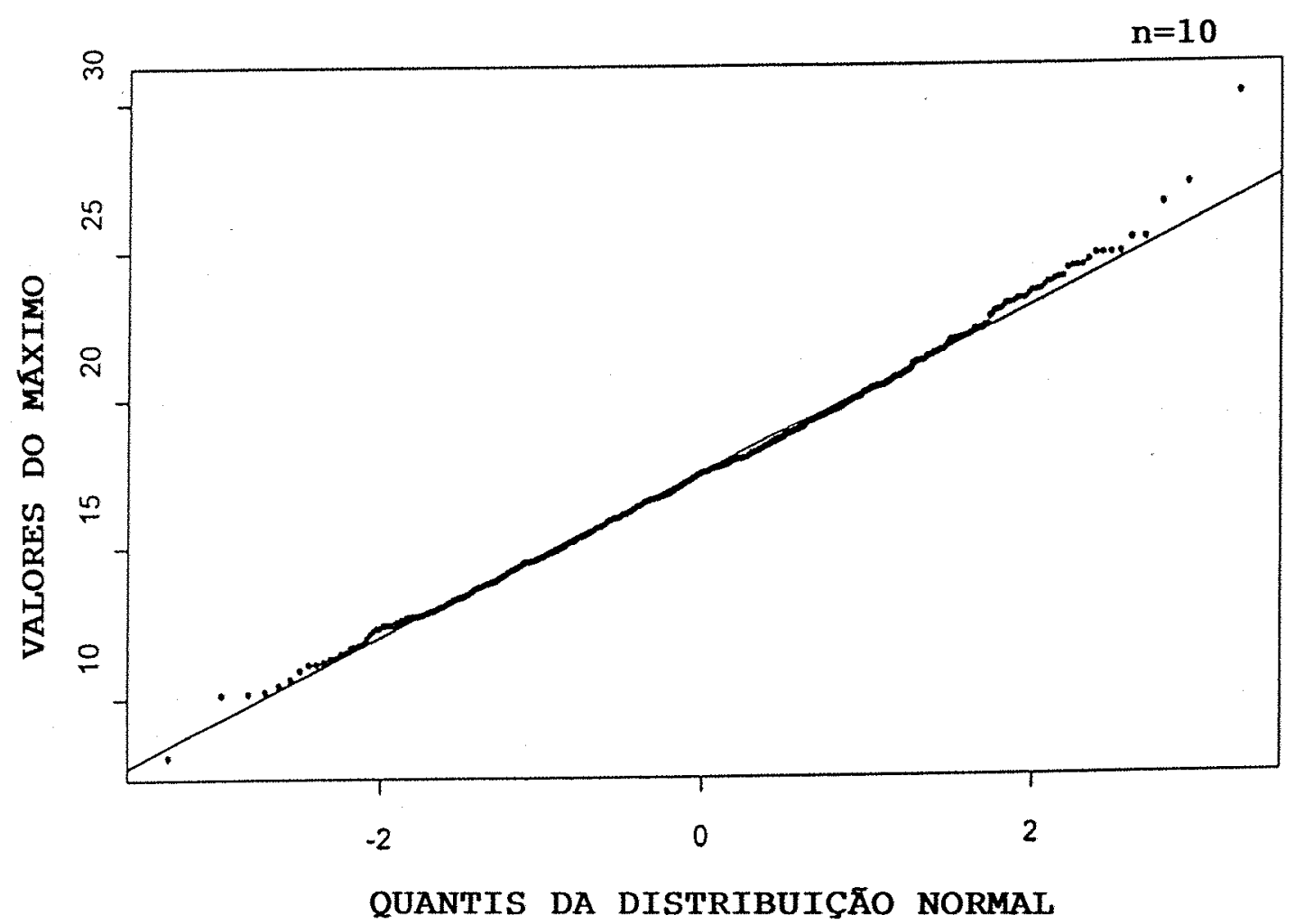

Figura 35. Quantís da distribuição do máximo de uma distribuição normal com $\mu=10$ e $\sigma^{2}=25$ a partir de dados simulados de uma amostra de tamanho $n=10$. 


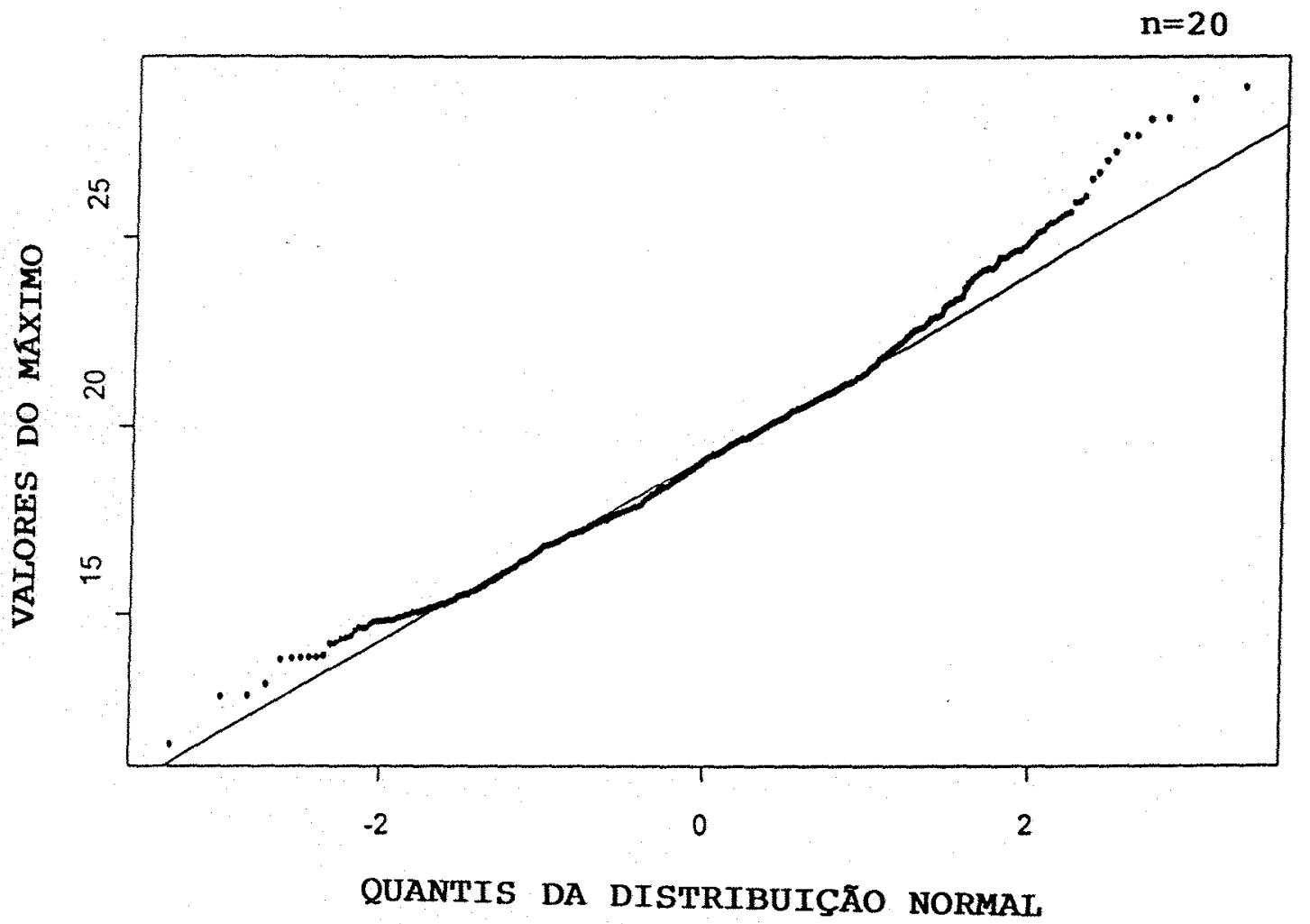

Figura 36. Quantís da distribuição do máximo de uma distribuição normal com $\mu=10$ e $\sigma^{2}=25$ a partir de dados simulados de uma amostra de
tamanho $n=20$. 


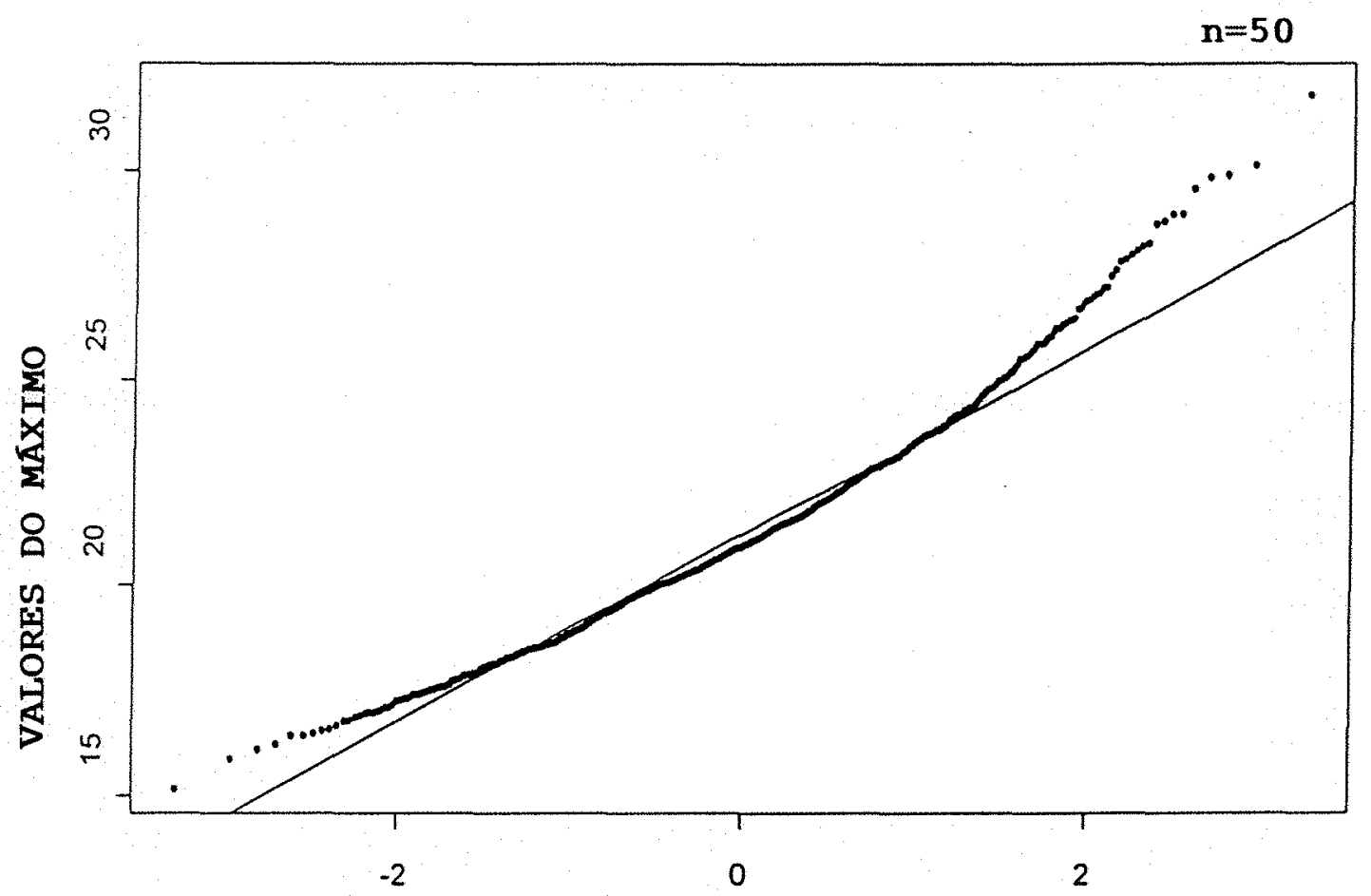

QUANTIS DA DISTRIBUIÇÃO NORMAL

Figura 37. Quantís da distribuição do máximo de uma distribuição normal com $\mu=10$ e $\sigma^{2}=25 \mathrm{a}$ partir de dados simulados de uma amostra de tamanho $n=50$. 


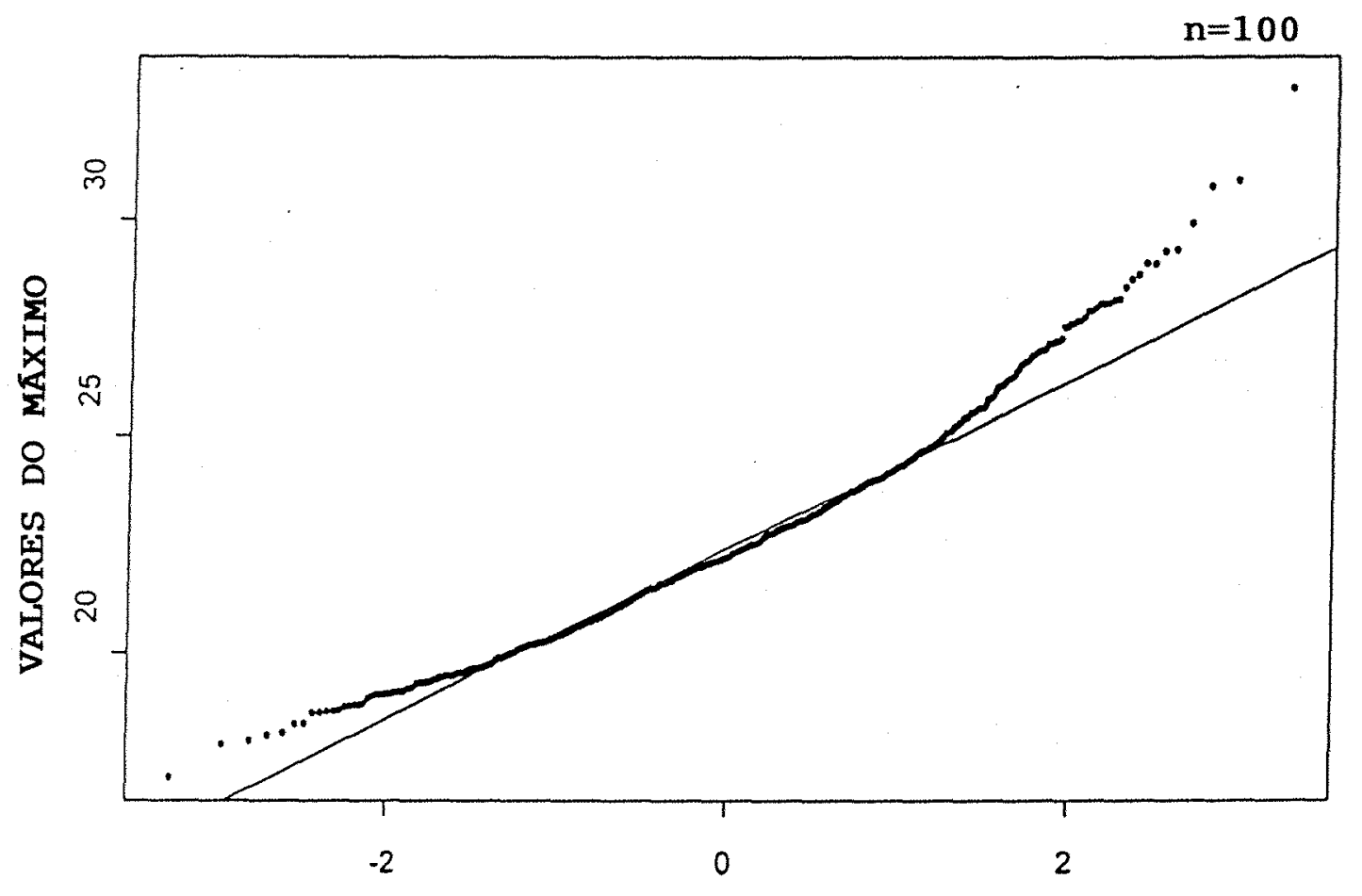

QUANTIS DA DISTRIBUIÇÃO NORMAL

Figura 38. Quantís da distribuição do máximo de uma distribuição normal com $\mu=10$ e $\sigma^{2}=25 \mathrm{a}$ partir de dados simulados de uma amostra de tamanho $n=100$. 


\section{CONCLUSÕES}

Com base nos resultados obtidos, concluiu-se que :

1. A metodologia utilizada permitiu classificar os tratamentos avaliados de acordo com seu afastamento em relação a um genótipo conceitual considerado o melhor, na análise de grupos de experimentos. Trata-se de mais um critério para auxiliar na seleção de genótipos superiores.

2. Esta metodologia foi útil ainda, para determinar o desempenho de híbridos em todos os locais, nos ambientes desfavoráveis e favoráveis. Desse modo pôdese saber se um híbrido tem adaptabilidade geral ou especifica para os locais testados.

3. Uma vez que, a cada ano, são obtidos novos híbridos para serem testados nos diversos locais, a metodologia 
baseada em distâncias, permitiu avaliar o desempenho destes frente aos já existentes. Também forneceu subsidios para se quantificar a evolução do comportamento dos novos materiais com o decorrer dos ciclos de melhoramento de um dado programa.

4. Através dos resultados de simulações pôde-se concluir não ser possivel aplicar um teste $F$ às variáveis de distâncias, $O$ que discorda de LIN $\varepsilon$ BINNS (1988) que apresentaram um ponto de corte baseado na interpolação do teste $F$. E como não foi possível determinar um erro especifico para as estimativas de distância, sugerem-se futuros estudos que possibilitem a sua obtenção e aplicação de uma metodologia para este caso.

5. Na aplicação da metodologia de distância ao melhor genótipo foram utilizadas apenas duas variáveis (produtividade e porcentagem de tombamento). É perfeitamente possivel a utilização de outras variáveis que sejam importantes para o pesquisador, aplicando-se análises de agrupamento ou outros processos multivariados. 
6. Os resultados obtidos demonstraram que o estudo da estabilidade fenotípica fornece informações consistentes e coerentes sobre o comportamento de híbridos em diversos ambientes. Com base nos coeficientes de regressão pôde-se concluir que, no grupo de híbridos estudados, há genótipos para todas as condições ambientais, sendo a maioria deles com adaptabilidade geral.

7. Com base nos resultados de distância ao melhor genótipo e da análise de estabilidade e adaptabilidade, pôde-se verificar que o melhor genótipo possui adaptabilidade geral e é altamente estável. Como este material conceitual apresentou coeficiente de regressão em torno de 1,00 , sugerem-se estudos adicionais que expliquem tal tendência e a validade teórica do teste $t$ aplicado aos resultados obtidos.

8. O hibrido AG 5011 que mais se aproximou do melhor genótipo para a produtividade, foi altamente estável, mostrando ser possivel obter materiais estáveis que possuam alto rendimento. 


\section{REFERÊNCIAS BIBLIOGRÁFICAS}

ALIARD, R.W. \& BRADSHAW, A.D. Implications of genotypeenviromental interactions in applied plant breeding. Crop Sciense. Madison, 4:503-508, 1964.

BARRIGA, H.M.P. Caracterização de Cultivares de mandioca (Manihot esculenta, Crantz) Com relação a produção e Estabilidade. Piracicaba, 1980, 128 p. (Mestrado - ESALQ/USP).

BECKER, H.C \& LEON,J. Stability analysis in plant breeding. Plant Breeding. Berlim, 101: 1-23, 1988.

BonATO, E.R. Estabilidade Fenotípica da Produção de grãos de dez cultivares de soja [Glycine max (L.) Merril] nas Condições do Rio Grande so Sul. Piracicaba, 1978, 75 p. (Mestrado - ESALQ/USP). 
BRASIL, E.M. Comparação de Métodos o Estudo da Interação de genótipos com ambientes em milho (Zea mays I.). Goiânia, 1990 , 181 p. ( Mestrado - Universidade Federal de Goiás).

CAMPOS, H. Análise Conjunta de Experimentos. Estatística Aplicada à Experimentação com Cana-de-Açucar. Ed.1, São Paulo, FEALQ, 1984, cap.9, 197-203.

COCHRAN, W.G. The combination of estimates from different experiments. Biometrics, Alexandria, 10:101-129, 1954.

CROSSA, J. A comparison of results obtained with two methods for assessing yield stability. Theor. Appl. Genet., Berlim, 75: 460-467, 1988.

CRUZ, C.D. Estabilidade e Adaptabilidade. Apostila Curso de Modelos Biométricos Aplicados ao Melhoramento, Viçosa, Universidade Federal de Viçosa, 1993, cap.2, 41-86. 
CRUZ, C.D. $\varepsilon$ REGAZZI, A.J. Interação Genótipos $x$ Ambientes. Modelos Biométricos Aplicados ao Melhoramento Genético. Ed.1, Viçosa, Universidade Federal de Viçosa, 1994, Cap. 1, 1-34.

CRUZ, C.D; TORRES, R.A.A.; VENCOVSKY, R. An alternative approach to the stability analysis proposed by Silva and Barreto. Revista Brasileira de Genética, Ribeirão Preto, $12(2): 567-80,1989$.

EBERHART, S.A. $\varepsilon$ RUSSEL, W.A. Stability parameters for comparing varieties. Crop Sciense, Madison, 6:3640,1966 .

FINLAY, K.W. $\varepsilon$ WILKINSON, G.N. The analysis of adaptation in a plant-breeding programe. Australian Journal of Agricultural Research, Melborne, 14: 742-54, 1963.

HARDWICK, R.C, ; WOOD, J.T. Regression methods for studying genotype-environment interactions. Heredity, Edinburg, 28:209-222, 1972 . 
HARVARD GRAPHICS for Windons. Versão 3. Using Harvard Graphics 3.0 for Windows. SPC Software Publishing Corporation. USA, 1994.

HICKS, C.R. Fundamental Concepts in the Design of Experiments. Second Edition. By Holt Rinehart and Winston, 1973.

HILL, J. Genotype-environment interactions - a challenge for plant breeding. Journal of Agricultural Sciense, Cambridge, 85:477-493, 1975.

HUEHN, M. Nonparametric measures of phenotypic stability . Part 1: Theory. Euphytica, Wageningen, 47:189-94, 1990a.

JOWETT, D. Yield Stability Parameters for Sorghum in East Africa. Crop Science, Madison, 12:314-317, 1972.

KENDALL, M.G \& STUART, A . The Advanced Theory of Statistics. Vol I, II e III. Charles Griffin, London, 1963. 
LIN, C.S $\varepsilon$ BINNS, M.R. A superiority measure of cultivar performance for cultivar $x$ location data. Can. J. Plant Sci., Otawa, 68:193-198, 1988.

MARIOTTI, J.A.; OYARZABAL, E.S.; OSA, J.M.; BULACIO, A.N.R. e AIMADA, G.H. Analisis de estabilidad y adaptabilidad de genotipos de caña de azucar. I. Interacciones dentro de una localidad experimental. Rev. Agron. N.O. Argent., Argentina, XIII (1-4): $104-126,1976$.

MIRANDA G.V. Comparação de métodos de avaliação da adaptabilidade e estabilidade de comportamento de cultivares, exemplo com a cultura do feijão (Phaseolus vulgaris I. ). Viçosa, 1993, 120 p. (Mestrado Universidade Federal de Viçosa).

MIRANDA EILHO, J.B. $\varepsilon$ VIÉGAS, G.P. Milho Híbrido. In: PATERNIANI, E. $\varepsilon$ VIÉGAS, G.P. Melhoramento e Produção do Milho. Ed.1, Campinas, Fundação Cargill, 1987, vol.1, cap. $7,277-280$

MSTAT. USER'S GUIDE TO MSTAT-C. A Software Program for the Design, Management, and Analysis of Agronomic Research Experiments. Michigan State University, 1991. 
OLIVEIRA, A.C de. Comparação de alguns métodos de determinação da estabilidade em plantas cultivadas. Brasilia, 1976, 62 p. (Mestrado - Universidade de Brasilia) .

OLIVEIRA, M.D.X. Comportamento da Cultura de Milho (Zea mays L.) em diferentes épocas de semeadura nas regiões Centro e Norte de Mato Grosso do Sul. Lavras, 1990, 90 p. (Mestrado - Escola Superior de Agricultura de Lavras) .

PHAM, H.N. $\varepsilon$ KANG, M.S. Interrelationships among and repeatability of several stability statistics estimated from international maize trials. Crop Sci., Madison, 28: $925-928,1988$.

PIMENTEL, F.G. Curso de Estatistica Experimental. Ed.13, Piracicaba, Livraria Nobel S.A. 467 p., 1990.

PLAISTED, R.L. A shorter method for evaluating the ability of selections to yield consistently over locations. American Potato Journal, Washington, 37: 166-72, 1960. 
PLAISTED, R.I. $\varepsilon$ PETERSON, L.C. A technique for evaluating the ability of selections to yield consistently in different locations or seasons. American Potato Journal, Washington, 36: 381-5, 1959.

RAMALHO, M.; SANTOS, J.B.; PINTO, C.B. Genética na Agropecuária. Ed.2, São Paulo, Editora Globo, 1989, cap.9, 173-180.

ROBERTSON, A. The Sampling Variance of the Genetic Correlation Coeficient. Biometrics. Alexandria, 15:459485 .

RoUSSAS, G. G. A First Course in Mathematical Statistics. Addison-Wesley Publishing Company. Reading, Massachusetts, 1972, $505 \mathrm{p}$.

SANTOS, J.B. Estabilidade Fenotípica e Cultivares de Feijão (Phaseolus vulgaris L.) nas condições do sul de Minas. Piracicaba, 1980, 110 p. (Mestrado - ESALQ/USP)

SHUKLA, G.K. Some statistical aspects of partitioning genotype-enviromental components of variability. Heredity, London, 28:237-245, 1972. 
SILVA, J.G.C. da $\varepsilon$ BARRETO, J.N. Aplicação da regressão linear segmentada em estudos da interação genótipo $\mathrm{x}$ ambiente. In: SIMPÓSIO DE EXPERIMENTAÇÃO AGRÍCOLA, 1., Piracicaba, 1985. Resumos. Campinas, Fundação Cargill, 1985, p. $49-50$

SIIVA, J.G.C. Análise da adaptabilidade através de regressão linear segmentada. 1. Fundamentos. Pesquisa Agropecuária Brasileira, Brasilia, 30-4: 435-448, 1995.

S-PLUS for Windows. User's Manual Volume 1 e 2. Statistical Sciences Inc. 1993.

STORCK, L. Modelo de regressão bi-segmentado descontínuo com erros de medida aplicado na análise da estabilidade de cultivares. Piracicaba, 1989, 217 p. (Doutorado ESALQ/USP) .

TAI, G.C.C. Genotypic stability analysis and its application to potato regional trials. Crop Sciense, Madison, 11: 184-90, 1971. 
TIPPET, L.H.C. On the Extreme Individuals and the range of samples taken from a normal population. Biometrika, Alexandria, $17,364,1925$.

TOLER, J.E. Patterns of Genotypic Performance over Enviromental Arrays. Clemson, 1990, 154 p. (Doutorado Graduate School of Clemson University).

VENCOVSKY, R. $\varepsilon$ BARRIGA, P. Componentes da Variação fenotipica, análise em vários ambientes. Genética Biométrica no Fitomelhoramento. Ed.1, Ribeirão Preto, Revista Brasileira de Genética, 1992, p. 233-333.

VERMA, M.M.; CHAHAL, G.S.; MURTY, B.R. Limitations of conventional regression analysis: a proposed modification. Theorethical and Applied Genetics, Berlim, 53:89-91, 1978 .

VIRK, D. S.; VIRK, P. S.; MANGAR, B. K.; HARINARAYANA, G. Linear and non-linear regression analysis of genotype $\mathrm{x}$ environment interactions in pearl millet. Theor. Appl. Genetic. Berlim, 75: 736-40, 1988 . 
WESTCOTT, B. A method of assessing the yield stability of crop genotypes. J. Agric. Sci., Cambridge, 108:267274,1987 .

WRICKE, G. Zur Berechnung der Ökovalenz bei Sommerweizen und Hafer. Z. Pflanzenzüchtung. Berlin, 52(2):127$138,1965$.

YATES, F. $\varepsilon$ COCHRAN, W.G. The analysis of groups of experiments. J.Agric. Sci., Cambridge, 28: 556-80, 1938. 